\title{
JOURNEYS OF ETHNO-CULTURAL CONTINUITY: \\ COMPARING THE LONG-TERM ACCULTURATION OF \\ JEWS WITH MĀORI AND CHINESE
}

\section{Michelle AMIE GEZENTSVEY}

\author{
A thesis \\ submitted to the Victoria University of Wellington \\ in fulfilment of the requirements for the degree of \\ Doctor of Philosophy in Psychology \\ Victoria University of Wellington \\ Wellington, New Zealand





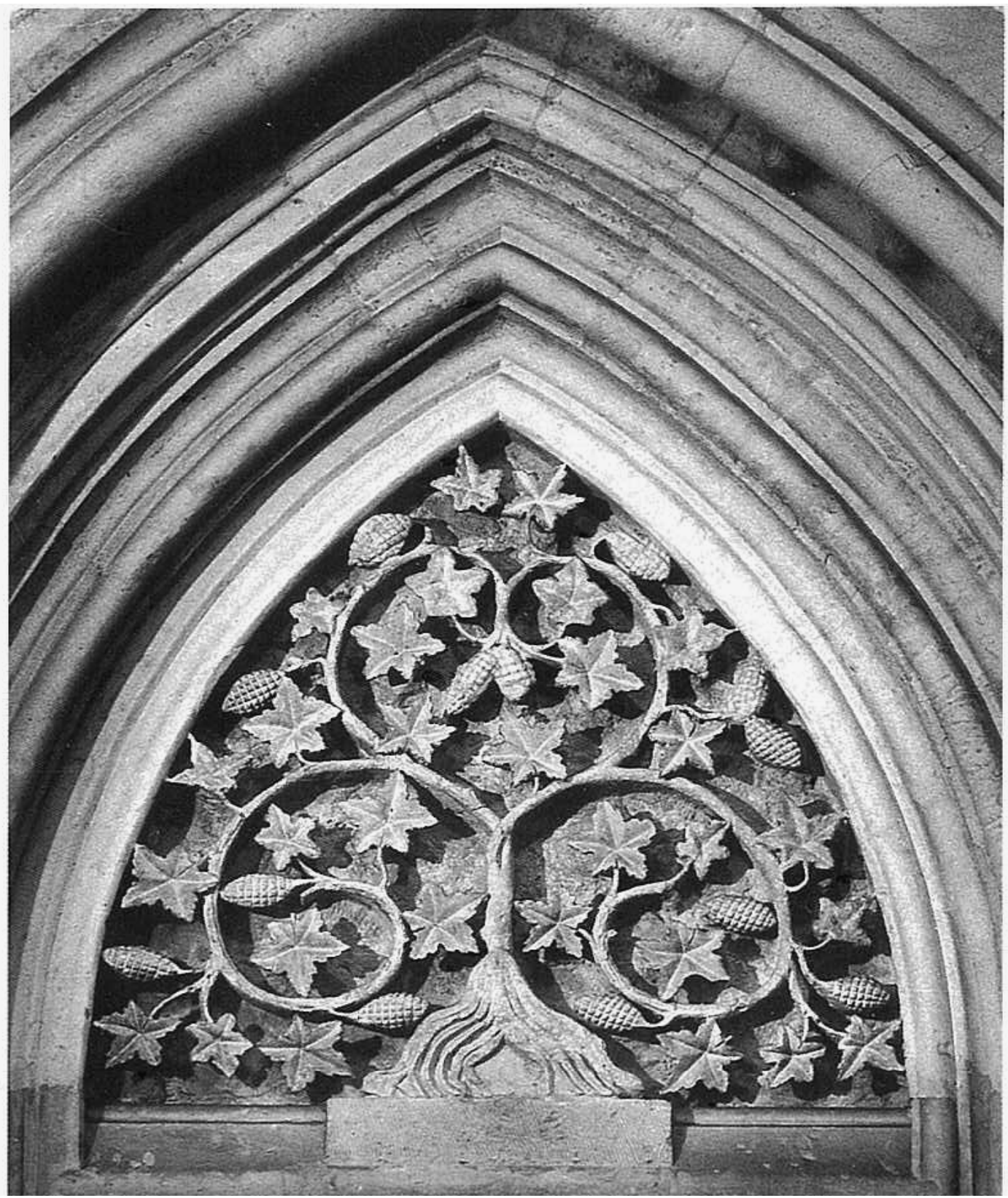

Vine relief above the entrance of the Old-New Synagogue, Prague (the oldest functioning synagogue in Europe, $1270 \mathrm{CE}$ ) 


\section{ACKNOWLEDGEMENTS}

I would like to thank my supervisors, Colleen Ward and James Liu for all your guidance and support over the last four and a half years; for being my PhD 'mum' and 'dad', for taking turns playing good cop/bad cop and for giving me the freedom to be creative while trying to reign me in!

I am very grateful to John Berry for his assistance in the conceptual development of my model in Wellington; Fabio Sani for sharing his measure of PCC and brainstorming with me in Aix-en Provence, Richard Lalonde for giving me access to his fantastic literature in Toronto, John Hattie for his assistance with SEM in Spetses, Fons van de Vijver for his advice on quantitative analysis in Groningen, and $\mathrm{Hal}$ Levine for his qualitative perspectives in Wellington. Thank you Ann Weatherall, Paul Jose, and Marc Wilson for help with qualitative and quantitative analyses, Paul Callister for his research on ethnic intermarriage in New Zealand, and Ewan Jonasen at Statistics New Zealand. Thanks to the cross-cultural lab students and staff, the administrative team in the School of Psychology and Faculty of Science: Ngaire Lavery, Nicola Panapa, Jebi Jayapalan, James Millington, Michael France, Doug Drysdale, Doug Flux and Keith Willet, to Timothy VaughanSanders for proof-reading and Pablo Sektman for organising the videoconference.

I am very grateful to those who assisted with data collection by providing contacts and emailing my surveys: Janine Gaddie, Deborah Levy, Jo Scher, Rael Cohen and Rachel Bolstad (New Zealand Jewish sample); Eva Robey, Elyse Chiert, Yair Miller, Josh Levin, Deon Kamien and Yaron Daffan, (Australian Jewish samples); Lisa Isen Baumal, Stephanie Krasman and Talia Klein (Canadian Jewish sample); David Newman and David Hollander (American Jewish sample); Te Ripowai Higgins, Hollie Smith, Mary Waru, Nepia Stewart, June Tam, Avril Martin and Greg Henderson (Māori sample); Kirsten Wong, Justine Kohing, Steven Young, Kelvin Chu and Shijun Li (Chinese sample). 
Thank you to Marc Wilson (Victoria University of Wellington), Elsie Ho (University of Waikato) and Gabriel Horenczyk (The Hebrew University of Jerusalem) for examining my thesis!

Last but not least, I would like to thank my parents Desirée and Yury who encouraged me to study hard and study what I love, as well as my grandfather Samuil, my sisters and brothers-in-law Lara, Nathan, Yael and Storm for their moral support nosostros nos queremos mucho! Thank you Shoshana for your companionship on my Jewish journey of spiritual growth; and mon amour Benoit, you are a blessing for my present and my future.

This thesis is dedicated to my family - those who have already journeyed, those who are on their journey and those whose journeys are yet to begin.

\section{ברוך אל ההודאות}

Blessed be G-d to whom thanksgiving is due

This doctoral research has been supported by:

TEC Bright Future Top Achiever Doctoral Scholarship (2004-6)

Todd Foundation Award for Excellence (2004)

Freemasons Postgraduate Scholarship (2004)

New Zealand Postgraduate Study Abroad Award (2007)

Jacob Joseph Scholarship (2007)

Victoria University of Wellington PhD Completion Scholarship (2007)

BRCCS Doctoral Scholarship (2007)

Thank you $\sim$ Thank you $\sim$ Thank you!!! 


\begin{abstract}
This thesis sought to establish a new field of research in cross-cultural psychology: Longterm acculturation. In Chapter one, ethno-cultural continuity was introduced as a grouporiented acculturation goal for diaspora and indigenous peoples, and the impact of the ethno-cultural group and the larger society on ethno-cultural continuity was recognised. In Chapter two, cultural transmission was considered as the central mechanism for ethnocultural continuity, with endogamy playing a key role in ensuring coherent enculturation. As such, individual behaviour in terms of marital choice can also shape the future of the ethno-cultural group.

Thus far, research on factors such as perceived similarity, attraction and social network approval that predict ethnic endogamy and its prelude, selective dating, has been interpreted as a manifestation of ethnocentrism. In contrast, a predictive model was posited wherein a greater ideological impetus underlies both endogamy and selective dating - that of individual concerns for collective continuity. Furthermore, it was suggested that such concerns were shaped by individual awareness of social representations of ethnic history.

In Chapter three, the continuity of diaspora Jewry was compared to indigenous Māori and diaspora Chinese in order to understand how shared and unique collective experiences in the past and present shape the current acculturation of individuals. Hypotheses on the intensity of endogamy intentions, incidence of selective dating behaviour, and the importance and function of individual concerns for ethno-cultural continuity and awareness of ethnic history were drawn from ethnographic material on the long-term acculturation of these three ethno-cultural groups.
\end{abstract}

The constructs of Motivation for Ethno-cultural Continuity (MEC) and measures of individual awareness of social representations of ethnic history were conceptualised in Chapter four based on qualitative analysis of three focus group discussions with Jewish 
$(\mathrm{n}=8)$, Māori $(\mathrm{n}=5)$ and Chinese $(\mathrm{n}=5)$ New Zealanders. In Chapter five, quantitative measures of MEC, subjects of remembrance (WHO), ethno-historical consciousness (WHAT), and vicarious experience of ethnic history (HOW) were developed and validated against measures of Collective Self-Esteem, Perceived Collective Continuity, Perceived Group Entitativity and Assimilation in a pilot study with 152 Jews from Sydney, Australia. Two quantitative studies were subsequently conducted to test the predictive model of endogamy: A cross-cultural study in Chapter six compared New Zealand Jews $(n=106)$, Māori ( $\mathrm{n}=103)$, and Chinese ( $\mathrm{n}=102)$; a cross-national study in Chapter seven compared Jewish continuity in New Zealand $(n=106)$, Australia $(n=108)$, Canada $(n=160)$ and the United States ( $\mathrm{n}=107)$.

The conclusions drawn in Chapter eight highlight that vitality affects continuity across ethno-cultural groups such that MEC is more important and functionally predictive of endogamy intentions only for 'small peoples'; and within ethno-cultural groups endogamy intentions and selective dating is thwarted in small communities. For the Jewish and Māori samples, MEC fully mediated the relation between ethno-cultural identity and intentions for endogamy and was a consistent and stronger predictor than similarity, attraction, and social network approval. For the Chinese sample, attraction and approval were the only significant predictors. Furthermore, individual awareness of social representations of ethnic history mediated the relation between ethno-cultural identity and MEC such that identity predicted ethno-historical consciousness (WHAT), that predicted a vicarious experience of ethnic history (HOW), that in turn predicted MEC. Overall the results demonstrate that in the field of long-term acculturation it is important to examine psychological variables such as MEC and individual awareness of social representations of ethnic history that provide internal momentum for the continuity of ethno-cultural groups. 


\section{TABLE OF CONTENTS}

Acknowledgements

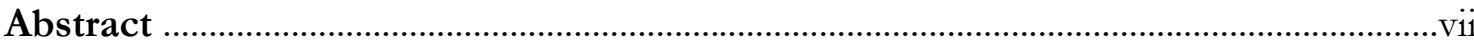

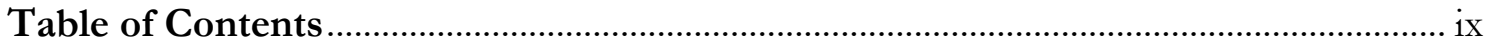

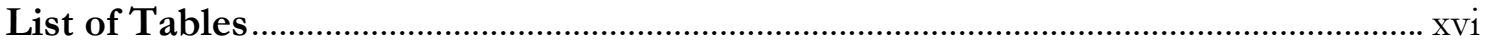

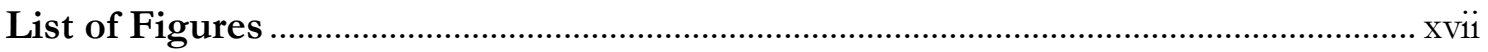

Chapter 1: Long-term Acculturation and Ethno-cultural Continuity ...........................19

The Value of Cultural Diversity and the Psychology of Culture Contact............................ 19

The Universal Declaration on Cultural Diversity............................................................... 19

Understanding culture contact: Definitions of acculturation at the group and

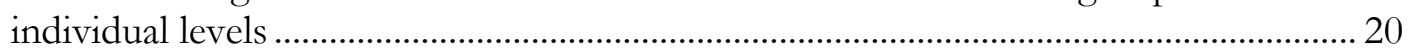

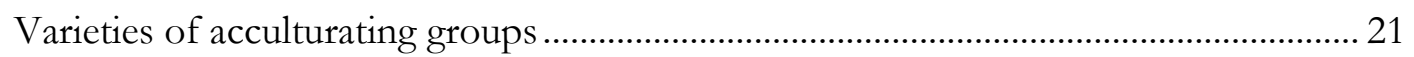

Current Approaches to Acculturation Research.................................................................... 22

Examining the individual and collective experience of acculturation ............................. 22

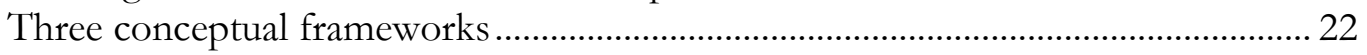

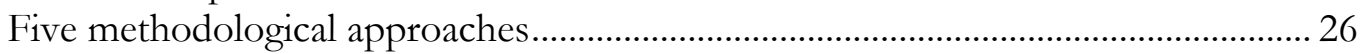

Impact of the larger society on individual and collective acculturation...........................29

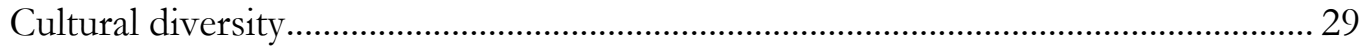

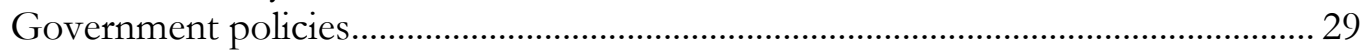

Acculturation expectations of host society members .................................................. 31

Discrimination and inter-group attitudes..................................................................... 32

A new psychological approach: Investigating the long-term acculturation of

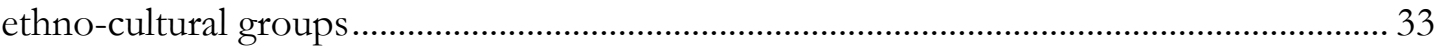

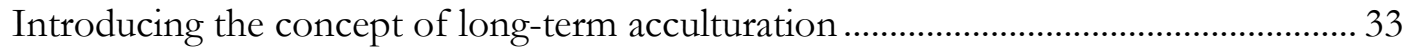

Continuity as an acculturation goal for diaspora and indigenous peoples ..................... 35

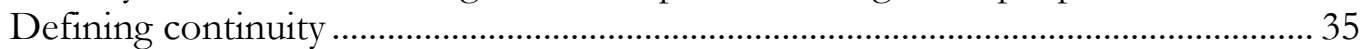

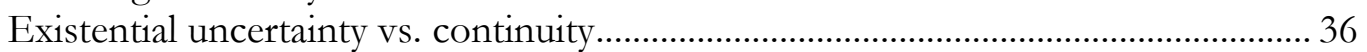

The impact of post-modernism and globalisation on continuity ................................ 38

Group-level indicators of continuity: psycho-socio-cultural .............................................. 39

Impact of the ethno-cultural group and larger society on collective continuity........... 40

Chapter 2: Internal Dynamics of Continuity: Cultural Transmission, the Centrality of Endogamy, and the Influence of Ethnic History ……………………... 45

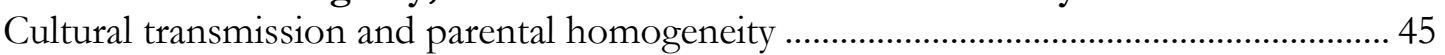

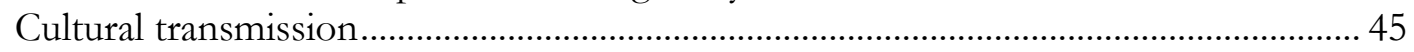

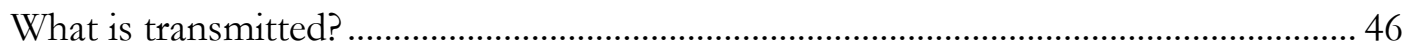

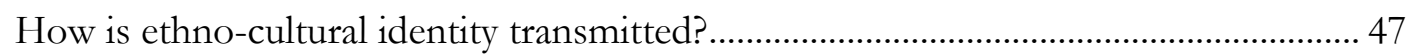

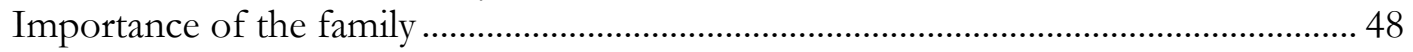

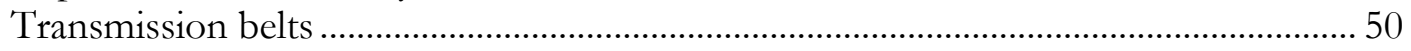

When I do affects how we do: Consequences of individual behaviour for

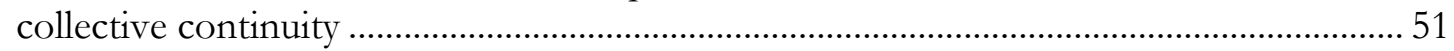

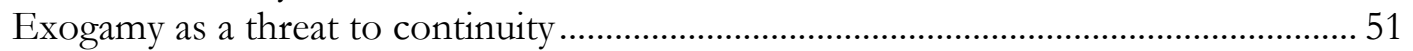

On mixed heritage: Effects for the individual vs. collective............................................. 52

Prelude to marriage: Preferences in romantic partners and selective dating.................. 53

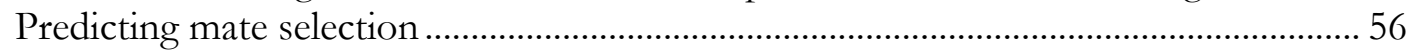

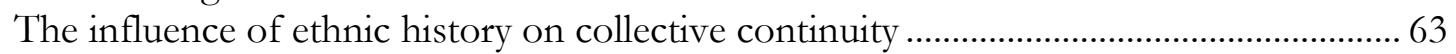




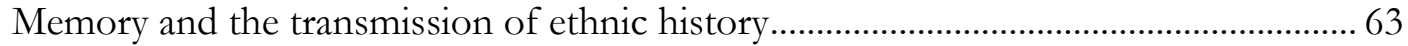

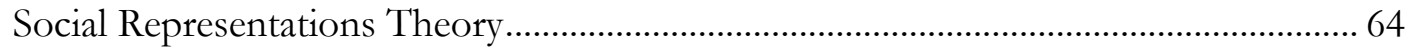

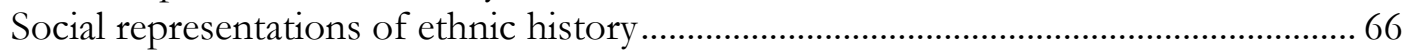

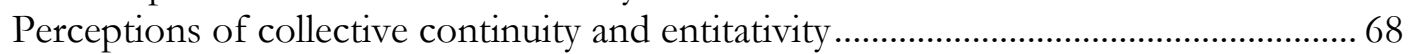

Representations of ethnic history at the group vs. individual level ..................................69

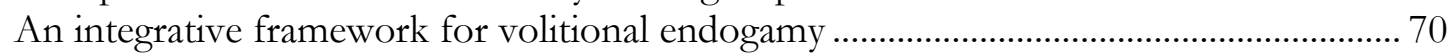

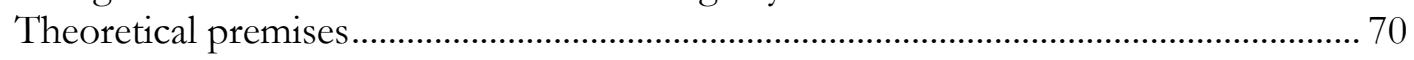

Defining endogamy and selective dating as dependent variables ................................. 70

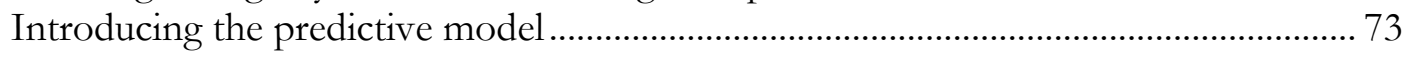

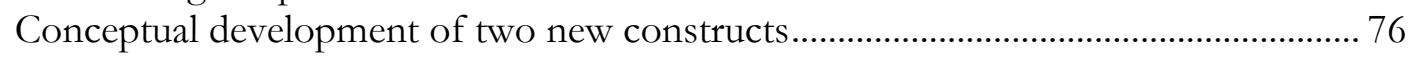

Chapter 3: The Long-Term Acculturation of Jews, Māori and Chinese ........................ 77

The Jewish Diaspora as a Case Study of Ethno-cultural Continuity .................................... 77

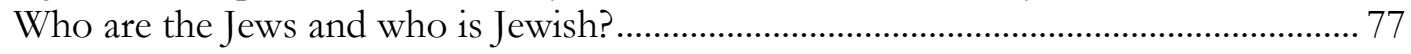

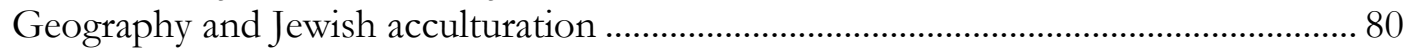

Historical and contemporary influences on long-term Jewish acculturation.................. 84

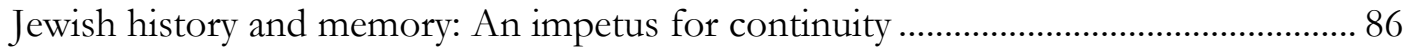

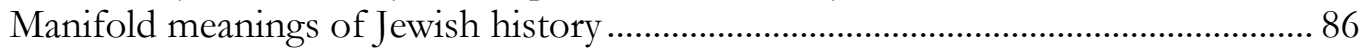

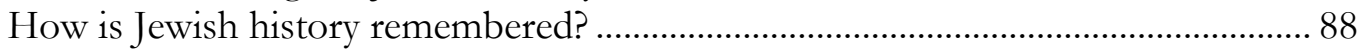

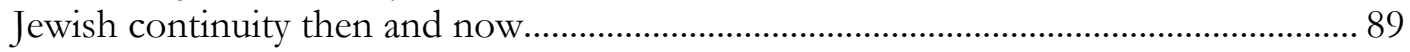

Strategies for ensuring future Jewish continuity …………………........................... 92

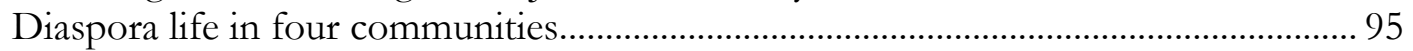

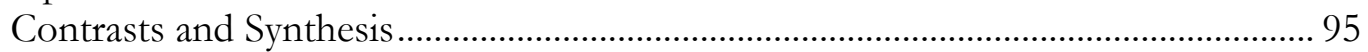

Māori as a Case Study of Indigenous Continuity....................................................................... 99

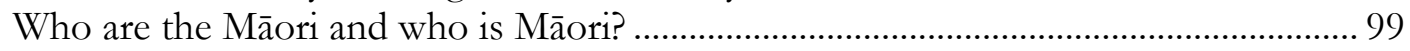

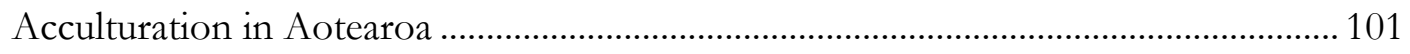

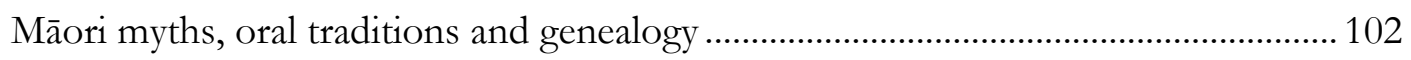

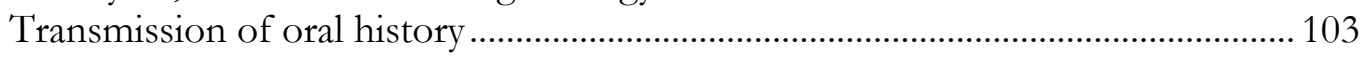

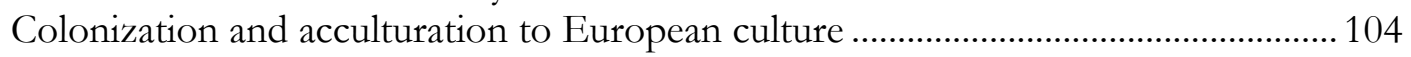

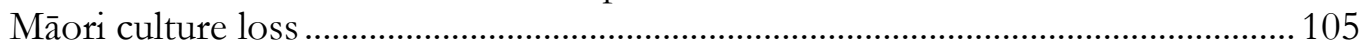

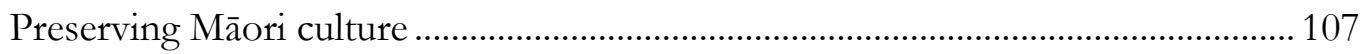

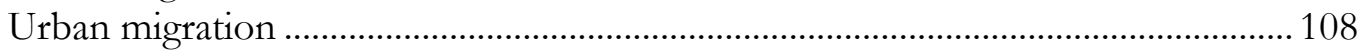

Māori vitality indices and socio-economic disadvantage _.........................................109

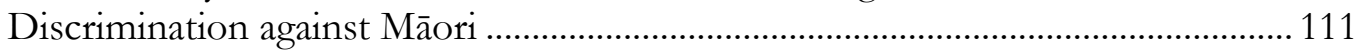

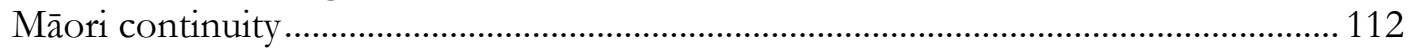

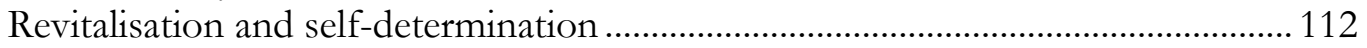

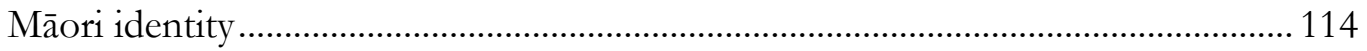

Exogamy, identification and transmission................................................................. 115

Chinese in New Zealand: A Case Study of Ethno-cultural Continuity of a Visible

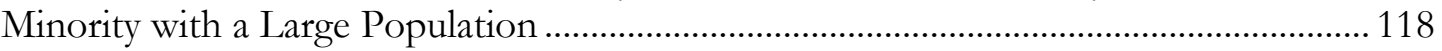

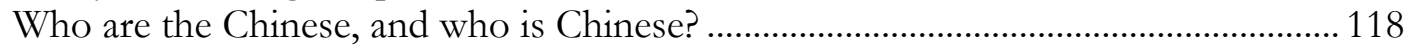

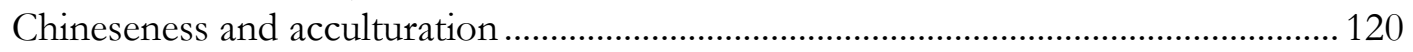

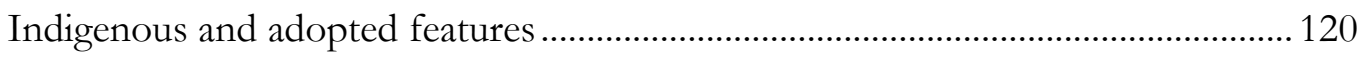

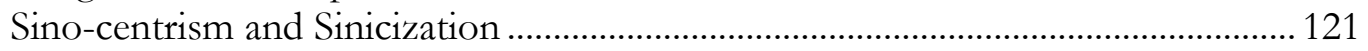

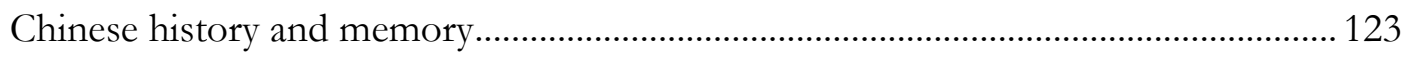

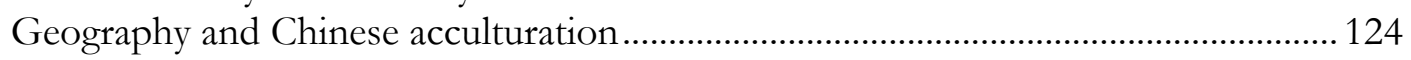

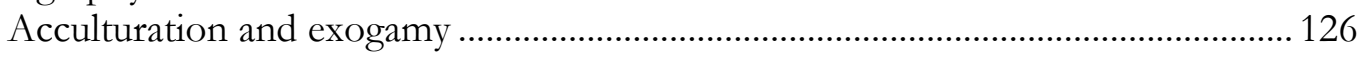

Division and Continuity ............................................................................................. 127

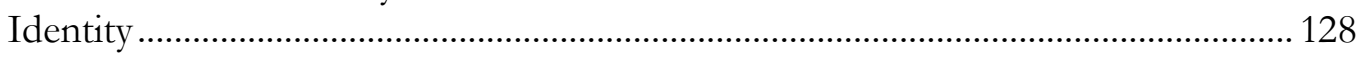

Chinese continuity: Endurance at the global and local levels.......................................... 129

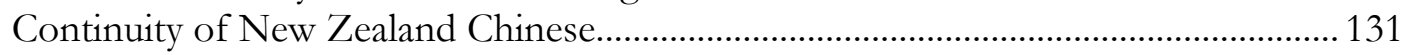


Sojourners, Immigrants, and 'Yellow Peril' ................................................................. 131

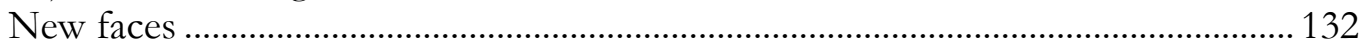

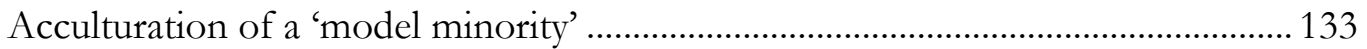

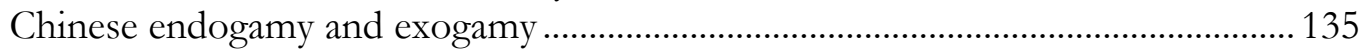

Issues for Comparing the Acculturation Patterns of Fiddlers with

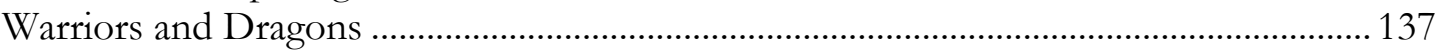

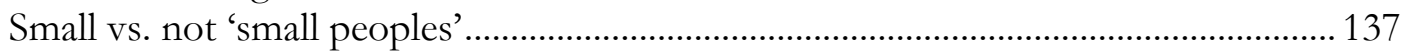

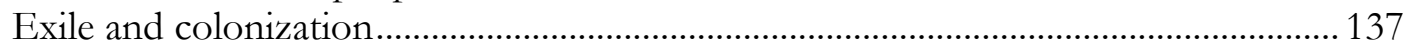

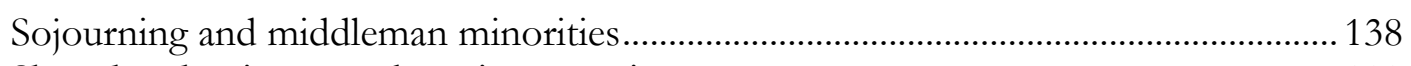

Shared and unique acculturation experiences .................................................................. 139

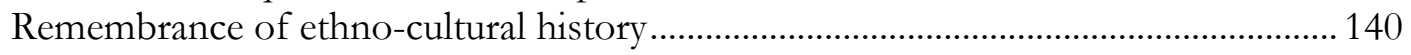

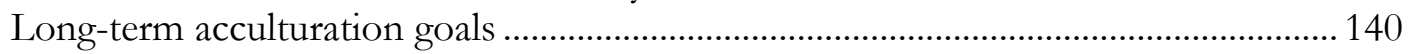

Intermarriage and endogamy as a strategy for continuity .............................................. 141

General hypotheses on the influence of vitality and collective acculturation

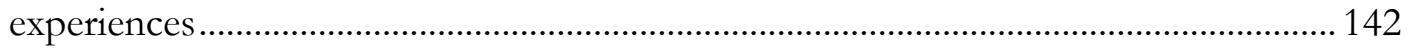

Chapter 4: A Qualitative Study of Endogamy, Continuity and History......................145

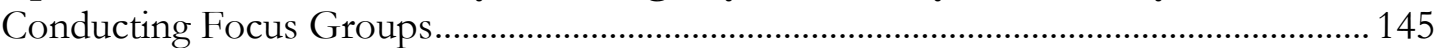

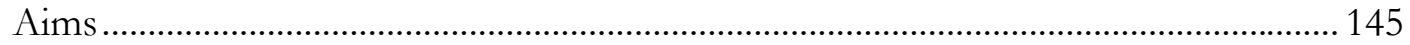

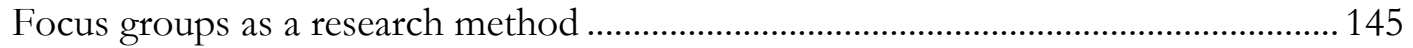

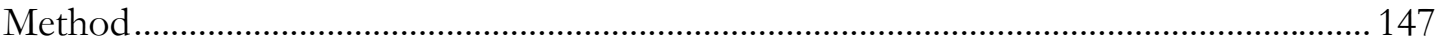

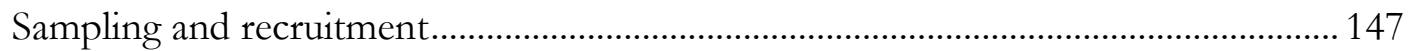

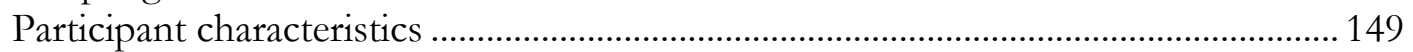

Focus group question guide ....................................................................................... 150

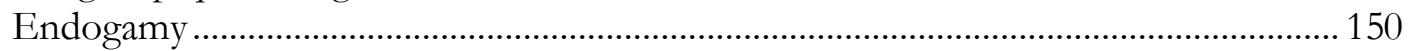

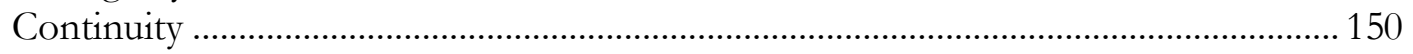

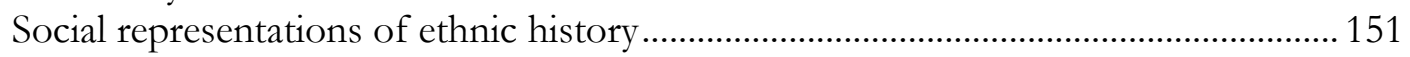

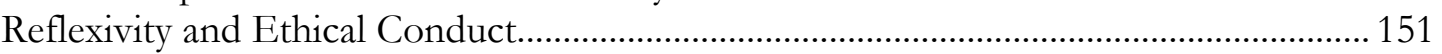

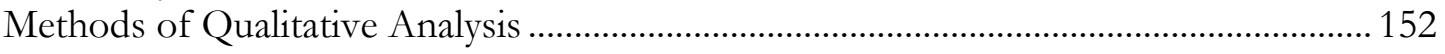

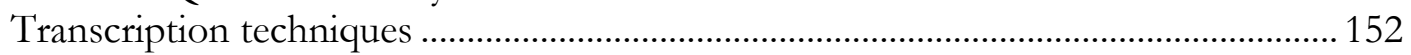

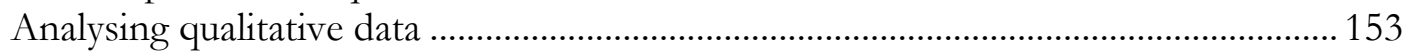

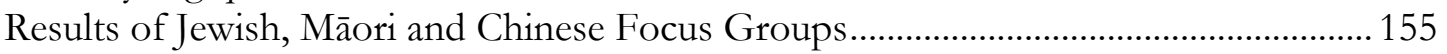

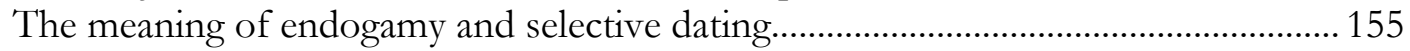

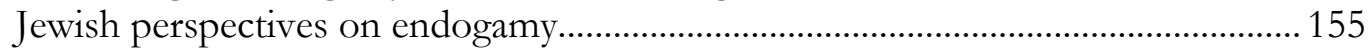

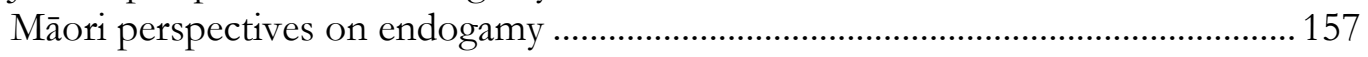

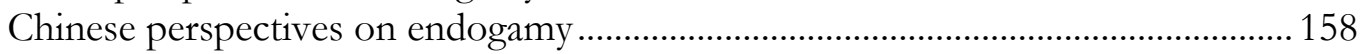

I Don't, I Don't Care and I Do: Perspectives on endogamy and selective dating

of Jews, Māori and Chinese ......................................................................................... 161

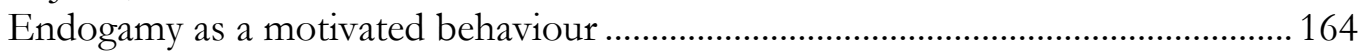

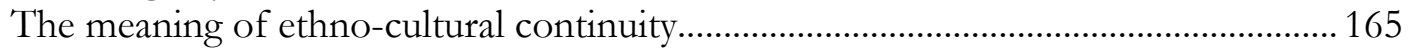

Ethnic heritage and the self: Cultural maintenance and the polemics of

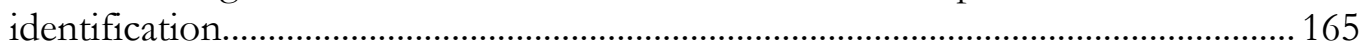

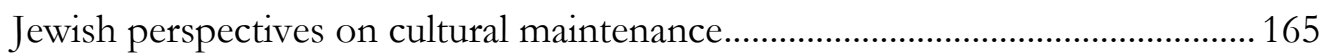

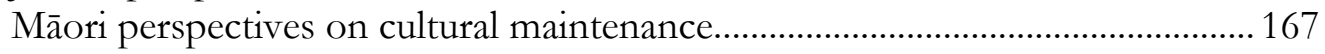

Chinese perspectives on cultural maintenance …….................................................. 169

Jewish, Māori and Chinese perspectives on cultural maintenance ....................... 170

To be and to belong: Internal polemics of identification ...................................... 171

Ethnic heritage and the family: Cultural transmission ............................................... 172

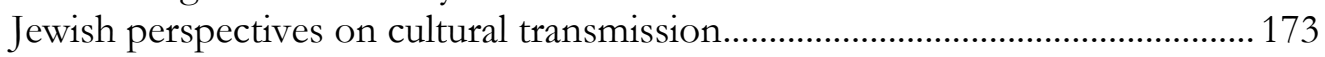

Māori perspectives on cultural transmission................................................................ 174

Chinese perspectives on cultural transmission ..................................................... 175 
Suggested methods of cultural transmission and ensuring ethno-cultural continuity

Jewish comments on methods of cultural transmission ....................................... 179

Māori comments on methods of cultural transmission .........................................180

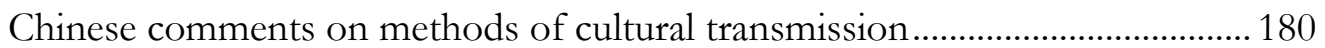

Methods of ensuring ethno-cultural continuity..................................................... 181

Ethnic heritage and the collective: Cultural endurance and issues of

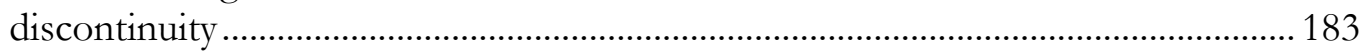

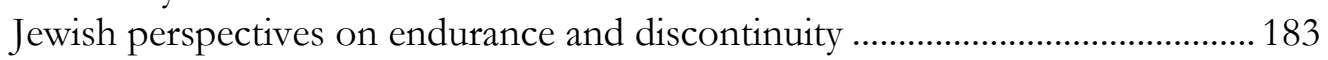

Māori perspectives on endurance and discontinuity ............................................ 185

Chinese perspectives on endurance and discontinuity ............................................ 187

Emerging theoretical construct: Motivation for Ethno-cultural Continuity ......... 188

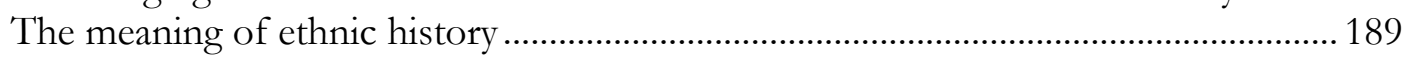

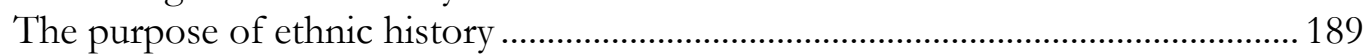

The importance of ethnic history for Jews .............................................................. 189

The importance of ethnic history for Māori........................................................... 190

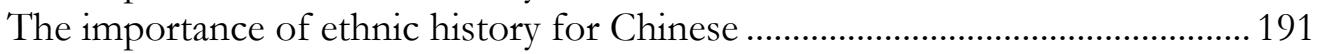

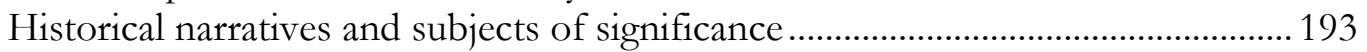

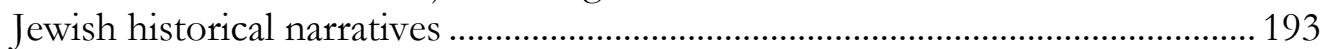

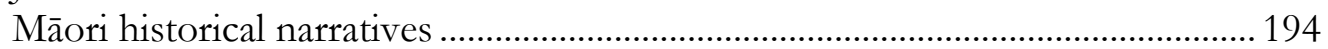

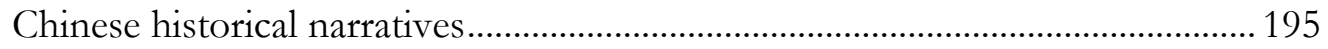

Subjects of remembrance in Jewish, Māori and Chinese history......................... 195

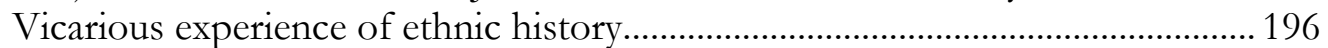

Emerging theoretical constructs: Individual awareness of social representations

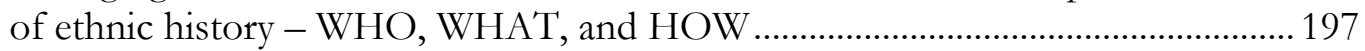

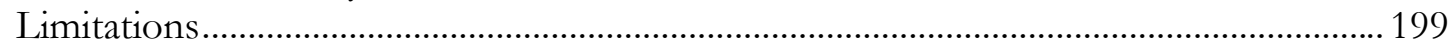

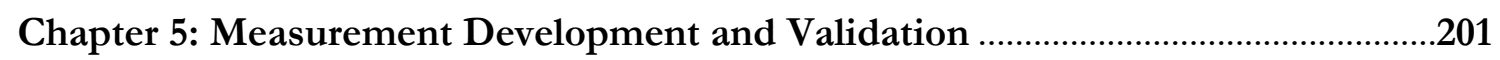

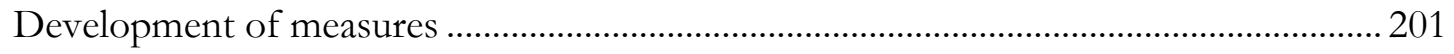

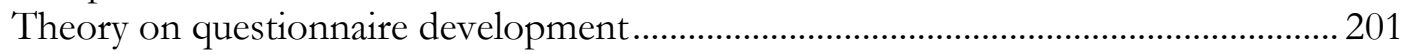

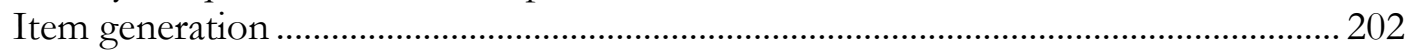

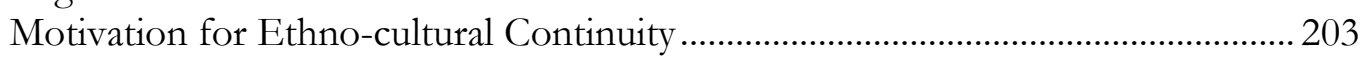

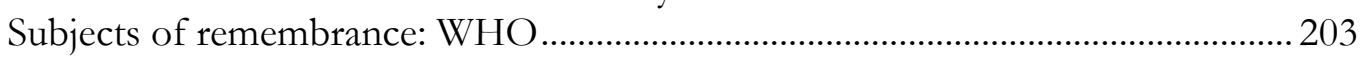

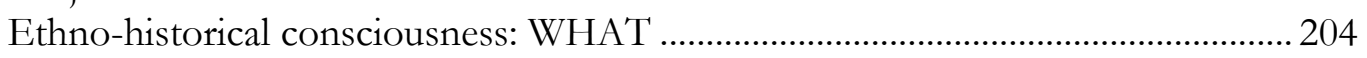

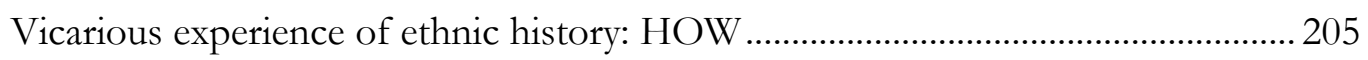

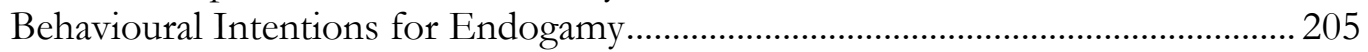

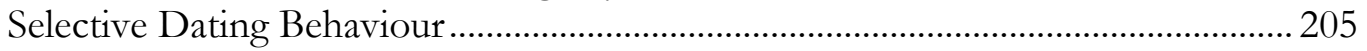

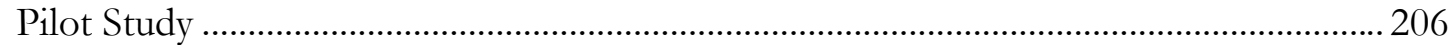

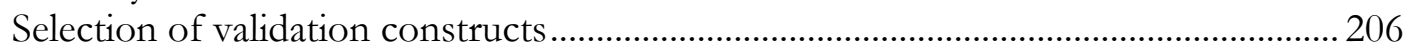

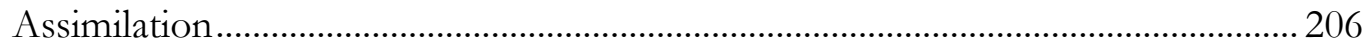

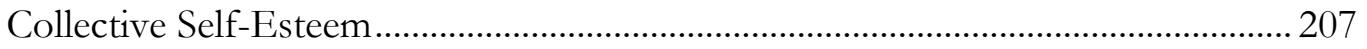

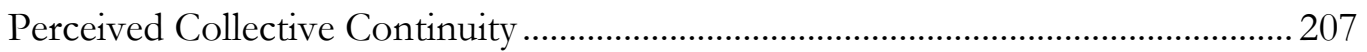

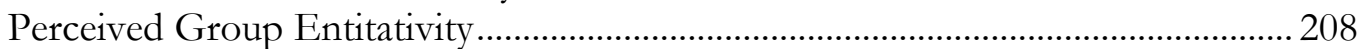

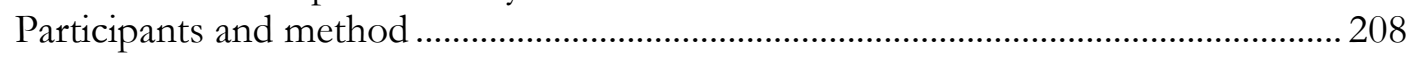

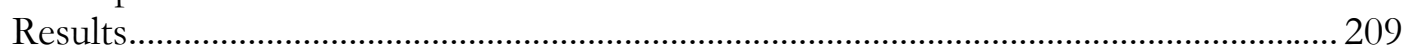

Motivation for Ethno-cultural Continuity (MEC) scale ........................................... 210

Subjects of remembrance - WHO scale ......................................................................... 212

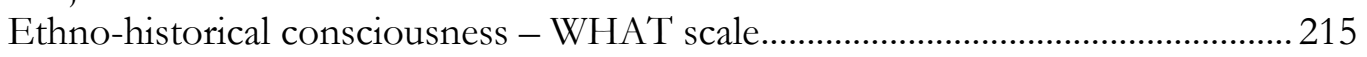

Vicarious experience of ethnic history - HOW scale .............................................. 217

Behavioural intentions for endogamy and selective dating behaviour ....................218

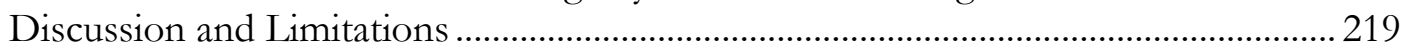




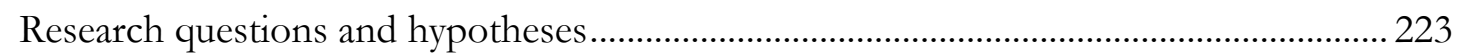

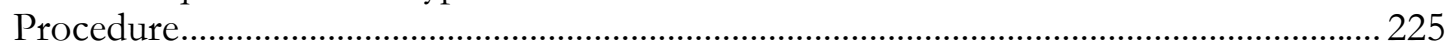

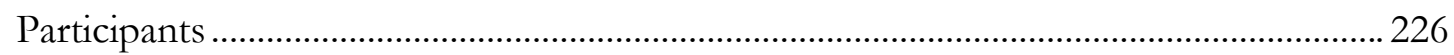

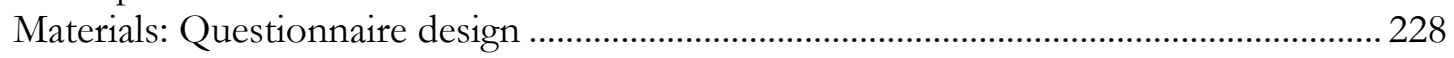

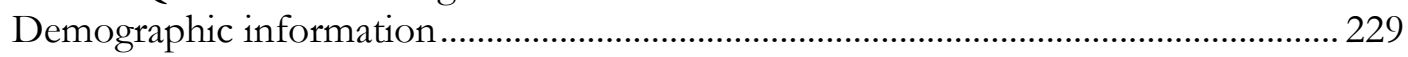

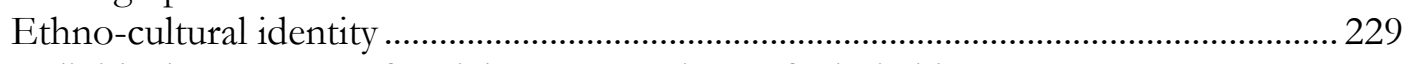

Individual awareness of social representations of ethnic history:

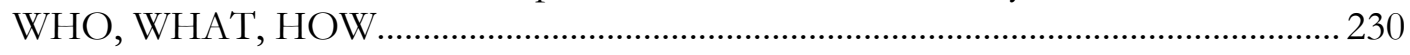

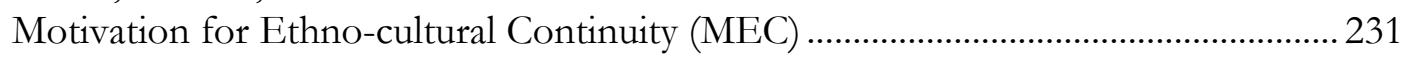

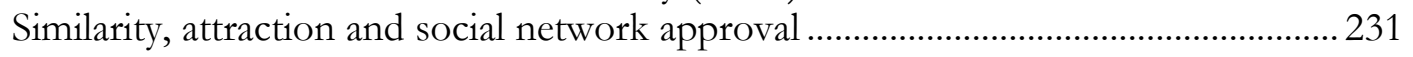

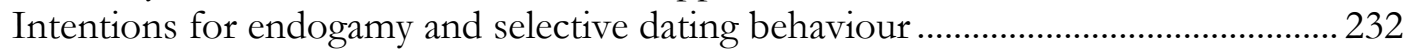

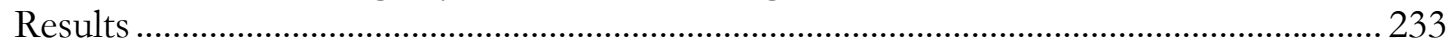

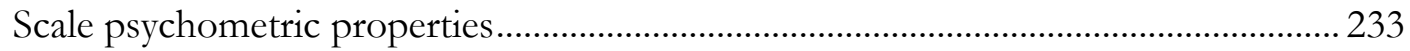

Ethno-cultural identity, similarity, attraction and social network approval ............ 234

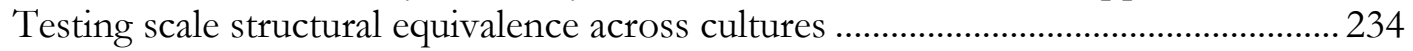

Testing the structural equivalence of Motivation for Ethno-cultural Continuity.. 235

Testing the structural equivalence of subjects of remembrance ...............................2240

Testing the structural equivalence of ethno-historical consciousness ...................... 244

Testing the structural equivalence of vicarious experience of ethnic history ......... 246

Summary of structural invariance across groups ......................................................... 249

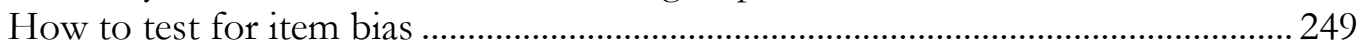

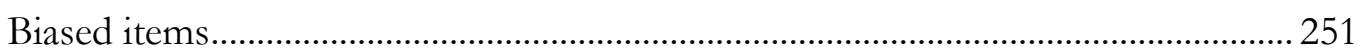

Integrating results from the CFA and item bias analysis.......................................... 251

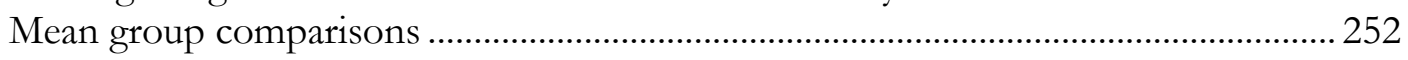

Testing the predictive model of volitional endogamy across samples of

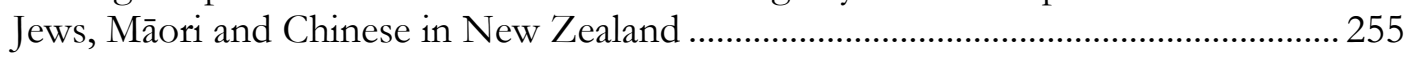

Testing the model among New Zealand Jews ............................................................. 257

Testing the model among Māori............................................................................. 259

Testing the model among Chinese ............................................................................. 262

Testing the cross-cultural generalisability of the predictive model ............................ 263

How to test for invariant paths across ethnic groups .........................................263

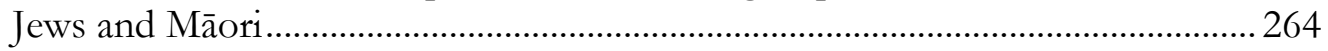

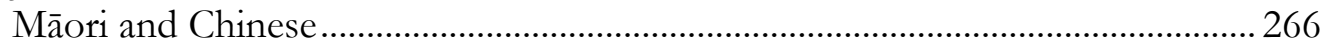

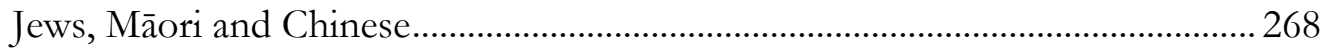

Discussion: Comparing the Ethno-cultural Continuity of Fiddlers with

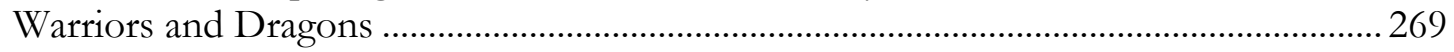

Investigating mean group differences across three ethnic groups..................................269

Investigating the predictive model across three ethnic groups ...................................... 271

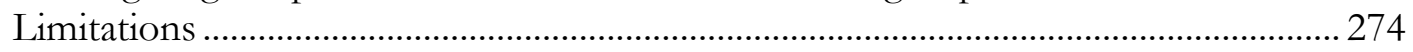

Chapter 7: A Cross-national Comparison of Jewish Continuity in the Diaspora .... 277

Testing a predictive model for volitional endogamy across Jews in

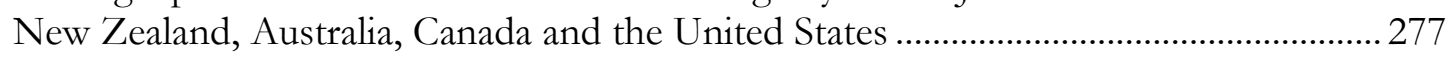

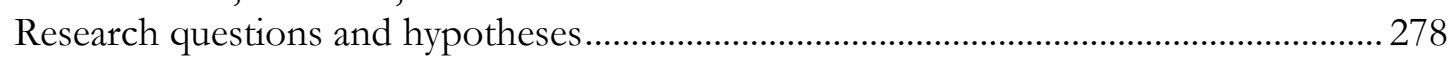

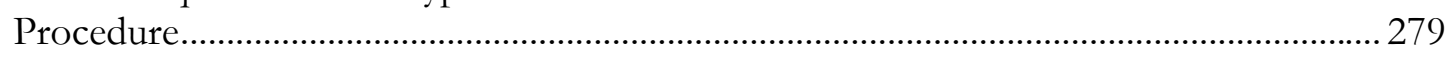

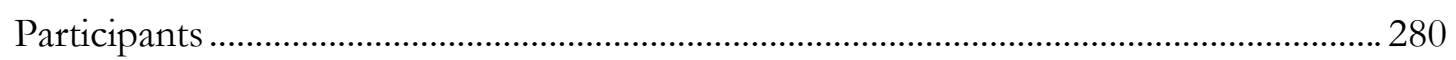

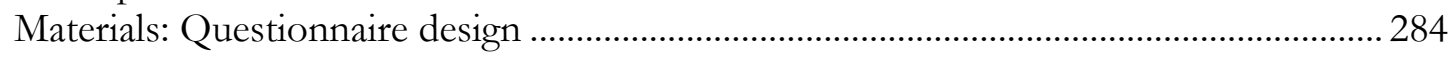

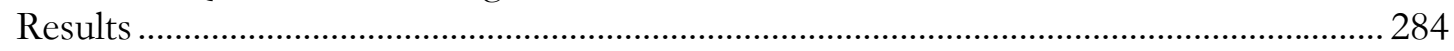




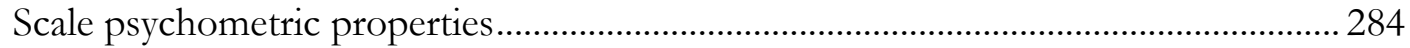

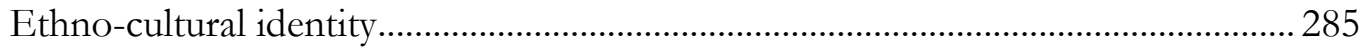

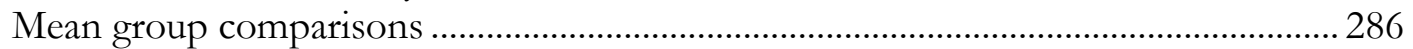

Testing the predictive model across four samples of diaspora Jews ............................... 288

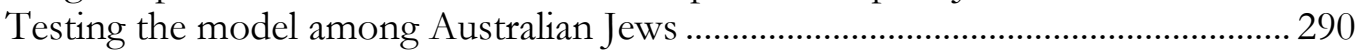

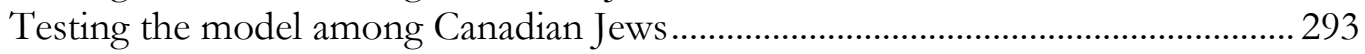

Testing the model among American Jews ...............................................................296

Testing the generalisability of the model across communities that vary in vitality 298

Shared paths across New Zealand, Australian, Canadian and American Jews .. 299

Summary: Shared and unique paths across four diaspora Jewish samples.......... 303

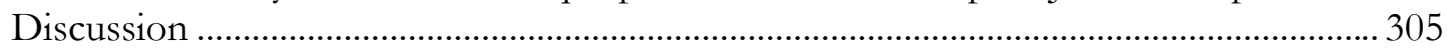

Investigating mean group differences across four Jewish communities ........................ 305

Investigating the predictive model across four Jewish communities ............................ 309

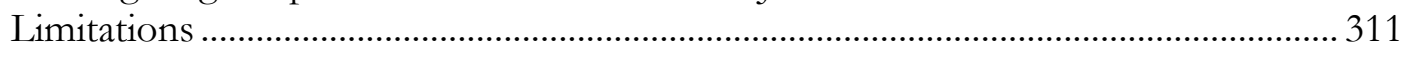

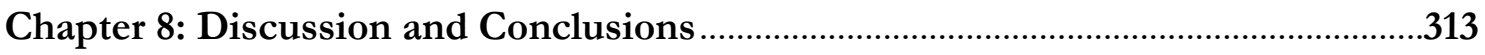

Contribution to research on mate selection ........................................................................... 313

The role of Motivation for Ethno-cultural Continuity in predicting endogamy

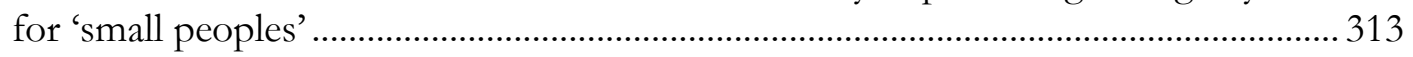

Contribution to research on social representations of history............................................ 315

The structure of individual awareness of social representations of ethnic history..... 315

The function of ethno-historical consciousness and vicarious experience of ethnic

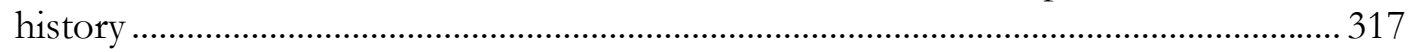

Contribution to acculturation theory and research ............................................................ 317

Investigating long-term acculturation and ethno-cultural continuity ............................ 317

The influence of ethno-cultural vitality on continuity ..................................................... 319

'Small peoples' and the effect of vitality across ethno-cultural groups .................... 319

Small communities and the effect of vitality within ethno-cultural groups............ 320

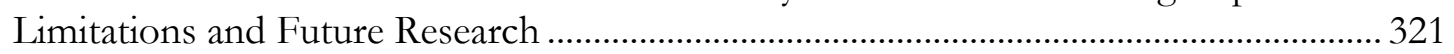

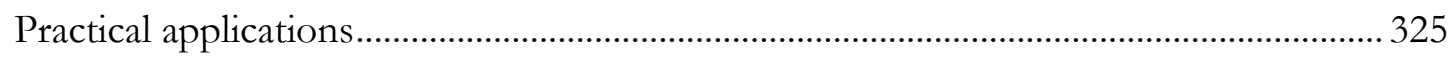

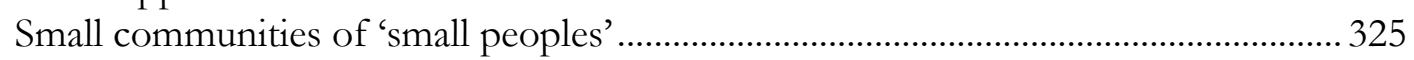

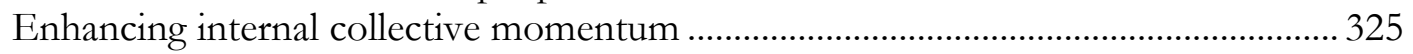

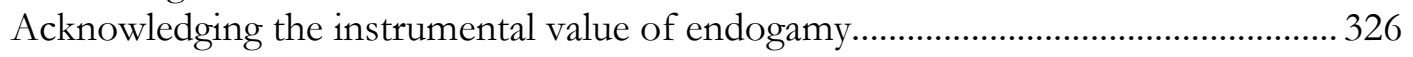

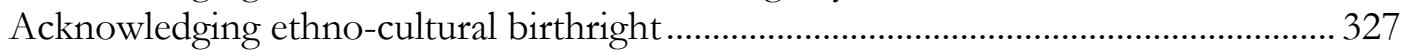

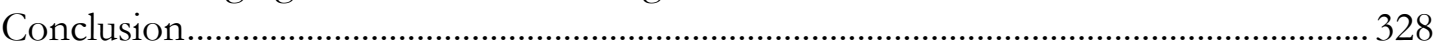


Appendix A: Cultural streams of the Jewish people due to long-term acculturation in the diaspora.

Appendix B: Jewish religious diversity due to different approaches to acculturation ....... 367

Appendix C: Sources for Diaspora Life in Four Communities ........................................... 369

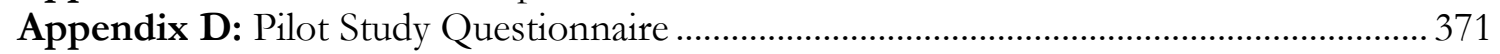

Appendix E: Questionnaire for Cross-cultural and Cross-national Studies ......................... 381

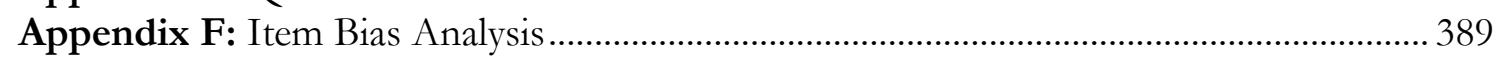

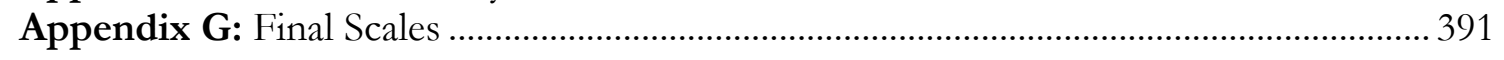




\section{LIST OF TABLES}

Table 1.1: Impact of the larger society on individual vs. group acculturation ......................... 42

Table 3.1: Geographical distribution of world Jewry................................................................. 83

Table 4.1: Methods of cultural transmission and ensuring ethno-cultural continuity ......... 178

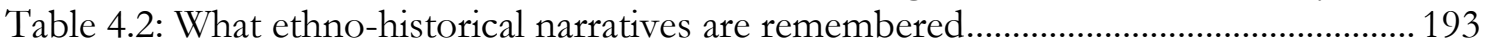

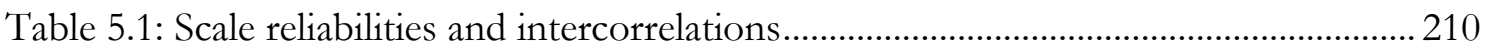

Table 5.2: MEC item loadings, 1-factor structure MLE (6 iterations) .................................... 211

Table 5.3: WHO item loadings, 3-factor structure MLE with oblique rotation

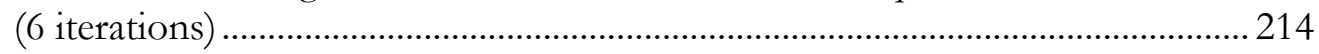

Table 5.4: WHAT item loadings, 1-factor structure MLE (4 iterations) ……….................... 216

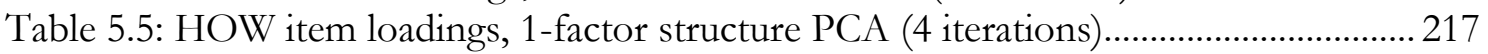

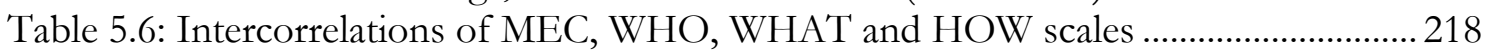

Table 6.1: Participant characteristics in the cross-cultural study.............................................226

Table 6.2: Scale psychometric properties (cross-cultural comparison) .................................... 233

Table 6.3: Factor loadings of the 18-item MEC scale for Jews, Māori and Chinese ........... 238

Table 6.4: CFA fit indices for the 18-item MEC scale for Jews, Māori and Chinese .......... 239

Table 6.5: CFA fit indices for the 10-item MEC scale for Jews, Māori and Chinese .......... 239

Table 6.6: CFA fit indices for the 12-item WHO scale for Jews, Māori and Chinese......... 241

Table 6.7: Factor loadings of the 3-factor 12-item WHO scale for Jews ............................... 242

Table 6.8: Factor loadings of the single-factor 12-item WHO scale for Māori and Chinese.

Table 6.9: CFA fit indices for the single-factor 9-item WHO scale for Māori and Chinese

Table 6.10: Factor loadings of the single-factor 12-item WHAT scale for Jews, Māori and Chinese

Table 6.11: CFA fit indices for the 12-item WHAT scale for Jews, Māori and Chinese ... 246

Table 6.12: CFA fit indices for the 8-item WHAT scale for Jews, Māori and Chinese ..... 246

Table 6.13: Factor Loadings of the 7-item HOW scale .......................................................... 247

Table 6.14: CFA fit indices for the 7-item HOW scale for Jews, Māori and Chinese......... 248

Table 6.15: CFA fit indices for the 6-item HOW scale for Jews, Māori and Chinese......... 248

Table 6.16: Scale reliabilities including unbiased items for Jews, Māori and Chinese ......... 252

Table 6.17: Descriptive statistics (adjusted mean, std.error) for the revised scales for Jews, Māori and Chinese ........................................................................................... 252

Table 6.18: Reliability of item parcels for the latent variables

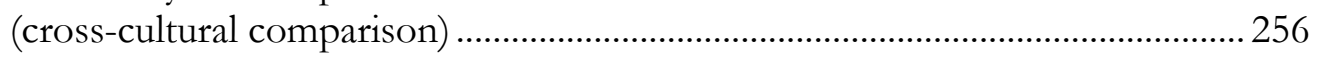

Table 7.1: Population and sample characteristics in the cross-national study .......................281

Table 7.2: Scale psychometric properties (cross-national comparison) ………...................... 285

Table 7.3: Descriptive statistics (adjusted mean, std.error) for

New Zealand, Australian, Canadian and American Jews.....................................2 286

Table 7.4: Reliability of item parcels for the latent variables (cross-national comparison) 290

Table 7.5: Shared and unique paths among New Zealand, Australian,

Canadian and American Jews. 304 


\section{LIST OF FIGURES}

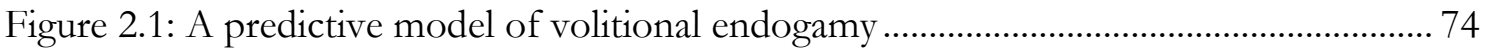

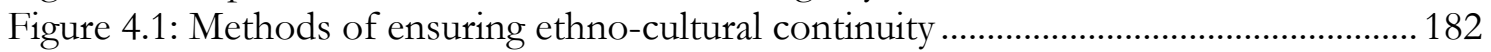

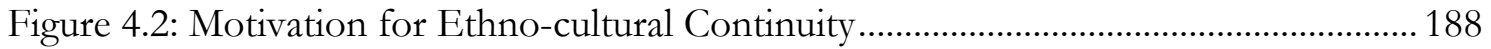

Figure 4.3: Individual awareness of social representations of ethnic history ......................... 198

Figure 6.1: An individual-level predictive model for volitional endogamy ...........................222

Figure 6.2: CFA of Motivation for Ethno-cultural Continuity (1-factor) ................................235

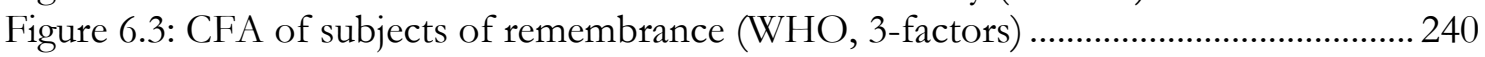

Figure 6.4: CFA of subjects of remembrance (WHO, 1-factor) ............................................... 240

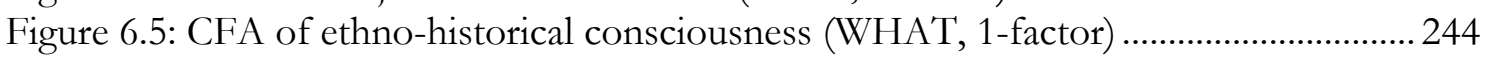

Figure 6.6: CFA of vicarious experience of ethnic history (HOW, 1-factor) ....................... 247

Figure 6.7: Testing a predictive model of volitional endogamy ................................................ 256

Figure 6.8: A predictive model of endogamy among New Zealand Jews ............................ 257

Figure 6.9: Including ethno-historical consciousness in a predictive model of endogamy

among New Zealand Jews ................................................................................. 259

Figure 6.10: A predictive model of endogamy among Māori.................................................. 260

Figure 6.11: Including ethno-historical consciousness in a predictive model of endogamy among Māori ........................................................................................................... 261

Figure 6.12: A predictive model of endogamy among Chinese .............................................. 262

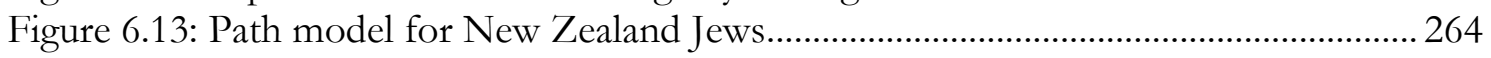

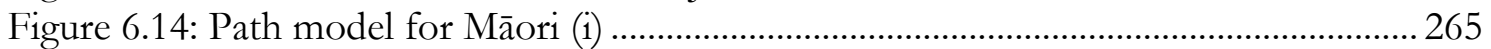

Figure 6.15: Multi-group path model for New Zealand Jews and Māori ............................. 265

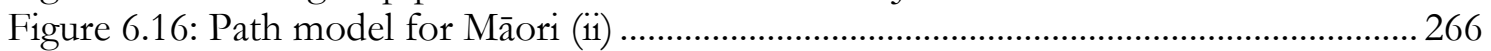

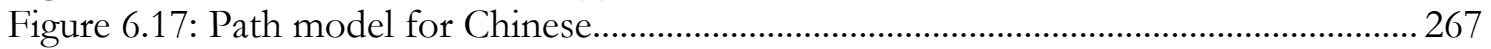

Figure 6.18: Multi-group path model for Māori and Chinese ..............................................267

Figure 7.1: Religious identity profiles of Jewish community samples ....................................2. 283

Figure 7.2: Testing a predictive model of volitional endogamy ............................................... 289

Figure 7.3: A predictive model of endogamy among Australian Jews ................................... 291

Figure 7.4: Including ethno-historical consciousness and vicarious experience of ethnic

history in a predictive model of endogamy among Australian Jews .................. 292

Figure 7.5: A predictive model of endogamy among Canadian Jews ...................................... 294

Figure 7.6: Including ethno-historical consciousness and vicarious experience of ethnic

history in a predictive model of endogamy among Canadian Jews ..................... 295

Figure 7.7: A predictive model of endogamy among American Jews ..................................... 296

Figure 7.8: Including ethno-historical consciousness and vicarious experience of ethnic history in a predictive model of endogamy among American Jews ................. 297

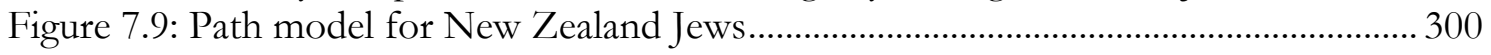

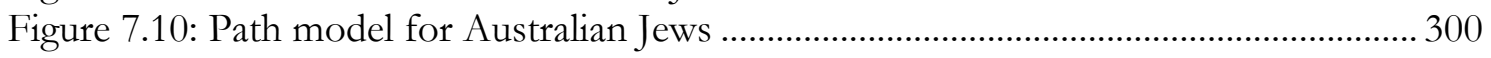

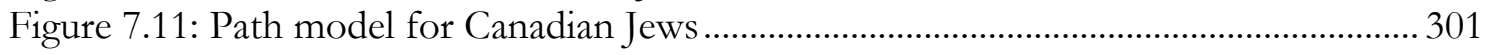

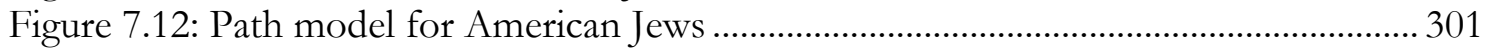

Figure 7.13: Multi-group path model for New Zealand, Australian,

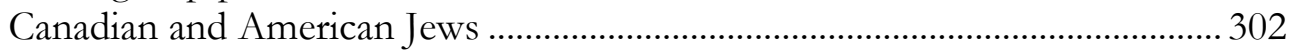

Figure 7.14: Shared and unique paths in a predictive model of endogamy among diaspora Jews. 


\section{CHAPTER 1: LONG-TERM ACCULTURATION AND ETHNO-CULTURAL CONTINUITY}

\section{The Value of Cultural Diversity and the Psychology of Culture Contact}

\section{The Universal Declaration on Cultural Diversity}

"The UNESCO Universal Declaration on Cultural Diversity [...] raises cultural diversity to the level of 'the common heritage of humanity', 'as necessary for humankind as biodiversity is for nature' and makes its defence an ethical imperative indissociable from respect for the dignity of the individual” (Koïchiro Matsuura, Director-General of UNESCO, 2001, p. 1).

The 192 Member States of the General Assembly of the United Nations unanimously adopted the guiding principles in this declaration, defining culture as "the set of distinctive spiritual, material, intellectual and emotional features of a society or a social group", encompassing "in addition to art and literature, lifestyles, ways of living together, value systems, traditions and beliefs" (UNESCO, 2001, p.2). This revolutionary document of the likes of the Universal Declaration of Human Rights goes beyond the acknowledgement of cultural diversity, to affording it protection for posterity and recognising it as the source of human creativity.

As stated in Article 7:

"Creation draws on the roots of cultural traditions, but flourishes in contact with other cultures. For this reason, heritage in all its forms must be preserved, enhanced and handed on to future generations as a record of human experience and aspirations, so as to foster creativity in all its diversity and to inspire genuine dialogue among cultures" (UNESCO, 2001, p. 14, my italics).

The need to take action for the preservation of cultural diversity is all the more called for in the face of globalisation, a force that has enabled massive intercultural dialogue while rendering diversity vulnerable (UNESCO, 2005). Thus, the benefits of culture contact, 
namely dialogue and creativity, are juxtaposed with the disadvantages of this contact, namely challenges to cultural continuity. Chief Emeka Anyaoku, Commonwealth Secretarygeneral, expounds that "the challenge is to devise a 'vision' of the way in which people can live harmoniously in the larger society, while at the same time being able to maintain, rather than dilute or lose, a strong sense of belonging to their particular cultural, ethnic, religious or other community" (UNESCO, 1999). To take up this challenge we must understand the dynamics of culture contact, and cross-cultural psychology affords us the necessary tools.

\section{Understanding culture contact: Definitions of acculturation at the group and individual levels}

The phenomenon of culture contact has been examined under the rubric of acculturation. Traditionally studied in anthropology and sociology at the group level, acculturation was defined as follows by Redfield, Linton and Herkovits (1936, p. 149) "Acculturation comprehends those phenomena which result when groups of individuals having different cultures come into continuous first-hand contact with subsequent changes in the original culture patterns of either or both groups." At this level, socio-political and economical changes can occur, through both external forces, such as the introduction of literacy, and internal forces stemming from innovation (Berry, 1990). In addition, culture change can be indirect, delayed and reactive (Berry, 2003). These group-level changes can be contrasted to transformations that occur at the individual level, through personal experiences of intercultural contact (Graves, 1967), the latter being the principal focus of psychological research. This distinction is particularly important, considering individual variation in cultural identification, attitudes and behaviour (Berry, 1990; Berry \& Sam, 1997). These variations can be examined as both an actual individual state and as a process that evolves over time, incorporating predictive and outcome variables (Ward, 1996). In addition, the context of culture contact has been examined, differentiating contact that occurs when individuals move between nations from contact within culturally diverse nations (Ward, 
Bochner \& Furnham, 2001). Although the above definitions of acculturation acknowledge that culture change can occur in both groups, in practice the larger group or host society does not have the same potential for culture change that the smaller groups or minorities experience. This vulnerability is recognised by UNESCO in the Universal Declaration on Cultural Diversity.

\section{Varieties of acculturating groups}

Smaller acculturating groups in plural societies may be distinguished according to the three dimensions of mobility, permanence and voluntariness (Berry \& Sam, 1997). First, psychological research distinguishes between individuals who make cross-cultural relocations, such as refugees and immigrants, from members of sedentary groups, in particular indigenous peoples and established ethno-cultural communities. Second, temporary cross-cultural travellers such as sojourners are distinguished from immigrants who move permanently. Third, the voluntary engagement in intercultural contact of immigrants and sojourners is distinguished from the forced, involuntary intercultural experiences of refugees and indigenous peoples. Those individuals who undergo culture contact involuntarily are "pushed" in contrast to those who experience contact voluntarily and are "pulled" towards the culture of the larger society. Furthermore, these groups may differ in their level of involvement in the larger society, ranging from observation, participation and contribution, to conversion and exploitation (Ward, Bochner \& Furnham, 2001).

There are three major categories of sojourners: tourists, international students and business expatriates. They all share similar culture-contact experiences of a short, finite duration with specific goals in mind, expecting to return to their home country (Bochner, 2006). In contrast, asylum seekers and refugees share negative experiences such as famine, war and natural disasters in their homeland as they are "pushed" to a country of 
resettlement; often one they have not expressly selected (Allen, Basilier Vaage \& Hauff, 2006). Underlying their experiences of culture contact may be a shared motivation for selfpreservation (Tartakovsky \& Schwartz, 2001). On the other hand, pulled by a range of personal and socio-political factors, immigrants relocate voluntarily to a selected country with expectations of improving their economic status and family reunification (van Oudenhoven, 2006). As far as ethno-cultural groups are concerned, they are composed of individuals who continue to identify with their heritage culture many generations after the original migration (Berry, 1990). Last but not least, indigenous peoples are recognised as original occupants of territories subject to colonisation and have entitlements to land and to cultural and political resources (Maaka \& Fleras, 2000).

\section{Current Approaches to Acculturation Research}

\section{Examining the individual and collective experience of acculturation}

Psychological research on the acculturation of individual members of the groups described above has examined individual adaptation through the lenses of three different conceptual frameworks, using five methodological approaches.

\section{Three conceptual frameworks}

To begin with the stress and coping framework, cultural transitions are viewed as lifechanging events that are by their very nature stressful, eliciting coping strategies that deal with them in more or less effective ways (Ward, 2001). Note that this approach only examines the individual acculturation experience. Cross-cultural research in this area has been influenced by research on stress, coping and appraisal by Lazarus and Folkman (1984). Investigating individual and context-related factors that encourage or inhibit positive psychological adaptation, researchers have examined life changes, individual cognitive appraisal of change, and selected coping strategies that range from withdrawal, 
detachment and avoidance to active coping and problem-focused strategies (Ward, 2001; Ward \& Kennedy, 2001). Additional factors that affect coping include individual differences in personality and availability of social support.

Next, the culture learning approach considers what factors predict successful sociocultural adaptation and the importance of learning specific skills that are valued in the host society culture (Bochner, 1986). Again, this approach is directed at the acculturation of individuals. Work by Argyle (1969) on social skills and interpersonal behaviour has shaped research in this field, which understands that difficulties with everyday social interactions give rise to intercultural problems. Studies in cross-cultural psychology have examined the influence of culture-specific knowledge and language fluency, cultural intelligence and selfefficacy, as well as culture distance, contact and intercultural training (Ward, 1996).

The third framework is the social identity approach, important for the theoretical and methodological development of this thesis as it considers both individual and collective experiences. Social identity has been defined as "that part of an individual's selfconcept which derives from his knowledge of his membership of a social group (or groups) together with the value and emotional significance attached to that membership" (Tajfel, 1978, p. 63). According to Cameron (2004), it is best interpreted as a 3-factor structure: 'centrality' incorporates how often individuals think about their group and its subjective importance to their self-definition; 'in-group affect' is the emotional state associated with being a member of one's group; and 'in-group ties' is the extent to which individuals feel bonded to their particular group. Ethnic identity is defined as an individual's sense of self in connection with being a member of their ethnic group, whereas national identity entails individual attitudes towards and feelings of belonging to the larger society (Phinney, Horenczyk, Liebkind \& Vedder, 2001). Investigating the relationship between ethnic and national identities, the social identity approach emphasises cognitive factors that lie behind individual attitudes and behaviours in inter-group settings (Ward, 2001). 
Over the years various models have been used to understand changes in ethnocultural identity. First, a unidimensional model held that adaptation to the environment occurred through assimilation as minority groups replaced their heritage culture identification with host culture identification. In the second bicultural model, identification with heritage and host cultures were counterbalancing and interdependent forces. However, such a conceptualisation could not clearly distinguish between those individuals who strongly or weakly identified with both identities. The third and current model considers heritage and host culture identities as two independent dimensions. The seminal acculturation framework by Berry $(1994,2003)$ distinguished between an individual's preference for maintaining their heritage culture and engaging with the larger society, giving way to four possible acculturation strategies: integration (both are important), separation (only heritage culture maintenance is important), assimilation (only participation in the host society is important) and marginalisation (neither is important). Of all the acculturation strategies, integration is associated with better individual psychological and socio-cultural adaptation, assimilation and separation are associated with intermediate levels and marginalisation with the lowest levels of adaptation (Berry, Kim, Power, Young \& Bujaki, 1989; Phinney, Horenczyk, Liebkind \& Vedder, 2001).

Which of the four acculturation strategies individuals adopt is influenced by factors such as voluntary contact with members of the larger society (increased contact encourages assimilation and integration), perceived similarity (facilitates assimilation), visibility (reduces possibilities for assimilation due to discrimination), and vitality of the cultural group (increases opportunities for heritage maintenance) (Berry, 2003). The integration and separation strategies can only be successfully pursued by individuals if they are shared by fellow members of the cultural group as this enables cultural maintenance (Berry, 2001). However, according to Social Identity Theory (Tajfel, 1982), individuals will only want to continue identifying with their ethnic group if it is a source of positive distinctiveness in 
comparison with other group identities available in the social context (thereby enhancing self-esteem). If, through group comparison their ethnic identity is deemed unfavourable, individuals can decide to engage in either social mobility strategies when inter-group boundaries are permeable or in social change strategies when boundaries are impermeable. Assimilation as an acculturation strategy at the individual and collective levels is only possible when inter-group boundaries are permeable (Verkuyten, 2005). However, individuals from visible minorities may not be able to assimilate at will because of discrimination (Barry \& Grilo, 2003) and rigid inter-group boundaries. As such, they may turn to collective strategies (Lalonde \& Cameron, 1993), including reliance on cultural organisations and engagement with the larger society to enable social advancement (Moghaddam, Taylor \& Lalonde, 1987).

The Relative Acculturation Extended Model (RAEM) goes beyond the traditional models of acculturation where individuals adopt only one strategy at a given time (although they are free to move between the four strategies), to considering different strategies adopted in seven acculturation domains: political, work, economic, family, social, religious beliefs and customs, and principles and values (Navas, Garcia, Sanchez, Rojas, Pumares \& Fernandez, 2005). Overall, immigrants "“adopt quite a lot and keep only a little" in some domains and “acquire only a little and keep quite a lot" in others' (Navas, Rojas, Garcia \& Pumares, 2007, p. 17).

The recent ICSEY project (International Comparative Study of Ethnocultural Youth) surveyed over 5,000 immigrant adolescents, producing four acculturation profiles that match the previously identified strategies (Berry, Phinney, Sam \& Vedder, 2006). The 'integration' profile was most common with 36 percent of participants displaying high ethnic and national identities. Language use was balanced, however ethnic language proficiency was lower than national language proficiency. Peer contacts were established in both heritage and host groups. Individuals in the 'ethnic' profile demonstrated a clear 
preference for the separation acculturation strategy. This comprised 23 percent of the sample, with high levels of ethnic identification, ethnic language preference and strong links to ethnic peers. The 'national' profile was found in 19 percent of the sample and was linked to the assimilation acculturation strategy, strong national identification, proficiency in the national language and strong ties to peers from the larger society. The last profile was termed 'diffuse' and could be identified in 22 percent of the adolescent sample. These individuals endorsed the assimilation, separation and marginalisation strategies; yet their national and ethnic identification were both low. Furthermore, they exhibited good proficiency in their ethnic language but not in the national language and had few established contacts with their national peers. Although this profile was difficult to understand, it suggests that these youth are ambivalent regarding their place in society as they demonstrate a desire to participate but lack the necessary skills. Overall, 59 percent of the adolescents who participated in the ICSEY study expressed a clear preference for heritage culture maintenance (integration and ethnic profiles combined), although this percentage varied within selected countries. These preferences concord with the Universal Declaration on Cultural Diversity which safeguards individual rights for cultural maintenance and mandates the preservation of heritage cultures; not only for the benefit of individuals, but also for all of humankind.

\section{Five methodological approaches}

Acculturation research examining individual adaptation has been conducted through three conceptual frameworks (stress and coping, culture learning, and social identity), using five distinct methodological approaches: cross-cultural, cross-national, developmental, longitudinal, and generational. The main approaches used in cross-cultural psychology are cross-cultural and cross-national. Berry (1989) distinguishes between two forms of crosscultural research: 'emic' research within single cultures seeks to understand the meaning of 
a particular phenomenon from an indigenous perspective; 'etic' research compares cultures with the aim of understanding a supposedly universal phenomenon. Much research has been conducted that is essentially 'imposed etic' in that psychologists have assumed a certain behaviour to be functionally equivalent across cultures, applying theory and measurement tools from one culture to another. However, Berry advocates research that is 'derived etic' by first conducting emic studies in separate cultures to understand local meanings of the phenomenon, and then comparing cultures based on common features. He also comments about the ability of non-native researchers to conduct quality emic research as long as their 'cultural baggage' is set aside.

One accepted paradigm of acculturation research is that group-level variables have an impact on the individual and specified acculturation outcomes (Ward, 2007; see Berry and Sam's (1997) framework for acculturation research). A popular methodological approach is to compare individuals from selected cultures (Culture 1, Culture 2 vs.

Culture 3) to understand which factors impact individual behaviour and discern similarities and differences in the acculturation process.

Cross-national research features individuals from one selected culture and compares their acculturation in different national settings (Country 1, Country 2, vs. Country 3). Individuals in the country of origin are compared to those who migrate to other societies, mapping changes in identity, values and behaviour. Research examines how variables in different host societies impact the acculturation of individuals from the same heritage culture.

Other approaches that examine acculturation within the same culture take a developmental perspective, comparing individual acculturation at different life-stages (Age 1, Age 2, vs. Age 3). This research is cross-sectional in nature and involves a large number of participants from selected cohorts. For instance, research has investigated differences in predictors of stress among young, middle-aged and older immigrants (Ritsner 
\& Ponizovsky, 2003); differences in assimilation rates between parents and children (Birman \& Trickett, 2007); and differences in friendship expectations between immigrants and national peers in early and middle adolescence (Horenczyk \& Tatar, 1998).

Developmental research has also been conducted in conjunction with the longitudinal approach, looking at changes that occur within the same individual over a period of time (Time 1 vs. Time 2, and even Time 3). For instance, studies on immigrant acculturation have compared indicators at initial entry into the host country and five years subsequent to arrival (Suárez-Orozco \& Todorova, 2006). Two extensive longitudinal studies have been conducted on adolescent development in the United States providing a rich database for acculturation comparisons: the National Longitudinal Study of Adolescent Health (Add Health Project by Harris, Florey, Tabor, Bearman, Jones \& Udry, 2003) sampled over 20,000 adolescents in 1995 and again in 1996; and the Children of Immigrants Longitudinal Study (CILS) sampled 3,600 adolescents three times over a span of ten years, starting in 1992, 1995-06 and 2001-03 and specifically targeted 1.5 and 2 generation migrants of Asian and Latin American origin (Portes \& Rumbaut, 2005; Portes, Fernández \& Haller, 2005). Both studies are sociological in nature, emphasising the influence of family structure and socio-economic status on adaptation outcomes and social mobility success.

The final approach examines generational differences in acculturation (Generation 1 vs. Generation 2 and even Generation 3). This research considers how participants who have been subject to different contextual factors vary in rates and domains of acculturation. Studies have examined two generations of Greek immigrants in Australia (Rosenthal, Bell, Demetriou \& Efklides, 1989), two generations of Asian immigrants in the United Kingdom (Robinson, 2006) and four generations of Italian immigrants in the United States (Moro, 1997), demonstrating cultural behaviour loss although a strong cultural identity persists. In terms of socio-cultural adaptation, academic ability has been shown to improve from 1 to 
2.5 generations (Ryabov \& Van Hook, 2006). As for psychological adaptation, higher risks for eating disorders have been found for third compared to first generation European migrants in the US (Sussman, Truong \& Lim, 2006).

To summarise, a wide range of methodological approaches have been employed (often in combination), in the study of acculturation. Most research has been conducted at the individual level while taking into account the effect of group-level factors.

\section{Impact of the larger society on individual and collective acculturation}

Various aspects of the larger society influence the maintenance of heritage culture and/or adoption of host society culture among minority individuals and groups. These include cultural diversity, government policies, acculturation expectations of members of the larger society, and discrimination and inter-group attitudes.

\section{Cultural diversity}

Societies are culturally plural when various cultural groups live together under a social and political framework (Skelton \& Allen, 1999). In the recent ICSEY study (Berry, Phinney, Sam \& Vedder, 2006) cultural diversity of the larger society was calculated according to a composition of three indices: cultural homogeneity (variations in ethnic origin), ethnolinguistic fractionalisation (the probability that two individuals of the same country will not speak the same language), and ethnic diversity (homogenous vs. heterogeneous ethnic composition). Overall, cultural diversity reflects the likelihood that individuals will engage in intercultural interaction within a given society. Note that while such diversity may be due to immigration, it may also be a reflection of established ethnic communities coexisting for long periods of time.

\section{Government policies}

The official policy that the government takes in response to cultural diversity affects the manner in which ethno-cultural individuals and groups acculturate. When the larger society 
expects ethno-cultural individuals to relinquish their heritage culture in favour of the national culture they espouse a 'melting pot' ideology (Berry, 2001). This limits efforts of ethno-cultural individuals to maintain their culture and enforces the assimilation acculturation strategy. When the larger society insists that ethno-cultural individuals and groups remain separate, this is segregation and corresponds to the separation acculturation strategy (which should only be considered a 'strategy' when freely chosen). When ethnocultural groups are not at all welcome in society this is exclusion. According to Berry (2005), societies that endorse cultural pluralism and expect ethno-cultural individuals to integrate into the national culture espouse a multicultural ideology. Support is offered through state institutions that enable the settlement of ethno-cultural groups (Murphy, 1965). Indicators of multiculturalism include official government policies, diversity education in schools, media representation of ethnic interests, and also funding ethnocultural language instruction and community organisations (Berry et al., 2006).

Although multicultural policies were associated with greater integration of ethnocultural youth in the ICSEY study (Berry et al., 2006), it should be noted that national policies that espouse one particular ideology may have an unintended impact on acculturating individuals and groups. For instance, the multicultural Dutch immigration policy which funds ethno-cultural organisations has actually encouraged separated identities among Turkish migrants, and the assimilationist Finnish immigration policy is in fact related to marginalised immigrant identities (Phinney, Horenczyk, Liebkind \& Vedder, 2001). Furthermore, despite initial multicultural orientations, the identity of some ethnocultural and religious groups may be incompatible with the national culture. For instance, research in the Netherlands has demonstrated that Turkish and Muslim identity is negatively correlated with national Dutch identity (Verkuyten \& Aslan Yildiz, 2007). 


\section{Acculturation expectations of host society members}

The Interactive Acculturation Model (IAM) (Bourhis, Moïse, Perreault \& Senécal, 1997), distinguishes between five different acculturation expectations of members of the larger society. Integration, segregation and assimilation correspond to three acculturation strategies identified by Berry. Host society members that hold the exclusion acculturation expectation see immigrants as threatening and do not want to include them at all in society (this corresponds somewhat to Berry's marginalisation acculturation strategy). An additional perspective is added by including an individualism acculturation expectation that is in favour of immigrants adapting in a way that each person sees fit. This model can map the discrepancies between individual acculturation strategies and the acculturation expectations of members of the host society. Tensions can arise, for instance, when the host society expects assimilation while the ethno-cultural group prefers integration, as do Russian migrants in Israel, or when the host society expects integration while the ethnocultural group is separated, as are Turkish migrants in the Netherlands (Phinney, Horenczyk, Liebkind, Vedder, 2001). Furthermore, members of the host society may hold integration and individualism acculturation expectations for valued migrants but segregation and exclusionism for devalued migrants, as Canadians do for French as opposed to Haitian migrants (Montreuil \& Bourhis, 2001).

The RAEM (Navas et al., 2005) also considers the perspectives of the host or 'native' and immigrant acculturation strategies in specific acculturation domains. While native Spaniards preferred North African and sub-Saharan migrants to assimilate in the domains of family and ways of thinking, the immigrants themselves preferred to integrate. In contrast, the Spaniards and migrants both held integration acculturation attitudes in the social relations domain and assimilation attitudes in the work domain. Pinpointing the domains in which the discrepancies between hosts and migrants arise may be critical in promoting more positive intercultural relations and acculturation experiences. 


\section{Discrimination and inter-group attitudes}

The incidence of actual discrimination may differ from levels of reported and perceived discrimination. The latter has predominantly been examined in acculturation research, with links to negative outcomes for acculturating individuals such as poor health, higher stress levels, drug use and delinquent behaviour, lowered self (and group) esteem, identity conflict, poor work adjustment and decreased job satisfaction (Ward et al., 2001). Perceptions of discrimination increase with greater cultural distance (Sodowsky \& Plake, 1992).

Negative attitudes of members of the larger society towards ethnic groups and of ethnic group members towards the larger society (and other ethnic groups) can be understood through the concept of ethnocentrism, a universal phenomenon where individuals hold more positive representations of their own group than other groups in the social context (LeVine \& Campbell, 1972). While ethnocentrism does consist of intragroup expressions (need for group cohesion and sentiments of devotion), inter-group expressions are the primary causes of out-group negativity (in-group preference, belief in ethnic superiority, desire for ethnic purity, endorsement of out-group exploitation for ingroup needs) (Bizumic, 2006).

The media is a further source of discrimination, legitimizing powerful groups (Hindman, Littlefield, Preston \& Neumann, 1999) and playing an active role as a gatekeeper of information (Macpherson \& Spoonley, 2004). Majority groups are represented more often and evaluated more positively than minorities (Gardikiotis, Martin \& Hewstone, 2004). In contrast, minority groups are overrepresented in negative events, known as 'race-tagging'. In acculturation research, faux media representations have been used to prime positive or negative stereotypes of immigrants and create conditions of threat to enhance zero-sum beliefs and increase negative attitudes and behaviour towards immigrants (Esses, Jackson \& Armstron, 1998). 
On the whole, interpersonal, inter-group and institutional discrimination have one shared outcome: defining ethno-cultural individuals and groups as outsiders, and constructing and enforcing inter-group boundaries (Verkuyten, 2005). Thus far, acculturation research has devoted considerable attention to the impact of characteristics of the larger society on individual and collective acculturation. This thesis contributes to the literature by examining the impact of characteristics of the ethno-cultural group on individual acculturation; namely the vitality of the collective as a whole, and of specific diaspora communities.

\section{A new psychological approach: Investigating the long-term acculturation of ethno-cultural groups}

\section{Introducing the concept of long-term acculturation}

Psychological research thus far has examined consequences of the acculturation process for the present well-being of individuals. Cross-cultural and cross-national studies have compared how individuals from different groups experience acculturation in the moment at hand; generational studies compare current differences in acculturation between generations; developmental studies examine how individuals at different life stages presently experience acculturation; and longitudinal studies track changes in acculturation to determine how individual differences and past experience affect their current adaptation. Limited studies have been conducted that are future-oriented, and those that have been conducted do not have an intrinsic interest in the future. For instance, factors that predict individual intentions for migration have been examined (Boneva \& Frieze, 2001), however little significance was attached to whether people actually migrate or not. 
In a powerful critique of research on minority ethnic groups, Verkuyten (2005, p. 120) notes that:

"the predominant concern with status and power leads to the presupposition that the relationship with the majority group is all that matters. This is a restricted and one-sided view of the ways that people from ethnic minority groups define and locate themselves in interactions. This view ignores or underestimates the importance of continuity or the imagined history, culture, and homeland of many of these groups."

The time has come to invest real interest in how individuals and groups will acculturate in the future. This brings us to a new realm in cross-cultural psychology, that of long-term acculturation: It is of vital importance to understand how established ethno-cultural communities who have been living outside their native country for decades, centuries or millenia manage to both interact with the larger society and preserve their cultural heritage. This includes indigenous peoples who have parallel interests in the context of colonisation. Issues regarding individual concerns for the future of their ethno-cultural group - and its ramifications for behaviour in the present - remain unexplored.

This is not surprising since psychological research in general has been time-bound, although the influence of the past and the future on individual behaviour was noted over half a century ago by Lewin (1951), in his definition of time perspective. Brought forward by Nuttin (1985, p. 54), "future and past events have an impact on present behaviour to the extent that they are actually present on the cognitive level of behavioural functioning." Recent research has examined individual differences in five different time perspectives: past-negative, past-positive, present-hedonistic, present-fatalistic and future (Zimbardo \& Boyd, 1999). Investigating whether individuals conjure up personal past or future events, this construct has been used in areas such as risk taking, substance abuse, and homelessness to understand how actions taken by individuals are influenced by their temporal frame of mind. A fresh angle could be brought to acculturation research simply 
by extending its time frame to examine how past experiences and future projections of one's ethno-cultural group affect individual and collective acculturation.

\section{Continuity as an acculturation goal for diaspora and indigenous peoples}

\section{Defining continuity}

To gain an understanding of ethno-cultural continuity, the construct of ethnicity warrants examination. According to Weber's (1968, p. 389) definition:

'We shall call 'ethnic groups' those human groups that entertain a subjective belief in their common descent because of similarities of physical type or of custom or both, or because of memories of colonization and migration; this belief must be important for the propagation of group formation; conversely it does not matter whether or not an objective blood relationship exists..."

It is important to note that aside from shared cultural characteristics, beliefs of common origin and descent are what matters, rather than its scientific confirmation. Verkuyten notes that ethnicity affords groups not only a commonality but also "a particular social and historical position. The continuity with the past gives an anchor in time, provides a social location in the present, and serves as a starting point for the future" (2005, p. 81, citing work by De Vos, 1995). Ethnicity has been described as "an umbilical pull of continuity", affording individuals with a sense of identity and security (King, 2002, p. 82). Furthermore, ethnicity entails "a sense of commitment and obligation towards former and future generations, for example, as a wanting to maintain and protect the symbolic and cultural heritage" (Verkuyten, 2005, p. 83). This commitment, past-based and future-oriented, has yet to be theoretically developed and lacks empirical testing.

To understand this process of wanting to maintain and protect one's heritage, we can look at people who want it, namely diaspora and indigenous peoples. The term diaspora has different connotations. At a negative, historical level it describes "communities of people dislocated from their native homelands through migration, immigration, or exile as 
a consequence of colonial expansion"; at a positive, consequential level it implies "the fertility of dispersion, dissemination, and the scattering of seeds" (Braziel \& Mannur, 2003, p. 4). Indeed, the previous tendency to view larger societies as 'inauthentic' environments for the expression of ethnicity is diminishing.

Overall, both diaspora and indigenous peoples are interested in collective sustainability over generations. This can be investigated using the construct of ethnocultural continuity: (a) When ethnicity is recognized as membership through direct ancestry to a cohesive cultural collective that shares common origins; (b) consisting of a core set of affective, cognitive and behavioural features; (c) acknowledging the heterogeneous nature of ethno-cultural groups and (d) individual variation in identification and adherence to customs; (e) such groups, as enduring, living entities, undergo change; (f) while retaining their uniqueness as they travel through time (socio-historical contexts) and space (larger societies). When long-term acculturation is understood as a collective journey which takes place within specific socio-historical contexts, continuity is seen as a grouporiented acculturation goal for diaspora and indigenous peoples.

\section{Existential uncertainty vs. continuity}

It is of interest to examine the experience of ethno-cultural groups that are sensitive to the concept of continuity precisely because they have faced (and some continue to face) existential uncertainty. Kundera's notion of 'small peoples' captures their experience:

"Small peoples. The concept is not quantitative; it points to a condition; a fate; 'small peoples' do not have that felicitous sense of an eternal past and future; at a given moment in their history, they all passed through the antechambers of death; in constant confrontation with the arrogant ignorance of the mighty, they see their existence as perpetually threatened or questioned; for their existence is the question" (Kundera, 1993, p. 225).

Individuals who belong to 'small peoples' cannot take continuity for granted. It is likely that this affects their acculturation experiences compared to those who belong to 'large' 
peoples or groups that have a large source population and do not contend with collective existential uncertainty.

The existential uncertainty of 'small peoples' can be divided into epistemic insecurity, referring to physical and political survival, and ontological insecurity which is identity-based (Abulof, 2007). The epistemic and ontological insecurity of 'small peoples' throughout history was due in large part to discrimination at the inter-group and institutional levels.

Theorising about persistent cultural systems, Spicer (1971) cited ten peoples who have experienced external pressures to assimilate and outlived state entities: the Jews, the Basques, the Irish, the Welsh, the Catalans, the Mayas, the Yaquis, the Senecas, the Chereokees, and the Navajos. According to Spicer, the persistent identity system is a product of the process of continued inter-group opposition. Thus, a perpetual state of conflict and resistance between the ethno-cultural group and the larger society is what drives cultural continuity. Indeed, psychological research on inter-group relations demonstrates that discrimination enhances in-group solidarity (Stein, 1976; Verkuyten \& Aslan Yildiz, 2007). The question remains, can continuity transpire under positive conditions such as those expounded in multiculturalism? Under these circumstances, where lies the impetus for continuity?

It is important to note that under positive external conditions, epistemic (physical) insecurity is no longer in question, rather ontological (identity) insecurity takes centre-stage: "Dying is a terror, an agony, a strangling finish, to be fought off by sheer instinct, by the will to live on, to the last breath. Melting is a mere diffusion into an ambient welcoming warmth in which one is dissolved and disappears, as a teaspoon of sugar vanishes into hot tea" (Wouk, 2000, p. 259).

If continuity is due to oppositional forces, then in the absence of external threat, ethnocultural continuity may depend upon the continued refusal of individuals to 'melt' or to assimilate into the larger society. 


\section{The impact of post-modernism and globalisation on continuity}

Gans (1979) noted that individuals in larger societies develop a sense of 'symbolic ethnicity'. As the communal networks that bind ethnicity are left behind, such as homogenous neighbourhoods and occupations, ethno-cultural identity increasingly encompasses symbolic features such as food and remnants of language. Ethnicity becomes more a matter of choice, retaining subjective importance for individuals. However, Alba (1990) notes that in the absence of social structures to perpetuate core cultural content, individualised ethnicity undermines collective continuity (Levine, 1997). Indeed, postmodernism has had a large impact on the psychology of individual identification whereby ethnic (and religious) identity is becoming more of a tool that serves individuals in their personal journeys in search of meaning and fulfilment, rather than any collective purpose (Cohen \& Eisen, 2000). Ethno-cultural (and religious) identities are further marked by an increasing voluntarism and fluidity as individuals select which aspects of their heritage are meaningful, which can be discarded and which are worthy of transmission. At the other extreme of the identity spectrum, the choice not to identify at all with one's ethnic heritage is an option available for non-visible minorities (Frye Jacobson, 1998).

The impact of globalisation on collective continuity is mixed. On one hand, globalisation can facilitate collective continuity by encouraging networking and communication amongst diaspora communities and facilitating travel to home countries. An increase in imported goods provides communities with cultural specific resources such as food, music and literature. On the other hand, globalisation can lead to increased homogenisation of cultures. It can also result in changes in identity as individuals who routinely engage in culture-contact see themselves as members of the world, evolving a cosmopolitan identity (Polek \& van Oudenhoven, 2007). The growing perception of universalism may compromise attachment to one's ethno-cultural group. Even so, 
globalisation can also produce a resurgence of ethnic identity, such as reaffirmation or revitalisation movements (Berry, 2007).

\section{Group-level indicators of continuity: psycho-socio-cultural}

What indicators can be used to examine collective as opposed to individual acculturation? A contentious distinction lies between quantitative vs. qualitative aspects of continuity:

If future generations continue to identify with their ancestral heritage culture but perform very few behaviours in accordance with established tradition, does this constitute ethnocultural continuity?

How many people self-identify as part of a collective has been a standard measurement of ethnic vitality in national censuses. One could also count how many ethno-cultural organisations, schools, clubs, and restaurants are in existence, and the size of their patronage. Birth-rate is a particularly important indicator of long-term acculturation where a negative ratio of births to deaths is a sign of collective decline ${ }^{1}$. For continuity to occur there must either be a balance in this ratio to obtain a stable population size or births must outnumber deaths for population growth. Note that population growth of minority groups usually remains within certain limits otherwise this could threaten established power structures within the larger society. One could also decipher the quality of a generation, where culture as a living entity is measured by how many people can speak their native language, adherence to core customs and production of cultural knowledge and arts. However, this is fraught with problems as suggestions that one person is more 'ethnic' than another because of their behavioural aptitude touch sensitive points about culture and authenticity.

${ }^{1}$ The importance of bearing children for ethno-cultural continuity can be written in law as in La Loi des 12 Enfants - the Law of 12 Children - implemented in 1670 by the King of France to encourage population growth in New France (Québec). The success of such policies resulted in a "heroic fecundity" otherwise known as la revanche des berceaux, or the revenge of the cradles (Langellier, 2002). 
Ethno-cultural continuity encompasses not only the quantity and quality of future generations, but also power structures or the degree of self-governance, especially for indigenous peoples. Indeed, for indigenous peoples, "without any sense of control, independence or autonomy, endurance is probably best called existence" (Durie, 2005, p. 235). The continuity of indigenous peoples is thus dependent upon their ability to influence their own fate and to live in accordance with their own cultural patterns, social institutions and legal systems (Kvernmo, 2006). Finally, leadership is an important marker of ethnocultural continuity as good community leaders (political, spiritual and professional) are vital to the management of internal dynamics as well as external relations with the larger society (Maimon, 2007).

\section{Impact of the ethno-cultural group and larger society on collective continuity}

Forces that come from within the ethno-cultural group influence collective continuity. Maimon's (2007) conception of internal 'momentum' of the collective is composed of the various factors mentioned above such as demography (decreasing, stable or increasing population), social aspects (identification, knowledge and social capital), power structures (political and communal organisations, networks), economics (financial sustainability, philanthropy) and leadership. Collective continuity is also shaped by external forces in the larger society such as who are the main global actors, energy dependence, terrorism and production of weapons of mass killing; globalisation, development of an international economy, religious conflict, discrimination and developments in science and technology that facilitate communication. To this can be added national factors such as multicultural policies (or counter policies).

Maimon contracts the internal and external factors discussed above into broad categories of high and low internal 'momentum' and positive and negative external conditions to create a two-by-two matrix of four possible alternatives for collective 
continuity (note the Jewish people are used as a case study but this framework can be extended to other groups). On one hand, under positive external conditions, when internal momentum is high collectives are 'thriving'; but when internal momentum is low, collectives are 'drifting'. On the other hand, under negative external conditions, if internal momentum of the collective is high, collectives are 'defending' and if internal momentum is low collectives are 'dying'. Thus, larger societies can be seen as conducive to continuity under (a) positive external conditions of multiculturalism but if this is not accompanied by a high internal momentum, ethno-cultural continuity cannot ensue - individual assimilation and collective dissolution will transpire in its stead; and (b) when negative external conditions in the larger society are accompanied by a high internal momentum; here ethnocultural continuity can occur (barring collective annihilation). These four alternatives for the long-term acculturation of groups can correspond to Berry's individual acculturation strategies and government policies, presented in Table 1.1. 
Table 1.1: Impact of the larger society on individual vs. group acculturation

\begin{tabular}{|c|c|c|c|c|}
\hline $\begin{array}{l}\text { Individual } \\
\text { acculturation } \\
\text { strategies } \\
\text { (Berry) }\end{array}$ & $\begin{array}{l}\text { Alternatives for } \\
\text { ethno-cultural } \\
\text { groups } \\
\text { (Maimon) }\end{array}$ & $\begin{array}{l}\text { Approaches of } \\
\text { Larger society } \\
\text { (Berry) }\end{array}$ & $\begin{array}{l}\text { External } \\
\text { conditions } \\
\text { [Tolerance] }\end{array}$ & $\begin{array}{c}\text { Internal } \\
\text { conditions } \\
\text { [Momentum] }\end{array}$ \\
\hline $\begin{array}{l}\text { Integration/ } \\
\text { Separation }^{2}\end{array}$ & Thriving & $\begin{array}{l}\text { Multicultural } \\
\text { ideology }\end{array}$ & + & + \\
\hline Assimilation & Drifting & Melting pot & + & - \\
\hline Separation & Defending & Segregation & - & + \\
\hline Marginalisation & Dying & Exclusion & - & - \\
\hline
\end{tabular}

Just as the collective strategy of a thriving community can be pursued under positive external conditions (multiculturalism), the individual acculturation strategies of integration or separation can also be pursued. As collective drifting occurs when group members lack an internal drive for group endurance under positive external conditions (melting pot and even multiculturalism), so too the individual acculturation strategy of assimilation involves a lack of volition to continue identifying with one's group. While collectives are defending in the face of negative external conditions, individual separation ensues when people are highly motivated to live according to their heritage culture (they may have no other choice under conditions of segregation). Finally, as collectives are dying, lacking the will to live on under negative external conditions, individual marginalisation ensues when people are not motivated to live in accordance to either heritage or host cultures (they do not have the ability to participate in the host society culture under conditions of exclusion). Note that some individuals are marginalised even in positive external conditions of multiculturalism.

\footnotetext{
${ }^{2}$ Volitional separation is possible in multicultural societies that allow for individual variation in acculturation strategies.
} 
On the whole, the most favourable setting for the ethno-cultural continuity of minority groups - a thriving collective - involves positive external conditions in the larger society and high internal momentum. A thriving collective encompasses both the quantitative and qualitative domains of continuity, i.e. continued ethno-cultural identification and participation. This thesis will examine the influence of collective vitality within and across cultures as a principal source of internal momentum. One study will compare the continuity of minority groups who belong to 'small peoples' with those who belong to large peoples: Jews as the quintessential 'small people'; Māori as indigenous people vs. Chinese as a large people (Chapter six). Another study will compare the continuity of the same minority group that differs in vitality in four different acculturation settings: Jews in New Zealand, Australia, Canada and the United States (Chapter seven). These are all settler societies that support cultural maintenance through multiculturalism. New Zealand, Australia and Canada are characterised as high in diversity policy, and the United States is characterised as medium (Berry et al., 2006).

The role of internal structural factors in sustaining internal momentum has been noted, such as residential concentration, economic life, family, language, religious institutions and ethnic associations (Warner and Srole, 1945, cited in Fenton, 2003). However, other factors are also critical in maintaining internal momentum and deserve particular attention, such as cultural transmission, ethnic endogamy and remembrance of ethnic history. These factors encompass not only behavioural but also psychological sources of momentum, and are considered in detail in the following chapter. 


\section{CHAPTER 2: INTERNAL DYNAMICS OF CONTINUITY: Cultural Transmission, THE CENTRALITY OF ENDOGAMY, AND THE INFLUENCE OF ETHNIC HISTORY}

The internal dynamics of continuity are examined in this chapter, commencing with the importance of cultural transmission for ethnic group persistence. The primary role of parents in enculturation and the advantages of ethnic endogamy are then discussed, followed by an outline of factors that influence mate selection for minority group members. Next, the influence of ethnic history on collective continuity is described. Finally, an integrative framework is presented for the prediction of volitional endogamy, an individual behaviour that cumulatively shapes the continuity of the collective.

\section{Cultural transmission and parental homogeneity}

Ethno-cultural groups are self-sustaining and self-perpetuating. The process of intergenerational cultural transmission will be examined, acknowledging the existence of multiple paths - some of greater importance than others.

\section{Cultural transmission}

According to the anthropological research of Cavalli-Sforza and Feldman (1981), a collective continues its cultural heritage through teaching and learning across generations. Indeed, social transmission is the key to cultural persistence (Schönpflug, 2001b). Boyd and Richersen emphasised that "the cultural continuity of groups is due to inheritance of beliefs and values, and is not merely a result of the effects of individual learning and correlated environments" (1985, p. 32). They further note that transmission is rarely exact, nor at the other extreme a complete failure. Were individuals a carbon copy of the previous generation, there would be no room for cultural innovation; and were transmission an utter failure, coordinated action between generations would be rendered impossible. 


\section{What is transmitted?}

Driedger (2003) summarises six factors that comprise ethnic identification. One factor is territory, the place within which ethnic living occurs in accordance to ethnic customs. For diaspora communities, identification can be with the country of origin, of settlement, or more localised areas of residence. A second factor is identification with the culture that includes language and customs. Another is identification with historical symbols that carry knowledge of the collective's common origins and experiences (positive and negative), furnishing a sense of belonging and continuity. Identification with an overarching ideology is a fourth factor. This encompasses religious or political beliefs and is the groups' raison d'être, or purpose in life. Indeed, links between religious beliefs and ethnicity abound (e.g. Jews, Confucian Chinese and Ringatu Māori). There is also identification with leaders, which appeal to historical symbols, ideologies and in-group solidarity to mobilise the collective in a positive direction. Finally involvement in ethnic institutions (educational, welfare, religious, political and economic) serves collective sustainability. Driedger acknowledges that identification with these dimensions can vary across ethnic groups. In sum, these are the factors that constitute ethnic identification and form the content of the social transmission process. 


\section{How is ethno-cultural identity transmitted?}

Two processes are involved in cultural transmission: enculturation and socialisation. The process of enculturation was originally conceptualised by Herskovits (1948), referring to: "an individual [that] is encompassed or surrounded by a culture; the individual acquires, by learning, what the culture deems to be necessary. There is not necessarily anything deliberate or didactic about this process; often there is learning without specific teaching. The process of enculturation involves parents, and other adults and peers, in a network of influences ... all of which can limit, shape and direct the developing individual. The end result $\ldots$ is a person who is competent in the culture, including its language, its rituals, its values, and so on" (Berry, Poortinga, Segall \& Dasen, 2002, p. 29-30).

In contrast, socialisation refers to the conscious teaching of culture to an individual. Socialisation is incorporated into Boyd and Richersen's (1985) dual inheritance model as the key mechanism of the cultural inheritance system, as opposed to the biological mechanisms in the genetic inheritance system. While cultural transmission is a collective process, "People learn as individuals. Therefore, if culture is learned, its ultimate locus must be in individuals rather than in groups." (Goodenough, 1981, p. 54). At the individual level, this can occur through a kind of behavioural conditioning where transmitters reinforce the imitation of appropriate cultural behaviour.

A distinction can be made between informal vs. formal culture learning, or 'indoctrination for minority-group membership' (Fishman, 1961). While informal socialisation takes place among family and peers, formal socialisation occurs in community schools, clubs and other institutions. Overall, ethnic socialisation serves not only to transmit cultural content, but also to develop psychological boundaries necessary for collective continuity. As Isajiw (1974) proposed, the 'boundary from within' is maintained 
through socialisation, as opposed to the 'boundary from without' that is sustained through inter-group relations.

Who are the transmitters of cultural heritage? In their theory of cultural evolution, Cavalli-Sforza and Feldman (1981) outline ten distinct modes of transmission which constitute different paths for ensuring ethno-cultural continuity. They include vertical and oblique modes (the transmitters are from a different generation: parents, relatives, teachers) and horizontal modes (the transmitters are from the same generation: siblings, peers). Of these, vertical transmission from parents to children is particularly crucial. They note that in cultures with high gender role specialisation, transmission occurs in unequal proportions and is often uniparental. Overall, the family ensures the physical and cultural perpetuation of the ethno-cultural group (Bossard and Stoker Boll, 1972).

\section{Importance of the family}

The singular importance of the family has been emphasised by Alba (1990, p. 185):

"No issue carries greater weight for the survival of ethnic groups than the socialization of children to have a distinct consciousness of their ethnic background, an identification with their ethnic group. Should the transmission of ethnicity from one generation to the next be interrupted, then ethnic groups are obviously imperilled. The family plays the paramount, albeit not the only, role in instilling ethnic identity in children [my italics]."

Parents are responsible for actively creating a family home environment conducive to the transmission of ethnic content and the formation of ethnic identity over and above the 'passive' parental role of transmitting ethnic ancestry to their children.

The role of parents in their children's ethno-cultural socialisation is incorporated in LeVine's 'parental goals' theory (1974) in which parents' desires for their children encompass not only basic survival but also economic capability and acquisition of cultural values. These goals, as LeVine understood them, were largely unconscious. In contrast, the 
concept of 'parental heritage' involves the conscious transmission of valued assets (Moss \& Abramowitz, 1982). This construct captures the active role of parents in ethno-cultural transmission. Lasker and Lasker (1991) examined 'parental heritage' in a study on Jewish parents who wanted their children to acquire values and behaviours that they themselves held in high regard, such as feeling connected to the Jewish people (ethno-cultural identity) as well as observing Jewish practices (behaviour). However, their research is characterised by a narrow conceptualisation of transmission in that parents wish to imbibe their children with valued characteristics of themselves, without considering broader collective goals such as ethno-cultural continuity. This was included in a recent study on first generation Asian Indian parents in the United States wherein participants expressed conscious efforts to ensure cultural continuity for their children in terms of having Indian friends, being vegetarian, speaking the native language and marrying a fellow Indian (Inman, Howard, Beaumont \& Walker, 2007). Strategies involved modelling and maintaining traditional religious practices at home. The researchers noted challenges to cultural transmission: limited guidance from extended family and community, and limitations imposed by the larger society such as work schedules that preclude cultural practices.

Rituals are important tools used by parents to facilitate ethno-cultural socialisation. Friesen (1990) defines rituals as behaviours or activities that are valued; have symbolic meaning for family members; and extend across generations. Ethno-cultural rituals are effective as (a) children's learning is enhanced through repetition and (b) the collective past is actively experienced in the present (Wolin \& Bennett, 1984). Ethno-cultural celebrations furnish a transcendent, collective identity (linking past and future generations), core values and beliefs, promote a sense of belonging (Turner, 1967, cited in Fiese, Tomcho, Douglas, Josephs, Poltrock \& Baker, 2002), and are also responsible for coordinating individuals and families with the larger community. 
Note that women as 'kin-keepers' or cultural gatekeepers often bear primary responsibility for the continuation of family rituals (Leach \& Braithwaite, 1996).

\section{Transmission belts}

Schönfplug (2001a) noted the influence of transmission belts - conditions or factors that enhance transmission, and investigated the roles of parenting styles and acculturation context; some parenting styles may be more effective transmission belts than others (empathetic vs. authoritarian), and some contexts may be less conducive to transmission than others (host country vs. country of origin). Schönfplug (2001b, p. 132) emphasised that the "Homogeneity of transmitters with reference to the transmitted contents ensures the greatest transmission effects." This suggests that inter-generational cultural transmission and thus ethno-cultural continuity is facilitated by parental homogeneity, i.e. endogamy (intra-ethnic marriage).

Indeed, research has shown that exogamy (intermarriage) reduces the parents' ability to transmit a coherent ethnic culture to their children (Pagnini \& Morgan, 1990). Overall, children of mixed-marriages are less likely to identify themselves with a single ethnic group (Kalmijn, 1998). It is not due to intermarriage per se, but to the weakening of the ethnocultural home environment when one parent is not a member of the same ethnic group (Phillips \& Chertok, 2004). In contrast, research has shown that "endogamously married parents are more likely than others to attempt to instill a sense of their ethnic background in their children" (Alba, 1990, p. 198). This includes direct and self-conscious teaching of ethnic language, ethnic foods, customs, history, and homeland. Thus, endogamy, in facilitating the creation of a home environment conducive to consistent ethno-cultural socialisation, constitutes a transmission belt and a particularly important path for ethno-cultural continuity. 


\section{When I do affects how we do: Consequences of individual behaviour for collective continuity}

\section{Exogamy as a threat to continuity}

While endogamy facilitates cultural transmission and hence collective continuity, exogamy (intermarriage) on the other hand, increases the possibility of individual and collective assimilation $^{3}$. Assimilation encompasses the process by which individuals and collectives lose hold on characteristics that relate to their heritage culture, and can lead to collective dissolution. Waters and Jiménez (2005) outline four core sociological dimensions used to measure the assimilation of immigrants into the larger society, of which intermarriage - the "litmus test of assimilation" - carries considerable weight. Other factors include socioeconomic status (educational attainment, occupational specialisation, earning parity), residential segregation, and language use (national and native language proficiency). Variables that influence assimilation include the geographic distribution of migrants and replenishment of local communities through continued immigration.

Recently, Alba and Nee (2003) in their reformulation of classic sociological assimilation theory, acknowledge the increasingly permeable and blurred inter-group boundaries and ensuing intermarriage as paramount factors in assimilation in the United States. Furthermore, while minority individuals "may not intentionally seek to assimilate, the cumulative effect of pragmatic decisions aimed at successful adaptation can give rise to changes in behaviour that nevertheless lead to eventual assimilation” (p. 38). Research demonstrates the impact of intermarriage in reducing the number of individuals who identify with a particular ethnic group (Stephan \& Stephan, 1989). Furthermore, children whose parents have intermarried are themselves likely to marry outside of their ethnic

\footnotetext{
${ }^{3}$ Note that in some cases, exogamy has enabled continuity, e.g. intermarriage between native Māori and European colonizers, as children of mixed heritage inherited immunity to disease. However, the primary facilitator of continuity was increased fertility (Durie, 2005; see also Chapter 3 on Māori acculturation).
} 
groups (Alba \& Golden, 1986). Research shows that in the United States, individuals of mixed heritage are more likely to marry White Americans than individuals who identify with a single group (Qian \& Lichter, 2007), further reducing the likelihood that the next generation identifies with the minority heritage culture. For Jews in the United States, the National Jewish Population Survey (2000-01) highlighted that 74 percent of adults from intermarried families engaged in intermarriage themselves.

Precipitating the assimilation of Jews, exogamy is of growing concern, constituting "the greatest single threat to Jewish continuity, both on an individual level and on a group level" (Cohen, 2006, p. 11). Only 7 percent of grandchildren in intermarried families are raised solely as Jews. Although assimilation is not the only outcome of intermarriage as individuals can identify with multiple ethnic groups (see below), by decreasing the chances of cultural transmission from a single coherent source, exogamy threatens continuity.

\section{On mixed heritage: Effects for the individual vs. collective}

Previously, researchers interpreted intermarriage as having a negative effect for children, adopting a deficit model where dual or mixed-heritage identity was associated with negative individual adaptation outcomes such as anxiety (Ward, 2005). This was largely due to discrimination directed towards families of mixed-marriage and that these marriages were more unstable that endogamous marriages. Ward rejects the deficit model in favour of an acculturation framework, demonstrating that the values, identity and adaptation of dualheritage adolescents (Māori and New Zealand European) fall between those of sole Māori and sole New Zealand European heritage. In Ward's sample, 61 percent of participants who descended from both Māori and New Zealand European parents self-identified as dual-heritage, whereas 10 percent identified solely as Māori ${ }^{4}$.

\footnotetext{
${ }^{4}$ Ethnic visibility plays a key role in identification for mixed heritage individuals; Americans of both African and White descent have identified themselves primarily as Black (Davis, 1991, cited in Qian \& Lichter, 2007).
} 
Individuals of mixed-heritage may search to conciliate their multiple heritage (Georgas \& Kalantzi-Azizi, 1992), and to create a valid hybrid identity (Verkuyten, 2005). The 'additive biculturalism' strategy was coined by Verkuyten and de Wolf (2002) wherein Chinese bicultural individuals (single-heritage migrants who adapt to the larger society), described how they actively selected the more valuable features of their heritage culture and blended it with the preferred aspects of national Dutch society. LaFromboise, Coleman and Gerton (1993) outline an alternation model of biculturalism, whereby individuals have affinity to two cultures, are knowledgeable in both and actively change their behaviour in different contexts.

At the group level, however, identifying as mixed-heritage has its consequences as the cultural heritage individuals will transmit to their children is contentious. Overall, the phenomenon of multiple heritage impacts directly on the demography of the collective, in the present and in the future. While immediate effects on the individual are certainly not interpreted from a deficit perspective, long-term effects on the collective comprise a challenge to ethno-cultural continuity.

\section{Prelude to marriage: Preferences in romantic partners and selective dating}

The associations between marriage, romantic love and dating are important in understanding the process of endogamy. The ideology of romantic love incorporates intense mutual attraction, idealisation, and focuses on personal fulfilment, serving as a basis for marriage in individualistic and traditionally Western cultures (Dion \& Dion, 1996). In contrast, family alliance is of particular importance in collectivistic and traditionally Eastern cultures. In such cultures, traditional practices of arranged marriages and formal introductions guide partner selection. Romantic love has the opportunity to blossom through the process of dating, although there is considerable variation in its meaning and function - serving as an opportunity for recreation, status grading, companionship, and as 
a means of mate sorting and selection, influenced by factors such as individual maturation, social influences and opportunities (McDaniel, 1969; McCabe, 1984). Developmental changes are also influential as dating for marriage is not of central concern in adolescence but more relevant for young adults.

Tang and Zuo (2000) investigated the dating attitudes of Chinese college students in China and American college students in the United States, demonstrating that Chinese participants date later and date less frequently than American participants due to a lack of opportunities and endorsement. The function of dating also differed where 42 percent of Chinese viewed dating in instrumental terms (finding a marriage partner), in contrast to 14 percent of American students.

With regards to mate preferences, a large cross-cultural study in 37 cultures revealed that the most valued characteristic was 'mutual attraction-love' (Buss et al., 1990). In terms of the structure of qualities in an ideal partner and an ideal relationship, Fletcher, Simpson, Thomas and Giles (1999) found three factors: partner warmth-trustworthiness, vitalityattractiveness, and status-resources. They distinguish between short-term and long-term mating strategies and their role in individual trade-offs in these ideals. Interestingly, the characteristic of an ideal partner being of an appropriate ethnicity was only by mentioned 6 percent of participants, loading on the status-resources factor. This may be due to their sample which consisted primarily of majority participants. Overall, these studies are characterised by minimal attention and theorising on dating fellow ethnic group members.

The fact is that there are disproportionately high endogamy rates for minority group members (Brown, McNatt \& Cooper, 2003). Statistics from the 1990 US Census show that 26.4 percent of American Indians, Eskimos and Aleutians married within the same racial category even though they comprised less than one percent of the national population. Similarly, in-group preferences were found among Asians, Pacific Islanders, Latinos, and African Americans with endogamy rates reaching 73 percent. Logically, such high 
endogamy rates must be preceded by a high frequency of intra-ethnic dating. Thus far, this phenomenon has been studied from the perspective of ethnocentrism, where selective dating is seen as a function of in-group favouritism (Liu, Campbell \& Condie, 1995; Brown, McNatt \& Cooper, 2003). Outcome variables traditionally studied include preference in dating partners and likelihood of dating a person from the same ethnic group.

In a comprehensive study on ethnocentrism in dating preferences among college-age Asian, African, Latino and European Americans, Liu, Campbell and Condie (1995) demonstrated that social network approval (perceived approval of family and peers) was the strongest predictor of ethnocentrism. Similarly, Mok (1999) found that parental influence was a significant predictor of selective dating for Asian American females, and Lalonde, Hynie, Pannu and Tatla's (2004) research on second generation South Asian Canadians found that family expectations of endogamy mediated the relation between cultural identity and preference for traditional attributes in a partner.

Similarity is also a significant predictor of ethnocentrism in dating (Liu et al., 1995), but its effect is weakened and even reduced to non-significance when strength of ethnic identity is taken into account (Brown et al., 2003), whereby higher identification is related to greater in-group dating preferences. A fourth significant predictor is attraction to fellow ethnic group members (Liu et al., 1995; Mok, 1999). Social status perceptions also influenced dating partner preferences where overall ratings for Whites were higher than those for Latinos, Asians and Blacks (Liu et al., 1995). While favourable ratings for White partners may be reminiscent of individual social mobility strategies ('marrying out and up'), overall ethnocentrism was evident as members of other groups were rated less positively than in-group members.

For minority members, intra-group ties (ethnic identification, social network approval) constitute strong predictors of dating preferences (Brown et al., 2003). This has been interpreted in terms of ethnic identity salience due to minority status that amplifies 
positive evaluations of fellow ethnic group members. However, the time has come for research to move beyond ethnocentrism as the framework for understanding selective dating among minority groups and investigate the role of collective continuity. Do individuals prefer in-group members because they bear in mind the grand scheme of cultural transmission and ethno-cultural continuity?

\section{Predicting mate selection}

Marriage has been viewed as a natural institution, described by philosopher John Locke as humankind's "first Society"; as a sacramental institution based on promises which are regulated by religious communities; as an economic unit of consumption and exchange; and as a social unit for raising children and establishing the husband-wife relationship. Logan (2004, p. 67) notes that "the institution of marriage was designed less for the accommodation of adults in love than for the proper functioning of society, especially regarding the care of children."

Endogamy, as a transmission belt, facilitates the enculturation and socialisation of children. Consequently, an understanding of the variables that predict endogamy is imperative when conducting research on collective continuity. Since most research has been conducted on ethnic exogamy and its associated factors, these findings from the fields of demography, sociology and psychology will be reviewed first, followed by a discussion of the variables that predict ethnic endogamy. Note, however, that factors that predict marriage to a fellow in-group member are not simply the inverse of those that predict marriage to an out-group member.

Intermarriage refers to "married persons whose religious, racial or ethnic background is or was different from each other's, either prior to or after their marriage" (Gordon, 1972, p. 6). In an era where antimiscegenation state laws (forbidding inter-ethnic, inter-racial and inter-religious marriage) are relegated to history books, in an open society where ethnic 
boundaries are permeable, individuals have the right to live where they wish, with the marriage partner of their choice (Berman, 1968). Forty years ago, Gordon hypothesized that intermarriage would increase due to social and institutional factors such as greater attendance at tertiary institutions (resulting in propinquity and increased similarity among individuals), increasing secularisation, desegregation at the government level and concessions by religious institutions (namely the Church), and a weakening of parental authority. These trends correspond to a change in the function of marriage, where "its major purpose is now personal happiness, not family service and the perpetuation of the group" (Gordon, 1972, p. 40). He notes that lower birth rates and higher divorce rates are a consequence of this trend.

Overall, the incidence of intermarriage at a national level should not be exaggerated as only 2.2 percent of all marriages in the United States in 1992 were intermarriages (Qian, 1997), increasing to 6 percent in the year 2000 (Simmons \& O'Connell, 2003). However, a greater incidence of intermarriage has been reported in regional analyses, such as in the Los Angeles County and in Hawaii (Kitano, Yeung, Chai \& Hatanaka, 1984) 5 .

When examining intermarriage, demographic and sociological research outcome variables have usually consisted of national census data and marriage license records. A variety of structural group-level variables that predict exogamy have been studied, ranging from ethnic group differences, group size, visibility, gender and sex-ratio, cultural regulations and religious diversity. Qian and colleagues (1997; Qian \& Lichter, 2007) examined exogamy among different groups in the United States using data from the 1980, 1990 and 2000 national censuses. In terms of differences across racial or ethnic groups, intermarriage with White Americans is highest among native-born Hispanics, followed by American Indians (indigenous peoples), Asians and lastly African Americans (Qian \&

\footnotetext{
${ }^{5}$ Note that marriage patterns of Jews, Māori and Chinese are described in detail in Chapter three. The research outlined here presents independent variables to be integrated in a predictive model of endogamy.
} 
Lichter, 2007). Furthermore, the size of the ethnic group is a key factor, where smaller group size is associated with greater exogamy (Blau, Blum \& Schwartz, 1982; Qian, 1997; Tubergen \& Maas, 2007). Visibility represents a continuing barrier to intermarriage among African Americans (Qian \& Lichter, 2007) and non-white immigrants in the Netherlands (Tubergen \& Maas, 2007). Gender has also been examined as a predictor variable, with a greater incidence of Asian women engaging in intermarriage than Asian men, whereas African and Hispanic men intermarry more frequently than African and Hispanic women (Qian, 1997). These trends may be aggravated by sex ratio imbalances which encourage spouse-seeking from other ethnic groups. Indeed, this was the case in a study of Arab American intermarriage, where the shortage of available Arab women for marriage led Arab men to look for alternatives (Kulczycki \& Lobo, 2002). In addition, greater withingroup religious diversity promotes exogamy (Tubergen \& Maas, 2007). Specific cultural regulations regarding patrilineal vs. matrilineal descent may limit exogamy, where for instance the Islamic patrilineal law prohibits Muslim women from marrying non-Muslims since ensuring the Muslim identity of the children is of utmost importance (the inverse is true of Jewish Orthodox matrilineal regulations).

With regards to individual-level factors that predict exogamy, inter-group contact through employment and social networks increases with individual socio-economic mobility, of which educational attainment is a key indicator (Qian, 1999; Qian \& Lichter, 2007). While ethnic group differences in educational attainment are related to group trends in exogamy for Asian Americans, colour divides curtail the impact of increased educational attainment on exogamy rates for Blacks. With regards to generation effects, the more time an individual and their family has spent in the larger society, the greater the frequency of intermarriage (Qian, 1999). In a study of acculturation differences between three generations of Japanese families in the United States, changes occurred in terms of marriage practices as over 90 percent of the issei (first generation) had arranged marriages, 
while the sansei (third generation) engaged in dating and interethnic marriage and were described by their parents and grandparents as "completely Americanised" (Connor, 1974). Behavioural acculturation in terms of second language acquisition favours intermarriage (Hwang, Saenz \& Aguirre, 1997; Tubergen \& Maas, 2007), as well as decreasing levels of religiosity evident among Jews in the United States (Podhoretz, 2000).

In terms of group-level variables that predict endogamy, some are mirror opposites of the above-mentioned factors that predict exogamy, while some are unique. With regards to group-level factors, the influence of national policy on intermarriage was considered by Kitano, Yeung, Chai and Hatanaka (1984), where they note the residual effects of U.S. antimiscegenation laws enacted in 1850 that precluded intermarriage until 1948; only in 1967 did the government declare such laws as unconstitutional. Exclusionary immigration policies led to disproportionate sex ratios for ethnic groups such as the Chinese. Historical discrimination in the form of state-supported segregation, and continued visibility perpetuate rigid inter-group boundaries between African and White Americans and are related to high levels of endogamy (Qian \& Lichter, 2007). Concerning group size, recent and continuous immigration illustrated in the growing Asian and Hispanic communities in the United States "has given demographic impetus to racially homogamous marriages [endogamy] among immigrants themselves, and it also has slowed the pace of intermarriage for their native-born counter-parts" (Qian \& Lichter, 2007, p. 81). Endogamy between local and foreign-born in-group members occurs more often than exogamy with White Americans. Favourable sex ratios are conducive to endogamy (Tubergen \& Maas, 2007), as well as residential segregation and geographical concentration where small group size may be buffered through concentrated residence as opposed to isolation experienced by members of a dispersed population (Kalmijn, 1998). 
In a study of marriage patterns in the United States using census manuscripts and marriage register records in New York City between 1907 and 1912 of White citizens and British, Irish, Scandinavian, German, Jewish, Italian and Polish immigrants, Pagnini and Morgan (1990) noted that employment segregation predicted endogamy (where 90 percent of tailors in NYC were Jewish and many fruit vendors were Greek), as well as negative attitudes of members of the larger society (beliefs of inferior foreign blood), and social distance between older immigrants (pre-1880s from central Europe) and newer immigrants (from southern and eastern Europe). Ethno-cultural organisations provide cohesive social structures that promote opportunities for in-group contact and encourage endogamy (Kitano et al., 1984; Kalmijn, Liefbroer, van Poppel \& van Solinge, 2006).

As for individual-level factors that predict endogamy, there is behavioural acculturation and in particular proficiency in native language, individual educational attainment (low) and ethnic visibility (high) (Tubergen \& Maas, 2007). Kalmijn (1998) noted that people may have individual preferences for certain cultural characteristics in a spouse, so that common values, tastes and knowledge facilitate the development of a mutually satisfying lifestyle.

The influence of third parties was considered, including pressures from the family, the 'church' and the state. Third parties function by increasing awareness of common history and encouraging group identification which increases the internalisation of ethnocultural norms of endogamy (Merton, 1941). In addition, sanctions can be imposed and support withdrawn to ensure compliance. Parental socialisation for endogamy has been considered (Inman et al., 2007. p. 98), where Asian Indian parents emphasise the need for their children's marriage partners to be fellow Indians because of "a fear that intermarriage would challenge the continuation of cultural values by changing children's values or creating distance between participants and their grandchildren.” 
Recently, Kalmijn, Liefbroer, van Poppel and van Solinge (2006) demonstrated that one third of the variation in Jewish endogamy is attributed to family influence given that endogamy rates among siblings in the Netherlands are very similar. Two mechanisms account for 75 percent of family influence: inter-generational transmission of ethnic identity and the provision of endogamous meeting and mating opportunities (place of birth, school). As endogamy is less likely to occur among children of mixed marriages than children whose parents are both Jewish, the researchers interpret this in terms of direct inter-generational transmission of endogamy and evidence for the influence of ascription, where one third of the variance is due to family of origin.

While the majority of research on intermarriage has been conducted in North American and Western European contexts, a recent study stands out because of its focus on ethnic exogamy/endogamy in China using data from the 1990 national census (Mamet, Jacobson \& Heaton, 2005). Besides the majority Han group, in China there are 55 minority groups composing eight percent of the total national population (just less than 100 million minority individuals!). Intermarriage rates in Beijing, the capital of China where Han comprise most of the local population are compared with Xinjiang Province, a poor and culturally diverse area that has experienced immigration of Han over the last 50 years. Although China officially encourages intermarriage (between Han and minority groups), this is opposed by minorities who perceive this as a push towards assimilation (Banister, 1987). Overall, individual freedom to marry the person of choice is limited as arranged marriages constitute a prevailing part of life for many minority groups. Nonetheless, predictive factors in Western contexts are also valid in this context: ethnic group differences, culture distance, normative constraints, discrimination from the larger population, small relative group size, geographical concentration - and major isolation are all related to higher rates of endogamy, as are lower levels of individual educational attainment. The potential influence of historical conflict, traditional lifestyle and cultural 
resurgence are mentioned as additional predictors. In Xinjian, the most important factor that accounted for high endogamy rates among Uighur was an 'ethnic consciousness', encompassing pride and efforts for cultural preservation. However, its nature and function were not empirically tested.

Stopes-Roe and Cochrane (1988) assessed marriage choices of White and Asian Indian youths in Britain, examining attitudes towards intermarriage in general and definitions of possible marriage partners. While 58 percent of Asians pronounced themselves as open to intermarriage in general, they preferred not to engage in it themselves. Furthermore, Asians demonstrated a clear definition of ethnic groups they would include as potential marriage partners (fellow Asians), whereas the White sample did not have particular groups in mind, but rather defined possible marriage partners in terms of ethnic groups they would exclude ('colour' being the most frequently described). This study is important since it emphasises the premeditated endogamous behaviour of members of the ethno-cultural group.

In general, most of the research conducted on endogamy and its prelude, selective dating, has examined the effects of structural group-level and individual-level factors. Studies have established that different variables predict inter- and intra-group dating and marriage, with identity and group ties being of unique importance for selective dating and endogamy for minority individuals. Ethnocentrism in romantic preferences has been emphasised, with scarce attention paid to deeper collective-oriented drives. Is endogamy among ethnic minority individuals influenced by concerns for ethno-cultural continuity?

Overall, because endogamy is a transmission belt that enables continuity, when individuals say 'I do' it has a cumulative impact on the collective. This statement breaks away from the traditional research paradigm in cross-cultural research which examines the impact of the collective on the individual, and in so doing it provides a fresh perspective to acculturation research. 


\section{The influence of ethnic history on collective continuity}

As previously mentioned, ethno-cultural identification provides an umbilical pull of continuity, linking individuals to their ancestors (King, 2002). What constitutes this umbilical cord, the matter which binds one generation to the next? It is memory.

\section{Memory and the transmission of ethnic history}

Ethno-cultural groups can be considered as communities of memory - communities that are shaped by their shared history - and in order to not forget that past, such groups retell their constitutive narrative (Bellah, Masden, Sullivan, Swidler \& Tipton, 1985). According to Halbwachs' (1925) concept of collective memory, it is “a social reality transmitted and sustained through the conscious efforts and institutions of the group", a social reality which endows history with meaning and in which ritual overshadows chronicle (Yerushalmi, 1982, p. xv). Indeed, through ethno-cultural rituals, the collective past is actively experienced in the present, affording a transcendent, collective identity that links generations. Rituals help shape vicarious memories that "an individual holds with great personal and emotional commitment, yet is a memory of an event or experience that the individual has not experienced directly" (Friesen, 1990, p. 118).

Memory, like an umbilical cord, serves not only to attach the present generation to the past, but also to provide nourishment for the ethno-cultural group to move forward into the future. Indeed, group identification and mobilisation are based on memory (Cattell \& Climo, 2002). Remembering is not for memory's sake: “Indigenous groups have survived by virtue of historical and cultural memories that articulate their plight, shape their story, and are the basis for intense resistance and eventually...recognition" (Cattell \& Climo, 2002, p. 31).

\footnotetext{
${ }^{6}$ The ritual of the Passover seder provides Jews today with vicarious memories of the Exodus from Egypt.
} 
This thesis investigates ethno-cultural continuity and examines not only whether concerns about group sustainability in the future impact individual behaviour in the present, but also whether an individuals' awareness of the collective past influences their concerns about group sustainability.

\section{Social Representations Theory}

The social nature of memory can be understood under the rubric of Moscovici's (1961) Social Representations Theory (SRT) which focuses on the processes and structures that are involved in the sharing of knowledge and beliefs in society. Social representations are shared understandings of the world: "Societies break apart ... if there is not the sum of ideas and values in which they believe, which binds them to a common passion and which is transmitted from one generation to the next" (Moscovici, 1993, cited in 1998, p. 214).

It is important to note that while Halbwach's concept of collective memory was devoted to preserving past group experiences, SRT was originally formulated to deal with the transformation of scientific knowledge (i.e. psychoanalysis) into new, common sense knowledge, emphasising the dynamic nature of representations (László \& Wagner, 2003). SRT emphasises the social construction of meaning while simultaneously examining cognitive representations (Castro, 2003).

In SRT, Moscovici (1984, p. 24) states that "the purpose of all representations is to make something unfamiliar, or unfamiliarity itself, familiar." This is achieved through two central processes: anchoring and objectification. Anchoring sets novel ideas in a familiar context through naming and classification, where language and articulation play a key role in animating representations (Moscovici, 1984). After all, social representations are social only through communication. Objectification, in contrast, involves the "materialisation of an abstraction" and incorporates symbols in the reproduction of a concept as an image. Images thus move concepts from the world of thought to the material realm. 
Overall, "experiences and memories are neither inert nor dead. They are dynamic and immortal. Anchoring and objectifying are therefore ways of handling memory" (Moscovici, 1984, p. 43).

Theorists in Discourse Analysis have criticised SRT for its socio-cognitive reductionism (Harré, 1984; Billig, 1988; Potter \& Wetherell, 1998). However, Moscovici (1998) emphasized that both language - social communication systems, and representation - individual cognitive systems, are as essential to social representations as are a person's left and right legs. Indeed, representations are mediators between stimuli and the behavioural response they elicit. Individual responses are due to the internal categorisations and representations held about the object (Moscovici, 1984). Castro (2003) summarised the inter-disciplinary argument as distinguishing between two poles of meaning, the social and personal, where mental representations are or are not considered as meaningful objects of investigation. SRT falls within the former category, enabling the operationalisation of collective memory in social science research through examining the content and meaning of representations that are created and portrayed through language and symbols; the media as a source of dissemination, propagation and propaganda (Moscovici, 1961).

Representational structure has also been investigated, where Abric (1993) distinguishes between core and peripheral elements: while core elements are stable and designate the meaning and organisation of the representation, peripheral elements link the core to real-life. Moloney and Walker (2002) demonstrated that the representational field can consist of opposing and conflicting core images, constructed through debate and argumentation.

Regarding the basis of social representations, "if individuals or groups search for evidence of the truth concerning that object, the resulting social representations are knowledge-based. If, on the other hand, representations are formed and maintained through the consensus with others, representations are belief-based" (Markova, 2003). In 
terms of social representations of history, when autobiographical memory and recorded documentation exist for those events (e.g. the Holocaust, September 11), representations are knowledge-based. Belief-based representations are of historical events in the distant past carried by cultural tradition (e.g. Polynesian migrations to New Zealand). Thus, the collective memory of ethnic groups is composed of both knowledge- and belief-based social representations.

\section{Social representations of ethnic history}

Understanding how the collective memory of ethno-cultural groups shapes individual concerns for continuity can be pursued through the study of social representations of history, defined as shared meanings of objective events, transformed with the passage of time into a network of concepts and images (Liu \& Goldstein-Hawes, et al., 2005).

"History is the story of the making of an in-group" (Liu, Wilson, McClure \& Higgins, 1999, p.1023). Indeed, historical representations are vital for intra-group dynamics, playing an important role in constructing group values and norms, fostering social cohesion, and the development of a people's identity where "in-group ontogeny" refers to a collective narrative that serves self-verification and group navigation.

Social representations of history also have a defining role in guiding inter-group relations. On a national level, in New Zealand for instance, the signing of the Treaty of Waitangi between the British Crown and Māori tribal chiefs constitutes the national foundational narrative and as a hegemonic or consensual representation serves as a keystone for continuing relations and resource allocation among New Zealand Europeans (Pākehā) and Māori. In contrast, polemical or conflicting social representations within a nation are used to differentiate and challenge the legitimacy of group positioning within society (Liu \& Hilton, 2005; Sibley \& Liu, in press) and even perpetuate negative intergroup relations. The multiple meanings of iconic representations of historical events was 
examined in relation to the Hindu-Muslim conflict in India, where politicians drew upon images that have nationally-shared cognitive content but ethnically opposed affective representations in order to stir mass action and promulgate inter-ethnic conflict (Sen \& Wagner, 2004). Overall, social representations of history are a resource for culture-specific understandings of inter-group relations (Liu, 2004).

On an international level, social representations of history are characterized by an emphasis on inter-group conflict (World War II is nominated as the most important historical event in the world), centrality of European history, and a recency effect whereby events in the $20^{\text {th }}$ century dominate historical narratives (Liu, 1999; Liu \& GoldsteinHawes, et al., 2003). Furthermore, relative in-group ontogeny is evident whereby nations refer to historical events that are of particular relevance to their group.

What are the specific functions of social representations of history? At the intergroup level, Breakwell (1993) refers to social identity theory, suggesting that social representations - like stereotypes - can serve for social causality (scapegoating), social justification and social differentiation. At the intra-group level, Liu et al., (1999) distinguish between two roles: self-enhancement whereby important events and figures from one's group enhance self-esteem; and self-verification whereby memory of negative events and figures have an informative purpose. It is proposed that a third function exists one that is not based on individual motivations from social identity theory - that of selfpreservation where recall of negative events such as collective suffering and positive events such as collective achievement enhance cohesion and vigilance (especially for minorities and 'small peoples') to ensure group survival. Memory detemporalizes the past (Swora, 2001). As such, ethno-cultural groups call upon social representations of ethnic history to appreciate their continued existence and guide their future. 
Overall, while social representations shape collective identity, it is hypothesized that at the individual-level, the stronger an individuals' identification with their ethnic group, the more exposed they will be to social representations of ethnic history and the greater the salience of these representations.

\section{Perceptions of collective continuity and entitativity}

Sani and colleagues (Sani, Bowe, Herrera, Manna, Cossa, Miao \& Zhou, 2008) have investigated Perceived Collective Continuity (PCC). As individuals perceive continuity of the self through time (Chandler \& Proulx, 2008), so groups see themselves as continuous entities. PCC is composed of two related conceptual domains: perceived cultural continuity, which concerns the inter-generational transmission of cultural content and norms, and perceived historical continuity that encompasses the causal interconnection of events in the group's history (Sani, Bowe \& Herrera, 2008). Based on a sample of Italians, their measure of PCC has been internationally validated.

PCC has also been established as a precursor of Perceived Group Entitativity (PGE) which Campbell (1958) defined as a perception of tangible collective existence. Perceptions of group entitativity are influenced by perceptions of common fate, perceived similarity, proximity and permeability or boundary flexibility (McMinn, 2003). Thus, “an ingroup will be seen as a more cohesive, unified, and somehow tangible whole if the group members are seen as the carriers of a trans-generationally transmitted culture, and if the group history forms a coherent narrative" (Sani, Bowe, Herrera et al., 2008, p.1129). People like to be a part of entitative groups where high levels of PGE are related to strong identification (Castano, Yzerbyt \& Bourgignon, 2003). Sani and colleagues demonstrated that both PCC and PGE have positive effects on Collective Self-Esteem and this in turn predicts subjective well-being. The researchers expound on the socio-political implications of PCC, citing examples of the promotion of collective continuity in Israel to foster social cohesion 
and pride. Overall, while PCC is important in understanding group cohesion, it is largely a content-free construct, with items such as "The main events in Italian history are part of an 'unbroken stream"' Although PCC takes an important perspective on representations of history in emphasising cultural and temporal continuity, by side-stepping culture-specific content and personal relevance it fails to capture all the power of social representations of ethnic history.

\section{Representations of ethnic history at the group vs. individual level}

Social representations of ethnic history, if not absorbed by the individual and bestowed with meaning, are of limited use in real life. The subjective importance of representations and the extent to which an individual draws upon them to guide motivations, attitudes and behaviour is variable. The need to move from representations at the collective level to the individual level was expounded by Breakwell (2001), who refers to "personal representations." Five dimensions of variability are described which influence the incorporation of social representations (SR) into personal representations: awareness of the SR; understanding of the SR; acceptance of the elements of the SR (some elements may be fully accepted, others partially, and some modified or rejected); assimilation of the SR into existing representational networks (anchoring at the individual level); and salience of the SR which can change across time and context. Recently, Liu and Sibley (2006) have examined intrapersonal attitude certainty as an individual-level measure of social representations. However, most research on social representations of ethnic history has looked at how representations at the group-level affect individual attitudes. In contrast, this thesis moves ahead by examining across cultures the structure of social representations of ethnic history at the individual level and its influence on concerns for ethno-cultural continuity. 


\section{An integrative framework for volitional endogamy}

\section{Theoretical premises}

This thesis sets out to examine some of the psychological mechanisms behind long-term acculturation. Collective continuity is conceived as a group-oriented acculturation goal for diaspora and indigenous peoples. An endogamous marriage contributes to ethno-cultural continuity by facilitating the creation of a home environment conducive to consistent ethnic socialization. It follows that an understanding of the variables that predict ethnocultural endogamy at an individual level is essential in understanding some of the psychological processes that lie behind collective continuity.

This research incorporates factors at the group and individual levels that predict endogamy and its prelude, selective dating, moving beyond the perspective of ethnocentrism that has dominated previous studies. The first research question of this thesis examines the role of individual concerns for ethno-cultural continuity and its ability to predict endogamy among minority group members. The second research question draws upon ethno-cultural groups as communities of memory and investigates how individual awareness of social representations of ethnic history shape collective concerns for continuity. Although this thesis is concerned with long-term acculturation and the continuity of ethno-cultural groups, research is conducted at the individual level.

\section{Defining endogamy and selective dating as dependent variables}

Aside from sociological research on endogamy that has examined marriage license records and national census data, psychological research typically examines preferences in romantic partners. For the purposes of this research, two outcome variables are defined, but not in terms of preferences. The first is behavioural intentions for endogamy. Intentions can be defined as "any desire, plan, purpose, aim or belief that is oriented toward some goal, some 
end state" (Reber, 1995, p. 381). In this case, the end state is endogamy. The second is selective dating behaviour. Individuals who intend to marry endogamously should to that effect date only fellow ethnic group members.

Although behavioural intentions are not fixed, they signal a conscious will to perform an action. Will is a unique human factor that psychologists understand to be a result of the perception that one's thoughts lead to actions (Wegner \& Wheatley, 1999). Thus, when an individual has the following intention: 'I want to marry someone who is also X', (where X is a fellow ethnic group member), this will lead to them eventually marrying X. Will is similar to the concept of volition, which can be defined as the "conscious, voluntary selection of (a) particular action or choice from many potential actions or choices" (Reber, 1995, p. 848). Both will and volition are related to individual freedom as expounded in Self Determination Theory (Deci \& Ryan, 1985). Accordingly, a specific behaviour such as endogamy is only genuinely chosen if other options are seriously entertained. The volitional nature of endogamy and selective dating for ethnic minorities living in tolerant larger societies is evident precisely because individuals have many alternative actions to choose from, such as interethnic dating, intermarriage, cohabitation, and so on. This smorgasbord of opportunities is open to ethno-cultural young adults who are on the dating scene but not yet married. As such, they serve as the target population for the studies in this thesis.

Azjen's (1991) Theory of Planned Behavior (TPB) has been used in predicting a wide range of behaviours such as voting, losing weight and academic achievement. It has also been applied to the acculturation field by Hooft, Born, Taris and Flier (2006) who investigated job-seeking intentions among Dutch and Turkish migrants in the Netherlands. TPB attempts to predict behaviour from two factors: the subjective norm which encompasses whether significant others believe the behaviour should be performed (this parallels the concept of social network approval), and attitudes towards the target behaviour. Both of these contribute to predict behavioural intentions which can be 
understood as internal declarations to perform the behaviour (Vaughan \& Hogg, 1998). In general the stronger the behavioural intentions, the more likely the performance of the behaviour (Azjen, 1991). However, this applies only when the target behaviour is subject to control. By including perceived behavioural control as a predictor of both behavioural intentions and behaviour itself, TPB empirically accounts for volition, whereby a behaviour that is perceived to be controllable is consciously and deliberately performed.

The conception of control in TPB is likened to the construct of self-efficacy. If individuals do not believe they have the ability to create desired outcomes, there remains little or no motivation to act. In general, self-efficacy beliefs will influence effort expended in achieving specific goals and endurance through obstacles in the environment. A metaanalysis of 185 studies found that the inclusion of perceived behavioural control added 6 percent on average to predicting intentions and that TPB as a whole accounted for 27 percent of the variance in behaviour (Armitage \& Conner, 2001).

Although the integrative framework for volitional endogamy presented below is not a test of TPB, it does incorporate the central role of intentions in predicting behaviour. As it stands, attitudes towards endogamy and perceived control of endogamy are not included. Bagozzi (1992) expounded that there was still a missing motivational link in TPB in that "the existence of a desire, in the presence of a belief that one can act, is a sufficient motivator to activate an intention" (p. 184). Desires encompass a commitment to act, are commonly expressed with words that indicate a want, a wish and a like, and are placed ahead of intentions. As such, it is hypothesized that the construct of collective continuity is some sort of desire for ethno-cultural continuity, which predicts behavioural intentions for endogamy. 


\section{Introducing the predictive model}

Figure 2.1 introduces a predictive model of volitional endogamy and selective dating for ethnic minority groups, synthesizing variables in previously conducted research and incorporating two new constructs. The layout of this model is inspired by Berry and Sam's (1997) framework for acculturation research, which separates group-level variables from those at the individual level as predictors of individual psychological and socio-cultural adaptation. On the left of Figure 2.1, contact is established between the ethno-cultural group (specifically diaspora and indigenous peoples) and the larger society. Next, grouplevel variables in the larger society and ethno-cultural group are presented in the vertical rectangle. Recall that the most favourable setting for ethno-cultural continuity (a thriving collective) relies on positive external conditions in the larger society such as those expounded by multiculturalism, and high internal momentum as indicated by demographic and socio-cultural factors of the ethno-cultural group. 


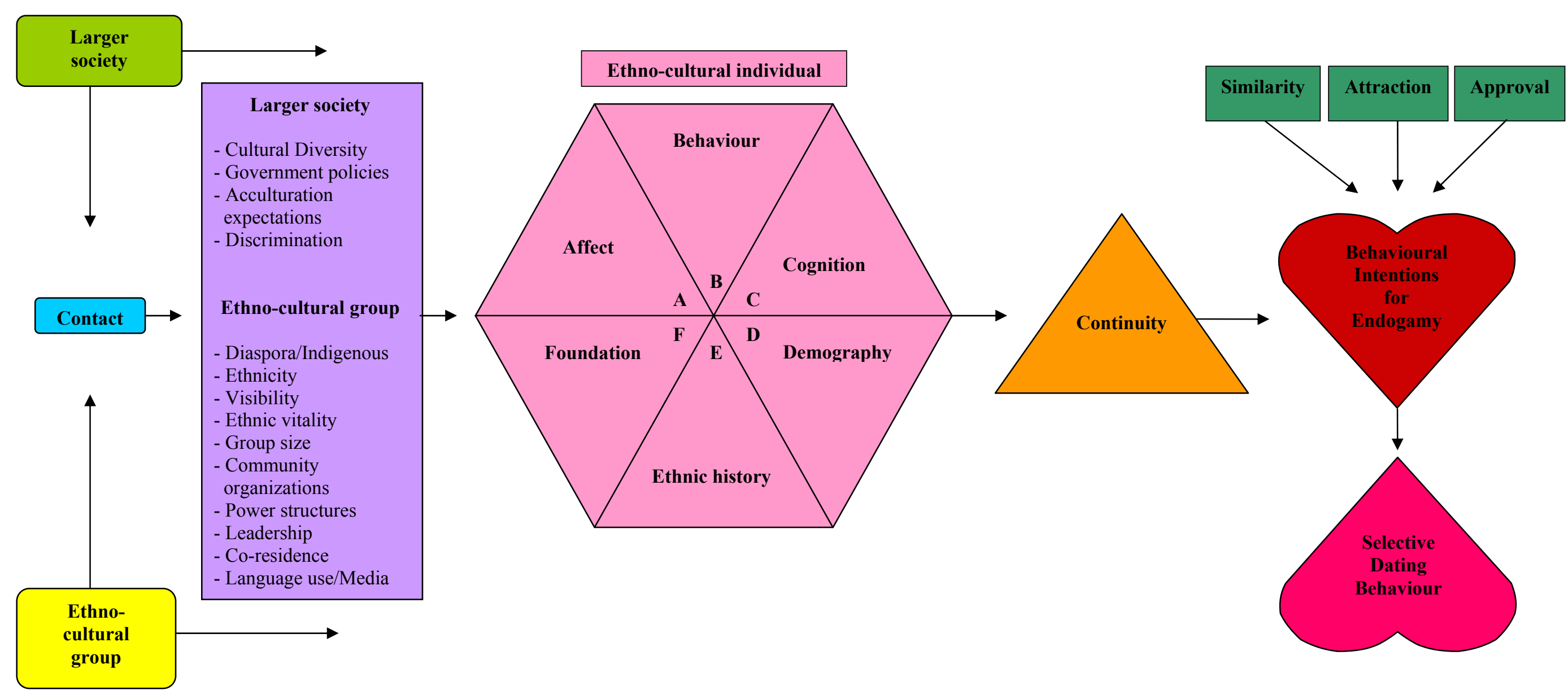

Figure 2.1: A predictive model of volitional endogamy 
As summarised in the previous chapter, four principal factors in the larger society influence the acculturation of individuals and collectives: national cultural diversity, government policies, acculturation expectations and inter-group attitudes of host-society members as well as discrimination. While not all of these variables will be measured in the studies that follow, they are included in the broad theoretical framework. In terms of group-level factors of the ethno-cultural collective, there is status as a diaspora or indigenous people, as well as the ethnicity and visibility of the group. In terms of ethnic vitality, indicators include: group size, number of community organisations, power structures, leadership, coresidence, language use and ethnic media. Although not all of these variables will be included in the studies that follow they are included in the conceptual framework. Overall, these group-level factors are included in the model because they impact acculturation and are hypothesized to have an indirect effect on individual behavioural intentions for endogamy (represented in the heart shape) through the individual-level variables (represented in the hexagon).

Firstly, individual factors that are hypothesized to predict endogamy include affect (positive feelings) towards one's ethnic group, behaviour such as ethnic language competence and adherence to traditional customs, as well as cognition in terms of the centrality of one's ethnic identity and a sense of belonging. Note that both affect and cognition come under what is typically studied as social or ethnic identity (Cameron, 2004). Demographic variables are next such as gender, parental ethnic heritage and migrant generation, followed by individual awareness of ethnic history. This requires conceptual development and will be described in Chapter four. Finally, foundation refers to an individuals' attachment to their ancestral land. Rarely studied, it is included in the framework because land is particularly important to diaspora and indigenous peoples.

These individual-level variables predict endogamy whereby the relation is hypothesized to be mediated by individual concerns for ethno-cultural continuity 
(represented by the triangle). This also requires conceptual development and will be described in Chapter four. Three traditionally studied predictors of endogamy are included in the model: perceived similarity and attraction towards fellow ethnic group members, and social network approval which consists of parental and peer support for endogamy.

Finally, it is hypothesized that behavioural intentions for endogamy predict selective dating behaviour (represented by the upside-down heart). While previous acculturation research on ethnic dating and endogamy has not examined such a relationship, when individuals choose goals (such as endogamy) they engage in behaviour that is directed towards attaining those goals (such as selective dating) (Deci \& Ryan, 1985). Thus, it is logical that if individuals intend to marry a fellow ethnic group member, this should influence their actual dating behaviour. Literature from other fields in psychology supports this contention, in particular the Theory of Planned Behavior (Azjen, 1991).

\section{Conceptual development of two new constructs}

Two constructs, individual awareness of social representations of ethnic history and individual concerns for collective continuity require (a) theoretical development and (b) the creation of quantitative measures to enable the empirical testing of the model crossculturally (Jews, Māori and Chinese in New Zealand, see Chapter six) and cross-nationally (Jews in New Zealand, Australia, Canada and the United States, see Chapter seven). A fertile method of examining new constructs is through the use of exploratory focus groups. Before presenting the results of the qualitative research, however, it is important to understand the long-term acculturation experiences of Jews, Māori and Chinese over the past decades, centuries and even millennia. Indeed, experiences of collective acculturation in the past are likely to influence individual acculturation in the present. As such, Chapter three follows with an ethnographic description of the long-term acculturation of the Jewish, Māori and Chinese peoples. 


\section{CHAPTER 3: THE LONG-TERM ACCULTURATION OF JEWS, MĀORI AND CHINESE}

\section{The Jewish Diaspora as a Case Study of Ethno-cultural Continuity}

\section{Who are the Jews and who is Jewish?}

Defining who the Jews are is not an easy task. Changes to the definition of Jews and Judaism over more than 2,000 years reflect variations in societal emphases on kinship, religion, politics, essentialist views and minority visibility. First of all, the operational definition of a Jew used by social scientists and demographers today is that of selfidentification as a Jew in survey research, or as indicated in census data whether by religion or ethnic group membership (DellaPergola, 1993). A further distinction is made between the core population which consists of individuals who self-identify as Jews and those of Jewish heritage who have not converted to other religions, and the enlarged population which encompasses non-Jewish family members of Jewish households and people of Jewish heritage who espouse a different faith. In general, the Jewish core consists of those who not only identify themselves to be Jewish but are so identified by non-Jews (Porton, 1999).

Cohen (1999) defines Jews as an ethnic community based on shared ancestry and connections to a particular territory, whose unique characteristic consists of their religious beliefs and practices. The Greek word Ioudaios and the Latin word Iudaeus stem from the Hebrew word Yehudi: originally designating a Judaean, a person from the tribe of Judah who is from the geographical region of Judea. However, in English the word Jew has lost its geographical connotations. Maintaining its ethnic connotations, during the Hasmonean period the definition of a Judean was extended to include a political community who could 
grant citizenship rights, as well as a religious community who accepted converts. Overall, Jewish identity is conceptualised as ethno-religious.

Emphasis has been placed on common ancestry or kinship as a defining characteristic of Jews. Anthropological research has shown that the political organisation of human society was primarily organised on extended ties of kinship, followed by ties of territoriality (Holy, 1996). Unilineal descent is a key principle of social structure upon which the continuity of a group is based. Three types of genealogical descent are distinguished: patrilineal/agnatic (lineage through the father), matrilineal/uterine (lineage through the mother), and cognatic (lineage through either the father or mother). For Jews, patrilineal descent was normative in biblical times: The forefather Abraham bore a son called Isaac, Isaac bore a son called Jacob (whose name was changed to Israel), who in turn bore twelve sons: Reuben, Simeon, Levi, Judah, Dan, Naphtali, Gad, Asher, Issachar, Zebulun, Joseph and Benjamin. Their respective families/clans became known as the Twelve Tribes of Israel $^{7}$. The principle of matrilineal descent appeared in the Mishna (Jewish oral law compiled by Rabbis) around the second century CE. Today, Jewish Orthodox law only acknowledges the maternal descent rule, although cognatic descent (through either the mother or father) is recognised by Reform Judaism.

Judaism is also a theological community whereby adults who willingly convert and enter the covenant between G-d and the people of Israel, as well as children who are adopted, are Jewish (Neusner, 1999a; Schwartz, 1999; Tobin, Tobin \& Rubin, 2005). Conversion involves learning, public appropriation of Jewish beliefs and practices, immersion in a purification bath and circumcision for men. Over the centuries, Jews were persecuted and forcibly converted to Christianity or Islam. However, essentialist views of Jews as a distinct ethno-cultural group persisted among Christians such that Jewish converts and their descendents remained distinct from born-Christians. 
The visibility and racial distinctiveness of Jews has wavered over the course of history. In antiquity, Jews were not recognisable from gentiles (Cohen, 1999). Over the centuries, Jews were categorised as "other", as unChristian or Infidels, and were designated by special clothing to enable anti-Jewish sentiment and behaviour from members of the larger society. In contrast, the concept of Jews as a race - Orientals, Semites, or Hebrews was based on the apparent traits of Jewish physiognomy, such as nose shape. The supposed racial inferiority of the Jew was taken to extremes in the Holocaust (CohnSherbok, 2002). Frye Jacobson (1998) outlines the journey of Jews in the United States from a religious 'other', to a racial group, to being White in contrast to Blacks, and finally to passing and being accepted as Caucasians.

As an ethno-religion, Judaism encompasses a distinct world view and a way of life, and as a social group it exercises boundary maintenance (Salkin, 1999). The Old Testament or Torah contains the formative narratives of the Jewish people, recounting a historical and prophetic story of a covenant between the people of Israel and G-d, of communal exile (interpreted as a punishment for not following G-d's commandments) and return to the land of Israel. Laws which govern many facets of intra and interpersonal life are stipulated in the Torah, as are methods of boundary maintenance. In particular, the prohibition against exogamy is enforced to defend against idolatry (Exodus 34:15, Deuteronomy 7:3-4) and to preserve Jewish identity while living amongst other nations or goyim (Ezra 9-10 and Nehemiah 13).

Jews are responsible for one another according to the tenet "Kol Israel arevim ze bazeh." While Jews may be characterized as hyper-collectivist (MacDonald, 2002), according Elazar (1999), Jews are distinguished by a reciprocal individualism, a "community where people are different from each other but not indifferent to each other" (p. 1,100). Jewish communities or Kehillot had complex social infrastructures to take care

\footnotetext{
${ }^{7}$ Note that Joseph's two sons Manasseh and Ephraim became leaders of separate tribes.
} 
of their collective needs (Cohen, 1999). Overall, ethnic solidarity coupled with a lack of power in the host society (described below), served to characterize Jewish communities as parochial.

In the diaspora, until citizenship rights were granted in the late 1700s and early 1800 s Jews were sojourners in foreign lands. Not permitted to own land and allowed to exercise only a small range of occupations, Jews survived by economizing and working as commercial middlemen, depending upon extended kin networks to provide what local rulers needed (Zenner, 1991). Although their lack of power placed Jews in a vulnerable position in society, imposed and voluntary segregation led to successful identity maintenance and reproduction; as such sojourning was a viable strategy for Jewish continuity (MacDonald, 2002).

\section{Geography and Jewish acculturation}

The twelve tribes of Israel lived in separate areas under the rule of King Saul and King David. Due to inter-tribal tension and warfare, after the death of King Solomon, the realm split into two Kingdoms in $796 \mathrm{BCE}$; the North (Israel) and South (Judah). The two kingdoms differed radically in terms of their approach to acculturation; Israel had greater contact with foreign cultures than Judah (Asa-El, 2004). After the conquest of the Kingdom of Israel by the Assyrians, the ten northern tribes assimilated - since known as the Lost Tribes of Israel. The remaining Judeans are the people who are now known as Jews. Thus, Jewish diaspora history is predominantly that of three tribes, Judah, Benjamin and Levi. Many Judeans were driven into exile by the Babylonian captivity in 586 BCE. Under the reign of King Cyrus the Great of Persia, the Jews were allowed to return to Jerusalem where they rebuilt the temple, although many did not return to Israel. By the time the Second Temple was destroyed by Romans in 70CE, the majority of Jews lived in exile (Asa-El, 2004). The destruction marked the end of Jewish sovereignty until the 
establishment of the State of Israel in 1948. Today, the term 'lost tribes' is used to refer to Jewish communities who are thought to descend from the Kingdom of Israel but are no longer Jewish, as well as exotic Jewish communities in Africa and Asia which became isolated over millennia.

According to Asa-El (2004, p.28), the Jewish nation is "so geographically stretched and culturally fluid that its dispersion set it apart from other nations even more than its distinctive laws, rules, tradition, languages, and dress." Over 2,000 years, the acculturation of Jews to different host societies at different rates and to different degrees has led to massive cultural heterogeneity in terms of language, food, dress, norms, and religious observance. While diaspora communities around the world were successful under regimes of tolerance, they also lived a precariousness existence under regimes of oppression in both Christian and Muslim lands ${ }^{8}$.

Acculturation to the local environment led to separate branches of Jews with distinct cultural characteristics who nevertheless maintained their identification with the Jewish people: Ashkenazi Jews originate near the Rhône basin (Franco-Germany and the PolishRussian territories); Sephardi Jews originate from the Iberian peninsula (Spain and Portugal); Mizrahi Jews remained in the Middle East, in North Africa (Morocco, Tunisia, Algeria), Egypt, and Asia (Persia, Syria, Lebanon, Yemen, Afganistan, Kurdistan); Bene Roma are an ancient Italian Jewish community; ancient communities in India include Bene Israel and B'nei Menashe from China; Beta Israel are from Ethiopia; ancient African communities include the Lemba of South Africa, the Igbo in Nigeria, and the House of Israel in Ghana; and a separate group of Karaite Jews existed separately (see Appendix A for more details on these branches; Asa-El, 2004; Tobin, Tobin \& Rubin, 2005).

\footnotetext{
${ }^{8}$ Jews had the alien status of dhimi.
} 
Anti-Semitism in Europe, civil and international war, and massive migration patterns over the last two centuries brought thousands of Jews to North and South America, Africa, Oceania and Israel. This thesis focuses on the continuity of Jews who migrated to the former British colonies of the United States, Canada, Australia and New Zealand; most are Ashkenazi in origin. Details of these communities are provided later. In 2004 while the core world Jewish population numbered 12,990,000 people, it was characterised by zero growth rate - from 1970 to 2003 the global population increased by 70 percent, although the Jewish population only increased by 2 percent (Jewish People Policy Planning Institute, 2005). Table 3.1 provides an overview of the geographical distribution of the world's Jewish population today ${ }^{9}$.

\footnotetext{
${ }^{9}$ Sources: Jewish People Policy Planning Institute (2004-05) and American Jewish Committee (2005).
} 


\section{Table 3.1: Geographical distribution of world Jewry}

\begin{tabular}{|c|c|}
\hline North America & $\begin{array}{l}43.6 \% \text { of the world Jewish population }-5,661,000 \text { Jews. The USA has the } \\
\text { second largest population }(5,290,000) \text {; Canada has the fourth largest }(371,000) \text {. }\end{array}$ \\
\hline Central America & $\begin{array}{l}0.4 \% \text { of the world Jewish population }-52,000 \text { Jews; Mexico is the largest } \\
\text { community }(39,900) \text {. }\end{array}$ \\
\hline South America & $\begin{array}{l}2.70 \% \text { of the world Jewish population }-346,000 \text { Jews; Argentina is the largest } \\
\text { community }(185,000) \text { followed by Brazil }(96,800) \text {. }\end{array}$ \\
\hline $\begin{array}{l}\text { European Union } \\
\text { (25 states) }\end{array}$ & $\begin{array}{l}8.6 \% \text { of the world Jewish population }-1,121,600 \text { Jews; the largest community } \\
\text { is in France }(496,000) \text { followed by the United Kingdom }(299,000) \text {. }\end{array}$ \\
\hline $\begin{array}{l}\text { Former Soviet } \\
\text { Union }\end{array}$ & $\begin{array}{l}2.80 \% \text { of the world Jewish population }-360,000 \text { Jews; Russia has the largest } \\
\text { community }(244,000) \text {. The Baltic States have } 34,400 \text { Jews; Turkey is the largest } \\
\text { community }(17,900) \text {. }\end{array}$ \\
\hline Asia & $\begin{array}{l}0.30 \% \text { of the world Jewish population }-40,000 \text { Jews, the largest community is } \\
\text { in Iran }(10,900) \text {. }\end{array}$ \\
\hline North Africa & $\begin{array}{l}\text { Less than } 0.04 \% \text { of the world Jewish population }-5,400 \text { Jews; the largest } \\
\text { community is in Morocco }(4,000) \text {. }\end{array}$ \\
\hline Africa & $\begin{array}{l}0.60 \% \text { of the world Jewish population }-73,600 \text { Jews; the largest community is } \\
\text { in South Africa }(74,000 \text {, mostly migrants from Lithuania). }\end{array}$ \\
\hline Oceania & $\begin{array}{l}\text { Australia is the ninth largest Jewish community in the world with } 0.78 \% \text { of the } \\
\text { world Jewish population }(101,000) \text {; New Zealand has less than } 0.05 \% \text { of the } \\
\text { world Jewish population }(6,800) \text {. }\end{array}$ \\
\hline & orld Jewish population $-5,165,400$ Jews. \\
\hline
\end{tabular}

\footnotetext{
10 The mass return to Israel as the historical homeland began in the late 1800s. Jewish immigration was permitted under British rule with the Balfour Declaration in 1917, and increased rapidly with post-war immigration in 1950.
} 


\section{Historical and contemporary influences on long-term Jewish acculturation}

Many factors have affected Jewish acculturation in the diaspora over two millennia that shape the way individual Jews experience acculturation today:

a) Greek civilisation constituted an opposing force that solidified Jewish identity (Johnson, 1987; Cohen, 1999).

b) The canonization of Jewish texts in the first and second centuries CE strengthened ingroup identity and homogenized Jewish belief and practice (Johnson, 1987).

c) Christianity emerged as a new theology that retained principal Jewish ethos while disregarding Torah law, marking a major discontinuity from Judaism (Johnson, 1987).

d) The synagogue or beit Knesset ingeniously countered the exile and decentralisation of the Jewish nation as a place for communal gathering, worship, education ${ }^{11}$ and welfare ${ }^{12}$. A central mechanism responsible for ensuring the continuity of the Jewish people: "the synagogue, wherever it stood, was extraterritorial, much as embassies are today ... whenever Jews entered the house of prayer they were in Israel, speaking its language, remembering its past, dreaming its future” (Sacks, 2000, p. 151).

e) Enlightenment and Emancipation: In 1789 the French National Assembly made a declaration against religious discrimination and Jews were granted rights of citizenship. However, as the Enlightenment separated Church and State, so the duality of Judaism as an ethno-cultural group and religion became problematic (Stanislawski, 1999). In the West, where Jews became national citizens, Judaism was redefined solely as a religion; in the East, where religious difference was not tolerated, an ethno-cultural Jewish identity persisted ${ }^{13}$. Jewish religious heterogeneity emerged based on disagreements in acculturation, and what

\footnotetext{
${ }^{11}$ Communities were centred on schools, where the teacher or Rabbi was revered (Johnson, 1987).

${ }^{12}$ Religious, civic and social functions are fulfilled in a large complex with study rooms, libraries, purification baths, butchering rooms, kosher food shops, kitchens, dining rooms, schools, community halls and the main prayer hall with the ark housing the Torah.
} 
constitutes the core of Judaism (see Appendix B; Sarna, 2004; Asa-El, 2004; Brown \& Lightman, 1999).

f) Anti-Semitism has had a major impact on long-term Jewish acculturation. PaganHellenistic anti-Semitism transformed into religious anti-Semitism and then into statesponsored anti-Semitism. Langman (1999) cites Beck's (1982) seven categories of antiSemitism: religious ${ }^{14}$ - Jews accused for killing Christ and their refusal to convert to Christianity; social - negative attitudes and restrictions on civil rights (e.g. citizenship, land ownership, residence, education, employment, enforced wearing of clothing with visible markers); political - Jews blamed for negative world events such as communism and capitalism; economic - Jews accused for controlling local and world economies; psychological - displacement and projection of negative affect and traits; sexual contradictory stereotypes such as being tempters and defilers yet impotent; and racial Jews seen as biologically impure. In the $20^{\text {th }}$ century, the Final Solution to the Jewish question - genocide through gassing in specifically constructed death camps was implemented by the Nazis with assistance from local collaborators in 1941 (Neville, 1999). One third of world Jewry was killed. The Holocaust or Shoah is the biggest tragedy to befall the Jewish people since the destruction of the Second Temple in terms of physical, cultural and intellectual loss. Psychological effects of intergenerational trauma range from the internalisation of negative attitudes, feelings of inferiority, insecurity and 'justified' paranoia $^{15}$, and ambivalent Jewish identities (Langman, 1999).

\footnotetext{
${ }^{13}$ Jewish identity was also enforced by the larger society. When my father left Ukraine as a refugee in 1979, his passport specified Jewish nationality.

${ }^{14}$ Jews were falsely accused of killing Christian children, using their blood for rituals, and blamed for the Black Plague in 1348 by poisoning Christian wells. The Protocols of the Elders of Zion was a 19th century anti-Semitic forgery that claimed Jews were planning to take over the world.

${ }^{15}$ Portrayed in films by Woody Allen, and recently in Borat.
} 
g) Zionism is a political movement of Jewish self-determination established by Theodore Herzl who believed that only a Jewish state would provide security ${ }^{16}$ (Cohn-Sherbok, 2002). After the Holocaust, in 1948 the United Nations voted in favour of the establishment of the State of Israel, a safe haven where Jewish life is normalised (Sheffer, 2005).

Diaspora Jews once perceived their exile to be "abnormal, divine, and temporary" (Asa-El, 2004, p. 38). Today, many remain voluntarily in their host countries ${ }^{17}$ (Sheffer, 2005).

h) The revival of the Hebrew language is both ideological and functional as diaspora Jews are reunited in Israel. Hebrew remained the universal Jewish language for religious rituals and core Jewish texts, although its use as the lingua franca had ceased towards the end of the Second Temple era in favour of Greek and Aramaic (Asa-El, 2004) ${ }^{18}$.

\section{Jewish history and memory: An impetus for continuity}

\section{Manifold meanings of Jewish history}

"What are we on earth for? Is history merely a series of events whose sum is meaningless? ... Or is there a providential plan of which we are, however humbly, the agents? No people has ever insisted more firmly than the Jews that history has a purpose and humanity a destiny" (Johnson, 1987, p. 2).

The Jews see history in a linear fashion, progressing from actual to ideal, distinguishing what has been from what will be. Jewish history is also characterised by circularity as the cycle of growth, blossoming and decay of the Jewish people has repeated over millennia (Graetz, 1846, cited in Meyer, 1974). In history is found the raison d'être of the Jewish people, "narrated as to teach lessons, reveal patterns, tell what people must do and why, predict what will happen tomorrow" (Green, 1999, p. 380).

\footnotetext{
${ }^{16}$ Herzl observed the persistence of anti-Semitism as crowds shouted "Death to the Jews" in the 1895 Dreyfus affair when a French Jewish army officer was falsely accused of treason.

${ }^{17}$ Orthodox Jews in the diaspora and Israel view their status as exile until the arrival of the Messiah.

${ }^{18}$ Dialects combined Hebrew with local languages, such as Ladino (Spanish written in Hebrew characters) and Yiddish (German written with Hebrew characters).
} 
The Old Testament and canonized texts provide an integrated narrative of history from the creation of the world until the first centuries CE, serving as a family record of the Jewish people, a constitutional narrative and a prophetic document. Indeed, Jewish history is a touchstone of Jewish collective identity.

"There are two ways in which individuals coalesce into a group with its own distinctive identity. The first is the way of history. Individuals feel bound to one another because they share the same ancestry, the same ethnic origins, the sense of a shared past. ... They are a community of fate, an am, a people. The second is based on the future. Individuals can be bound together as a group ... not by history but by destiny" (Sacks, 2000, p. 112).

Traditional Jewish memory is selective, emphasising divine guidance. Jewish collective suffering, interpreted in terms of divine punishment, was only bearable in light of future redemption.

Jewish collective history has consequences for individual Jews, for the collective Jewish people, and for the world at large. It directly implicates the individual in the journey of collective continuity "each of us has significance precisely insofar as we are part of a story" (Sacks, 2000, p. 41). Consequences for the Jewish people include the formation of collective memory upon which a shared ethno-cultural/national identity is based (Dubnow, 1893, cited in Meyer, 1974). Consequences for the world at large are evident as millions of people continue to take an interest in and learn ethical lessons from the first half of Jewish history - pre-exile - as preserved in the Old Testament. 


\section{How is Jewish history remembered?}

Jewish history is embodied in sacred texts and composed of three key narratives: origin, rise, and fall (Schwartz, Zerubavel, \& Barnett, 1986). The Exodus from Egypt (G-d leading Jews on a journey from slavery to freedom) constitutes the master narrative of the Jewish people. Collective memory is transmitted through the two mechanisms of recital and ritual. From a psychological perspective, these mechanisms can be divided into cognitive, behavioural and affective components. Firstly, Jewish history is recited weekly as texts are read publicly in the synagogue. The repetition of the readings in a yearly cycle, affording Jewish history with atemporality, ensures successful cognitive remembrance. Secondly, the behavioural dimension is evident in the institutionalisation of commemorative rituals in the yearly festival cycle, such as the Passover Seder which incorporates the reading of historical texts with the eating of symbolic foods to retell and relive the exodus from Egypt (Yerushalmi, 1982). Thus, participants of such rituals undergo an affective, vicarious experience of Jewish history, commanded in the Haggadah, the book that is read during the Passover seder: In every generation one must look upon himself as if he personally had come out from Egypt. Overall, Jewish emphasis on the manifold meanings of history as well as the cognitive, behavioural and affective methods of remembrance has provided impetus for Jewish continuity. 


\section{Jewish continuity then and now}

"If the statistics are right, the Jews constitute but one quarter of one percent of the human race. It suggests a nebulous dim puff of stardust lost in the blaze of the Milky Way. Properly, the Jew ought hardly to be heard of; but he is heard of, has always been heard of. He is as prominent on the planet as any other people, and his importance is extravagantly out of proportion to the smallness of his bulk. His contributions to the world's list of great names in literature, science, art, music, finance, medicine and abstruse learning are very out of proportion to the weakness of his numbers. He has made a marvellous fight in this world in all ages, and has done it with his hands tied behind him. He could be vain of himself and be excused for it. The Egyptians, the Babylonians and the Persians rose, filled the planet with sound and splendour; then faded to dream-stuff and passed away; the Greeks and the Romans followed and made a vast noise, and they are gone; other peoples have sprung up and held their torch high for a time but it burned out, and they sit in twilight now, or have vanished. The Jew saw them all, survived them all, and is now what he always was, exhibiting no decadence, no infirmities of age, no weakening of his parts, no slowing of his energies, no dulling of his alert and aggressive mind. All things are mortal but the Jew; all other forces pass, but he remains. What is the secret of his immortality?"

Mark Twain (1897).

This passage illustrates how the phenomenon of Jewish continuity in the face of circumstances which would have suggested otherwise has captured the minds of nonJewish scholars. As described in the previous sections, the long-term acculturation of Jews in the diaspora has been achieved due to internal factors such as boundary maintenance through endogamy, canonization of texts, the centralising powers of the synagogue, and the centripetal forces of collective memory. Continuity has also been due to external factors such as the status of Jews as sojourners, parochialism, and anti-Semitism. Thus, Jewish continuity can be conceptualised as a consequence of internal and external forces. Jewish continuity can also be understood as a religious commitment to the covenant between the Jewish people and G-d as the survival of the Jewish people is perpetually safeguarded (Neusner, 1999b). 
Today, Jewish continuity is a matter of individual choice:

"Jewish identity in the contemporary world is being transformed from fate to choice, from a fact of birth to a consciously-chosen commitment; and significant numbers of young Jews are evidently unwilling to make that commitment" (Sacks, 2000, p. 18-19)

In the $21^{\text {st }}$ century, collective continuity cannot be taken for granted because of individual choices in the most intimate spheres of marriage and family life. The prerogative of continued Jewish identification and choice of marriage partner have been examined by many Jewish social scientists in the diaspora, particularly in the United States. Horowitz (2000) employed a bi-dimensional framework: "doing" and "being" Jewish, composed of behavioural manifestations such as religious rituals, cultural/communal involvement as well as cognitive and affective dimensions of Jewish identification. However, a third dimension, "wanting", a volition or motivation to live a Jewish life, has yet to be examined and is the central focus of this thesis.

Research on factors that influence individual choices in marriage partners has pointed to ritual observance, tertiary education, Jewish formal and informal education, synagogue affiliation, personal friendships, parental intermarriage, gender, generation, and population density. Sklare and Greenblum (1967) examined parents' attitudes towards their children's potential intermarriage, where more negative attitudes towards intermarriage were held by those with greater ritual observance and who belonged to earlier generational cohorts. Medding (1968) examined individual attitudes towards intermarriage, where the unaffiliated and those with higher education and more non-Jewish friends and expressed less negative attitudes towards exogamy than those who were affiliated, had lower educational attainment and had few non-Jewish friends. However, in terms of their reasons for negative attitudes towards exogamy, few participants in either of the above studies mentioned collective survival as a motivating factor; most mentioned practical reasons relating to a successful marriage and avoiding conflict associated with intermarriage. Sklare 
and Greenblum (1967, p. 313) concluded that this was a "safe way of expressing the desire to continue the chain of tradition while at the same time avoiding the appearance of ethnocentrism.”

Analysis of the 1990 National Jewish Population Survey also pointed to generation as an important predictor of exogamy: among those individuals who married only once, 80 percent of first and second generation Jews were endogamously married, in contrast to 55 percent of third and fourth generation Jews (Keysar, Kosmin, Lerer \& Mayer, 1991). Two additional factors include religious identification of individuals, whereby Orthodox Jews are less likely and Reform Jews are more likely to engage in intermarriage; and the population size of the local community whereby Jews in smaller communities are more likely to intermarry (Waite \& Friedman, 1997).

More recently, the National Jewish Population Survey (2000-01) of American Jews found that parental intermarriage strongly impacts the marital patterns of their children: while only 22 percent of intermarried individuals come from endogamous families, 74 percent come from exogamous families. In terms of dating, 36 percent of Jewish college students who have two Jewish parents date only Jews in contrast to 0 percent of students who have one Jewish parent. With regards to subjective importance of having a Jewish spouse, 44 percent of students with two Jewish parents said it was very important vs. 2 percent of students with one Jewish parent; and 18 percent of students with two Jewish parents said it was 'not at all important' in contrast to 59 percent of students with one Jewish parent. Gender differences are also evident, where 18-34 year old men have greater exogamy rates than women (47 percent vs. 37 percent). Participation in formal Jewish education acts as a buffer for exogamy, as 43 percent of intermarried individuals did not receive formal education. Informal Jewish education is another contributing factor: individuals in endogamous marriages are twice as likely to have attended Jewish youth groups and summer camps as those in exogamous marriages (Cohen, 2006). Overall, social 
science research has examined the problem of Jewish continuity in terms of increasing exogamy, and factors that predict endogamy have been isolated in the hopes of countering those trends.

\section{Strategies for ensuring future Jewish continuity}

According to the adage: two Jews, three opinions; many solutions have been generated to remedy the current crisis of Jewish continuity in the diaspora. Communal approaches hold that "Jewish survivalism is conscious, deliberate and planned" (Weiss-Rosmarin, 1977, p. 184). This stems from the value in traditional Jewish thought of taking initiative, as written in the Talmud: "Lo B'shamayim", our destiny is not in the heavens (Dershowitz, 1997). The Jewish People Policy Planning Institute (JPPPI) promotes research and assessment on issues of concern to the survival of world Jewry, emphasising the need for intervention to ensure continuity. Other organisations include the World Jewish Congress, American Jewish Committee, the Joint Distribution Committee, the Alliance Israelite Universelle, Hillel and the World Union of Jewish Students (the latter two organisations served as sources for participants in New Zealand, Australia, Canada and the United States).

Communal strategies differ in terms of approaches, ranging from outreach to unaffiliated Jews and inclusion of 'half-Jews' and non-Jewish family members (a 'quantitative' approach), to inreach which aims at increasing the knowledge and observance of already committed Jews (a 'qualitative' approach) (Bayme, 2002; Jewish Outreach Institute, Tobin, Tobin \& Rubin, 2005;). Some advocate a religious approach to Jewish continuity that emphasises the covenant with G-d and a creative spirituality (Buber, 1967; Sacks, 2000).

Another school of thought emphasises Jewish education, both formal ${ }^{19}$ and informal, as the answer to Jewish continuity (Buber, 1967; Dershowitz, 1997, Sacks, 2000). Jews are

\footnotetext{
${ }^{19}$ Franz Rosenzweig (1886-1929) emphasised the importance of Jewish education and opened centres for adult learning in Germany.
} 
known as the people of the book and Jewish education is the primary mechanism to increase Jewish human capital - knowledgeable and active Jews - (Chiswick \& Chiswick, 2001). Sources of Jewish education range from Jewish day schools, Hebrew Schools, youth groups and summer camps. Others yet focus on the centrality of social structures such as the synagogue and increasing family affiliation (Sheffer, 2005). However, costs in terms of time and money inhibit Jewish living (Chiswick \& Chiswick, 2001).

Making Judaism more creative and attractive is another strategy for promoting Jewish continuity. As Weiss-Rosmarin (1977, p. 194) noted four decades ago, "The tragedy of modern Jewish life is not anti-Semitism, but the loss of the sense of the worthwhileness of being a Jew." What is needed is a re-branding of Jewish life to provide convincing arguments to Jews for continued identification, as Rabbi Waldoks notes, emphasising the joys rather than the "oys" of Judaism (cited in Kamanetz, 1994).

With due respect to the approaches discussed above, the primary strategy for ensuring Jewish continuity is fostering the creation of Jewish families. This is achieved by addressing the problem of intermarriage through "prevention, conversion, and continued outreach to the mixed-married" while simultaneously and primarily encouraging endogamy (Bayme, 1994, p. 285). Several methods include increasing opportunities for Jewish socialisation (at Jewish and secular venues) and increasing Jewish education. In terms of facilitating conversion, social and institutional barriers must be overcome (within and between religious denominations, as converts through Reform Judaism are not accepted by Orthodox standards). Further communal initiatives include providing opportunities for Jewish youth to visit Israel on programmes such as Birthright (launched in 1999) and MASA (instigated in 2003), with the aim of affectively connecting individuals to their Jewish heritage, the land of their ancestors, and the Jewish people in general. The longterm impacts of such visits show that trips to Israel increase participants' willingness to date only Jews and raise Jewish children (Saxe, Kadushin, Hecht, Rosen, Phillips \& Kelner, 
2004). Another programme is the March of the Living (launched in 1988), which takes youth to Jewish sites in Europe relating to the Holocaust. Participation in this programme has positive influences on an individual's willingness to have a Jewish spouse and give their children Jewish education (Helmreich, 2005).

Increasing fertility rates is also another solution for the crisis of Jewish continuity; Wertheimer (2005) praises the natal-centered lifestyle of Orthodox Jewry, where women give birth to 3.3 to 7.9 children, in contrast to the birthrate of 1.86 children for the average Jewish woman. Rather than placing the blame on career-minded women for low fertility rates among Jews, however, Reinharz (2005) advocates the availability of free child care and day school education to facilitate the formation of larger Jewish families.

Overall, many strategies have been tabled to foster Jewish continuity, from communal approaches, outreach, inreach, a faith-based approach, an education-based approach, re-emphasising the synagogue, re-branding Judaism, creating Jewish families through endogamy and increasing fertility rates. Initiatives have also been launched to enable Jewish youth to travel to Israel and Jewish sites in Europe to strengthen their identification with the Jewish people. Despite the extensive sociological and demographic research on factors that predict Jewish endogamy and selective dating (Sklare \& Greenblum, 1967; Medding, 1968; Keysar, Kosmin, Lerer \& Mayer, 1991; Waite \& Friedman, 1997; NJPS, 2000-01; Cohen, 2006), the studies that emphasise psychological factors have been limited to examining the influence of identity and behaviour (Horowitz, 2000; Brown, McNatt \& Cooper, 2003, DellaPergola, 2003). This thesis contributes to the field of Jewish continuity by examining additional psychological factors such as motivation and individual awareness of social representations of ethnic history. 


\section{Diaspora life in four communities}

Four major diaspora Jewish communities that vary greatly in vitality will be sampled from four countries: New York City in the United States has a population of 2,051,000 Jews, (38.8\% of the national Jewish population); Toronto in Canada has a population of 180,000 Jews (48.5\% of the national Jewish population); Melbourne in Australia has a population of 37,779 Jews (37.4\% of the national Jewish population); and Auckland and Wellington in New Zealand have a population of 3,132 and 1,188 Jews respectively (a total of 63.5\% of the national Jewish population). Note that all four countries are characterised as Anglosaxon settler societies in the ICSEY study (Berry, Phinney, Sam \& Vedder, 2006); while the Australian population has the greatest proportion of immigrants of all four countries $(24.6 \%)$, it is the lowest in terms of its actual diversity index (-0.08); New Zealand follows in terms of proportion of immigrants (22.5\%) and is third in actual diversity (0.04); Canada is third in terms of proportion of immigrants $(18.9 \%)$ and is highest in actual diversity (1.42); and the United States is fourth in terms of proportion of immigrants $(12.4 \%)$ and second in terms of actual diversity (0.10). While Australia, New Zealand and Canada all score high on multicultural policies and attitudes, the United States is medium. Characteristics of American, Canadian, Australian, and New Zealand Jewry were drawn together from sources listed in Appendix C, and are summarised below.

\section{Contrasts and Synthesis}

Jews are a minority in all four nations, representing less than 2 percent of the total national population. The Australian Jewish community (101,000 Jews) is almost 15 times the size of the New Zealand community (6,800 Jews), the Canadian Jewish community (371,000 Jews) is almost four times the size of the Australian community, and the American Jewish community $(5,290,000$ Jews) is over 14 times the size of the Canadian community. The New Zealand Jewish population is so small that the Jewish 'centres' of Auckland and 
Wellington are equivalent to a very minor 'fringe' community in the United States, Canada, and Australia. In all four nations, Jews are an aging population and suffer from low birthrates. In terms of socio-economic adaptation, Jews are highly educated and economically successful; they have the means to survive as a community. The major source for Jewish population growth in Canada and Australia has been immigration. Over the next generations, as immigration declines both communities will need to combat assimilation trends. Overall, while the American, Canadian and Australian Jewish communities are currently thriving (though large-scale intermarriage and un-affiliation pose a threat), the New Zealand Jewish community is drifting.

In terms of community origins, the older American Jewish community (late 1400s 1600s) and Canadian Jewish community (late 1700s - 1800s) comprised of Sephardi migrants. In contrast, the initial Australian Jewish community arose from the settlement of Anglo-Jewish convicts (late 1700s - 1800s), whereas New Zealand's first Jews were free British men (1800s). All four nations experienced the influx to greater and lesser degrees of German and then Eastern-European Ashkenazi Jews. The first arrivals in all four nations struggled with physical survival and acculturation, reflected in the heterogeneity and laxity in Jewish observance. One could argue that for those who went to geographically isolated New Zealand, religion was not of primary importance. The Australian and Canadian Jewish communities were particularly influenced by the settlement of large numbers of Holocaust refugees. As far as the new lifestyle was concerned, Jews in these four nations worked in the clothing industries, as middlemen, labourers, and businessmen. Overall, Jews were pushed by anti-Semitism and pulled by socio-economic prospects to these four communities. Subsequent generations became educated and established themselves in professional occupations. 
Regarding national policies, Jews in Canada and New Zealand have had to acculturate to a dual-identity nation. In Canada, Jews were a pariah as distinctions were based on majority religions (Anglo-Protestants vs. French Catholics). In New Zealand, primary distinctions were between the British/Pākehā and Māori as indigenous peoples. As a non-visible minority, Jews have merged with Pākehā. In Australia, Jews acculturated to the British majority while in the United States Jews were engaged in the formation of a new American identity. In all four nations, Jews forged local identities as American-CanadianAustralian-New Zealand Jews.

In terms of adherence to Jewish traditions (Orthodox, Conservative, Reform, Reconstructionist, Traditional, Secular), the community in the United States is most heterogeneous, followed by Canada. Australia and New Zealand have a more restricted range of options. Of affiliated American Jews, 38\% identify as Reform, $32 \%$ as Conservative and 10\% as Orthodox; of affiliated Canadian Jews, $43 \%$ are Conservative, $25 \%$ are Orthodox, and 14\% are Reform; of Jews in Melbourne, Australia 33\% identify as traditional religious/Orthodox, $15 \%$ as Reform and 6\% as strictly Orthodox; of affiliated New Zealand Jews, 70\% are nominally Orthodox and 30\% identify as Reform. In all four nations the most popular Jewish tradition is attendance of a Passover seder, followed by lighting Hannukah candles and fasting on Yom Kippur. While only a minority strictly observe Shabbat and eat kosher, many individuals keep symbolic levels of customs that do not intrude on everyday secular life. In terms of Jewish religious, secular, academic and artistic creativity today, the American community surpasses all diaspora communities.

With regards to the manifestation of historical anti-Semitism, in all four countries over different periods of time the government was reluctant to allow Jewish immigration and established quotas. Jews were seen as unassimilable people. In the United States and Canada, Jews were discriminated against in occupations, education, and social clubs. In all four countries, extremist anti-Semitic groups and Holocaust deniers are present and anti- 
Semitic crimes are increasingly due to the conflation of Israel with the local Jewish community. Security groups protect local Jewish centres.

Intermarriage, an indicator of assimilation, is on the rise in all four countries, with rates in the United States and New Zealand near 50 percent, followed by Canada with 27 percent and Australia with 22 percent. The vitality of the Canadian and Australian communities plays a key role in the low incidence of exogamy as they are characterised with high residential concentration, excellent Jewish day schools, and stronger Jewish observance. In contrast, assimilation is a problem in the United States because American culture and individualistic values are so pervasive that communal ties are losing meaning. In New Zealand, assimilation is a problem because of the tiny Jewish population where individual Jews do not wish to become isolated from the wider society by traditional practices such as Shabbat. At a local community level, vitality limits exogamy rates such that intermarriage of Jews in greater New York is half the national rate at $23 \%$, and intermarriage in Toronto and Melbourne is also lower than the national rate at $15.6 \%$ and $18.4 \%$ respectively. Note that vitality in terms of absolute and relative community size impacts intermarriage rates, where greater absolute numbers of Jews indicates a larger marriage market, and a greater proportion of Jews in relation to the larger society indicates an increased likelihood of contact with fellow Jews (whereas small relative size increases the likelihood of outgroup contact). Indeed, a study by Rabinowitz (1989) found that relative community size was correlated negatively to Jewish intermarriage.

Overall, there are very similar social structures in all four countries, with local Jewish Community Centres and branches of international Jewish organisations. Note that social structures usually originated to provide welfare services, beginning with Jewish burial societies - Chevra Kadisha. In terms of education, Jewish day schools and supplementary schools are established in all four countries; although the quality of education differs dramatically (New Zealand cannot compete). As for residential concentration, there are 
clear Jewish neighbourhoods and a Jewish presence is felt in New York, Toronto and Melbourne, but the equivalent is not found in Auckland and Wellington. With regards to kosher food, the New Zealand Jewish community has severely limited resources compared with the other three communities.

To summarize, the long-term acculturation of Jews in the past has been largely due to boundary maintenance through the external forces of anti-Semitism and internal forces of endogamy. Jewish continuity in the present is threatened in multicultural societies as both anti-Semitism and endogamy decrease. While past research has investigated primarily sociological variables, this research examines the psychological variables that predict endogamy in an effort to ensure Jewish continuity, such as collective concerns for continuity and individual awareness of social representations of ethnic history.

\section{Māori as a Case Study of Indigenous Continuity}

\section{Who are the Māori and who is Māori?}

Māori are Polynesians who, by virtue of living approximately 800 years in New Zealand before the European arrivals, are an indigenous people. However, Māori only became a 'people' in the colonial period. Indeed, the term 'Māori ' means 'normal' and is one that was used in contrast with the new European settlers (King, 2004). Māori are in fact a collection of tribes who share similar customs and common experiences of migration and language, while maintaining distinct identities in terms of genealogy and geographic location (Durie, 2005).

Metge (1967) identified forty-two tribes or iwi from various regions in New Zealand: Northern tribes (Tai-Tokerau), Tainui tribes, Taranaki tribes, Wanganui tribes, Manawatū tribes, Wellington tribes, Arawa tribes, Bay of Plenty tribes, East Coast tribes (Tai-Rāwhiti), Tākitimu and South Island tribes (see Metge, 1967, pp. 129-131 for a full listing of iwi). Tribes vary greatly in size; in 2001 three iwi were predominantly larger: 103,000 individuals 
or 23 percent of the Māori population affiliated with Ngā Puhi, 62,000 people or 13.8 percent affiliated with Ngāti Porou and 52,000 or 11.6 percent affiliated with Ngāti Kahungunu (Durie, 2005).

Affiliation with a particular iwi operates on a kinship system of cognatic descent (Holy, 1996). That is, individuals claim descent from a common male or female ancestor (patrilineal and matrilineal descent). Individuals may trace descent from multiple ancestors and affiliate with multiple iwi, however, residence within a particular iwi limits potential identification. Hence, membership is usually salient for one: the iwi with higher status (Scheffler, 1964).

In terms of defining who is Māori in the post-colonial phase when intermarriage with Europeans rendered boundaries fluid, the pre-1926 definition of a Māori person was one who had a minimum of 50 percent Māori blood, and a half-caste was classified as Māori. Post-1926, the definition was simplified to those with more than 50 percent Māori blood, formalised in the 1953 Māori Affairs Act. However, in 1974 this was amended to "a person of the Māori race of New Zealand and includes any descendant of such a person" (Durie, 2005). Thus, biological ratios were replaced by claims of descent. These were the means by which Māori were defined by the dominant, New Zealand European society. In contrast, Māori self-definition is much more holistic and inclusive in outlook:

“Māori have always defined 'Māoriness' in terms of Whakapapa or genealogy. When children are born with Whakapapa they are grandchildren or 'mokopuna of the iwi'. They are Māori ... The parts of their heritage which might be English, Chinese or Samoan is never denied, but in Māori terms they are simply mokopuna because it is impossible to have only a 'part grandchild' (Jackson, 2003, p. 62).

Acknowledging the diversity of the Māori population, The New Zealand Census of Population and Dwellings classification allows for individuals to indicate multiple ethnic heritage in terms of descent and identification, and multiple or no tribal affiliations. 
Kukutai (2004) suggests that the core Māori population is constituted by individuals who simultaneously claim Māori ancestry, self-identify as ethnic Māori and also know their tribal affiliation.

\section{Acculturation in Aotearoa}

Māori were originally Polynesian tribes who migrated over a period spanning two to three hundred years - from about 900 till 1200 AD, most likely from islands in East Polynesia, such as Tahiti and Raratonga (Durie, 2005). Speculation on motivations for coming to Aotearoa/New Zealand includes a population explosion and/or tribes searching for autonomy. The voyage was possible with skilful navigation techniques that included knowledge of the stars, tides, and technology such as twin-hulled outrigger canoes (King, 2004). Once in New Zealand, acculturation of the Polynesians to the colder climate and different natural resources, and the formation of kinship groups tied to specific geographic locations led to the evolution of Māori culture (Durie, 2005). Lifestyles were heterogeneous across tribes and yet there were many homogeneous features. Tribal life centred in the village or kāinga, with principle subsistence activities of food gathering and cultivation, trading and warfare. Māori life before the arrival of the Europeans was at the stone-age, with developed art forms including carvings on wood, stone and bone.

Although intra-tribal relations were characterised by the principle of reciprocity and kinship-specific collectivism, inter-tribal relations were characterised by competitive tribalism (King, 2004). Māori social structure distinguished between aristocrats, commoners and slaves, with special veneration for elders or kaumātua and priests or Tohunga. Cannibalism was practiced as part of warfare. Marriage patterns varied from individual mate selection according to attraction, to the common practice of marriage arrangements for the benefit of tribal alliances. Polygamy was present among high ranking men. 
Whilst the family or whānau was the centre of enculturation for individuals, the centre of collective village life was the marae, a central open space with an adjoining ancestral house for meetings or hui, as well as funerals or tangihanga. This is where “oratory, language, values and social etiquette are given their fullest expression" (Walker, 1981, p.28-29, cited in Moeke-Pickering, 1996). Overall, tribal ancestry (whakapapa), tribal land (tūrangawaewae), and Māori language (te reo), form the key ingredients of Māori culture (Durie, 1997).

\section{Māori myths, oral traditions and genealogy}

Māori conceptions of history are heterogeneous across tribes and encompass (a) cosmic mythology, (b) narratives of ancestral canoe migrations to New Zealand, and (c) family and tribal genealogy. In terms of mythology, there are three main narratives relating to the Gods, Creation, and the fabled land of origin by the name of Hawaiki (Walker, 2004). A key feature regarding the Māori conception of history is the emphasis placed on the interconnection between the supernatural and physical worlds, and between the people and the land (Durie, 1997).

Canoe traditions are centred upon tribal ancestors, specifically the first arrivals to Aotearoa and their initial settlement. These traditions highlight selected key figures as a basis for tribal genealogy. Some tribes also share narratives about great navigators called Kupe and Toi (Walker, 1996). The founding ancestral canoes were as follows: Aotea, Arawa, Tainui, Kurahaupō, Tākitimu, Horouta, Tokomaru and Mātaatua (Bateman, 2000). Walker (1996) notes that in the $15^{\text {th }}$ century, oral traditions incorporated inter-tribal warfare, which served to establish tribal boundaries and consolidate political relations between tribes. 


\section{Transmission of oral history}

Māori history was solely an oral tradition prior to colonization. Educated priests or Tohunga were in charge of tribal genealogy, which validated tribal status or mana and claims to specific lands. Traditionally, while select Māori youth were educated by Tohunga in their tribal history, parents also took responsibility for the intergenerational transmission of history. Place names serve as a record of history, and memory mnemonics such as the genealogy staff or whakapapa rākau were used, including rhythm as a learning mechanism (Te Ara, 2008; Durie, 1997). Memory was preserved and transmitted in mōteatea traditional songs or chants, and children were taught specific oriori that carried myths and tribal history.

While history was transmitted orally, it was also embodied in traditional carved ancestral houses or whare whakairo (Bateman, 2000). Ancestors are represented by the structure of the house, where the spine is embodied by the ridgepole, the ribs by the rafters, and in individual carvings on the poles inside the house. In the interior of the house, flax tukutuku panels in between the poles also illustrate genealogy.

Oral history is central to Māori cultural identity (Walker, 1996). It is an umbilical force that binds individuals to their ancestors and to their land:

"As whakapapa is told and retold, the interconnections between the living and the ancestors, the deities and the land becomes clear ... the shaping of individual and collective Māori identity is set within the context of the personal, the collective and the total environment" (Durie, 1997, p. 147).

Māori also call upon history to brace the unforeseen: "The future was unknowable, but the past was there to learn from. Māori proceeded backwards into the future while looking to the past at what their ancestors did.” (Hemara, 2000, p. 72). 
Māori history provides a sense of continuity, embodied in the metaphor of the rope of mankind - Te Here Tangata, stretching from generations been to generations to come (Maaori.com, 2008). The continuity of Māori life is also captured in the following saying or whakatauāki: "Mate atu he tētē kura whakaete mai he tētē kura - A fern frond dies, but another rises to take its place" (Hemara, 2000, p. 75).

Overall, the transmission of history through language to children is interwoven in the goal of Māori collective continuity, forming an organic dynamic:

"Children are viewed as part of a Whakapapa continuum. Their contributions (mana tangata) simultaneously feed into the past, present and future and ensure the survival of themselves and their communities. Reciting Whakapapa, kōrero tawhito, waiata [songs] and whakatauāki [sayings] teaches children about their communities' histories and offers them a variety of options for their futures (mana aotūroa). The acts of reciting and teaching (mana reo) ... empower children by offering them the medium of language" (Hemara, 2000, p. 71)

\section{Colonization and acculturation to European culture}

The arrival of European explorers and British settlers marked a challenge to Māori culture and a catalyst for further acculturation, this time to a new power and civilisation. In 1642, the first brief contact with Europeans occurred with the anchoring of Dutch Explorer Abel Tasman. He was followed in 1769 by the English explorer James Cook. Acculturation began with the arrival of explorers, sealers, whalers, traders and missionaries as Māori began to appropriate tools, food, clothing, and muskets in exchange for native timber, flax and other commodities (King, 2004).

While a nominal pan-tribal Māori identity was being forged in opposition to British identity, pan-tribal unity was formally recognised in the Declaration of Independence of the Chiefs of the Confederated Tribes in 1835 (Durie, 1998). Māori intended to form a nation state at that time, although five years later sovereignty was ceded to the British Crown with 
the signing of the Treaty of Waitangi in 1840 . While the original aim of this treaty was to protect Māori from unorganised settlement, it had detrimental results to Māori culture through the loss of power and land. In retrospect, discrepancies between the English and Māori versions of the Treaty were at fault; Māori thought they were ceding governance or kāwanatanga to the British, while retaining their sovereignty or mana as in the Declaration of Independence. Māori soon became a minority in their own land.

\section{Māori culture loss}

In 1860 Māori comprised 50 percent of the national population; in 1891 they comprised 10 percent of the population and owned just 17 percent of the land through sales and confiscations due to clashes in conceptions of ownership, occupation and inheritance (King, 2004; Durie, 2005).

Major forces of acculturation included 'civilising' by Anglican, Wesleyan, and Catholic evangelists and the development of language to written form by Kendall and Williams, and linguist Lee (Bateman, 2000). The first Māori bibles were printed in 1827. Māori literacy, however, resulted in the inadvertent decrease of oral narrative transmission. Evangelists contributed positively to the development of agricultural techniques, however, negative impacts were also felt as Christian patriarchal values were imposed. The subservience of women to men eroded the respect or mana of Māori women (Adair \& Dixon, 1998). Interesting fusions also occurred as Māori spirituality was incorporated with Christianity and Māori churches were formed such as Ringatū, Rātana, and Rua Kēnana. Christianity and Māori culture were simultaneously reconciled and compartmentalised. For instance, individuals adhered to Christian customs in church and enacted Māori rituals during funerals or tangihanga, and when planting crops (King, 2004). In an interesting psychological twist, some Māori identified with the Israelites in the Old Testament (Rua Kēnana), searching for a way to safely cross the (White) sea of acculturation. 
In the 1840s Māori expressed concern regarding the qualitative survival of their culture due to colonization with phrases describing saltwater contaminating freshwater, and the shark devouring the kahawai:

"Let's work together," said the shark to the kahawai. "Great" said the kahawai with a trusting smile. "Fool," thought the shark as it opened its mouth and swallowed the kahawai... "That's partnership," said the politician. "That's integration," said the bureaucrat. "That's assimilation," said the Māori” (Reedy, 1991, p.7).

Due to low immunity to diseases brought to New Zealand by the Europeans, the survival of Māori culture was also threatened in quantitative terms. The Māori population was estimated at 150,000 in 1800 ; fifty years later the population was reduced to 50,000 and in 1896 it had further declined to 42,113. Aside from sickness, the population decline was also due to musket war casualties and low fertility. In 1874, The New Zealand Herald acknowledged that "the native race is dying out in New Zealand there is, of course, no doubt" (cited in Durie, 2005, p. 16). Indeed, Māori despondency was noted by Archdeacon Walsh in 1907:

“The Māori has lost heart and abandoned hope. As it has already been observed in the case of the individual, when once the vital force has fallen below a certain point he died from the sheer want of an effort to live; so it is with the race. It is sick unto death, and is already potentially dead" (cited in King, 2004, p. 58).

Fortunately, internal momentum was regained as the Māori population began to spontaneously recover; numbers increased slightly to 45,000 Māori in 1901, to 56,987 in 1921 and then to 63,000 in 1926. This was due to a gain in immunity and increased fertility. However, living conditions were unsanitary and working conditions poor; Māori constituted approximately 40 percent of the unemployed labour force while receiving benefits that were lower than those of non-Māori (King, 2004). Indeed, the New Zealand administration had essentially neglected Māori welfare, allocating unequal financial support, 
housing and health care. The disproportionate death rates of tuberculosis, typhoid and other illnesses in the 1930s prompted Māori to fight for better living and working conditions, improved literacy and technology, implemented by the Labour government in the mid-1930s.

\section{Preserving Māori culture}

The first steps taken by some tribes to prevent Māori culture from being completely engulfed by the Europeans was to prevent further sales of land through the formation of Land Leagues (King, 2004). The Kìngitanga movement aimed to unite Māori, retain as much land as possible, and enable some form of self governance in cooperation with the Queen, under the protection of G-d (Durie, 2005). In 1858, Pōtatau Te Wherowhero was anointed as the inaugural Māori King. Further movements include Māori unity or Kotahitanga $^{20}$. Significant efforts for continuity by the Young Māori Party rested on the tenet of Reverend John Thornton, headmaster of Te Aute Anglican College, of survival through emulation of the stronger nation (King, 2004). Key leaders of this group were Āpirana Ngata, Māui Pōmare, Peter Buck and James Carroll, the latter advocating a predominantly assimilationist survival orientation for Māori as a people (Durie, 2005; King, 2004). These leaders saw Māori collectivism as adaptive for the Māori people during the pre-colonial phase but maladaptive for the post-colonial phase. Maintenance of Māori identity was encouraged while relinquishing some customs and adopting New Zealand European or Pākehā ways.

At that time, a dualistic representation of life was widespread among Māori : the New Zealand European world or Taha Pākehā vs. the Māori world or Taha Māori. Māori opinion varied in terms of participation in these two worlds; some leaders advocated

\footnotetext{
${ }^{20}$ A Māori Parliament or Pāremata Māori was established in 1882 and dissolved in 1900 with the New Zealand government Māori Councils Act.
} 
integrating Pākehā aspects into Māori life, others were more radical advocating separatist ideologies e.g. Ngā Tamatoa, the tribe of Tūhoe, and activist Tame Iti.

Significant efforts by women were also made for the well-being of Māori people and the preservation of Māori culture with the establishment of the Māori Womens Welfare League in 1951. Eminent female leaders of the Māori people include Whina Cooper, first president of the Welfare League, leader of the 1975 land march (see below) and known as Mother of the Nation or 'Te Whaea o te Motu'; the influential Te Puea Hērangi helped promote the Kingitanga movement, founded the Tūrangawaewae marae in 1921 and endorsed western education as a tool to strengthen Māori ties.

\section{Urban migration}

Māori voluntarily participated in the First World War and again in the Second World War as a demonstration of equality to New Zealand Europeans (King, 2004). A major impact was urbanisation, due largely to the Māori War Effort Organisation as 11,500 Māori left rural areas to work in industries ${ }^{21}$. In 1900, 95 percent of Māori were living in rural districts; in 1945, 19 percent were in urban areas, increasing to 68.2 percent in 1971 and over 90 percent by the 1980s. This ‘silent migration' was related to major changes in Māori social structures from the communal orientation of villages or kāinga with an extended family or hapū base, to individualist, nuclear families separated from their tribal lands. Māori experienced cultural alienation as the New Zealand government implemented assimilationist policies of residential 'pepper potting'. Further cultural loss occurred through the educational system as children were forbidden to speak Māori; the decline of the language was such that while 90 percent of Māori school children could speak te reo Māori in 1913, this decreased to 26 percent in 1953 and by 1975 only 5 percent could speak Māori. In addition, adoption laws hindered Māori children from knowing their heritage and

${ }^{21}$ The Māori labour force was concentrated in meat processing, railways, wool sheds and wharves (Durie, 2005). 
lineage (Durie 2005). Traditional Māori diet also changed from foods including fern roots, sweet potato or kūmara, berries, fish, and birds, to British foods (bread and potatoes), leading to malnutrition ${ }^{22}$.

In terms of current geographic distribution, in the 2001 Census, almost 90 percent of Māori lived in the North Island. 60 percent of Māori in New Zealand live in Northland, Auckland, Waikato and Bay of Plenty regions combined. Māori concentration is especially high in the Gisborne area with 45 percent ethnic Māori. One quarter of Māori (127,629 people) live in greater Auckland. As the total Māori population in a particular geographic area increases, the more likely Māori are to live in segregated residential areas. This is due to negative factors such as discrimination and economic disadvantage, as well as positive cultural factors. "When they are relatively more numerous...Māori are more likely to be disadvantaged in the lower strata of the labor market, and hence in the housing market too, and more concerned to concentrate in separate areas to enhance their economic and cultural security” (Johnston, Poulsen \& Forrest, 2005, p. 128)

\section{Māori vitality indices and socio-economic disadvantage}

According to Kukutai (2004), the core Māori population in 2001 was 399,941 people (see the section below on exogamy, identification and transmission for details of the enlarged Māori population which is 526,281 people). An additional 92,000 Māori live in Australia (Australian Bureau of Statistics, 2008). Overall, Māori identification is complex: In the 2001 Census 3,322 individuals identified ethnically as Māori without having Māori ancestry and 6,846 people uncertain about their ancestry identified ethnically as Māori (Callister, 2004).

\footnotetext{
${ }^{22}$ In the Te Hoe Nuku Roa project, participants reported limited access to traditional foods like kina, pūhā and rēwena bread; only one third of respondents said they were regularly consumed. Just over half participated in making a hāngī or earth oven (Durie, 2003).
} 
The predicted population growth is 17 percent by $2021(770,000)$ and 22 percent by 2051 $(800,000)$. One third of New Zealand children will be Māori. This predicted growth is in spite of a decrease in fertility amongst Māori women, from 6.18 children in 1962 to just over 2.14 in 1986 and 2.5 kids in 2001. Māori are a comparatively youthful population, the median age is 21.9 years vs. 34.8 for the total New Zealand population. Over one third is less than 15 years of age and one third is above 65 years; indeed, Māori are aging but not as much as the general population. Māori life expectancy is still significantly below that of the total New Zealand population: 69 years for Māori males and 73.2 years Māori females vs. 77.2 years for males and 81.9 years for females in the total New Zealand population.

Regarding the state of Māori language, in 2001 one quarter of Māori could speak everyday Māori conversation; half of these are under 25 years of age. Just over 1 percent spoke only Māori (elderly). One third of Māori in Gisborne could speak Māori. As for educational attainment, Māori have higher rates of leaving secondary school with no qualification, 35 percent vs. 15 percent in the total New Zealand population. Only one in five Māori have a post-school qualification, and non-Māori are three times more likely to enrol at university than Māori. Māori have greater incidence of teenage pregnancy, smoking, diabetes heart disease, mental disorders and suicide. Māori children are more likely to not be immunised, to live in single parent and low income homes, and have no working parent (Durie, 2005; Human Rights Commission, 2005).

Overall, Māori ethnicity is negatively correlated with socio-economic status (Kukutai, 2004). Unemployment rates from 1984-1990 increased from 7 percent to 20 percent as Māori were specifically affected by economic policies of decreasing government subsidies. In 2003, the unemployment rate of Māori was 12 percent vs. 5 percent in the total New Zealand population, with three in eight Māori adults using the benefit in 2001. Māori tend to be employed in low wage jobs (service and sales for Māori females; plant and machine operators and assemblers for Māori males). Māori are also overrepresented in the criminal 
system with 50 percent of prisoners being Māori in 2004-05 vs. 36 percent European, 11 percent Pacific and 4 percent Asian/Other prisoners.

\section{Discrimination against Māori}

Institutional racism has been a consequence of colonization whereby Māori became dependant on government welfare (Walker, 2004). ACORD, the Auckland Committee on Racism and Discrimination, was a group founded by Dr. Oliver Sutherland to counter discrimination against Māori, examining for instance the unfair sentencing of Māori. The Women Against Racism Action Group wrote a report in 1984 about racial discrimination in the Department of Social Welfare through an ethnic imbalance of providers (New Zealand European) to consumers (Māori). The 1986 Puao-Te-Ata-Tu report by the DSW Committee on a Māori Perspectives recommended to the government:

"To attack all forms of cultural racism in New Zealand that result in the values and lifestyles of the dominant group being regarded as superior to those of other groups, especially Māori “ (cited in Walker, 2004, p. 280).

In 1986 the Labour government moved that all future legislation incorporate bicultural principles of the Treaty. To combat discrimination against Māori, a dual-strategy was incorporated that involved increasing the responsiveness of mainstream institutions as well as the devolution of service providers to Māori organisations to increase autonomy (Fleras \& Spoonley, 2002). Such social structures include Te Puni Kōkiri, the Ministry of Māori Development established in 1992 to provide policy advice to Government, agencies, and services for Māori.

Negative media representation led to negative stereotypes of Māori as 'dirty' and ‘lazy’ (King, 2004). However, these were countered by the manner in which Māori excelled in the national sport of rugby, a source of positive collective self-esteem. Overall, New Zealand media contributed to the marginalisation of Māori by providing a mainstream European perspective (Macpherson \& Spoonley, 2004). Moves to counter this include 
training Māori journalists, increasing the cultural sensitivity of European journalists, an increase in coverage of Māori affairs, inclusion of Māori language in mainstream media and the establishment of Māori media thanks to institutional support for the protection and propagation of te reo Māori (see below). There are radio frequencies reserved for Māori, Mana News Radio, Radio Aotearoa, Ruia Mai, Mana Magazine, tribal newsletters, Te Karere and Marae programmes on mainstream New Zealand television, the launch of Māori TV in 2004, and Cyberwaka enterprises.

In terms of perceived discrimination, a UMR research poll for the Human Rights Commission (2007) noted that of 48 percent of New Zealanders surveyed said that Māori experienced a great deal or some discrimination and 31 percent of Māori in the survey felt personally discriminated in contrast to 20 percent of non-Māori New Zealanders.

\section{Māori continuity}

\section{Revitalisation and self-determination}

As a result of colonization and urbanisation, Māori were losing or lost links to their land, to their extended family, and to their language - the three crucial components of Māori identity and culture. However, Māori were determined to "remain distinct and strong even when submission and assimilation were on the state's agenda" (Durie, 1998, p. 1). In a powerful demonstration of the will to live on and regain some degree of self-determination or tino rangatiratanga in their own land, the 1970s and 80s were characterised by protesting such as the 1975 Land March or Hīkoi down the North Island to Parliament in Wellington. These marches raised collective consciousness regarding Māori continuity, calling attention to the threat faced by Māori in terms of qualitative survival. They were protests for the reclamation of Māori language, and the improvement of their socio-economic status. Pantribal unity was an important means to generate the mass needed for political influence. 
In response, the New Zealand government established the Waitangi Tribunal in 1975 to deal with tribal and collective grievances regarding breaches of faith with the Treaty in terms of land retention and cultural protection (King, 2004). In 1984, the Māori economic summit or Hui Taumata was held and the Decade of Māori Development declared (Durie 1998).

A major step towards the revitalisation of Māori culture was the 1987 Māori Language Act which rendered Māori an official New Zealand language and gave individuals the right to speak it in legal settings. Māori language is seen as a national treasure or taonga that is protected by the Treaty. The establishment of Language Nests or Kohanga Reo schools for early childhood in 1981 became a new government-sanctioned force of enculturation in Māori knowledge or mātauranga and customs or tikanga. In 2003, one third of Māori children who went to preschool attended a Kohanga Reo. Kura Kaupapa primary schools were also established, following a collectivist family model of learning. In 1999, there were over 60 schools with close to 5,000 students. Most Māori students attend public primary school, many of which offer bilingual classes (Bateman, 2000). In terms of Māori tertiary institutions, Te Wānanga O Raukawa opened in 1981, followed by Te Wānanga o Aotearoa in 1983 and Te Wānanga-o-Awanuiārangi in 1990. The impact of the re-introduction of Māori cultural resources (which should have been a birthright) in amplifying Māori identity is highlighted in the following passage:

"In spite of her lack of knowledge in many things concerning Māori people, my mother always tried to instil in us the recognition that we were Māori. She would defend our Māori identity to the bitter end, yet it is not until very recently that I have had access to resources which enabled me to be successful as one. I now have to learn te reo and tikanga Māori, things which I believe I should have had access to at birth" (McArdell, 1992, p. 89, cited in Adair \& Dixon, 1998). 
In retrospect, Durie (1998) sees the current stage of cultural reclamation as the last of five stages of responses to European colonization, beginning with a positive engagement, followed by opposition, then withdrawal, and accommodation. He sees Māori selfdetermination encompassing strength numerically, socio-economically, politically and culturally, as well as the protection of the environment.

The nature of Māori continuity is such that:

"without any sense of control, independence, or autonomy, endurance is probably best called existence ... Sometimes autonomy is premised on a resolve to cede from the new state, although more often it is simply the expression of a desire to shape an indigenous destiny, protect a threatened heritage, and manage indigenous resources. Autonomy is the antithesis of assimilation.” (Durie, 2005, p. 236).

To enable the continuity and growth of Māoridom, Durie (2003) emphasises the central role of family or whānau (championed by the Māori Womens Welfare League) as the guardian of culture, a source of empowerment for individuals, and entry into the Māori collective. Overall, Durie presents a framework of Māori continuity that encompasses the human level: Te Manawa (cultural identity) and Te Kāhui (collective synergy); and the resource level: Te Kete Puāwai (cultural \& intellectual) and Te Ao Tūroa (Māori estate).

\section{Māori identity}

European culture is the counter-force to a collective Māori identity; it is simultaneously the cause of the weakening of Māori identity and the catalyst for the drive to ensure the endurance of Māori culture. Acknowledging that "The current reality is that Māori identity is embedded in a Pākehā ecology" (Moeke-Pickering, 1996), what are the characteristics of Māori identity today? The Te Hoe Nuku Roa study (Massey University) takes into consideration multiple facets of Māori identification, including self-identification, awareness of ancestry, and behavioural aspects like participation in collective marae events, contact with the family and other Māori, use of Māori language and connections to 
ancestral land (Durie, 1998). In this study, the multiplicity of Māori identity in New Zealand is evident as slightly more than half preferred Māori as a sole indicator of identity, 11 percent of Māori identified as Kiwi and 15 percent as New Zealander (Callister, 2004). Kukutai (2004) demonstrates that individuals who live in residential areas with a high Māori concentration and have a Māori partner are likely to identify solely as Māori. She also showed that socio-economic disadvantage is more evident among multi-heritage Māori women who identify solely or mainly as Māori in contrast to those who mainly identify as European. Consequently, she advocates for policies that target those who solely or mainly identify as Māori.

\section{Exogamy, identification and transmission}

Historically, intermarriage rates have been quite high; in 1960, research by Harré (1968, cited in Callister, Didham \& Potter, 2005) using marriage registrations demonstrated that 42 percent of Māori were married to a New Zealand European. In the 2001 Census, for Māori individuals who identified ethnically, female endogamy was 51 percent and male endogamy was 52 percent. In contrast, endogamy for females and males of Māori descent was lower at 43 percent and 45 percent respectively (note that the descent category includes those who also identify ethnically; the lower rates reflect the weaker identification and involvement of Māori who do not identify ethnically).

The Māori population is increasingly diverse due to large-scale intermarriage with European and Pacific Islanders. In the 2001 census, 294,726 people identified as sole Māori, 193,500 as Māori/European, 15,606 as Māori/Pacific and 14,103 as Māori/Pacific/European to bring the total count of the Māori ethnic group to 526,281 people (Callister, 2004). Thus, only 56 percent of the total Mãori population identifies solely as Māori. 
Riddell (2000) claims that intermarriage has not resulted in the disappearance of Māori as a collective; rather it has contributed to the number of individuals who do identify as Māori. However, by examining the discrepancy between the numbers of individuals in the 2001 Census who claim Māori descent - 604,110 in contrast to the number of individuals who ethnically identify as Māori - 526,281, one can see that exogamy does lead to a loss in total population mass. Thus, 87 percent of the total possible Māori population actually identify as such.

This quantitative cultural loss due to exogamy is paralleled by a qualitative cultural loss, as a study of young Māori adults in Christchurch found that sole Māori individuals participate more in Māori cultural events and are more proficient in Māori language than individuals who claim Māori decent but do not identify as ethnic Māori (Broughton et al., 2000). More specifically, one in three sole Māori females can speak te reo in contrast to one in eight females who identify both as Māori and European (Howard \& Didham, 2004). These differences in behavioural competency are likely due to their enculturation environment, whereby individuals who identify as sole Māori may have greater access to cultural resources than individuals who identify with their mixed heritage.

In terms of intergenerational patterns of exogamy, Howard and Didham (2005) calculated that males who solely identify as Māori are more likely to marry endogamously (22,335 sole Māori males married sole Māori females vs. 13,752 sole Māori males married European only females), while males who identify both as Māori and European are more likely to intermarry with a European only female (13,972 Māori and European males married European only females vs. 4,983 Māori and European males married Māori and European females and 2,112 Māori and European males married Māori only females). This indicates an intergenerational cycle whereby Māori who identify with their mixed heritage are more likely to intermarry than Māori who solely identify as Māori. 
Factors that are related to Māori endogamy include speaking te reo and living in residential areas with a higher concentration of Māori population (e.g. North vs. South islands, and Gisborne where 64.3 percent of males are partnered with Māori only females in contrast to 8.4 percent in Dunedin). In contrast, higher education is related to higher exogamy rates (Callister, Didham \& Potter, 2005).

With regards to cultural transmission, in the 2001 Census, of children less than five years of age, 28,275 were sole Māori, 29,508 were Māori and European, 3,867 were Māori and Pacific and 4,143 Māori and Pacific and European (Callister, 2004). Thus, only 43 percent of Māori children less than five years of age have sole Māori identities ${ }^{23}$. The diversity of Māori children today has potentially serious consequences for the qualitative continuity of Māori culture in the future given that research on exogamy has shown that mixed heritage individuals are less likely to be raised in a consistent cultural environment (see Chapter two). Furthermore, as described above, individuals who identify with their mixed heritage are not as strong in Māoritanga as sole Māori individuals (Howard \& Didham, 2004).

Overall, Howard and Didham (2004, p. 20) conclude that "intermarriage itself is currently fuelling population growth amongst Māori and there is no evidence that it is resulting in a diminished sense of Māori identity" (identity here refers to demographic categorisation of Māori as opposed to psychological identification). However, the research reviewed above shows that intermarriage does pose a challenge to Māori collective continuity in quantitative and in qualitative terms given that the number of identifying Māori adults and children decreases with exogamy, and the cultural competence of sole Māori individuals is greater than that exhibited by individuals who identify with their mixed heritage.

${ }^{23}$ Children are more likely to be allocated Māori ethnicity when the mother is Māori only and partnered with a Euro-Māori male, as opposed to a Māori only male partnered with a Euro-Māori female. 
Thus far, the majority of strategies favoured by Māori are inter-group in nature, and directly engage with the colonial power/host society, such as political movements to raise public consciousness, compensation from the government for land loss, the institutional recognition of Māori language, and the establishment of Māori educational institutions. It seems that Māori have not formally emphasised the role of endogamy and individual agency in the creation of sole Māori families as an intra-group strategy for ensuring collective continuity. Māori as a 'small people' need to pursue as many avenues as possible to ensure ethno-cultural continuity. As such, endogamy warrants further attention.

\section{Chinese in New Zealand: A Case Study of Ethno-cultural Continuity of a Visible Minority with a Large Population}

\section{Who are the Chinese, and who is Chinese?}

The origins of the Han Chinese people lay by the Yellow River in Northern China, from the Xia dynasty period, ca. 2000-1550 BCE (Shaughnessy, 2005). Over centuries, the Chinese people gradually absorbed southern, nomadic and conquering peoples (Fitzgerald, 1967); formally united in 221 BCE under the Qin dynasty by the first Emperor Qin Shi Huang. The native Chinese population bear the name Han from the succeeding dynasty in 202-220 AD. Today, the People's Republic of China consists of 56 different ethnic groups; Han constitute a majority of 92 percent of the total population with 1.2 billion people effectively the largest ethnic group in the world.

The unity of the Chinese people was centred on the notion of being a great civilization as Chinese identity was predominantly cultural (Fitzgerald, 1967). In contrast, the concepts of Chinese nationalism and citizenship or chung-kuo did not exist amongst ancient Chinese and only came to the fore in the $20^{\text {th }}$ century when China became a Republic (Chun, 2000). Differing notions of Chineseness are captured by distinct 
terminology; although in mainland China ethno-cultural and national identity as Chinese are confounded by the term zhonghua minzu, representations held by Chinese in Taiwan are of traditional Chinese culture or hua-xia, a Chineseness based on history - in particular the first dynasty (Chun, 2000).

To define who is Chinese, according to the encyclopaedia of the Chinese Overseas (Pan, 1998), there are four distinct groups, represented by a series of concentric circles:

a) The first circle in the centre encompasses the Chinese people who are citizens of the People's Republic of China and permanently live in the land of China, and who are also members of the dominant Han ethnic group;

b) The second circle includes Chinese nationals who live and wish to settle overseas as migrants, international students who may also settle overseas, Chinese who live in the Republic of China/Taiwan and who nationally identify as people of Taiwan, and Chinese who live in Hong Kong and identify as Hong Kong people;

c) The third circle includes the Chinese diaspora overseas, where people identify as ethnic Chinese by descent, are nationals of the country where they live, and have a localised identity such as New Zealand Chinese. The population of the diaspora Chinese today is approximately 40 million people;

d) The fourth circle incorporates people whose ancestors are Chinese but who no longer identify as Chinese due to assimilation and intermarriage. They are included because they may choose to identify as Chinese in the future.

Overall, Chinese people are designated by the terms huaren, and huayi refers specifically to those of Chinese descent. While the Chinese can have distinct political identities depending on their place of residence, they share a sense of ethno-cultural Chineseness (Skeldon, 2003). 


\section{Chineseness and acculturation}

\section{Indigenous and adopted features}

One core element of Chinese culture is language and its strong literary tradition based on classical texts such as the Classic of Changes, Classic of Documents, and Classic of Poetry - all written in Chinese script standardised by the first Emperor in the third century BC. The intransigent nature of literary Chinese language is a source of continuity for the Chinese people as ancient texts can be easily accessed over millennia, and is also a source of unity as people from varying regions who speak mutually incomprehensible dialects understand each other through written communication (Bodde, 1981).

Another key element of Chinese culture is its humanistic and metaphysical philosophy. Of the many indigenous schools of thought, Confucius (551-479 BCE) emphasised the Way of man, and Lao-tzu $\left(6^{\text {th }}\right.$ century BCE) focused on the Way of nature which developed into Taoism. Buddhism, one of the greatest external acculturating influences on Chinese culture, arrived in China via the Silk Route and became the official state religion between the $4^{\text {th }}-6^{\text {th }}$ centuries $^{24}$ (Shaughnessy, 2005). From the $20^{\text {th }}$ century, further acculturation ensued with the importation of Western philosophy and the development of its Chinese derivatives, particularly that of Marxism-Leninism and the implementation of Chinese communism under Mao Zedong.

The core value in Chinese culture is that of filial piety, which goes hand in hand with the traditional rituals of ancestor worship (Bloodworth, 1967). For Chinese, the family is sacrosanct; surnames are of key importance and sacred tablets bear the names of family ancestors. Families have traditional ancestral halls, temples and burial grounds. The extended family or clan can have several branches with hundreds of members. Property, economic resources and marriage were clan-based. Individual loyalty reserved for the 
Chinese people as a whole is weaker, illustrated by the saying: "Sweep snow from your door but not frost from the roof of your neighbour" (p. 113). The principle of filial piety does, however, extend to the government in terms of vertical loyalty. Overall, the influence of the filial piety value on interpersonal relations is such that according to Hsu (Hsu \& Serrie, 1998), the father-son dyad, encompassing the principles of continuity, inclusiveness, authority and asexuality is dominant in Chinese culture, in contrast to the dominant husband-wife dyad in Western culture.

\section{The traditional Chinese view of marriage couple formation and procreation were} thus expressions of filial piety (Bloodworth, 1967). Marriage was an alliance for patrilineal clans, with intra-clan couples formed in order to maintain resources within the family. A wife was re-identified as a daughter-in-law, and children were re-identified as grandchildren of the patriarchs. Girls were subservient first to their fathers, then as women to their husbands and mothers-in-law. In the multiplicity of marriage practices, love marriages were punishable by disinheritance, though polygamy and concubines were accepted.

\section{Sino-centrism and Sinicization}

The ostentatious dragon is a powerful symbol of Chinese vigour and strength, paralleling the Chinese frame of mind in its characteristic Sino-centrism: "the Chinese belief in their own superiority, and in the relative - or absolute - barbarism of other peoples" (Fitzgerald, 1967, p. 23). This sense of pride and self-sufficiency, nourished by its geographic isolation, was reflected in Chinese reticence towards external cultural and religious influences, such as Christianity. Sino-centrism was so strong that in the $18^{\text {th }}$ century, other nations were not viewed in equal terms ${ }^{25}$. An accompanying sentiment was that of xenophobia as strong barbarian conquerors could threaten the survival of the civilized but weak Chinese people

\footnotetext{
24 This occurred in spite of initial resistance as the celibacy of Buddhist monks ran counter to the core Chinese value of filial piety (see below) where reproduction and the perpetuation of the ancestral lineage comprise the key duties of man.

${ }^{25}$ Emperor Ch'ien Lung declined George III of England's request for permanent diplomatic relations.
} 
(Gungwu, 1991). This xenophobia was demonstrated by The Great Wall, a symbol separating the in-group from the out-group (originally the Xiongnu people), and in the last century with the Boxer Movement, a violent peasant uprising against foreign influence targeting both non-Chinese and Chinese people (Fitzgerald, 1967).

With a few exceptions, until the last century Chinese culture was characterised by the relative absence of acculturation in spite of contact with other great civilizations such as Rome, Persia and India. Rome was received as an equal in civilization, although it had little influence on Chinese culture apart from trade in commodities such as glass; the Roman introduction of Christianity was not well received ${ }^{26}$. The greatest acculturative influence was the introduction of Buddhism from India, characterized by the compartmentalisation and synthesis of Confucian and Buddhist thought and practice (Fitzgerald, 1967).

The manner in which Chinese civilization absorbed other peoples and conquerors is known as the process of Sinicization. Indeed, "China is a sea which salts all the rivers that flow into it" (Fitzgerald, 1967, p. 41). The Chinese urge to civilise is captured by the term wen-hua, where wen refers to culture and hua refers to change (in a positive manner, directed to others). Sinicization was largely accomplished through emulation, teaching (Gungwu, 1991), and exogamy - an effective tool for absorbing other cultures (Fitzgerald, 1967). Indeed, exogamy within China over the centuries has contributed to the overall Chinese population; in contrast, exogamy outside of China has resulted in the assimilation of individual Chinese into host society cultures. However, because of the small proportion of diaspora Chinese, this has born little consequence on the continuity of the Chinese as a collective.

Admiration for the accomplishments of Western civilization fused with China's longheld value of upward cultural mobility (Gungwu, 1991). China's willingness to "drink

\footnotetext{
${ }^{26}$ Belief in the supernatural was rejected and Chinese initially resisted Christian missionary efforts.
} 
foreign ink" (Fitzgerald, 1967, p. 38) was motivated by a desire to restore China's former glory. As such, a conscious acculturation took place if only to strengthen Chinese culture ${ }^{27}$.

\section{Chinese history and memory}

Chinese civilization is a record of the influence of manifold Emperors and dynasties which can be subdivided into three eras: (a) the Ancient Era, c.2000 BCE from the Xia (20001550 BCE), Shang (1550-1045 BCE) and Western Zhou (1045-771 BCE); (b) the Imperial Era which includes the famous Han (206 BC-220 AD) and T'ang dynasties (618-907 AD); and (c) the Modern Era which includes revolution, the formation of the Republic of China (1912), the People's Republic of China (1949), and its status as a rising global superpower.

Indeed, "China boasts the world's longest continuing civilisation" (Shaughnessy, 2005, p. 22). In general, the past is greatly venerated in Chinese culture - that of the immediate collective (family) as well as the broader collective (civilization):

"It has been called the Great Tradition, and that may be the best brief statement of the Chinese sense of their own history. They are the heirs of greatness, and they see themselves that way. Pride in sharing a continuous tradition whose civilisation and empire led the world for two thousand years is a basic part of being Chinese, and a part also of their hopes for the future." (Murphey, 1986, p. 5).

In terms of the content of Chinese history, it ranges from ancient mythologies of creation and the origins of humankind, to written records and historical accounts of the rise and fall of dynasties. In terms of recent history, conflict-laden historical narratives include the rise of communism and the Cultural Revolution. Chronological/biographical history has been preserved on different media such as oracle bones (turtle shells and ox bones) containing the earliest preserved instance of Chinese script from 1200 BCE (Shaughnessy, 2005). Bronze vessels and steles also hold historical accounts, and zishu nianpu are retrospective

\footnotetext{
${ }^{27}$ However, the adaptation of communist philosophy resulted in a deep-seated change in core Chinese values, such as a reduction of clan-centred collectivism to allegiance to the State.
} 
memoirs recounting personal experiences during the defeat of the Ming dynasty by the conquering Manchus and the establishment of the Qing rule ${ }^{28}$.

Archaeology or kaogu xue, the study of examining antiquity, has been an important means by which the Chinese people have gained a sense of their distant history. In contrast, rituals of ancestor worship or jingzu are a culturally institutionalised means for remembering more immediate clan history (preserved in genealogical records, temples, and burial grounds).

History has been remembered by the Chinese not only cognitively (written records) and behaviourally (ancestor worship rituals) but also affectively through a vicarious experience of history. This can be mobilized to influence individual beliefs and behaviour (Pillemer, 2004) in public and private spheres. Indeed, Zarrow (2004) describes how autobiographical memoirs written in the wake of the Qing conquest were used by Sun Yatsen to forge a common victim identity and fuel revolutionaries. Individuals were encouraged to vicariously experience atrocities that occurred two centuries prior: "the crimes of the seventeenth century were perceived, at least, as crimes against people's own families" (p. 73).

\section{Geography and Chinese acculturation}

In contrast to victim diasporas, labour and imperial diasporas and cultural diasporas, Cohen (1997) classifies the overseas Chinese as a trade diaspora. Chinese have historically left the mainland as voluntary sojourners (Gungwu, 2003). Permanent migration was interpreted as a lack of filial piety and for a period of time was officially banned in accordance with the norm of 'keeping Chinese in'. Emigration was easier after the end of the Manchu dynasty in 1911 (Zenner, 1991). Many Chinese terms are used to describe overseas Chinese: luju referred to travellers, huashong to middleman merchants (see below), and huagong to

\footnotetext{
${ }^{28}$ Yangz̧hou shiri ji - Account of ten days in Yangzhou written by Wang Xiuchu, and Jiading tucheng jilue -
} 
cheap labourers; designating a more permanent diaspora, the terms huaren and huayi are mentioned above, and huaqiao refers to overseas Chinese sojourners who remain loyal to China (Gungwu, 2003).

Push and pull factors have motivated Chinese to emigrate: peasant Chinese constituted cheap contract labour for the colonial powers in South-East Asia, namely the Dutch, Spanish and British; economic and political reasons came to the fore during the $19^{\text {th }}$ and $20^{\text {th }}$ centuries as Chinese fared poorly due to war and starvation. Chinese diaspora identity was primarily based on regional provenance rather than on China as a cultural and geopolitical entity (Cartier, 2003). Indeed, most migrants came originally from the Southern regions of Guangdong, Fujian and Zhejiang (Skeldon, 2003). A middleman minority, Chinese were heavily involved in trade, the rubber industry, money lending, laundry and restaurants (Zenner, 1991). Many have become successful capitalists, characterized by entrepreneurship, thrift and a value for education (Hsu \& Serrie, 1998).

The Chinese diaspora (approximately 40 million) represents less than 4 percent of the total Chinese population. Asia is home to 78 percent of the Chinese diaspora population (Ma, 2003; Wikipedia, 2008): 4.3 percent of diaspora Chinese live in Singapore, the only diaspora where they constitute the majority ethnic group; 11.7 percent live in Thailand and are a highly assimilated population; 11.7 percent live in Indonesia and have been targets of violent Sino-phobia with riots and legislation such as the banning of Chinese language signs in public; 12.1 percent live in Malaysia where government policies favouring native Malays were institutionalised due to the economic dominance of local Chinese; 3 percent and 2.4 percent live in Vietnam and the Philippines respectively with highly assimilated populations. Migration in the $19^{\text {th }}$ century extended to South America, the United Kingdom and Europe, as well as North America, Australia and New Zealand where 10 percent, 1.3 percent and 0.3 percent of the Chinese diaspora respectively reside. 


\section{Acculturation and exogamy}

Highlighting the diversity of life for diaspora Chinese, Gungwu (2003) speaks of a 'cultural spectrum of Chineseness' by comparing diaspora Chinese populations with those in the mainland, placing them along a continuum from one such as San Francisco, to Singapore, then Hong Kong and finally Shanghai. Overall, Chinese acculturation to their respective host societies has primarily occurred through interaction with the native population by trading, working, studying and living with non-Chinese.

The autonomy of Chinese communities was enabled through the formation of social structures that are based on the familial and familiar: organisations were based on kinship relations and common surnames, on familiar geography such as place of residence, origin and accompanying dialect, and finally on relationships of contract such as those concerned with communal welfare (Hsu \& Serrie, 1998). These organisations promote cohesion amongst diaspora Chinese by serving functions such as enabling ancestor worship, providing links to China, looking after social welfare, educational and financial needs, property assets, coordination of labour, economic and political control, socialising and recreation.

Factors that influence the acculturation process of diaspora Chinese include dietary customs as social mixing is limited with their Hindu and Muslim hosts who do not eat meat and pork (Hsu \& Serrie, 1998). Differing attitudes of the colonial powers regarding openness to intermarriage has played a major role, where Hispanics favoured intermarriage and assimilation while Anglo-Saxons favoured endogamy and exclusion (exogamy of Chinese among Anglo-Saxon cultures is now increasingly common). Mestizo populations resulting from intermarriage arose in the Philippines, Indonesia, Thailand and Cambodia.

The Chinese themselves had a pragmatic view of intermarriage, which most commonly occurred among male Chinese (Zenner, 1991). Where the proportion of the Chinese population is small, intermarriage frequently occurs with fellow Asians; in contrast, 
where there are greater proportions of Chinese, preference to marry endogamously may be according to criteria such as regional provenance (Djao, 2003). Summarizing a contemporary collection of individual journeys from the diaspora, Djao (2003, p. 177) states that:

"the narratives about marriage, family, and life in the diaspora in general all lead to the argument that retention of Chinese cultural heritage is important. To some, marrying a Chinese provides the advantage of ensuring that heritage. But for those who have married exogamously, retention of culture is viable if the partners at least make some efforts at being culturally Chinese."

\section{Division and Continuity}

Two interesting dichotomies have emerged as a result of Chinese settlement overseas: one reflects the relationship between China and diaspora Chinese; the other reflects the relationships between old and new Chinese settlers in a specific country. China's strength has impacted on its care of and concern for overseas Chinese (Gungwu, 2003). In bad times, diaspora Chinese have helped to ease China's suffering, contributing economic, physical and emotional resources during the Sino-Japanese war; in better times, after the 1978 economic reforms, they are investing in China's growth. Questioning any real influence the diaspora may exert on China as a nation, Tu (1994, p.33-34) notes that:

"the centre no longer has the ability, insight, or legitimate authority to dictate the agenda for cultural China. On the contrary, the transformative potential of the periphery is so great that it seems inevitable that it will significantly shape the intellectual discourse on cultural China for years to come."

Tu uses the metaphor of a living tree, demonstrating that thanks to its roots in China, the diaspora can sprout new life for Chinese culture.

Regarding the cleavage between old and new Chinese migrants, old migrants (who settled in a country before the latter third of the $20^{\text {th }}$ century) are more assimilated into the host society and have different geographical origins and socio-economic status - tending to 
come from Southern China and generally being poor and uneducated; in contrast, many new migrants have re-migrated from other countries in South-East Asia with greater educational and financial resources (Zenner, 1991). Nonetheless, old and new Chinese participate in what Gungwu (2003) calls cultural China - upon which the continuity of both communities depends, such as customs, food, and ethno-cultural organisations, as well as "the determination that one's children and grandchildren should master the Chinese language and maintain and even improve the quality of their Chineseness" (p. 95).

\section{Identity}

Chinese identity in the diaspora differs from Chinese identity in China (Kwok-bun, 2005). Chineseness in China is largely based on culture and is fluid to the extent that Sinicization has been and still is possible. In contrast, for overseas Chinese, identity is predominantly ethnic and immutable to the extent that individual behavioural competencies can vary greatly while their Chineseness remains. However, diaspora Chinese identity also varies: for older people Chineseness is linked to their homeland and history; the Chinese-educated in Singapore emphasise language as central to Chineseness whereas the English-educated emphasise ethnic heritage and values. The former consider it shameful when Chinese have no knowledge of their language, using derogatory terms for assimilated Chinese such as 'Bananas' (yellow or Chinese on the outside but white or European on the inside).

Due to the visibility of most overseas Chinese, while individuals cannot 'pass' as majority group members, they still possess agency in identification. This agency may be limited as Ang (2000) describes in a book chapter entitled "Can one say no to Chineseness?" that identification as a Chinese person may always be by descent, but it is only occasionally by consent. On the other hand, greater agency is evident in the emerging Chinese cosmopolitanism whereby individuals choose to maintain an intellectual identification to Chinese culture as a whole whilst being open to other cultures and national 
identities (Lee, 1994). Indeed, in the Chinese diaspora today, individuals form hybrid identities where citizenship is flexible and instrumental in times of political and economic change - illustrated by the adage 'a smart hare has three burrows'. This flexibility is evident in the phenomenon of astronaut families, whereby the primary caregiver (usually the father) travels back to work overseas while their family remains settled in the host country, e.g. the transnationalism of Hong Kong Chinese families in New Zealand (Ho, 2003).

\section{Chinese continuity: Endurance at the global and local levels}

Approximately 20 percent of the world's population is concentrated in China. The Chinese are not a 'small people'; sensing an eternal past and future, their existence has been occasionally but not perpetually threatened. Although the quantitative continuity of the Chinese people was partially threatened by the natural environment through flooding of the Yellow river (Shaughnessy, 2005), and invasion by foreign peoples and nations, the survival of the Chinese people has on the whole been an inverse issue - where problems of population control have dominated China (Goetz, 1987a). Between 1950 and 1975 there was a population explosion due to reduced mortality and continued fertility, from $554,000,000$ to $933,000,000$ people. Sustainability problems led to the institutionalisation of delayed marriage and enforcement of restricted fertility with the one child family policy in the 1970s (Goetz, 1987b).

As for the qualitative endurance of Chinese as a collective, due to Sino-centric views and the process of Sinicization, it was comparatively secure until sustained contact was established with modern Western civilization and its superior military prowess. Perceived as backward, Chinese culture (and sovereignty) was threatened. With cultural continuity as a goal, thanks to its willingness to 'drink foreign ink' and to appropriate the necessary scientific and economic tools for modernity, China has largely succeeded in preventing 
engulfment by foreign powers, strengthening Chinese culture and restoring its former glory (Fitzgerald, 1967).

In terms of the local continuity of Chinese culture in the diaspora, until recently, overseas Chinese had a sojourner mentality. Chinese culture was strong and centred in China. As such, the quality of Chinese diaspora life has had no real consequence for the continuity of Chinese culture as a whole. Although Chinese are not a 'small people' at the global level, at the local level the Chinese diaspora constitutes a minority ethno-cultural group. Rather than harbouring concerns about the collective survival of Chinese (as 'small peoples' do), Chinese diaspora communities are focused on their own journeys of acculturation and attaining individual success. As described above, the continuity of diaspora Chinese communities has been dependent on group-level factors such as the political climate of the host society, the presence or absence of discrimination, and continued migration of Chinese people (from the mainland and other diasporas, particularly from South-East Asia); and individual-level factors such as active participation in social structures that sustain Chinese language, and ethno-cultural endogamy which ensures the transmission of Chinese ancestry and identification of the next generation as Huaren or Huayi. Although the continuity of the local community and the Chinese collective by extension has been an outcome of endogamy, it is not appreciated as an active mechanism for ensuring ethno-cultural continuity. This is because the essential question for diaspora Chinese is not "will there be Chinese?" but "how Chinese do we want (and does the host society enable) our lives to be?" 


\section{Continuity of New Zealand Chinese}

\section{Sojourners, Immigrants, and 'Yellow Peril'}

The first twelve Chinese arrived in New Zealand in 1866 to work in the abandoned Otago goldfields (Ip, 1995). In the following years, 5,000 Chinese arrived mainly from the Guangdong Province around Canton with the aim of sending money back home to help their struggling families $(\mathrm{Ng}, 2003)$. In the 1880s as Chinese began to leave the depleted fields to establish work (in the market gardens ${ }^{29}$ ), negative attitudes towards Chinese gained impetus and the Chinese Immigrants Act was introduced in 1881 with an initial entry poll tax of 10 pounds, raised to 100 pounds in 1896 (Murphy, 2003). Chinese were objects of restricted entry and re-entry to New Zealand and denied naturalisation (citizenship rights) from 1908 until 1952; they were also excluded from receiving the old age pension and other welfare benefits and were continuously discriminated under a White New Zealand policy through to the 1960s.

Specific anti-Chinese organisations include the White New Zealand League, AntiAsiatic League, White Race League, and Anti-Chinese League (Sedgewick, 1998). The presence of these organisations as well as anti-Chinese legislation prompted the formation of Chinese networks to represent their interests. Indeed, local Chinese mobilised to fight against repatriation in 1932 and had to petition for Chinese family members granted shelter during WWII to be able to stay after the war's end (Ip, 2003). According to a UMR research poll on perceived discrimination for the Human Rights Commission (2007), 26.2 percent of New Zealanders surveyed thought that Asians experienced the most discrimination in New Zealand.

\footnotetext{
${ }^{29}$ In the 1950s Chinese produced more than 65 percent of green vegetables in New Zealand (Ip, 2003).
} 


\section{New faces}

From the 1950 s to the 1980s, the New Zealand Chinese community grew to 19,000 people. The 'Old' New Zealand Chinese community then witnessed a wave of 'New' Chinese as the 1987 Immigration Act opened New Zealand's doors to qualified immigrants in an effort to boost the economy (Ip, 1995). In contrast to the Old Chinese, the New Chinese came from economically successful backgrounds, and from many different source countries. While old migrants sent remittances to families in China, new migrants send money from Asia to support their families in New Zealand (Ip, 2003). More Chinese migrants were 'pushed' to New Zealand due to political instability in China with the 1989 Tiananmen Square massacres and the 1997 Hong Kong handover. In the 2001 Census, of the Chinese population, only 25 percent $(25,899$ people) were New Zealand born, 35 percent $(38,325$ people) came from mainland China, 12 percent (12,378 people) from Taiwan, 10 percent (10,458 people) from Hong Kong and another 17 percent (17,403 people) from overseas (Ip, 2003). Thus, although New Zealand Chinese are a very diverse community and identify with different groups, in relation to New Zealand (European) society as a whole, it is possible to speak of the continuity of New Zealand Chinese. Two thirds of New Zealand Chinese live in Auckland. They are a youthful population with over one-half under 30 years of age compared to 43 percent of the total New Zealand population. Two-thirds were employed full-time and more than two-thirds owned their own home (Office of Ethnic Affairs, 2005). In terms of cultural resources there are in abundance restaurants and shops selling Chinese food products, as well as Chinese language media with a radio station and six newspapers in Auckland, one in Wellington, and one in Christchurch. 


\section{Acculturation of a 'model minority'}

Overall, the New Zealand Chinese community has undergone four different stages of acculturation: first as voluntary 'alien' sojourners, (1865-1900), then as settlers who remained separate from New Zealand Europeans (1901-1951), followed by a phase of assimilation 'by consent' (1951-1986) and the final stage (1986 - ) is that of new migration and a move towards conscious integration by the established community ( $\mathrm{Ng}, 1999$; Young, 2005). Because of New Zealand's geographical remoteness, as a Chinese diaspora community they "stuck together and stuck to their ways" (Ng, 1999, p. 2); compensating for language barriers and providing more economic stability. The small population of local Chinese meant that although no Chinatowns were formed, Chinese streets could be found e.g. Haining St in Wellington (Ip, 2003).

Geographic and cultural isolation, government assimilation practices, participation in the public education system compounded with the tendency of first generation migrants to be uneducated in Chinese ways meant that the 'old Chinese' were rapidly assimilating until the arrival of new Chinese migrants (Ip, 2003; Young, 2005). This process was partly voluntary, as $\mathrm{Ng}$ recounts:

"Through our childhood friendships with our European peers, and respect for our teachers, we were convinced that we could settle in New Zealand. We knew that this meant assimilation and the loss of Chineseness, but we were not afraid of that" (Ng, 1999, p. 14).

Despite a considerable loss of Chineseness, visibility prevented total assimilation. In addition, social support, cohesion and enculturation were provided by various social structures such as multipurpose shops, associations, recreational clubs, Chinese Churches and Sunday Schools/local language schools (Sedgewick, 1998). The 'segmentary structure' of the Chinese community was such that organisations were largely based on place of origin in the homeland. The T’ung Meng Hui (1905), Chee Kung Tong (1907) and Chong 
Wah Wui Koon (1909) eventually became the New Zealand Chinese Association (NZCA). Other organisations include the Poon Fa Association, the Kwong Chew Association in 1920, the Tung Jung Association in 1924, Cultural clubs e.g. Hui Sur (1950) the AntiCommunist League (1952) and the Chinese Cultural Society (1951), the Chinese Grower's Association, the Hwa Hsia Society, the Hong Kong New Zealand Business Association and the New Zealand China Trade Association. These structures served inter-group and intra-group functions, as a mediator of political relations between the Chinese and New Zealand society, and as a manifestation of Chinese ethnicity. Over the years, communal structures have been characterised by waves of cooperation and conflict. Troubles in the homeland during the Sino-Japanese War (1937-1944) provided impetus for unity among Chinese as the NZCA mobilised donation campaigns. More recently, sports clubs e.g. the Wellington Chinese Sports and Cultural Centre have united the heterogeneous community in a politically-neutral environment.

In general, the old New Zealand Chinese community was considered a model minority by mainstream New Zealanders (Wong, 2003). They worked hard and held strong family values. Wary of inciting anti-Chinese sentiment as in years gone by, a low collective profile was favoured. Local Chinese were especially sensitive to the manner in which their welfare was linked to global perceptions of China ( Ng, 1999). According to Yee (2003), "Placating is ... the normative coping strategy of Chinese, as it offers a mechanism whereby Chinese can survive and gain a degree of security, while the host society gains a compliant minority." The old Chinese became anxious as their strategy was diminished by the arrival of vast numbers of new Chinese who did not share their experiences of acculturation in New Zealand. This was exacerbated by negative media coverage of the Asian Invasion in the early 1990s. Over the last two decades, Chinese New Zealanders have developed a positive political consciousness, demonstrated for instance by the election of Pansy Wong, New Zealand's first Asian MP. Furthermore, in 2002 an official 
government apology was given to New Zealand Chinese (and their descendents) who were discriminated by the Poll Tax, accompanied by a 5 million dollar grant for a community trust to promote Chinese history, culture and language.

Today, many New Zealand-born Chinese acknowledge their assimilated nature with cheeky national conference titles such as "Crouching Tiger, Hidden Banana", seeking to reappropriate their Chinese heritage and strengthen the local community.

\section{Chinese endogamy and exogamy}

Traditionally, Chinese parents clearly encouraged marriages within the Chinese circle for reasons such as a "sense of uniqueness of race" $(\mathrm{Ng}, 1995, \mathrm{p} .256)$; in order to avoid conflict associated with intermarriage; to avoid problems faced by half-caste Chinese children (Ip, 1996); $;^{30}$ and to prevent assimilation and loss of 'Chineseness' (Bol Jun Lee, 2003). This was illustrated in the expression 'bane ah fun kwie', whereby one risked being 'changed into the devil' ( $\mathrm{Ng}, 1995, \mathrm{p} .256)$. Due to differences in dialect between regions, suitors originating from the same region in China as their own family were preferred, and Chinese weddings were often venues for meeting suitable partners (Fong, 1959; Ip, 1996). The small Chinese population in New Zealand (with a sex ratio imbalance so great that in the 1921 Census there were 205 Chinese females in comparison to 2,905 Chinese males) meant that until the 1970s it was common for young people to travel back to find a partner (Ip, 1995). However, as New Zealand has become an increasingly tolerant society and individual prerogatives are prioritised, recent generations of New Zealand Chinese are less willing to limit potential marriage partners. Consequently, parents are more understanding of inter-ethnic relationships and marriage (Ip, 1996).

By 1986, the national Census count included 13,000 sole Chinese and 4,000 European-Chinese and Māori-Chinese people (Ng, 2001). Ten years later, by 1996 
intermarriage rates of Asians in New Zealand (of which Chinese constituted approximately one half) exceeded 32 percent (Statistics New Zealand, 2008). Nonetheless, figures from the 2001 Census show that there are still a large number of Chinese who are endogamously married: 81 percent of females and 87 percent of males are married to a fellow Chinese. The gender difference in exogamy among Chinese parallels that of Asian couples in general, with 90 percent of Asian men partnered with Asian women in comparison to 78 percent of Asian women partnered with Asian men and 20 percent with European men (Callister, Didham \& Potter, 2005). Generational differences in exogamy are evident whereby New Zealand-born Asians are more likely to intermarry than those born overseas.

The current trend is that intermarriage is on the rise as 28 percent of Asian children under five were identified with more than one ethnic group in the 2001 Census (Callister, 2004). Asians are in fact less likely to intermarry than Māori and Pacific New Zealanders (Callister, 2003). For the purpose of this thesis, questions arise as to how young New Zealand Chinese today feel about the future continuity of their heritage culture, whether endogamy is a personal preference, and if so, why? The answers may have implications for the long-term acculturation of the New Zealand Chinese community.

${ }^{30}$ From the 1920s through the 1940s relationships between Māori and Chinese developed through market gardens, condemned by Pākehā, Māori and Chinese. In the 2001 Census 4,080 New Zealanders identified themselves with both Māori and Chinese heritage. 


\section{Issues for Comparing the Acculturation Patterns of Fiddlers with Warriors and Dragons}

\section{Small vs. not 'small peoples'}

There are 13 million Jews (2 percent of the world's population), 618,000 Māori (0.1 percent of the world's population ${ }^{31}$ ), and over 1.2 billion Han Chinese in the world (20 percent of the world's population). Jews are very self-conscious about their collective struggle to survive and sense the existential uncertainty of a 'small people'. However, concerns over Jewish quantitative continuity are put in perspective when compared to the much smaller numbers of indigenous Māori who also constitute a 'small people' and have faced existential uncertainty. Nevertheless, it seems that the existential uncertainty of the Jewish people for over 2,000 years constitutes a greater part of their psyche today than it does for Māori, who have experienced colonization for less than 200 years and are focused more on reclamation than survival tout court. In contrast, Han Chinese constitute the largest ethnocultural group in the world - and while they have faced some existential uncertainties in the past, do not see their existence as perpetually threatened. As far as numbers are concerned, however, while the Chinese and Māori populations are growing, the world Jewish population is not only aging but also has zero growth.

\section{Exile and colonization}

In terms of shared experiences of long-term acculturation, Jews and Māori have both lived through a critical incident that propelled them to live as minorities within larger host societies: for Jews the primary catalyst was conquest and the destruction of the First and Second Temples; for Māori it was colonization. However, while Jews went into exile and ten of the tribes were 'lost' or assimilated, Māori stayed in Aotearoa/New Zealand (although many were dispossessed of their tribal lands). Both events marked an end to 
ethno-cultural self-determination and a journey towards reclamation - in the Jewish case, it has already been a journey of two millennia; for Māori...it has only just begun.

\section{Sojourning and middleman minorities}

As diaspora communities, both Jews and Chinese have shared the long-term acculturation experience of sojourning and the development of specific regional identities. However, while almost all diaspora Jews were forced into exile, diaspora Chinese were predominantly voluntary sojourners who came from selected regions in China (and later South-East Asia). Furthermore, although the majority of the Jewish people were in exile, the majority of the Chinese people still remained in China. Thus, Jewish continuity until the last sixty years has occurred in the diaspora whilst Chinese continuity has occurred within mainland China.

Both Jews and Chinese experienced citizenship restrictions in their host countries and played the role of middlemen; both were visible minorities and both were extremely family-oriented. While Jewish dietary customs (refraining from pork and non-Kosher meat) impeded social mixing with host society members, the inverse was true for some Chinese communities whereby dietary customs (partaking in pork and other meats) impeded host society members from mixing with them.

For Jews, the change in status from sojourners to citizens was a major event that drastically changed Jewish acculturation, leading to critical divides within Judaism regarding the philosophy of how to acculturate. The resulting diversity in Jewish life was accompanied by individual assimilation on a large scale which eventually became a threat to collective continuity. In contrast, the diversity in Chinese diaspora life is not so much due to philosophical orientation but to differences in experience between the old and new Chinese migrants. While the acculturation strategies of New Zealand Chinese moved from separation to assimilation from the time citizenship was formally granted, mirroring the

\footnotetext{
${ }^{31}$ This figure includes 526,000 Māori in New Zealand and a further 92,000 Māori in Australia.
} 
emancipation of the Jews, overall, the local assimilation of diaspora Chinese does not pose a threat to the survival of Chinese as a collective.

\section{Shared and unique acculturation experiences}

All three ethno-cultural groups shared an acculturating force to be reckoned with - that of Christianity - although Buddhism was stronger influence on Chinese and Islam was another counter-force for Jews. All three ethno-cultural groups understand the centrality of social structures for collective continuity, and their role in providing welfare services and facilitating social cohesion, enculturation, and socialisation: the Synagogue for Jews, the Marae for Māori and different clan and sports and cultural associations for Chinese. In addition, all three groups recognise the key role of language retention - Hebrew, Māori, and Chinese are preserved within these social structures and in the home.

What is not shared among all three ethno-cultural groups and is particular to the Jewish experience of long-term acculturation, is the constant victimisation in the scale of mass murders, the Inquisition, and the Holocaust. Neither Māori in the face of colonization nor Chinese as minorities in the diaspora experienced such targeted, repetitive, violent, and systematic discrimination and attempts at annihilation. This mass helplessness experienced by Jews was accompanied by the belief in the supernatural: continuity was based on a religious covenant as the Jewish people traditionally relied on and believed in protection from G-d. 


\section{Remembrance of ethno-cultural history}

In terms of the remembrance of ethno-cultural history, while all three groups are grounded in the past, Jews emphasise group history, Māori emphasise tribal history, and Chinese emphasise clan history. Differences arise with regards to the methods in which history is preserved. When it comes to cognitive remembrance, Jews and Chinese have a rich literary tradition whereas Māori have a rich oral tradition. As for behavioural remembrance, Jewish culture stands out for its use of rituals to preserve and transmit history. Finally, affective remembrance or the vicarious experience of ethno-cultural history is something that Jews, Māori and Chinese all share through a process of identification with their ancestors. Overall, Jewish history with its focus on the collective is much more reflexive and instrumental, providing the backbone to Jewish identity.

\section{Long-term acculturation goals}

Overall, the acculturation goals of the Jewish people are quantitative and qualitative continuity in two geographical locations: as a minority in the diaspora and as a selfdetermined group in Israel. Over the last 2,000 years, Jewish survival has been concentrated in the diaspora. Today, the goal is to ensure that Jewish life is secure in both places. The subject of importance for Jewish life has been the collective - the people of Israel (Am Israel), and the most valued action has been intergenerational transmission.

In contrast, the Māori goal as a people is ensuring the quantitative and qualitative endurance of Māori culture and increasing self-determination in New Zealand. The subject of importance for Māori life was traditionally the tribe (iwi), although to gain voice as a collective and ensure the endurance of Māoritanga, a superordinate Māori identity is increasingly valued. Both Jews and Māori share concerns about the decline and optimism about the blossoming of Jewish and Māori culture. 
As far as the Chinese people are concerned, since the quantitative and qualitative continuity of the collective is secure, the goal of the Chinese nation is to regain its former glory as a global power while the main goal for diaspora Chinese is not the well-being of Chinese as a collective, but rather the preservation and qualitative expression of local Chineseness.

An interesting comparison arises with regards to cultural exclusiveness/inclusiveness. While the Jewish people are concerned about increasing their numbers, they nevertheless have highly selective and exclusive criteria of belonging, regulated by religious authorities (conflict has arisen regarding the acceptance of patrilineal as well as traditional matrilineal descent). In contrast, Māori also want to increase numbers but are more welcoming and fluid in their emphasis on ancestry (cognatic descent).

\section{Intermarriage and endogamy as a strategy for continuity}

The intermarriage rate for Jews in New Zealand is 56 percent. Māori rates are comparably high at 48 percent. Chinese rates, however, are much lower at 16 percent. Speculation regarding the different rates of exogamy takes several different forms: Perhaps Jews intermarry more than Chinese in New Zealand because they are a non-visible minority? However, this argument does not hold considering similarly high rates of Māori intermarriage. A second plausible argument is the small available population of marriage partners for Jews. However, Māori have a much larger pool of potential marriage partners and have comparably high rates of exogamy. This points to a social climate of tolerance that facilitates intermarriage in New Zealand. The question then arises, why are Chinese exogamy rates particularly low? Once we recall that three quarters of New Zealand Chinese were born overseas and that exogamy increases with generations, we arrive at a plausible explanation. 
Finally, comparisons must be drawn regarding the function of endogamy across the three groups. Jews as a minority group have emphasised the importance of endogamy as an internal strategy for collective continuity to ensure the identification and enculturation of the next generation. In contrast, Māori as indigenous peoples with more political power than other minority groups have relied on inter-group strategies such as engagement at a government level and on social structures to ensure collective continuity, rather than intragroup strategies such as endogamy. This is especially so given that endogamy is not a prerequisite for the identification of the next generation as Māori (though it certainly facilitates enculturation). For Chinese, while diaspora continuity may certainly be an outcome of endogamy, it is not appreciated as a mechanism for ensuring collective continuity because continuity is essentially a non-issue.

\section{General hypotheses on the influence of vitality and collective acculturation experiences}

In this thesis, I examine whether individual Jews, Māori and Chinese in New Zealand (a) intend to marry endogamously and if so, who do they actually date? (b) Do they give importance to ethno-cultural continuity when considering a marriage partner? (c) Are Jews, Māori and Chinese are equally aware of their ethno-cultural history and (d) Does this influence collective concerns for continuity?

Given that endogamy has been a central strategy in the long-term acculturation of Jews but not for Māori and Chinese, and taking into account current rates of intermarriage and the social climate of tolerance in New Zealand,

a) It is hypothesized that young Jews, Māori and Chinese will exhibit mild intentions for endogamy and mild selective dating behaviour, and that Jews will exhibit higher levels of both endogamy intentions and selective dating behaviour.

Given that 'small peoples' have experienced existential uncertainty and that ethno-cultural continuity is not a central concern for larger peoples, 
b) It is hypothesized that individual concerns for collective continuity will be higher among Jews and Māori than among Chinese. It is also hypothesized that individual concerns for collective continuity will predict intentions for endogamy for Jews and Māori, but not for Chinese.

Given that ethno-cultural history is a resource that guides collectives on their journeys of continuity, and the greater instrumental value of history in Jewish tradition as a constitutional and prophetic narrative,

c) It is hypothesized that Jews will have a greater awareness of social representations of ethnic history than Māori and Chinese.

d) It is also hypothesized that across cultures, individual awareness of ethnic history predicts concerns for collective continuity.

This chapter has considered the influence of Jewish, Māori and Chinese collective acculturation experiences in the past on the acculturation of Jewish, Māori and Chinese individuals in the present, providing a socio-historical context for the integrative framework of volitional endogamy that is empirically tested in Chapters six and seven. Next, Chapter four describes the qualitative research conducted for the purposes of understanding the meaning of endogamy and selective dating for young ethno-cultural adults today, and developing the theoretical structures of two key constructs in the predictive model: individual concerns for collective continuity and individual awareness of social representations of ethnic history. 


\title{
Chapter 4: A QuAlitaTIVE STUdy OF ENDOGAMY, CONTINUITY AND HISTORY
}

As discussed in Chapter three, the collective experiences in the long-term acculturation of Jews, Māori and Chinese have unique and shared features. The past collective experiences of these three ethno-cultural groups summarised in the previous chapter are likely to influence the present acculturation of Jewish, Māori and Chinese individuals. This chapter describes the views of present generations of these ethno-cultural groups regarding the importance of endogamy, ethno-cultural continuity and social representations of ethnic history. A sequential mixed-methods approach was adopted (Tashakkori \& Teddlie, 1998), whereby the qualitative research described herein is used in the theoretical development of two original constructs and their quantitative measures that are required to quantitatively test the predictive model for volitional endogamy, presented in Chapters six and seven.

\section{Conducting Focus Groups}

\begin{abstract}
Aims
The primary research aims were to obtain qualitative emic (culture-specific) data from focus group discussions with Jewish, Māori and Chinese young adults that were used to (a) understand the personal meaning of endogamy and selective dating; and to construct original quantitative measures of (b) ethno-cultural continuity and (c) individual awareness of social representations of ethnic history. Three focus group discussions were analysed and culture-general aspects that emerged were synthesized to develop 'derived-etic' constructs.
\end{abstract}

\section{Focus groups as a research method}

Focus groups can be used in the preliminary stages of an investigation as a useful starting point for designing questionnaires and conducting subsequent studies by giving the 
researcher a deeper understanding of the area in question (Orfali \& Markova, 2002). Rich data are obtained by eliciting natural responses from participants (Krueger, 1994; Willig, 2001). Focus groups mirror discourse in everyday life and can be seen as a miniature thinking society (Farr \& Tafoya, 1992, cited in Markova, 2003). Although the topic of discussion is explicitly predetermined by the researcher, communications between participants in a focus group "are similar to discussions that people hold in cafés, restaurants, in streets or at political meetings, where participants negotiate meanings, create new meanings and generate diversity and difference as well as consensus of opinions" (Orfali \& Markova, 2002, p. 263). Furthermore, participants may voice certain views that are shared by others which they would be reluctant to express in a personal interview setting. However, it is not necessary that a consensus be reached in the discussion (Waldegrave, 2003). Overall, focus groups reveal the importance and personal relevance of the topic under investigation, specify links with other related issues, and are an effective technique for examining behavioural motivations (Krueger, 1994). The behaviours of interest in this case are ethnic endogamy and selective dating.

The characteristics of the participants are important in that interaction is maximised in more homogenous groups. Similarity is ensured along demographic variables such as age and ethnicity. Usually participants are recruited through convenience sampling methods, organisation membership lists and snowballing. Researchers recommend that focus groups consist of approximately five to ten participants to enable active involvement and facilitate data analysis (Flick, 2002). In addition, it is preferable that the researcher has no prior acquaintance with focus group participants to encourage explicit discussion.

The role of the moderator in a focus group is very important in setting the agenda and creating a comfortable and friendly rapport among participants (Krueger, 1994). They reframe participant statements, challenge contradictory views and intervene should conflict arise. On one hand, the moderator has to understand responses from the participants' 
perspective while being objective (Flick, 2002), and refrain from contributing their own opinions on the subject (Markova, 2003). On the other hand, the moderator also serves to promote a degree of intimacy amongst participants through personal contributions. Catalysts for discussion such as text or images are recommended (Flick, 2002). The discussion unfolds guided by the moderator's questions while allowing for the emergence of new ideas. Ideally a point of saturation should be reached whereby novel information is no longer introduced and participants feel they have covered all or most of the related issues (Asbury, 1995). When considering how many focus groups need to be conducted, for topics that are moderately diverse three to five groups can generally lead to theoretical saturation in that conducting additional groups would only lead to a repetition of ideas previously discussed (Morgan, 1998).

\section{Method}

\section{Sampling and recruitment}

Ethical approval for this research was obtained from the Victoria University of Wellington School of Psychology Human Ethics Committee. According to Stewart and Shamdasani (1990), focus group participants should represent the population as much as possible. Given that affiliated individuals are the people who are interested in their culture and should be thinking about issues relating to continuity, it was decided to sample these individuals from which to develop item pools to be assessed in subsequent survey studies. By consistently sampling participants who were voluntarily affiliated with ethno-cultural organisations in the qualitative and quantitative research, participants were matched as closely as possible along demographic characteristics. Thus, samples of the target populations (young, unmarried New Zealand Jews, Māori and Chinese) were recruited from ethno-cultural organisations as focus group participants. The expected number of participants was between 6 and 8 per focus group. Participants of all three groups had the 
following characteristics in common: self-defined ethno-cultural identity, age range from 21 to 30 years, New Zealand citizenship and single marital status. Given that the median age for marriage according to the New Zealand 2001 Census was 29.3 years for men and 27.5 years for women, the sampled age range was considered appropriate when researching motivations for endogamous marriage and selective dating.

To recruit participants, permission was requested from the Auckland branch of the Australasian Union of Jewish Students (AUJS) to contact individuals by telephone. Permission was requested from the Head of the School of Māori studies, Te Ripowai Higgins, who liaised with potential Māori participants from the School of Māori studies. Contacts were requested from the Chinese Students Association at Victoria University of Wellington and the Wellington Chinese Sports and Cultural Club.

Participants from all three groups were explained that I would like to run a focus group for my doctoral studies in psychology to know what they think about the future and history of Jews, Māori and Chinese, and issues relating to marrying another Jewish, Māori and Chinese person. It was also explained that participation was voluntary, that the focus group session would take approximately two hours and would be audio recorded and transcribed, and that participants would receive a movie voucher to thank them for their contribution. Contact details of the researcher and participants were exchanged. Participants were contacted to organise a convenient time and place for each of the three separate focus group sessions.

The research was confidential but not anonymous. Informed consent was obtained through a signed consent form. Oral debriefing of participants was conducted after the focus group. Further results were provided through the Centre for Applied Cross-Cultural Research website, and directly emailed upon request. 


\section{Participant characteristics}

The Jewish focus group was conducted on Tuesday 19 October 2004, 7-9 pm in the boardroom in one of the Jewish community buildings in Auckland. There were a total of eight participants, four females and four males, aged 20-26 years. Two had identifiable Jewish surnames. Five participants had two Jewish parents; two had Jewish fathers (one mother converted). Two participants named multiple ethnic heritage (Italian, Portuguese, English). Three participants were first generation, two were second, two were third and one was a fifth generation New Zealand Jew. All participants were engaged in or had completed tertiary qualifications and all were involved in Jewish community organizations. Four belonged to the Orthodox synagogue (Auckland Hebrew Congregation) and three belonged to the Reform synagogue (Beth Shalom); two belonged to both, one was missing.

The Māori focus group was conducted on Tuesday 12 October 2004, 2-5 pm in the Frank Walkey room in the School of Psychology, Victoria University of Wellington. Due to cancellations there were a total of five participants, three females and two males, aged 2021 years. Two participants had two Māori parents, two had Māori fathers and one had a Māori mother. Three participants named multiple ethnic heritage (Polynesian, Celtic, Western European) but all identified as Māori. All were engaged in tertiary study and all were involved in Māori community organizations.

The Chinese focus group was conducted on Monday 8 November 2004, 6.30-9 pm in the Frank Walkey room in the School of Psychology, Victoria University of Wellington. Due to cancellations, there were a total of five participants, two females and three males aged 19-25 years. Four had identifiable Chinese surnames. Four participants had two Chinese parents; one had Malaysian Chinese parents. Three were first generation; one was second and another third generation New Zealand Chinese. All were engaged in or had completed tertiary qualifications. Two were not involved in any Chinese community organizations, three were involved. 


\section{Focus group question guide}

According to Krueger (1994), an interview guide should not be composed of too many questions (less than a dozen) and should move from more general to specific questions. Issues should be worded simply and unstructured items should be combined with structured items to highlight hegemonic and polemic arguments. Follow-up questions investigate the reasons for their agreements and disagreements, allowing unexpected topics of discussion to unfold. The focus group question guide comprised of three sections:

\section{Endogamy}

Why do some people marry a person from the same ethnic group?

Black and white photographs of Jewish, Māori and Chinese weddings in New Zealand from last century were used as discussion aids. The images were photocopied from the book "I do: 125 years of weddings in New Zealand", (Coney, 1995).

Is it important for you to marry someone from your ethnic group?

What do you think the outcomes of marrying a person from your ethnic group will be?

\section{Continuity}

Do you think it is important to preserve the cultural traditions and language of your ethnic group? Is it important for you to be able to practice your traditions and language?

Do you think it is important to pass your traditions and language on to your children? Are you personally concerned to ensure that your ethnic group will endure? What are ways of transmitting your cultural heritage and ensuring that your heritage will endure? Participants were asked to write ideas down on paper.

Which ways of transmitting are more important and effective? Participants were asked to discuss and order the ideas on the table. 


\section{Social representations of ethnic history}

How important is knowing about the history of your ethnic group?

What events of your ethnic group's history are most significant to you?

When you think about these events, how do you feel? How important is each event in your personal life?

\section{Reflexivity and Ethical Conduct}

The issue of conducting cross-cultural research by researchers who do not belong to the cultures of interest has been raised briefly in Chapter one, whereby non-native researchers who can set aside their 'cultural baggage' are in a position to conduct such research (Berry, 1989). Issues to consider regarding ethical conduct include an understanding not only of who does the research, but also of who holds the power in society; accountability in terms of for whom and for what purposes the research is primarily conducted; researcher reflexivity and ensuring the safety and empowerment of the cultural group through the knowledge derived. Spoonley (1999) relates a personal communication by Māori scholar Mason Durie, that “anything involving matauranga Māori or traditional knowledge should not involve non-Māori researchers. A similar principle applies to other groups. If the knowledge is sensitive and it is important for the community to maintain control over this knowledge, then there are no grounds for outsiders to be involved." As the topics of interest for this thesis are not indigenous knowledge but rather comparisons of the collective continuity of Jews with Māori and Chinese, as a non-Māori and non-Chinese person I feel that my role as researcher with these two groups is justified.

Trimble and Mohatt (2006) outline the importance of researcher reflexivity as well as empathy and concern for the populations of interest. As a Jewish researcher, I acknowledged my position at the beginning of each focus group as a fellow ethnic minority group member. For Māori and Chinese it was made it clear that I was not Pākehā (New 
Zealand European) but rather a Venezuelan-born Jewish New Zealander with a personal understanding of issues relating to marriage, preserving one's culture, and remembrance of ethnic history. For the Jewish focus group it was clear to participants that as a fellow Jew we shared common interests.

Chin, Mio and Iwamasa (2006) criticize the prevalence of a deficit approach in research with Asian and Pacific Islander populations in the United States in that they are problematised and comparisons are nearly always drawn with the majority population. In contrast, the research in this thesis compares Chinese and Māori with another ethnic minority group, Jews, to understand the issue of ethno-cultural continuity which is of direct interest and benefit to all three ethno-cultural groups.

\section{Methods of Qualitative Analysis}

\section{Transcription techniques}

The detail in transcribing focus group discussions varies according to the purpose of the research, intended level of analysis, and whether attention is devoted to the linguistic features of communication, on the interactive dynamics, or on the content of the discussion (Flick, 2002; Wengraf, 2001; Ochs 1999; Macauley, 1991). Techniques for transcription come from conversation analysis (CA) where the transcript is not viewed as data itself but rather as a representation of the oral discussion. Transcribing, in general,

"is a process of writing down in as close detail as possible such features of the recorded interaction as the precise beginning and end points of turns, the duration of pauses, audible sounds which are not words (such as breathiness and laughter), or which are 'ambiguous' vocalizations, and marking the stresses, extensions and truncations that are found in individual words and syllables ... transcription is, first of all, an attempt to capture talk as it actually occurs, in all its apparent messiness" (Hutchby \& Wooffitt, 1998, p. 75). 
Although the Māori, Chinese and Jewish focus groups were conducted to develop theory and constructs based on the content of the conversation rather than the paralinguistic and interactive features, for this thesis transcription did include major speech characteristics using Jefferson's transcript notation (Atkinson \& Heritage, 1999), such as simultaneous and contiguous utterances, pauses, laughter and other major emotions. Verbal utterances were divided into informational phrases delineated by speech cues (Gumperz \& Berenz, 1993). These constituted cognitive units separated by lines in the transcript to facilitate analysis.

Transcription was conducted using the Adobe Audition software package and transcript matrices (Wengraf, 2001). On average, one hour was spent transcribing five minutes of real talk-time. In group interviews it is difficult to identify the speaker, to hear the words spoken and also note down interruptions and simultaneous talk. In total, there were approximately 8 hours of talk-time to be transcribed: 2.5 hours with Jewish participants (an 84-page transcript), 3 hours with Māori participants (134 pages), and 2.1 hours with Chinese participants (67 pages). Altogether, approximately 100 hours were dedicated only for the first transcriptions. A second round was conducted to note down paralinguistic features and confirm the transcript verbatim.

\section{Analysing qualitative data}

According to Krueger (1994), descriptive analysis of narratives is considered appropriate for exploratory research. However, as the purpose of this data was to enable the conceptual development of new constructs, an interpretative analysis was needed (Stewart \& Shamdasani, 1990). Thematic Analysis (Braun \& Clarke, 2006) entails the examination of important issues that recur in the data. However, as analyses were conducted in 2004 and Braun and Clarke's clarification of thematic analysis as a methodology only appeared in 2006, it was Strauss and Corbin's methodology of Grounded Theory (1998) that provided many of the tools used in interpreting the focus group data. The tripartite coding system 
encompasses open coding to develop concepts and categories for ideas discussed by the focus group participants, writing memos and developing the properties and dimensions of categories by making theoretical comparisons. Axial coding relates categories, distinguishes between process and structure, tries to separate categories into conditions, interactions and consequences through asking questions (who, what, when, why and how). Selective coding involves choosing several central categories and relates them through explanatory statements and models. The analyst moves between theoretical induction (data to theory) and deduction (theory to data).

Coding was conducted with the NVivo software package. While some coding categories were culture-specific, comparable categories emerged across all three groups, generating culture-general taxonomies for the constructs in question. Researcher reflexivity was employed as Braun and Clarke (2006) highlight the "dual position that analysts take: as both cultural members and cultural commentators" (p. 94). Care was taken in sampling extracts to illustrate the heterogeneity of opinions and represent the essence of each discussion. 


\section{Results of Jewish, Māori and Chinese Focus Groups}

\section{The meaning of endogamy and selective dating}

Culture-specific perspectives on endogamy and selective dating are described below, followed by a summary of culture-general attitudes.

\section{Jewish perspectives on endogamy}

Most of the Jewish participants spoke of the importance of marrying someone Jewish, or someone who is willing to convert, for the sake of cultural maintenance. Participants spoke of “trying to marry somebody who was Jewish because you've got that firm stable basis to base everything else on", and of sharing customs and traditions with one's spouse.

Some participants indicated a strong preference to marry a Jewish person for the sake of cultural transmission, so that "both parents come from the same angle", and "there's no confusion for the children." Intermarriage was mentioned as an obstacle to transmission, where there have been “instances of people who've married out, want their children to be Jewish but haven't had the support of their partners."

Avoiding marital conflict was another reason cited, as endogamy: "would make life a lot less challenging because there's so many other problems to deal with." However, endogamy is not straightforward. The heterogeneity of Jews was noted and the importance of finding someone who adheres to the same cultural traditions and religious laws was emphasised: "It's not just being Jewish, it's marrying somebody that's Jewish that has the same ideas as me."

Gender differences in the importance of endogamy were discussed because of the maternal line of inheritance. One participant said that: "men feel that it is different for them because they need a woman to bring up the children, well to have the children actually \#laughter\#" In contrast, another participant noted that: "both men and women 
are faced with the same problems - whether you're a man or a woman you're still going to have your children and children brought up in a marriage (that will shape their identity)." Overall, endogamy is a concern for both Jewish men and women.

Participants spoke of being a part of the Jewish community, of collective norms of endogamy and social network approval: "People kind of feel that they're expected to marry somebody in the same group as them." However, participants also noted that host society members rarely understand endogamy:

"In a society like New Zealand, that is the last thing that will occur to most people ... I've had these discussions with friends at work and (I said) I'd prefer to marry a Jewish girl - they were like \#funny voice\# 'Well I would never pick somebody based on what they were' and it was like: Dude, you don't have anything (a cultural heritage) so what would you pick!"

Efforts to find a Jewish spouse were discussed, with comments such as "you can exclude yourself only to dating Jewish people." However, the difficult reality of fulfilling internalised endogamy norms in New Zealand was noted: "I don't think New Zealand supports a lot of these ideals of marrying a Jewish person in terms of the size of the Jewish community and the lack of cohesiveness." As such, serious efforts to find a Jewish partner involve moving to countries where there is a bigger Jewish community (Australia is a popular destination), or to Israel to find a Jewish partner. However, this is self-destructive in that the local population of Jews becomes smaller and the problem is self-perpetuating ${ }^{32}$.

\footnotetext{
32 See Levine, H. (1995). Migration or assimilation? The predicament of observant Jews. In S.W. Grief (Ed.), Immigration and national identity in New Zealand (pp. 203-216). Palmerston North: Dunmore Press.
} 


\section{Māori perspectives on endogamy}

Participants described how previous generations of Māori submitted to government assimilation policies and were encouraged or preferred to marry a New Zealand European - and how this has been changing:

"M: Because in our parent's generation it was not cool to marry a Māori person it was good to marry a Pākehā person \#agreement \#

D: Yeah it's different

Moderator: And now?

M: And now it's - and now we've realized ...

H: Consequences -

L: The consequences of it all ..."

These Māori participants acknowledge the consequences of exogamy - culture loss - and link endogamy to a desire for cultural maintenance and revitalization: "Everyone's on this whole buzz of reviving it all so you would go back to your own people"; "Once I find a nice Māori girl, that's when I'll settle down."

Participants noted that a partner from a different ethnic background may be reluctant to educate their children in accordance with Māori culture and be involved in the community and marae. In contrast, endogamy makes it easier to create a Māori cultural environment at home within which to raise children: "If I was able to control the language they (the children) used and their values or what they considered normal, then I'd prefer marrying someone Māori to help do that.”

Participants also spoke about their whānau (family) and iwi (tribe) being more accepting if their partner is Māori. One participant said: "My father in particular doesn't like the idea of (me) marrying a Pākehā." It was noted that exogamy is more accepted for urban Māori, while it may pose problems for rural Māori: “it’s more accepted for Māori in 
the city to marry someone from another culture whereas if you live in the country, to take that person back to your marae ... there can be conflict."

Participants noted that previous generations emphasised tribal endogamy much more than the current generation: "back in your grandparents and great-grandparents (day) - you had to marry in your own tribe - now it doesn't really matter." This is largely due to social and political forces over the last 30 years that have been encouraging Māori unity (emphasising within-group homogeneity) for the sake of Māori self-determination. Thus, as far as endogamy is concerned today, for these Māori participants, in-group membership precedes tribal membership. Even so, as one participant noted, inter-tribal differences can persist: "and then you start your inter-tribal battles in your own house \#laughter\#"

Social representations of New Zealand history - of colonization - and negative relations between Pākehā and Māori were directly linked to support for Māori endogamy: "You see all the historical side I mean that would also push you to marry a Māori person." Overall, marrying a Polynesian is preferred to marrying a Pākehā, due to affinity with other brown-skinned people, shared experiences of discrimination, and attraction. As one participant said: “The blacker the berry the sweeter the juice \#laughter\#” When dating is concerned, however, participants noted the difficulties in visibly identifying potential Māori dates from other Polynesians.

\section{Chinese perspectives on endogamy}

The most salient factor for endogamy amongst Chinese was social network approval, more specifically parental pressure: “it's been pressed upon me by my folks"; “in some cases they'd almost demand that - oh not necessarily demand but ... prefer that you marry a girl from the same family background ... familiar cultural group." However, when asked for what reasons their parents encouraged endogamy, one participant responded "they don't really provide a good reason." Previous negative family experiences with exogamy were 
cited: "My family has had a few bad experiences with mixed marriages and I think that's why they'd prefer it if I stuck to a Chinese (girl)." One participant did refer to the importance of transmission: "I am the only boy from my generation so it's a matter of keeping the family line going." Transmission in this case relates to family heritage rather than the heritage of the broader Chinese people, reflecting a clan-centred collective orientation.

Participants spoke of resistance amongst children to parental pressures for endogamy and that "being the youngest in my family ... it's been a lot more relaxed when it's come to me ... everybody else has done practically everything else for me so that they've already broken down those barriers."

Advantages of endogamy were mentioned, as it affected maintaining traditions: "There would kind of be that common understanding, regarding all those traditions and practices and stuff - you wouldn't have to explain all the weird food." However, Chinese participants discussed the inconsequentiality of having a Chinese or non-Chinese spouse: "I don't think it would ultimately make any difference"; and "you'd like to think that it wouldn't have an impact - that it shouldn't matter." Furthermore, participants had little inclination to raise their future children in a specific culture, agreeing that the culture of the parents shouldn't have an impact on how children are raised. This was illustrated by comments such as "I'm not going to make my children to grow up Chinese anyway", and the following extract:

"Moderator: And you'd want your children to be identifying more as what?

D: Oh, I personally wouldn't have any preference to be honest."

In general, the participants in this focus group did not talk about making an effort to specifically marry a Chinese person. Aside from interpersonal attraction, many did not see a good reason for marrying a Chinese person and viewed endogamy as restrictive in New Zealand. Those who shared this perspective tended to have a weaker identification with 
and limited knowledge of Chinese culture. As one participant said, "I was born in Hong Kong and I grew up in New Zealand speaking English so I feel like a Kiwi and a Kiwi who just has a bit of knowledge about Chinese culture - but I don't really feel like a Chinese person."

Traditional gender roles were cited as deterrents of endogamy by a female participant: "In traditional Chinese culture I basically would be a slave to my husband's mother \#light male laughter\# I have grown up in a culture where there's a lot more freedom and I don't think I would suit that role at all.”

The importance of considering the effects of within-group differences on endogamy were noted; specifically regions of origin. These are related to differences in Chinese dialect (Mandarin vs. Cantonese), acculturation and 'Westernization”, especially amongst Chinese from Hong Kong, Malaysia, Taiwan or China. They have separate social circles, strong group identities and potential preferences of a marriage partners from the same sub-group. Shared historical experiences were mentioned when discussing endogamy amongst old New Zealand Chinese. Participants noted that an understanding of the historical struggle of the New Zealand Chinese community is not shared by new Chinese migrants:

"S: (old Chinese) have maybe similar upbringing, same core values and they're more likely to know the language (English) too

T: And I find a lot of the ones that do come over they don't understand what our parents and our grandparents have gone through to get to this stage where we are now."

Thus, participants noted the heterogeneity of Chinese and the importance of discerning a partner who has similar origins and formative experiences. 


\section{Don't, I Don't Care and I Do: Perspectives on endogamy and selective dating of Jews, Māori and Chinese}

Overall, desired outcomes and avoidances in relation to endogamy were discussed in all three focus groups. Jewish, Māori and Chinese participants suggested that endogamy may be preferred due to familiarity, shared background and traditional values, and practical reasons of avoiding conflict associated with inter-ethnic marriage. Cultural transmission as a desired outcome was raised by Jewish and Māori participants, highlighting the role of endogamy in passing on their ethnic heritage and identity to their future children. This is not surprising given that both Jews and Māori are 'small peoples', and that Jewish and Māori individuals have a greater investment in ensuring intergenerational transmission than Chinese individuals.

Social network approval was raised by all participants to explain why some people marry a person of the same ethnicity. While Chinese and Jewish participants emphasised parental pressure, only Jews mentioned group norms. Indeed, endogamy has been a method of boundary maintenance and continuity for the Jewish people in the diaspora. Although Jewish and Māori participants linked subjective norms to cultural survival, the pressure felt by Chinese participants could not be explained by collective ideological reasons. Attraction was additionally mentioned by Māori and Chinese participants as a contributing factor for endogamy. In general, Chinese participants did not see a good reason for marrying a Chinese person and experienced more difficulty discussing reasons for endogamy than Māori and Jewish participants. Comments were full of hesitations and some could not provide explanations ${ }^{33}$. It seems that endogamy was not as critical an issue for these participants. This is understandable considering that Chinese are not a 'small people' who have had to rely on endogamy as a means of survival.

\footnotetext{
${ }^{33}$ When conversation is stalled and participants find the subject is difficult to discuss, this can reflect a lack of interest, an issue's sensitive nature, or it can be a sign that the topic is not one which the participants have previously given a great deal of thought (Markova, 2003).
} 
Overall, attitudes towards endogamy across the three groups varied as follows:

a) Endogamy is restrictive and unappealing;

As one Chinese participant said: "in New Zealand there's a whole lot of people so you can't really restrict yourself to one kind of race" (the use of the word race in this discourse refers to ethnicity as used in this thesis).

b) Endogamy is unimportant / indifference;

According to one Jewish participant, "It wouldn't really be important to me whether I married a non-Jew or Jew." This view was even more strongly endorsed by a Chinese participant, who said: "Well there's no really good reason for it."

c) Endogamy is a clear preference.

As one Māori participant said: "I think that you got to follow your heart ... quite honestly my heart is fixed on a Māori girl." Similarly, one Jewish participant said: "Obviously it would be preferable if they were Jewish." Another endorsed this view even more strongly, “It's 100 percent important to me."

Similarly, attitudes towards selective dating varied as follows:

a) Selective dating is consciously rejected;

According to one male Chinese participant, 'it's quite restricted to say you can only marry a Chinese girl so I'm not only going out with a Chinese girl'. This view was similarly held by a female Māori participant: "I wouldn’t go out and only look at Māori boys."

b) Selective dating is simply a coincidence /indifference;

As one Māori participant said: "My boyfriend's Māori but that's by coincidence; that's not by choice."

c) Selective dating is consciously chosen.

As one Chinese participant remarked: "Chinese girls - I can relate to them better." In a more conscious manner, one Jewish participant said: "I've dated non-Jewish before and I've decided to choose not to." 
On the whole, while some Jewish, Māori and Chinese participants do intend to marry a person from the same ethnic group and do engage in selective dating behaviour, others do not intend to marry a person from the same group nor do they engage in selective dating. Jews noted that the low ethnic vitality in New Zealand means that despite a desire for endogamy, there is a high probability of exogamy.

One Māori participant noted that "We could talk about the ultimate goal that each of us has, whether we plan it or not, and you could fall in love with a person in the street!" This can be contrasted with a comment by a Jewish participant: "You can always influence the direction, \#laughter\# if you want to marry a Jewish person you can take the steps towards helping yourself find them." This raises the issue of perceived behavioural control or endogamy self-efficacy, where the perception that one cannot control who one dates and marries is contrasted with the awareness that one can exert some control: All in all, in multicultural societies ethnic endogamy is a volitional behaviour precisely because individuals have a choice and do exert some level of control regarding marriage inside or outside their ethno-cultural group.

In general, Jewish, Māori and Chinese participants emphasised that ethnicity is a valued characteristic but is not sufficient for the selection of one's future spouse. They all emphasised the heterogeneity of their ethnic groups and how this affects preferences for endogamy: Jews have different levels of religious observance and cultural lifestyles; Māori from different iwi have slightly different customs, history of intertribal conflict and levels of urbanization; and Chinese have different nationalities and degrees of 'westernization', regional and dialectal differences, and history of migration to New Zealand (old and new Chinese). Consequently, those participants who do wish to find an ethnic partner seek someone with similar ethno-cultural experiences and aspirations. 


\section{Endogamy as a motivated behaviour}

In general, motivation is concerned with the reasons why individuals act and concerns “energy, direction, persistence and equifinality" (Ryan \& Deci, 2000). Heider (1958, cited in Deci \& Ryan, 1991) noted that only actions that are predicted by intentions are motivated. As some participants from the focus group discussions spoke of intentions to marry within the same ethnic group, this situates ethno-cultural endogamy as a motivated behaviour. While some intentions to perform behaviour originate from the self and can be seen as intrinsically motivated other intentions emanate from the environment and are extrinsically motivated (Deci, 1975). Endogamy can be seen as an extrinsically motivated behaviour in which the reason for marrying within the same group is other than an inherent interest in endogamy. Indeed, socialization plays a key role in transmitting extrinsically motivated behaviour, such as norms for ethnic endogamy. Ryan and Deci (2000) identify four types of extrinsically motivated behaviours whereby:

(a) external regulation involves compliance with a normative behaviour to satisfy the demands of significant others; (b) introjected regulation is more internalised although it is not completely accepted by the individual; behaviours are regulated by emotions such as guilt or pride; (c) identified regulation involves the personal valuing of the specific behaviour; and (d) integrated regulation is when the behaviour is fully internalised and becomes self-determined. Comments from the focus group discussions indicate that for these Chinese participants, endogamy was more externally regulated (see a) compared to these Jewish and Māori participants for which endogamy was a mixture of introjected (b), identified (c) and integrated regulation (d). 


\section{The meaning of ethno-cultural continuity}

\section{Ethnic heritage and the self: Cultural maintenance and the polemics of identification}

Participants from all three focus groups said it was important for them to practice their cultural traditions. However, this affirmation was qualified in different ways: both Māori and Jews said it was important to preserve their culture because of experiences of threat to collective survival; Jewish participants added it was difficult to do so in New Zealand because of low ethnic vitality; and Chinese participants noted that they did not want cultural traditions to become forced or artificial.

\section{Jewish perspectives on cultural maintenance}

In terms of an individual desire to maintain Jewish identity and culture, one participant immediately situated individual journeys in the long-term acculturation of the Jewish people: "We've survived for thousands of years already, why give up now?" Thus, maintenance was viewed as a link in the chain of long-term acculturation. Participants also noted the influence of anti-Semitism in imposing individual identification, where one's ethnic identity can be enforced by the larger society:

"Judaism is an odd little cross to bear in some respects I mean its something you don't necessarily have a choice in ... you could grow up and not consider yourself Jewish and it just takes another Adolf Hitler to come and tell you yes you are ... I guess the awful spectre of the Nazis is something that's maybe lessened our choice to be Jewish - I feel quite proactive in wanting to maintain my Judaism partly because of things like that ... well if these guys are going to point a finger at me anyway then well I want to be Jewish - a Jew for my own sake not because some other asshole's going to come along and tell me I am for some repulsive reason." 
The legacy of the Shoah is that although a person may not identify with Judaism, by descent they can always be classified by others as Jewish. Thus, in the face of cultural ascription by the larger society, ethnic group members may as well appropriate their ethnic heritage. Furthermore, ethno-cultural identification is considered to be an asset in a larger society such as New Zealand:

"S: I think it's nice to hold on to something ... in the context of being a New Zealander there isn't that much culture - a lot of people came from England and stuff, you know - what is a New Zealand culture? So therefore when you are Jewish you've got at least one thing to identify with \#agreement from other participants\#

C: Yeah, I agree. It's nice to just have something like that, that you can identify (with) and it's cool you get to meet all these people who otherwise I wouldn't have a connection with

S: Otherwise you just fall into the gap of being a New Zealand Pākehā.”

Thus, although Jews in New Zealand as a non-visible minority could easily 'pass' as New Zealand Europeans, cultural maintenance as opposed to assimilation was valued by these participants. The advantages of belonging to one's ethnic group and having the Jewish community as a support network were also discussed as a reason for the importance of maintenance: 'It's that sense of belonging and there's a support network and there's people that you can lean on and they can lean on you."

Furthermore, Judaism, Jewish culture and the Jewish people are acknowledged as something that makes the world a richer and more interesting place, contributing to the foundations of Western society:

"I actually think the [Jewish] traditions are really good traditions and that there's a lot of purpose to them and a lot of wisdom and knowledge in them and that it's important to keep them from the perspective that if we lost those traditions you'd be losing a lot of understanding about life in general." 


\section{Māori perspectives on cultural maintenance}

The following quote illustrates the importance of cultural maintenance for Māori participants: "You've got to grasp on to whatever's there 'cause if you don't it's just going to fizzle out!"

Participants acknowledged that those who have been educated in mātauranga Māori (traditional Māori knowledge) and undertake formal Māori studies at tertiary level - where history and knowledge from a Māori rather than mainstream perspective is taught - do consider it important to preserve their heritage.

Participants respected more geographically isolated tribes that have maintained mātauranga Māori and spoke of urbanization as directly linked to the loss of traditional knowledge. In light of the residual effects of colonisation and discriminatory practices, participants explained that some Māori are so assimilated that they wouldn't understand the concept of cultural maintenance:

"D: Yeah that mentality that if you go the White - the Pākehā way, that's how you'll succeed and why waste your time doing Māori

J: 'Cause it was beaten out of him (my dad) at school like he wasn't allowed to speak Māori at school it was beaten out of him with canes, rulers ...”

In addition, participants spoke of a break in intergenerational transmission and how this adversely affected their ability to 'maintain' Māori culture: "Personally I felt it was lost. If it wasn't lost then my Dad would have taught me to speak Māori.” Most of these participants have to actively re-acquire their ethnic language through formal education. 
Perceptions of Māori cultural discontinuity are poignantly illustrated in the following extract whereby a participant as a child came to terms with his ethno-cultural identity:

“J: Until I was ... about seven, eight (years old) was when I realized that I was from [Tribe A]. Before that I thought I was a Samoan

\#shock and laughter\#

$\mathrm{N}$ : Really?

J: Well I went to a predominantly Samoan primary school. I was at a Catholic primary school with a lot of Samoan and Tokelauan (kids) and I thought I was Samoan or Tokelauan and my little sister's having exactly the same problem \#soft laughter\# she's just turned ten! ... Two years ago she asked my mum 'Am I a Tokelauan?' and she said 'No you're Māori'. So yeah, it's lost, for me it was lost it was broken

M: That's unbelievable."

What a shame it is when Māori as indigenous people do not feel compelled to or are not able to raise their children with a strong awareness of their Māori heritage in New Zealand. In fact a sense of bitterness was felt regarding the ability of Polynesians in New Zealand to speak their own language, whilst past assimilation policies have led directly to Māori language loss.

Participants viewed identification with their ethnic heritage as an asset in the context of the larger Pākehā New Zealand society which lacks a strong cultural identity:

"M: 'Cause we've got such a proud culture which is kind of in your face - the haka and whatever, and they (Pākehā) don't seem to have one ... they feel insignificant in their own culture ...

D: Yeah, they have no identity

M: Yeah it pisses them off real hard."

The politics of ethnic identification in the New Zealand context was also discussed as participants noted the role of skin colour and visibility in cultural ascription: 
"M: My last name is ... obviously English - now I know that a lot of Māori, even if they have English names don't identify as English at all ... we've been put into boxes, like if you're slightly Māori you're Māori and in a in a sense it's good because even if you don't look Māori you will still be Māori but that's kind of bad ... - you can't be Pākehā if you're Māori you just can't they don't really accept you \#agreement\#

D: I suppose it's the way you've been brought up

M: Yeah in my experience if I said I was Pākehā people would just laugh at me \#he laughs\# you know?

Moderator: But would you want to say you're a Pākehā?

M: I don't mind it

L: Going into a job interview, yeah it works pretty good \#soft laughter\#”

Hence cultural maintenance for individuals who are visibly Māori may in fact be enforced by the larger society through ascription. Participants commented that non-identification with Māori culture would be advantageous under some circumstances, due to latent discrimination. As such, participants implicitly suggested that Māori identity and Pākehā appearance seem like the best combination for success in the larger society and for ethnocultural continuity.

\section{Chinese perspectives on cultural maintenance}

The following extract illustrates the dominant perspective of Chinese participants whereby cultural maintenance is important, but efforts have to be moderate:

"R: I was thinking there has to be a balance, because you know we don't live in China - we don't live in a Chinese culture we live in a multicultural society so you have to kind of balance the two - I guess you can't let the Chinese culture overwhelm the one you are already living in to the point where it's just kind of very artificial really ...

Moderator: What do you mean by artificial? I think it's an interesting word, 'cause it kind of means you're trying to create something (quote continued...) 
R: Yeah you're trying to create something within an unnatural environment so I guess ... a hybrid kind of thing is what it is - like a Chinese and New Zealand culture, but trying to live in a totally Chinese cultural way of life is just kind of -

M: You're trying to bring a little piece of China over to New Zealand ...

T: I pretty much think the same way too but I think it should be emphasised not too much but enough for you to remember where you're from and where your ancestors came from so that you can pass it on to the next generation where they won't be left in doubt."

Thus, participants emphasised their preference for maintaining an integrated identity, a hybrid Chinese and New Zealand culture. They rejected over-emphasising Chinese culture; awareness of one's origins was all that was deemed necessary to transmit to the next generation.

Chinese participants noted the consequences of long-term acculturation whereby impaired cultural maintenance was reflected in language loss:

"I'm only second generation ... and I think it's quite bad that a lot (of Chinese New Zealanders) can't read (Chinese), we go to things like Chinese restaurants ... and in some cases I'm the only one who can speak or understand (the menu) and I think that's quite bad - I like to think that we should be able to understand something, you should know your roots."

Overall, a minimal behavioural competency was valued by these Chinese participants.

\section{Jewish, Mäori and Chinese perspectives on cultural maintenance}

In general, Jewish, Māori and Chinese participants all agreed that it is important to preserve their cultural traditions and language. Jewish participants expressed the uniqueness of Jewish traditions which make the world a richer place, and felt in debt to carry on their cultural traditions for the sake of previous generations. They highlighted the struggle of keeping cultural values while living in New Zealand, a small diaspora community. Māori participants acknowledged the negative consequences of colonization for cultural 
maintenance. Having Māori names changed and Māori culture physically beaten out of one's being was still living family memory. Jews and Māori both note that maintenance can occur involuntarily, through cultural ascription. However, they both feel that their own identity and culture is something worth keeping given the lack of a strong New Zealand cultural identity. Chinese participants stressed the importance of maintaining a balanced identity in New Zealand, so that Chinese culture is not overwhelming and artificial. Participants from all three ethno-cultural groups emphasised individual prerogatives in adherence to traditions.

\section{To be and to belong: Internal polemics of identification}

When it comes to cultural maintenance, individuals must not only identify with their heritage, but they also need to be accepted by fellow ethnic group members (vs. external cultural ascription by members of the larger society). Remarks by Jewish and Māori participants contrast two different outlooks on group membership: Jewish exclusiveness vs. Māori inclusiveness. Jewish participants discussed the maternal descent regulations recognised by Orthodox Jews in contrast to the cognatic descent regulations (through the mother and/or father) among Reform Jews, and the restrictions this places on identification and participation in Jewish communal life:

"B: My mother converted and she had a Reform conversion so I may not be considered Jewish to a number of people ...

C: I know my family is the same, hmm

B: and that's just fucking ridiculous ... I just think it's ludicrous anyway ... because the identity comes from the person ... it's just so full of ... ironies I mean ... I know this Jewish kid who is completely not Jewish at all ... he's more Jewish than me (because his mother is Jewish) ... I can always say well you're not Jewish enough for the ultra Orthodox, 'cause he's not - so it's a stupid little circle of people pointing fingers at each other. We're facing ... assimilation and then to find another door that we're keeping closed on whether or not you can be Jewish is dumb." 
Thus, belonging is a polemical issue for Jews. Due to collective experiences in long-term acculturation and the schism between Orthodox and Reform Judaism (see Appendix B), Jews today struggle with such internal exclusivity and the question of being Jewish 'enough'. As noted by the participant above, this exclusivity is counter-productive for Jews, a 'small people' who are faced with threats to continuity. This is contrasted with the more inclusive cultural regulations of Māori who formally recognise cognatic descent:

“As long as you've got one Māori in your line you can trace all the way back to them - lets say if I'm Māori, and my great-great-great-grandchildren end up marrying different races or whatever they'll still be Māori' cause of me Māori are pretty good like that, they don't disclaim anyone."

Due to intermarriage, participants acknowledged that Māori phenotype is considerably varied and yet: 'if you're even slightly Māori, you got blue eyes blond hair you're Māori... you're not judged (by other Māori) by how white you are or how black you are." Participants did, however, note the importance of being recognised by their extended family and qualified that the only time people would be questioned as to their Māori ancestry - whakapapa - would be regarding issues of claiming resources and government compensation $^{34}$.

\section{Ethnic heritage and the family: Cultural transmission}

Jewish and Māori participants expressed that if a conscious effort was not made to keep their culture alive, it would disappear. They were both aware that endogamy is a favoured way to create a cultural environment at home and transmit their culture to their future children, and that transmission in turn is a key mechanism for collective survival. In contrast, Chinese participants were not concerned about keeping their culture alive, and preferred to transmit to their children a general awareness of their heritage culture.

\footnotetext{
${ }^{34}$ The polemics of claiming descent from multiple tribes that are eligible for government compensation was also noted.
} 


\section{Jewish perspectives on cultural transmission}

Judaism was seen as an enriching heritage that participants wanted to transmit to their future children. One participant noted the critical role of intergenerational cultural transmission for cultural survival: “How else does it stay alive if you can't give it to the next generation and that's where it ends?"

Participants discussed differences in Jewish perspectives on continuity; for religious Jews transmission is seen as a collective and individual-level obligation, whilst for less religious and secular Jews it is more volitional in nature:

"M: Because we have no choice, we have no choice in the matter

R: No but we do have a choice. We have an intrinsic choice as an individual to pass on what you believe in ...

M: It's a religious point of view, it's a religious perspective

B: Ok so I suppose in terms of the laws in Judaism the Jews have an obligation to maintain the continuity, is that what you are saying?

M: Yes, yes yes that is correct ...

B: Ok and I guess the counter-argument is that not everyone is that devout."

Overall, each generation plays an active role in the continuity of the collective through cultural transmission by obligation, by volition, or both. Indeed, although the Torah (Deuteronomy, 11:13-21) specifies that "You shall teach them to your children..." this Divine commandment can become internalised (see earlier section on endogamy as a motivated behaviour and identified/integrated regulation) such that cultural transmission is self-determined. 


\section{Māori perspectives on cultural transmission}

The importance of transmission for Māori participants is illustrated with the statement: "I'd rather my kids be Māori than anything else."

Participants described how the current generation is engaging in formal education to regain their culture so that it can be transmitted to the next generation via the more natural process of enculturation in a Māori home environment. While those who are actively engaged in formal Māori education feel that transmission is important, one participant who does not have the same cultural competencies claimed that they were even more aware of the importance of transmission.

““cause I don’t learn Māori I know more than you guys how important it is, 'cause you guys are learning it you guys know it ... and I see how you guys are and how I am - I don't want my kids to be like this."

Participants also discussed giving their future children Māori names to enhance cultural transmission. However, participants noted that cultural transmission was possible within an inter-marriage if the partner was supportive, describing a role model who made a conscious effort to transmit Māori culture to her children:

“... when he proposed to her she said this is how it is - the kids are Māori and that's it ... they're going to go to Māori schools blablabla and he was like - fine - and that is what happened 'cause he was accepting, he accepted all her terms before marrying her."

Gender roles were also discussed, in particular the key role that women have as cultural bearers and transmitters and the likelihood of Māori women successfully transmitting their culture if they married a non-Māori man, as opposed to the potential difficulties encountered by Māori men married to non-Māori women: 
“L: You can't really tell your Mrs [how to raise her kids] \#laughter\#

H: 'Cause she wears the pants!

L: I wouldn't go that far but quite honestly she's the one who's got to carry it [Māori culture], you know you can't tell her this is how it is, the kids are going to be Māori I don't care if you are a Black African ... the kid's not going to be African - you can't do that, not to a woman! But they can do it to you \#laughter\#"

Finally, the central role of a Māori home environment in transmitting Māori culture was emphasised in contrast to pre-colonial times when the marae was the primary enculturating force:

"Back in the heydays ... you learned it from the marae, everything you learned was from there, whereas now when we have kids it's not going to be a marae-based thing, you've got to start it within your own house."

\section{Chinese perspectives on cultural transmission}

Transmitting a general awareness of one's Chinese cultural heritage was important for Chinese participants, rather than an enforced immersion in the home:

"I think it's important to preserve awareness of cultural heritage without necessarily forcing any particular values upon your children - so letting them grow up in the environment where they are able to assimilate the values of the social groups around them but then also just letting them know that's not the only way of life ... and being able to choose their own way so you're not letting all your own culture slide into the background, but not pushing it onto the child and saying - we're Chinese and we need to live this way - because that's going to clash with what they are seeing and hearing around them when they go to school \#nodding in agreement\#" 
When questioned regarding the role of endogamy in transmission, the consensus was:

"It depends on how much you want to pass on - how strongly you want to make your child grow up knowing those traditions and whether you want them to be fully absorbed in their home life in Chinese culture, or whether you just want them to be aware of Chinese culture in which case it doesn't really matter what culture your partner is because your child can grow up aware of two or three cultures."

The lack of urgency in transmitting a strong Chinese culture is likely a reflection of their status as members of a large people, whereby the continuity of Chinese culture as a whole does not rest upon the shoulders of individual Chinese:

“M: I don't feel like I want to control who - what my grandchildren are like or what they look like and what they grow up like whereas I think maybe for the older generation the reason why they want their children and their grandchildren to marry into the Chinese ethnic group is because they want to see that continuation of the line? Whereas I don't really care if the Chinese blood is diluted as you go down the line? It doesn't make any difference to me at all \#agreement\#

Moderator: The whole idea of continuation of the line ... Is continuity important for you guys? \#silence\#

R: Not really

T: I don't think so, no ...

D: I'm on the picket fence at the moment \#soft laughter\#"

Although continuity of Chinese culture was not of concern, participants did discuss the importance of celebrating traditional festivals and individual prerogatives in transmitting and learning Chinese language(s):

“D: I think culture-wise it's important to emphasise the Chinese culture but language wise I think it's just an option - personally I'm glad that I speak Chinese as well and I understand it because ... lots of Chinese students come here with the perception thinking that local Kiwis are sort of - there's that term Banana? \#laughter\#” 
Thus, transmission was framed not only with regards to cultural traditions but also in terms of ensuring a minimal language competency in an environment where three-quarters of New Zealand Chinese are overseas-born (and are fluent in Chinese).

Overall, transmitting a strong, positive ethnic identity, as well as enthusiasm and care for their cultural heritage was important for both the Jewish and Māori focus group. However, this was not explicitly articulated by the Chinese focus group. Nonetheless, all three groups acknowledged their future children's prerogative in adherence to traditions.

\section{Suggested methods of cultural transmission and ensuring ethno-cultural continuity}

Jewish, Māori and Chinese participants wrote down many different ways of ensuring that their culture will endure (see Table 4.1 below, in order of importance). While all three groups put forward similar ideas, Jewish participants emphasised marriage within the Jewish community and having Jewish children, and like Chinese participants, noted observing traditions. The most important mechanisms for Māori participants were having a Māori family or whānau, marrying a Māori and ensuring competency in te reo Māori. Chinese participants also highlighted language competency (Mandarin or Cantonese) and noted celebrating traditional events within the family and in public. All groups highlighted the importance of formal and non-formal education in transmitting cultural knowledge, community involvement in Synagogues, Marae, and Chinese Cultural Associations as well as fostering group unity across Jewish communities, different iwi, and Chinese migrants. Furthermore, Jewish, Māori and Chinese participants all emphasised the importance of host society policies, tolerant attitudes, and encouraging public displays of culture and ethnicity. Overall, while many strategies were suggested to ensure ethno-cultural continuity, endogamy was recognized by Jewish and Māori participants as particularly important. 
Table 4.1: Methods of cultural transmission and ensuring ethno-cultural continuity

\begin{tabular}{|c|c|c|c|}
\hline & Jews & Māori & Chinese \\
\hline 1 & $\begin{array}{l}\text { Having Jewish children and } \\
\text { marriage within the Jewish } \\
\text { community }\end{array}$ & $\begin{array}{l}\text { Whānau (family) and } \\
\text { Whakapapa (genealogy); } \\
\text { Marry the Māori }\end{array}$ & $\begin{array}{l}\text { Language competency - } \\
\text { Chinese dialects }\end{array}$ \\
\hline 2 & Observing traditions & Te reo Māori- Māori language & $\begin{array}{l}\text { Celebrating traditional events } \\
\text { in the family and in public }\end{array}$ \\
\hline 3 & $\begin{array}{l}\text { Families being actively } \\
\text { involved in the community } \\
\text { and life-cycle celebrations }\end{array}$ & $\begin{array}{l}\text { Marae - community and } \\
\text { Kōrero - use of language }\end{array}$ & $\begin{array}{l}\text { Formal and informal } \\
\text { education, learning about the } \\
\text { past; Displaying culture with } \\
\text { pride }\end{array}$ \\
\hline 4 & $\begin{array}{l}\text { Formal and informal } \\
\text { education, learning about } \\
\text { Jewish history }\end{array}$ & $\begin{array}{l}\text { Traditional Māori knowledge - } \\
\text { Tikanga, participate and create }\end{array}$ & $\begin{array}{l}\text { Visit home country; } \\
\text { Staying in touch with } \\
\text { relatives }\end{array}$ \\
\hline 5 & $\begin{array}{l}\text { Promoting Jewish pride } \\
\text { and confidence }\end{array}$ & $\begin{array}{l}\text { Knowing myths, legends, } \\
\text { history and Whakapapa }\end{array}$ & $\begin{array}{l}\text { Movies, public events, } \\
\text { exhibitions }\end{array}$ \\
\hline 6 & Youth organisations & Sense of community & $\begin{array}{l}\text { Being a member of cultural } \\
\text { groups; } \\
\text { Unity of Chinese people }\end{array}$ \\
\hline 7 & $\begin{array}{l}\text { Preserving language, arts } \\
\text { and culture }\end{array}$ & $\begin{array}{l}\text { Larger society accepting Māori, } \\
\text { inform non-Māori }\end{array}$ & $\begin{array}{l}\text { Sharing Chinese culture with } \\
\text { neighbours and friends }\end{array}$ \\
\hline 8 & $\begin{array}{l}\text { Israel (visiting or moving } \\
\text { there - 'making aliyah') }\end{array}$ & $\begin{array}{l}\text { Kapa haka (cultural groups), } \\
\text { Kōhanga, Kura, traditional } \\
\text { education systems }\end{array}$ & - \\
\hline 9 & Socialising with other Jews & - & - \\
\hline 10 & $\begin{array}{l}\text { Tolerance (within Jews and } \\
\text { between Jews and the larger } \\
\text { society) }\end{array}$ & - & - \\
\hline
\end{tabular}




\section{Jewish comments on methods of cultural transmission}

Having children was taken for granted as the single most important mechanism for Jewish continuity. "We're quite constrained in that ensuring continuity is kind of having a Jewish kid." This comment was qualified by another participant:

"We can all have millions of kids but then if we're all completely crap relaxed Jews then that may have absolutely no effect ... you really would want to have Jewish kids and try to maintain a sense of Jewish identity in your household you know, one without the other is kind of pointless."

Thus, having Jewish children and creating a Jewish environment in the home contribute to ensuring collective continuity. The central role of families was emphasised: "Families being actively involved in the community, this being the case everything else will fall into place." Furthermore, the importance of individuals situating themselves within the community was noted: “you've got to be involved; you can't just be isolated on an island by yourself and say well I'm Jewish, you've actually got to be involved."

In addition to efforts that ethno-cultural communities can make, participants emphasised the importance of tolerance from the larger society in ensuring the continuity of ethnic minorities: "we are mostly responsible for keeping our heritage and our religion and our culture and our ethnicity alive and for the continuity of it, but we're not ignoring the fact that people outside of this community ... have an influence as well." This comment was qualified by another participant who noted: "If we expect tolerance from everybody else we need to tolerate each-other." Thus, both internal and external tolerance can foster ethno-cultural continuity.

Interestingly, the role of Israel for Jewish continuity in the diaspora was discussed; participants noted that Israel was a place where Jews could be Jews, but that it did not define Jews. The consensus was that the Torah and traditions are what make Jews who they are, hence justifying continued Jewish existence in the diaspora. 


\section{Māori comments on methods of cultural transmission}

Māori language is a thread that runs through the different methods of cultural transmission; it cannot be separated from the Marae, Māori knowledge and education. Overall, emphasis was placed on internal efforts in terms of encouraging formal Māori education: "I think the main focus for us should be focusing on ourselves, as Māori - sending kids to Māori institutions ... you want to try and educate Māori themselves to put their kids through kura kaupapa or kōhanga, at least." On a political level, collective unity for continuity was seen as instrumental:

“J: Everyone's told for Māori to join as one ... a push on a political level Moderator: Whose idea was it?

J: Like you know John Tamihere - all the MPs are trying to push Māori as one big entity ...

L: Our grandparents would have forwarded themselves as [Tribe A] over being Māori... whereas now we all say we're Māori before our tribes.”

Participants also highlighted the importance for children to see their tribal lands, instead of just knowing from what mountains they originate. However, the loss of ownership of tribal land is a critical aspect of Māori consciousness; participants differentiated between knowing and owning their ancestral land.

\section{Chinese comments on methods of cultural transmission}

The importance of Chinese collective unity in the face of internal diversity was illustrated in the following comment: "well it's good to have subgroups, but it would probably be so much stronger than it already is - if we all came together and embraced the whole Chinese culture." Overall, Chinese participants spoke of attachments to family, distant relatives in China and the local areas from whence they came. A general interest in China from a cultural perspective was evident. However, these participants placed no emotional or psychological attachment to the land of China. 


\section{Methods of ensuring ethno-cultural continuity}

Overall, participant responses covered a range of methods to ensure continuity that span four distinct domains, illustrated in Figure 4.1. Circle A encompasses self-oriented methods that include affective ties to one's heritage culture, developing behavioural and cognitive competencies and attachment to ancestral land - a figurative and literal 'foundation'. Circle B encompasses family-oriented methods that include having children, creating a cultural environment at home conducive to transmission, enculturation and socialization. Circle C refers to internal mechanisms of the ethnic group such as formal education and ethno-cultural organisations, as well as ethnic vitality and intra-group unity. Finally circle D encompasses external mechanisms in the larger society such as enabling public displays of culture, acculturation attitudes, and tolerance and cultural awareness which could be fostered in the media - criticised for portraying a negative image of minority ethnic groups. Note that while endogamy is a family-centred strategy (circle b), it also enables the self to develop cultural competencies (circle a), and by producing children it contributes directly to the vitality of the ethno-cultural group (circle c). 


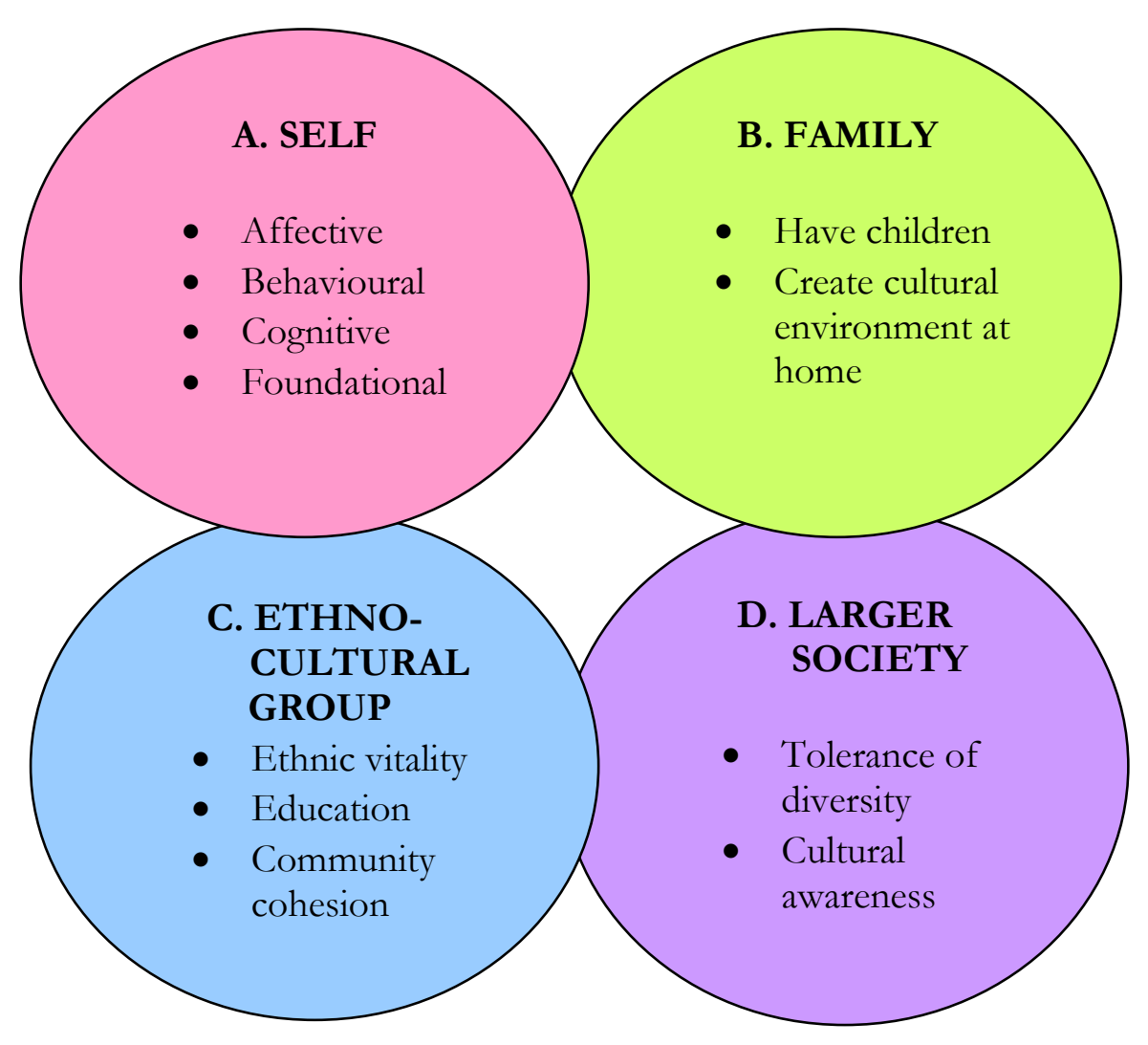

Figure 4.1: Methods of ensuring ethno-cultural continuity 


\section{Ethnic heritage and the collective: Cultural endurance and issues of discontinuity}

While Jewish participants spoke of a religious obligation to survive as a collective in conjunction with a personal choice to ensure continuity, they also voiced concerns about anti-Semitism and personal indifference as threats to collective continuity. Māori participants were concerned about the endurance of Māoridom and emphasised the effects of land loss as indigenous peoples. In contrast, Chinese participants were not troubled about the continuity of the Chinese people as a whole but did express minor concerns regarding the sustainability of the New Zealand Chinese community.

\section{Jewish perspectives on endurance and discontinuity}

For these participants, Jewish survival and continuity was of central importance in the face of low ethnic vitality of the New Zealand Jewish community and assimilation trends. The extract below illustrates the enthusiasm expressed by Jewish participants for ensuring the endurance of their traditions not only because of their intrinsic value, but also in light of past collective suffering to ensure Jewish continuity:

" $\mathrm{C}$ : The culture that is so vibrant and so unique ... there's just something you want to carry on as a legacy to the world

L: I think through the millennia as well, Jewish people have suffered so much and that it's still survived up to now and it's given me so much so you kind of feel in debt that you need to carry that on and not just for my sake but for the sake of my parents and my grandparents and the people before that."

The subjective importance of collective endurance was discussed by participants using a typical New Zealand pass-time - rugby - as a metaphor for continuity:

"Everyone wants to cheer on their own team, really I mean you want to see your group carry on - it's like - lets use a rugby game for instance, you're still going to cheer on your country and don't want them to just drop out of the game half way through." 
A complex discussion arose regarding how much change is acceptable for endurance to take place whereby participants emphasised the importance of adapting to the environment while maintaining a core ethnic integrity. Disputes arose as to what marks discontinuity:

"R: In order to have continuity you have to change and adapt to your surroundings

D: But I think as long as you keep the core essence of the meaning behind the values and the traditions ... the ways that you do things ... may change, and you may need to adapt to abide by the laws of the country it may be as simple as that but as long as there's that underlying grounded fundamental set of principles and morals and beliefs that's what's important

B: I'd love to know what they are ... for example - can women (publicly) read the Torah ... all these kinds of questions they're all looking at where is the core ... does the core allow for me to eat pork?

M: So what the hell is the core? ...

L: The whole thing is that if there's change it has to be change as a whole and it can't be change on an individual level because then everybody is changing in different directions - so you kind of need a body that's saying we're going to be changing in this direction and we're all going to be making the change together because that keeps the continuity ...

D: But that's why there's fifteen shuls (synagogues) in Brisbane \#laughter\# ... because everyone goes well we're going to be this body and we're changing this way ... the bad thing is that they still hate each-other

B: \#cynical voice\# ... My only big difference from general mainstream Reform (Judaism) is that I'm going to consider Jesus one of the many prophets from that era you see and ... that won't change the core

L: It's a good point, that once you start breaking some of the halakhah (Jewish laws) then you can break whatever you like ...

R: But why should the Reform (Judaism) be looked down upon (by Orthodox Judaism)?

L: 'Cause it's saying you're actually losing the core \#uncomfortable silence\#” 
Overall, the above comments demonstrate that while idiosyncratic acculturation takes place at the individual level, at a collective level, radical changes can lead to a loss of the cultural core and eventually to a perceived break in continuity (e.g. Christianity).

In general, for these Jewish participants, continuity was seen as important not only because their heritage was valued, but also to honour those who have previously carried the cultural torch (and lost their lives on the way). Identity struggles emerged between the Orthodox circle and the Reform circle. Contentions regarding who is considered a Jew and the heterogeneity of beliefs and practices sparked a very serious and emotionally-laden debate about authenticity, what constitutes the core of Judaism and what changes are or are not acceptable for continuity to occur? Definitions remain in the hands of religious authorities who have opted for a conservative, exclusive approach to Jewish belonging and continuity.

\section{Māori perspectives on endurance and discontinuity}

While Māori participants agreed that continuity was important and something they valued for the future, they emphasised that the current stage involves cultural revitalization due to colonization and the effects of discrimination:

"Moderator: ... what do you think about using the word continuity?

J: I don't know, I'd use revitalization myself \#agreement\#

M: 'Cause it's not continuity

J: It's been lost, my parents, my grand(dad) - my dad and the whole of his generation - all his brothers and sisters can't speak it. My auntie had to come here - the eldest daughter, had to come here (to university) and learn how to speak Māori. So there's a gap, I wouldn't say continuity I'd say revitalization.” 
In particular, the loss of Māori land was a marker of cultural discontinuity:

"M: ... land is very very important in Māoridom and to have that land stolen ... just broke our ancestors and without the Treaty of Waitangi we can't do anything about that

H: It debased the whole culture."

Thus, the Treaty of Waitangi is referred to as one mechanism for ensuring Māori endurance by enabling restitution. Participants spoke of Māori cultural loss and impending collective dissolution until the land marches and protests took place in the 1970s:

"M: Activism - Māori activism that was the start of the renaissance, really people started taking pride in being Māori... if that hadn't happened honestly that was the breaking point - you either get your culture back now or you lose it forever and that's why we say there wasn't any continuity? ... Before that it was so bad to be Māori you couldn't even say you were Māori

H: It became so bad they woke up."

And as for the future endurance of the Māori people, participants emphasised the importance of formal and informal Māori education in ensuring continuity: "We can look towards the future and fight for what is ours and fight for our heritage." Māori participants are concerned and dedicated to make sure that Māoridom endures. As one participant said, “That's why I'm learning Māori, and that's why I'm going to marry a Māori, and have Māori kids, hopefully beautiful Māori kids.”

In general, for these Māori participants, collective survival and future continuity were important and linked to current efforts for cultural revitalization. Participants spoke of the damaging effects of land and language loss and how the current generation is engaging on an individual level to regain their culture via formal education. On a collective level, efforts to ensure Māori continuity have involved political unification and engagement with the New Zealand government ${ }^{35}$.

\footnotetext{
${ }^{35}$ Some concerns were expressed that increased migration of other ethnic minorities could reduce their status as indigenous peoples.
} 


\section{Chinese perspectives on endurance and discontinuity}

The following extract illustrates how collective continuity is really a non-issue for Chinese participants:

"M: There's so many Chinese people in the world ... I've never been concerned about the Chinese people in particular

S: I think there's too many \#laughter\#”

Thus, because the Chinese are not a 'small people', continuity is not a central concern. Indeed, due to the large Chinese population, participants conceded that they have no apprehension of collective dissolution through intermarriage: “There's so many Chinese people in the world ... it doesn't seem like they're in any danger of being phased out by marriage with other communities and so I'm not personally worried about that."

However, participants feel differently in terms of not taking for granted the endurance of the local community. They noted the importance of internal efforts of the Chinese community as well as the effects of unstable external factors like the political climate in New Zealand:

"R: I do tend to worry that the future generations might take it for granted and they might or they might not care so much? And it won't be so sustainable in the future \#agreement\#

S: Yeah I agree I think it's great now we have you know the celebrations, Chinese New Year and all that stuff but maybe in ten years it might not be as strong? I think it depends on how this generation passes it on to the next one 'cause I think it might still be strong as long as the opportunities to celebrate are encouraged?... As long as all the different cultures encourage them R: Yeah it depends on the time and place like if New Zealand becomes more conservative maybe they won't want to have (cultural) parades down town."

In general, these Chinese participants did not feel responsible for the continuity of the Chinese collective. They did, however, express an interest in preserving the Chinese heritage of the local community in New Zealand. 


\section{Emerging theoretical construct: Motivation for Ethno-cultural Continuity (MEC)}

Recall that endogamy is a motivated behaviour and that the aim of this qualitative study was to develop a construct that captures collective concerns for continuity at the individual level that can be used to predict endogamy. The three focus groups of young New Zealand Jews, Māori and Chinese addressed culture-specific and culture-general issues relating to ethnic heritage and the self, family and collective. The emerging theoretical construct, Motivation for Ethno-cultural Continuity, is composed of three related desires:

a) Maintenance: A desire to maintain one's ethno-cultural heritage;

b) Transmission: A desire to transmit one's ethno-cultural heritage to one's children;

c) Endurance: A desire to see one's ethno-cultural group endure as a collective.

A graphic representation of this construct is shown in Figure 4.2 below. Motivation for Ethno-Cultural Continuity (MEC) is defined as an individual's desire to maintain their ethno-cultural heritage (self-oriented), transmit it to their children (familyoriented) and ensure collective endurance (group-oriented). This construct will be developed into a quantitative measure in order to examine its role in predicting volitional endogamy and selective dating.

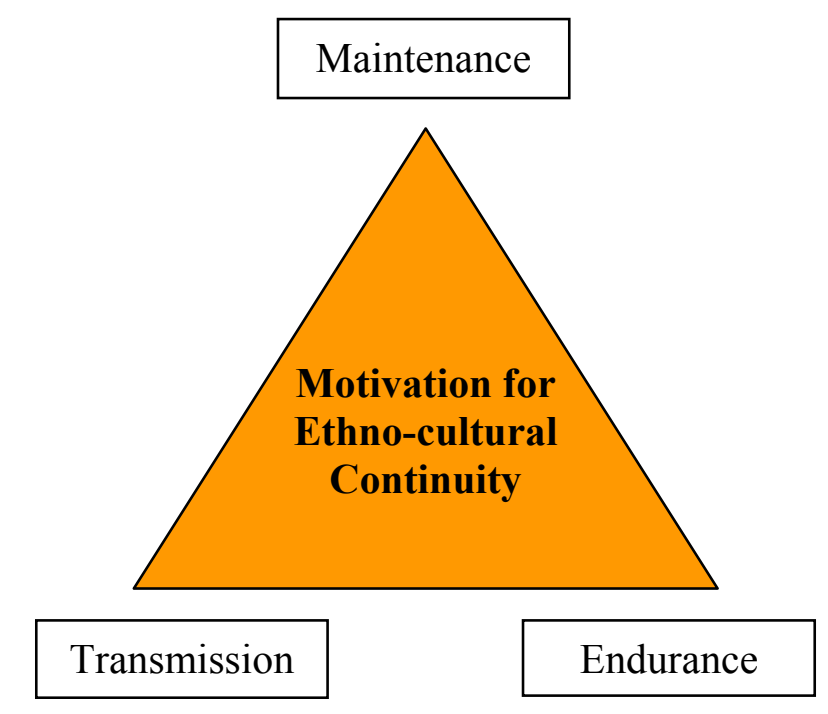

Figure 4.2: Motivation for Ethno-cultural Continuity 


\section{The meaning of ethnic history}

A further research aim of this qualitative study was to gain an understanding of individual awareness of social representations of ethnic history in order to develop quantitative measures that can be used to predict individual concerns for collective continuity.

\section{The purpose of ethnic history}

Jewish participants discussed how Jewish history provides them with a perception of collective continuity over time, and serves to situate their identity in a migrant society like New Zealand. Māori participants emphasised the difference between mainstream vs. Māori historical perspectives of Māori and New Zealand colonial history. Knowledge of history enables Māori to perceive breaks in continuity (comparing pre- and post-colonisation) and see how much work remains to ensure cultural revitalization. Both Jews and Māori discussed how knowledge of ethnic history increases ethnic pride and its importance for group endurance - for without history, there is nothing to transmit. Chinese participants did not have an intrinsic interest in general Chinese history; rather the history of local Chinese was more important. Both Chinese and Jews emphasised the importance of knowing family migration history.

\section{The importance of ethnic history for Jews}

Jewish participants discussed how knowledge of family Jewish history and general Jewish history is not only interesting, but provides meaning to life and is a temporal link between past and future generations: 
“C: It's important ... it's nice to know who you are and where you come from ... it just adds depth to the person

L: Yeah, you're also not just living your life for yourself but that you are living it because you're part of a line, and that line has been before you and is going to be in front of you and so ... you're part of something greater than yourself and that can give you meaning to your life \#agreement\# ...

S: Like having a family name, it's like a lineage that you carry on ... from generation to generation

B: I can't imagine caring if I didn't know anything, if I didn't know anything about my background I can't imagine why I would care about putting it forward or I wouldn't in a way have anything to put forward."

Thus, ethnic history provides the individual with a sense of transcendence, where the collective past and future are interconnected through oneself as a member of the Jewish people. In addition, knowledge of Jewish history leads to caring about transmitting one's heritage and moreover provides substance for transmission. Overall, social representations of ethnic history motivate individuals to ensure Jewish collective survival.

\section{The importance of ethnic history for Māori}

Māori participants discussed how knowing history from a Māori rather than mainstream (New Zealand European) perspective increases collective self-esteem:

“M: Basically people for years have said Māoris are dumb, Māoris are useless - and they come up with these stupid theories about how we came here on fishing drift boats, you know that we didn't have any navigation knowledge whatsoever- and rediscovering how we actually got here through Kupe and stories like that - and actually studying that ... And when (we) actually learn how (our) ancestors got here and how it's not an easy job to navigate and actually had knowledge of the stars and of the winds and of the tides and everything it actually gives us more confidence in ourselves ...

J: We're a fighting race." 
Learning about colonization, assimilation and the revitalization movement makes Māori appreciate the improvements in their culture today and also how much work needs to be done to improve the status of Māori in the larger New Zealand society. Note that tribal history was also valued by participants as a distinguishing feature between iwi.

\section{The importance of ethnic history for Chinese}

Chinese participants emphasised the importance of knowing about family history, as opposed to general Chinese history:

“R: Family history

D: Yeah family history is much more important than just the history of China or Chinese

Moderator: Why? \#silence\#

D: Because - as time goes by you're probably going to be the one person that everyone depends on about family history and then if you know nothing of it then you're pretty much screwed or just feel really embarrassed that you don't know? And as time goes by the whole thing will just collapse - the history of their family will be unknown

Moderator: What about your Chinese history, your ethnic group history?

D: It'll always be down in books whereas family history might be down in books but some families don't know about that and they just do it by mouth

Moderator: Ok, so is it important for you guys to read those books, to go out to make an effort to learn about Chinese history?

S: China - general Chinese history?

Moderator: Yeah

R: Each to their own."

Thus, knowledge of general Chinese history, relegated to history books, is left to individual interest. Participants do not discuss general Chinese history serving a greater purpose. 
However, participants did consider New Zealand Chinese history to be of importance, to ground their identity as a New Zealand migrant:

"R: But I think Chinese coming to New Zealand, (their) history is ... more specific than general Chinese history (and) is quite important

Moderator: Ok, what's the difference?

M: I think it's more personal to New Zealand \#agreement\#

D: ... that's what I learn about more like (their) parents and grandparents (coming) out of the war - that's more important than (the history of) China

R: ... it probably sounds really stink [bad] but I don't really care that much about Chinese history as in all the Dynasties ... doesn't mean that much to me but (what does interest me is) where we came from as a New Zealander."

The general attitude towards ethnic history espoused by Chinese participants is as follows: “what's happened is past ... understand what's happened and know about it - but don't dwell on it." Thus, an awareness of ethnic history is important, but it lacks substantive personal or collective purpose.

By and large, while Chinese participants valued family and local Chinese history so that future generations know about their heritage (past-oriented), both Jewish and Māori participants placed particular value on ethnic history because it provides meaning to cultural transmission (future-oriented). 


\section{Historical narratives and subjects of significance}

Overall, participants from all three focus groups spoke of culture-specific events which can be distinguished according to three conceptually distinct narratives:

a) Narratives of integrity: These refer to historical or putative origins as a people and are related to positive feelings;

b) Narratives of suffering: These encompass historical accounts and collective memory of affliction, and are linked to negative feelings;

c) Narratives of survival: These include accounts of collective resilience and strength, and are related to positive feelings.

A summary of the historical narratives discussed is outlined in Table 4.2 below, followed by a more detailed description for each ethnic group.

Table 4.2: What ethno-historical narratives are remembered

\begin{tabular}{|c|c|c|c|}
\hline & Jews & Māori & Chinese \\
\hline $\begin{array}{l}\text { Narratives of } \\
\text { integrity }\end{array}$ & $\begin{array}{l}\text { - Exodus from Egypt } \\
\text { - Receiving the Ten } \\
\text { Commandments }\end{array}$ & $\begin{array}{l}\text { - Māori } \\
\text { discovery/migration } \\
\text { to New Zealand }\end{array}$ & $\begin{array}{l}\text { - Family historical } \\
\text { events }\end{array}$ \\
\hline $\begin{array}{l}\text { Narratives of } \\
\text { suffering }\end{array}$ & $\begin{array}{l}\text { - Holocaust/Shoah } \\
\text { - Destruction of the } \\
\text { Second Temple by the } \\
\text { Romans }\end{array}$ & $\begin{array}{l}\text { - Signing of the Treaty of } \\
\text { Waitangi }\end{array}$ & $\begin{array}{l}\text { - Poll Tax and } \\
\text { Immigration } \\
\text { restrictions in } \\
\text { New Zealand } \\
\text { - Cultural Revolution } \\
\text { in China }\end{array}$ \\
\hline $\begin{array}{l}\text { Narratives of } \\
\text { survival }\end{array}$ & $\begin{array}{l}\text { - } 1948 \text { Establishment of } \\
\text { the State of Israel } \\
\text { - } 1973 \text { Yom Kippur War } \\
\text { - } 1967 \text { Six Day War }\end{array}$ & $\begin{array}{l}\text { - } 1970 \text { 's Land } \\
\text { Occupations and } \\
\text { resistance-revitalization } \\
\text { movement }\end{array}$ & $\begin{array}{l}\text { - Poll Tax apology and } \\
\text { restitution package }\end{array}$ \\
\hline
\end{tabular}

\section{Jewish historical narratives}

The exodus from Egypt and receiving the Ten Commandments are narratives of integrity as they define the Jewish people as a collective. As such they are related to positive feelings. The Holocaust/Shoah is one of the more recent narratives of suffering at the collective and familial levels. Negative feelings are associated to affliction and loss. The destruction of the 
Second Temple by the Romans is a great narrative of both suffering and integrity as it defined Jews as a diaspora community over the last 2,000 years. It is related to negative yet more neutral feelings because of its distal nature. The establishment of the State of Israel in 1948, the Yom Kippur War in 1973 and the Six Day War in 1967 are all narratives of survival as they define Jews as resilient and independent. As such they are linked to positive feelings. It is interesting to note that some narratives may carry more weight than others, in particular narratives of struggle and suffering. As one participant noted: "Just the physical representation of Judaism makes it very simple to look at it in terms of a conflict you know; here is Judaism at conflict with everyone else." Interestingly, knowledge of the most recent and one of the largest events of Jewish suffering was taken for granted:

"R: I think for me personally it was finding out about the atrocities of the Holocaust and listening to personal accounts especially ... and finding out on a personal level how it affected us as a nation

B: Did anyone not write down the Holocaust? \#laughter\#

D: Good question

M: The answer is no

Moderator: How did it affect Jews as a nation?

M: One third (murdered)! One flippin third! \#silence\#

R: The will to persevere and rise from persecution."

The last passage outlines that narratives of suffering are powerful motivators for individuals to ensure collective continuity.

\section{Māori historical narratives}

The Māori discovery/migration to New Zealand is a narrative of integrity as it shaped Māori as a people. As such, positive feelings are linked to this event. The signing of the Treaty of Waitangi is a narrative of suffering and is linked to both negative feelings regarding colonization and positive feelings related to self-determination as the Treaty 
represents the defining document of inter-group relations in New Zealand. The 1970's Land Occupations and resistance-revitalization movement is a narrative of survival as it encompasses Māori reclamation of their cultural heritage. As these events precipitated cultural growth, they are linked to positive feelings.

\section{Chinese historical narratives}

Family historical events comprise narratives of integrity, and are intrinsically ethnic in content. Positive feelings are associated with learning about their origins as New Zealand Chinese. The Cultural Revolution in China was a collective event which was related to family suffering. It is linked to negative feelings related to the loss of family history and possessions. As narratives of suffering, the Poll Tax and immigration restrictions in New Zealand are related to negative feelings of the struggles and collective discrimination that early settlers experienced. Simultaneously, the 2004 Poll Tax apology and restitution package constitutes a narrative of survival for the Chinese community, and thus is linked to positive feelings.

\section{Subjects of remembrance in Jewish, Māori and Chinese history}

Taken as a whole, participants from all three focus groups discussed the meaning of historical narratives that related to three different subjects:

a) Family;

b) Local ethnic community (this encompasses the New Zealand Jewish community; the New Zealand Chinese community; and tribal history for Māori);

c) General ethnic community (this encompasses the international communities of Jews and Chinese, and the Māori collective). 


\section{Vicarious experience of ethnic history}

The manner in which different historical narratives were described by participants demonstrated a personalised, vicarious experience of ethnic history. This insight comes from noting the use of first person plural pronouns or third person pronouns. For instance, Jewish and Māori participants tended to use the word "we" when describing past collective experiences. Discussing the Six Day War which occurred forty years ago, one participant in the Jewish focus group said:

"There we were - we were not a victim we were somebody who came out of there against all the odds and defeated all these armies ... we just reached a zenith ... not only are we here but ... now we've built it up to a level where we were able to defend ourselves against anybody."

A personal, vicarious experience was also noted for a negative event; regarding reasons for the destruction of the Temples in Jerusalem two thousand years ago (some cited corruption within Judaism): “We were kind of asking for it." The vicarious experience of Jewish history is enhanced by the institutionalisation of commemorative rituals.

Similarly, these Māori participants spoke in a vicarious manner about the original Polynesian migrations to New Zealand eight hundred years ago:

"M: Kupe discovered Aotearoa and then went to tell his mates in the Islands

$\mathrm{J}$ : - See he got blown off course, found it and then - used the stars and got back and told $u s$ and then we all came."

In contrast, the language used by these Chinese participants was more impersonal "The struggles that they had to go through to make it in New Zealand." Thus, the struggles of the old Chinese settlers in New Zealand were not really experienced in a vicarious manner. 


\section{Emerging theoretical constructs: Individual awareness of social representations of ethnic history - WHO, WHAT, and HOW}

Jewish, Māori and Chinese social representations of ethnic history were discussed in the three focus groups. Because I am interested in understanding variation in individual awareness of social representations, it is necessary to develop constructs at the individuallevel. The structure that emerged from the conversations demonstrated that individual awareness of social representations of ethnic history is marked by distinct subjects of remembrance (WHO is remembered), ethno-historical consciousness (WHAT narratives are remembered), and a vicarious experience of ethnic history (HOW history is remembered), illustrated in Figure 4.3.

Firstly, subjects of remembrance (WHO) can be divided into three parts: family ethnic history, local ethnic group history - the history of one's ethnic group in the country of residence, and general ethnic group history - the history of one's ethnic group as a whole. Secondly, ethno-historical consciousness (WHAT) is a measure of cognitive awareness that encompasses three types of narratives: integrity, suffering, and survival. Thirdly, a vicarious remembrance of ethnic history (HOW) is a measure of affective remembrance. The three separate WHO, WHAT and HOW constructs capture an individual's awareness of social representations of ethnic history.

In the following chapter, these constructs will be developed into culture-general measurement scales and validated with existing constructs in order to investigate their role in predicting Motivation for Ethno-cultural Continuity. 


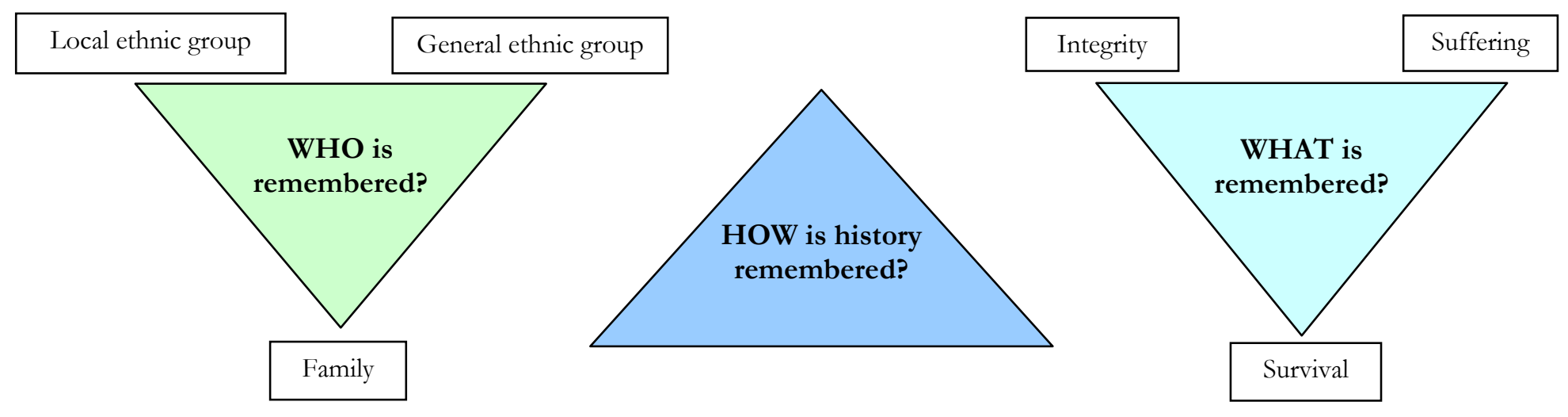

Figure 4.3: Individual awareness of social representations of ethnic history 


\section{Limitations}

The first limitation to be discussed is the issue of representative sampling, whereby participants were recruited from ethno-cultural organisations. On one hand, the views reported do not represent the whole spectrum of young ethno-cultural adults and in particular the unaffiliated; on the other hand, it was noted earlier in the chapter that affiliated individuals are precisely the people who would think about issues relating to continuity, ethnic history and endogamy. Thus, the discussions generated many useful concepts for the quantitative cross-cultural and cross-national research that follows in Chapters six and seven. Another limitation is that only one focus group was conducted per sample which also limits the generalisability of the results. However, the primary aim of the focus groups was to serve as a stepping-stone for quantitative research, constituting the first study of a sequential mixed-methods approach. In addition, researcher reflexivity as a minority-group member serving as both moderator and data coder should be noted. Although attention was given to coding culture-specific information in each focus group, the primary goal was to develop culture-general concepts and to construct 'derived-etic' measures. Next, Chapter five outlines the process of measurement development for the Motivation for Ethno-cultural Continuity (MEC), subjects of remembrance, ethno-historical consiousness, vicarious experience of ethnic history, endogamy and selective dating scales, and the examination of scale structure, reliability and validity in the pilot study. 


\section{CHAPTER 5: MEASUREMENT DEVELOPMENT AND VALIDATION}

\section{Development of measures}

\section{Theory on questionnaire development}

According to the sequential mixed-methods approach adopted in this thesis, the qualitative research described in the previous chapters was conducted not only out of an intrinsic interest in culture-specific conceptions of endogamy, continuity and ethnic history, but also for instrumental purposes - to construct quantitative derived-etic measures that will be used in survey-based studies to examine a predictive model of volitional endogamy for minority ethnic groups. While the small-scale nature of the focus groups served to gain a deep understanding of the issues at hand, the large-scale quantitative research that follows in Chapters five, six and seven with over 800 participants in total aims to generalize the motivations and behaviour of selected samples of ethno-cultural young adults to their broader population. In this regard, questionnaires are useful instruments as they can reach a large number of people. Participants provide answers to structured questions where fixed items are extrapolated as representatives of an underlying construct. Thus, questionnaire items will be developed to measure the constructs of Motivation for Ethno-Cultural Continuity (MEC) and individual awareness of social representations of ethnic history (WHO, WHAT, and HOW). In addition, items will also be developed to measure the two dependent variables, endogamy intentions and selective dating behaviour.

When developing measures, construct validity is important. This can be examined through face validity, and also through convergent and discriminant validity. Thus, the researcher forms a nomological network, "the network of positive, zero and negative relationships with other theoretical variables" (Fontaine, 2005, p. 805). When conducting 
cross-cultural research, it is also important to establish construct equivalence, which refers to the shared meaning of the construct in question across the cultural groups of interest (van de Vijver \& Leung, 1997). To this end, cultural decentering of an instrument is recommended which involves the simultaneous incorporation of various cultural perspectives. This is indeed the approach adopted in this thesis, as statements from the Jewish, Māori and Chinese focus groups were simultaneously selected for the development of scale items.

\section{Item generation}

Statements made by Jewish, Māori, and Chinese participants were extracted from the focus group data using NVivo software and compiled in a Word document for scale development. The sections below describe the process of item generation and then selection. For each construct it was noted how many statements were sourced from each ethno-cultural group. Although the natural statements given by participants usually combine several ideas, they were separated into distinct statements to avoid doublebarrelled items. Items were created that were both positively and negatively worded to avoid response acquiescence. Items were also made culture-general. This was achieved by selecting statements from all three focus groups, removing culture-specific information and inserting the words 'ethnic group' in their stead. Later on, relevant cultural nouns and adjectives, e.g. my Jewish/ Māori/ Chinese heritage, were reinserted for the samplespecific questionnaires. The process of selecting good items, modifying weak items, discarding poor items and in some cases creating new items was conducted with supervisor assistance by (a) examining face validity to see if items were applicable across all ethno-cultural groups, (b) item representativeness to see if items adequately represent the specified domains e.g. maintenance, transmission and endurance for the MEC scale, and (c) direction of item wording to achieve a balance between positively and negatively 
worded items. All developed scales were measured on a 7-point Likert scale from 1 (strongly disagree) to 7 (strongly agree).

\section{Motivation for Ethno-cultural Continuity}

Motivation for Ethnocultural Continuity (MEC) developed into a conceptual triad: maintenance is self-oriented, transmission is child and family-oriented, and endurance is ethnic group-oriented. The three domains were developed as subscales of the overarching MEC scale. Overall, initial item generation resulted in a pool of 72 statements with 25 sourced from the Jewish, 20 from the Māori, and 27 from the Chinese focus groups. According to the item selection criteria outlined in a, b and c above, the maintenance, transmission and endurance subscales were reduced to 10 items each to give a total of 30 items to be tested in the pilot study. The wording of items was balanced with 16 positive and 14 negative items; maintenance, transmission and endurance items were alternated (see Appendix D, Section 4).

\section{Subjects of remembrance: WHO}

WHO is remembered encompasses family, local ethnic history and general ethnic history. As such, three subscales were developed. Overall, initial item generation resulted in a pool of 65 statements with 24 sourced from the Jewish and 41 sourced from the Chinese focus groups. Explicit statements by Māori participants were scarce in this area. Using criteria outlined in a, b and c, the subscales were reduced to 6 items for the family, 4 items for the local ethnic group and 6 items for the general ethnic group to give a total of 16 items to be tested in the pilot study. The wording of items was balanced with 8 positive and 8 negative items; family, local and general ethnic history items were alternated (see Appendix D, Section 5). 


\section{Ethno-historical consciousness: WHAT}

WHAT is remembered encompasses narratives of ethnic integrity, suffering and survival. Content-specific material was considered in scale development e.g. asking Jewish participants about their historical consciousness related to the Exodus from Egypt, asking Māori participants about their historical consciousness related to the Great Polynesian migrations, and asking Chinese participants about their historical consciousness related to Chinese dynasties. The alternative was to construct culturegeneral measures of historical consciousness which would facilitate cross-cultural comparisons. The latter was chosen as the best strategy. This was achieved by deleting content-specific terms such as the Holocaust, Colonisation or the Chinese Poll Tax and reinserting words such as 'discrimination' and 'treated differently'. Furthermore, as this scale was designed to tap into a cognitive knowledge base (designated with the term 'consciousness'), phrases such as 'I know', 'I remember' and 'I am aware' were incorporated in sentence construction. Overall, initial item generation resulted in a pool of 84 statements with 38 sourced from the Jewish, 34 from the Māori, and 12 items from the Chinese focus group. According to criteria outlined in a, b and c, the subscales were reduced to 7 items for integrity, 8 for suffering and 7 for survival, to give a total of 22 items to be tested in the pilot study. The wording of items was balanced with 12 positive and 10 negative items; integrity, suffering and survival items were alternated (see Appendix D, Section 6). 


\section{Vicarious experience of ethnic history: HOW}

HOW history is remembered encompasses an affective remembrance or vicarious experience of ethnic history. Statements were drawn from all three focus groups that referred to a connection between the self and the experiences of their ethnic ancestors, providing a pool of 20 items of which 9 were sourced from Jewish, 8 from Māori, and 3 from Chinese participants. According to criteria outlined in a, b and c, the scale was reduced to a total of 7 items to be tested in the pilot study with four positively and three negatively worded items (see Appendix D, Section 7).

\section{Behavioural Intentions for Endogamy}

Different aspects of endogamy were discussed in the focus groups, encompassing a preference to engage in endogamy in the future, a rejection of endogamy, or an indifferent attitude. For the purposes of this research it was decided to develop a measure that taps into behavioural intentions for endogamy. An initial pool of 22 items were gathered that relate to a preference to engage in endogamy, of which 9 were sourced from Jewish, 12 from Māori and 1 from Chinese participants. Using criteria a, b and $\mathrm{c}$, the scale was reduced to a total of 4 items with 2 positive and 2 negatively-worded items (see Appendix D, Section 10a).

\section{Selective Dating Behaviour}

Different aspects of selective dating were discussed in the focus groups, encompassing a conscious choice to engage in selective dating, a decision not to date selectively, and indifference. For the purposes of this research it was decided to develop a measure that taps into actual dating behaviour. An initial pool of 25 items was gathered that related to engaging in selective dating behaviour, of which 14 were sourced from Jewish and 11 from Māori focus group participants. Explicit statements in this area were scarce for 
Chinese participants. According to criteria a, b and c, the scale was reduced to a total of 4 items with 2 positive and 2 negatively-worded items (see Appendix D, Section 10b).

\section{Pilot Study}

\section{Selection of validation constructs}

To develop a nomological network for Motivation for Ethno-cultural Continuity (MEC) and the measures of individual awareness of social representations of ethnic history WHO, WHAT and HOW and examine convergent validity (a positive relationship indicates conceptual relatedness) and discriminant validity (a lack of relationship indicates conceptual distinctiveness), four existing psychological measures were chosen for inclusion in the pilot study questionnaire: ${ }^{36}$

\section{Assimilation}

The assimilation scale provides a test of discriminant validity. It is hypothesised that assimilation will not have a significant relationship to MEC as Motivation for Ethnocultural Continuity does not simply measure the will to not assimilate, but expresses efforts to ensure cultural maintenance at the individual level, transmission at the family level and endurance at the group level. The assimilation subscale is from the Acculturation Attitudes scale that was used in the International Comparative Study of Ethno-cultural Youth (Berry, Phinney, Sam, \& Vedder, 2006). This subscale measures the acculturation strategy of assimilation across five domains: Cultural traditions, language, marriage, social activities and friends, on a 7-point scale from 1 (strongly disagree) to 7 (strongly agree). Since language competency is not perceived as an issue for the samples in this study, the language item was removed. While the marriage item

\footnotetext{
${ }^{36}$ The construct of ethnocentrism was excluded as a validation measure due to time constraints for participants and conceptual reasons given that ethnocentrism encompasses not only ingroup favouritism but also outgroup derogation, which according to the focus group discussions is not an inherent part of concerns for continuity and endogamy.
} 
overlaps with the behavioural intentions for endogamy, it was decided to include it conceptually at this stage ${ }^{37}$. Sample item: "I feel that Jewish people should adapt to Australian cultural traditions and not maintain those of their own." (see Appendix D, Section 2). Scale $\alpha=0.68$.

\section{Collective Self-Esteem}

This scale provides a test of convergent validity and is expected to correlate positively with MEC and WHO, WHAT and HOW as Motivation for Ethno-cultural Continuity and remembrance of ethnic history should go hand in hand with a positive valuing of ethnic group membership and hence Collective Self-Esteem. The private, public and identity subscales of the Collective Self-Esteem scale (Luhtanen, \& Crocker, 1992) were selected for this study to give a total of 12 items measured on a 1 (strongly disagree) to 7 (strongly agree) scale. Sample item: "In general, I'm glad to be a part of the Jewish people" (see Appendix D, Section 3). Scale $\alpha=0.66$.

\section{Perceived Collective Continuity}

This scale provides a test of convergent validity and is expected to correlate positively with MEC and WHO, WHAT and HOW as the perception of one's ethnic group as a continuous entity and the belief in the intergenerational transmission of cultural content should be directly linked to Motivation for Ethno-cultural Continuity and remembrance of ethnic history. Both subscales of the 12 -item Perceived Collective Continuity scale were used (Sani, \& Bowe, 2004): causal interconnectedness and norms transmission, measured on a 7-point scale from 1 (strongly disagree) to 7 (strongly agree). Sample item: "Jewish people have maintained their values across time" (see Appendix D, Section 8). Scale $\alpha=0.83$.

\footnotetext{
37This item was eventually dropped from analysis, leaving only 3 assimilation items relating to traditions, social activities and friends.
} 


\section{Perceived Group Entitativity}

This scale provides a test of convergent validity and is expected to correlate positively with MEC and WHO, WHAT and HOW as perceiving one's ethnic group as an entity should go hand in hand with Motivation for Ethno-cultural Continuity and remembrance of ethnic history. A 10-item scale was used (Castano, Sacchi, \& Gries, 2003), measured on a 7-point scale from 1 (strongly disagree) to 7 (strongly agree). Sample item: "Jews have many characteristics in common" (see Appendix D, Section 9). Scale $\alpha=0.82$.

\section{Participants and method}

As Jewish continuity is central to this thesis and comparisons are drawn with Māori and Chinese continuity, it was decided to test the scales on a sample of young, unmarried Jews only. Furthermore, this sample was collected from Sydney, Australia due to practical reasons: (a) the Jewish population in New Zealand is small and naïve participants were required for the main study; (b) I was attending a Jewish conference in Sydney during which data collection would be possible.

Ethical approval for this research was obtained from the Victoria University of Wellington School of Psychology Human Ethics Committee. The expected number of total participants was approximately 200-250, to enable examination of the psychometric properties of the scales given that a subjects-to-variables ratio of at least 5 is recommended for factor analysis (Bryant \& Yarnold, 1995). Overall, the number of participants was less than expected with a total of 152 Jews. Participants had the following characteristics in common: self-defined ethno-cultural identity as Jewish, Australian citizenship and single marital status. There were 94 females and 58 males. 95 percent had Jewish mothers and 93 percent had Jewish fathers. The mean age was 25.62 years. Of the participants, 77 percent had attended a Jewish community school for formal or informal education. 
Participation in the pilot study was through a voluntary and anonymous pen-andpaper survey as well as an online survey. Participants were told that the researcher wanted to learn about what young ethnic people think about the future continuity of their ethnic group, their ethnic history, and marrying a person from the same ethnic group in order to understand how ethnic communities endure over many generations. Data collection took place at the Limmud Oz conference in Sydney, Australia during July 2005. A few weeks later the questionnaire was distributed online through organisations in Sydney that included Limmud Oz, Hillel, Network and the Australasian Union of Jewish Students (AUJS). The incentive offered to participants was the chance to win an i-pod mini. After submitting the questionnaire another e-link invited participants to send their email address to a separate database for the draw to win an i-pod. In this manner, anonymity was ensured. Participants were advised of the outcome of the draw via email.

\section{Results}

The psychometric properties and the validity of the MEC, WHO, WHAT and HOW scales were examined, and Exploratory Factor Analyses (EFA) were conducted to examine the structure of the measures to see if the tripartite models that emerged in the three focus groups could be reproduced in the quantitative measures. The following sections describe the factor structure and process of measurement pruning for each new scale. Psychometric properties and correlations of the reduced scales with the validation measures are presented in Table 5.1 below. 
Table 5.1: Scale reliabilities and intercorrelations

\begin{tabular}{|c|c|c|c|c|c|c|c|}
\hline & & MEC & $\begin{array}{l}\text { WHO } \\
\text { Family } \\
\text { history }\end{array}$ & $\begin{array}{l}\text { WHO } \\
\text { Local } \\
\text { history }\end{array}$ & $\begin{array}{l}\text { WHO } \\
\text { General } \\
\text { history }\end{array}$ & WHAT & HOW \\
\hline $\mathrm{N}$ items & & 18 & 4 & 4 & 4 & 12 & 6 \\
\hline Reliabilities & & 0.95 & 0.86 & 0.79 & 0.79 & 0.88 & 0.78 \\
\hline \multirow[t]{3}{*}{$\begin{array}{l}\text { Validation } \\
\text { scales }\end{array}$} & $\begin{array}{l}\text { Collective } \\
\text { Self-Esteem }\end{array}$ & $0.67 * *$ & $0.21^{* *}$ & $0.18^{*}$ & $0.20 *$ & $0.34 * *$ & $0.46^{* *}$ \\
\hline & $\begin{array}{l}\text { Perceived } \\
\text { Collective } \\
\text { Continuity }\end{array}$ & $0.54 * *$ & - & $0.18^{*}$ & - & $0.38^{* *}$ & $0.37 * *$ \\
\hline & $\begin{array}{l}\text { Perceived } \\
\text { Group } \\
\text { Entitativity } \\
\text { Assimilation }\end{array}$ & $0.32 * *$ & - & - & - & $0.16^{*}$ & $0.28^{* *}$ \\
\hline
\end{tabular}

\section{Motivation for Ethno-cultural Continuity (MEC) scale}

Using SPSS an Exploratory Factor Analysis was conducted with the original 30 items using maximum likelihood estimation with oblique rotation ${ }^{38}$ to determine whether the factor structure was consistent with the qualitative research conducted earlier. The three factor solution was not a good fit as items did not load in a coherent manner across the three components and there was no clear elbow in the scree plot. Furthermore, component 1 had a very large eigenvalue of 15.07, while components 2 and 3 had very small eigenvalues (1.54 and 1.31 respectively). This indicates that a unifactorial model may in fact best represent the construct of MEC. A single-factor solution explained 48.66 percent of the variance, with all items loading strongly. Table 5.2 presents the factor loadings. [Note items constructed for the three conceptual domains: maintenance: $1,4,7$, 10, 13, 16, 19, 25, $27 \& 29$; transmission: 2, 6, 9, 11, 14, 18, 20, 24, $26 \& 28$; and endurance: $3,5,8,12,15,17,21,22,23 \& 30$.]

\footnotetext{
38 The three factors were conceptually related.
} 
Table 5.2: MEC item loadings, 1-factor structure MLE (6 iterations)

MEC 1: I would like to keep on living according to the traditions of my Jewish heritage

MEC 2: It is important for me to pass on my Jewish heritage to my children

MEC 3: The endurance of Jewish people is NOT really important to me*

MEC 4: Maintaining my Jewish traditions and language is NOT important to me*

MEC 5: The long-term preservation of Jewish heritage is important

MEC 6: The Jewish identity of my children does NOT really matter*

MEC 7: I think it's important to preserve my Jewish traditions

MEC 8: I want to keep Jewish culture alive

MEC 9: Ultimately I would like my children to identify as Jews

MEC 10: Maintaining my Jewish heritage is NOT something I care about*

MEC 11: I would like to encourage my children to learn Hebrew

MEC 12: The future continuity of our Jewish community is NOT a concern of mine*

MEC 13: Continuing to practice my Jewish traditions and celebrations is important to me

MEC 14: I will NOT force my children to identify with my Jewish heritage*

MEC 15:Long-term, I would like my grandchildren and great grandchildren to continue our Jewish heritage

MEC 16: My Jewish heritage and traditions are something I can easily disregard*

MEC 17: I want to ensure the future of our Jewish heritage

MEC 18: I would like to teach Jewish values to my children

MEC 19: Maintaining my Jewish heritage is something I value

MEC 20: It does NOT matter if my children don't identify with their Jewish heritage*

MEC 21: The endurance of Jewish people does NOT really matter*

MEC 22: I am worried that our Jewish heritage won't be sustainable in the future

MEC 23: I do NOT give much through to Jewish continuity*

MEC 24: I want to transmit to my children a love for and interest in their Jewish heritage

MEC 25: I do NOT mind setting aside the traditions of my Jewish heritage*

MEC 26: I do NOT care if my children are unaware of Jewish traditions and values*

MEC 27: It does NOT matter to me if I don't keep my Jewish traditions and values*

MEC 28: I think it's good to create an environment at home where my Jewish traditions can be a normal part of life for my children

MEC 29: I do NOT want to lose my Jewish heritage and values

MEC 30: I do NOT really care about ensuring the future of Jewish people*

\footnotetext{
* Reverse-scored items. Factor loadings in bold indicate selected items.
} 
Next, the pruning of the measure was conducted by examining both the alphas (reliability analysis) and betas (factor analysis; items with loadings less than 0.3 were omitted). Items which had (a) a low item-total correlation (b) those that had a narrow range of responses (c) those that did not load strongly on the latent variable (in general, items with a beta below 0.4), and those deemed redundant whereby another item with similar wording faired better in criteria a, b and c were removed. Overall, the original 30 item measure was reduced to 18 items with 6 items representing each of the three conceptual domains, although the structure was indeed unifactorial. Sample item: "I want to ensure the future of our Jewish heritage." As seen in Table 5.1 above, the scale exhibited excellent reliability and convergent validity with Collective Self-Esteem, Perceived Collective Continuity and Perceived Group Entitativity. Also as expected, no significant correlation was found between MEC and Assimilation, providing evidence for discriminant validity. Thus, Motivation for Ethno-cultural Continuity is not simply the will to not assimilate; rather it affords cross-cultural psychologists with a new construct relating to long-term acculturation that simultaneously encompasses a desire to maintain one's culture, transmit it to one's children, and see one's ethnic group endure.

\section{Subjects of remembrance - WHO scale}

An Exploratory Factor Analysis was conducted with the original 16 items using maximum likelihood estimation with oblique rotation. The three factor solution explained a total of 55.01 percent of the variance, with component 1 (family history) contributing 35 percent, component 2 (local ethnic history) contributing 10.65 percent and component 3 (general ethnic history) contributing 9.30 percent. The scree plot elbow concurred. This 3-factor structure will be tested again in the cross-cultural study using Confirmatory Factor Analysis. According to the criteria specified in a, b, c and d above, the original 16-item scale was reduced to 12 items with 4 items in each subscale. 
See Table 5.3 for the factor loadings. Sample item: "I have stories about my family's experiences related to being Jewish.” As expected, the WHO family history, local history, and general history subscales exhibited excellent reliability and convergent validity with Collective Self-Esteem (see Table 5.1). Convergent validity with Perceived Collective Continuity was evident only with the local history scale. Contrary to what was expected, no significant correlations were found with Perceived Group Entitativity. Overall, these results demonstrate that subjects of remembrance - whether they be family, local, or general history - are not related to perceptions of collective continuity and group entitativity. 
Table 5.3: WHO item loadings, 3-factor structure MLE with oblique rotation (6 iterations)

\begin{tabular}{|c|c|c|c|}
\hline & $\begin{array}{l}1 \\
\text { Family } \\
\text { history }\end{array}$ & $\begin{array}{c}2 \\
\text { Local } \\
\text { history }\end{array}$ & $\begin{array}{c}3 \\
\text { General } \\
\text { history }\end{array}$ \\
\hline $\begin{array}{l}\text { WHO 1: I remember stories about things that } \\
\text { happened to my family because they were } \\
\text { Jewish }\end{array}$ & 0.43 & - & - \\
\hline $\begin{array}{l}\text { WHO 4: I do NOT know much about my family's } \\
\text { Jewish background* }\end{array}$ & 0.86 & - & - \\
\hline $\begin{array}{l}\text { WHO 8: The part of Jewish history I am aware of is } \\
\text { personal, family history }\end{array}$ & - & - & - \\
\hline $\begin{array}{l}\text { WHO 9: I do NOT have many stories about my } \\
\text { family's experiences related to being Jewish* }\end{array}$ & 0.73 & - & - \\
\hline $\begin{array}{l}\text { WHO 11: The Jewish roots of my family are } \\
\text { something I do NOT know much about* }\end{array}$ & 0.91 & - & - \\
\hline $\begin{array}{l}\text { WHO 14: I know what Jewish life was like for my } \\
\text { family back in their home towns }\end{array}$ & 0.59 & - & - \\
\hline $\begin{array}{l}\text { WHO 2: I am NOT really aware of the experiences } \\
\text { faced by Jews in this country* }\end{array}$ & - & 0.47 & - \\
\hline $\begin{array}{l}\text { WHO 5: I am aware of the history of Jewish people } \\
\text { here, in the country where I live }\end{array}$ & - & 0.83 & - \\
\hline $\begin{array}{l}\text { WHO 10: I know about the experiences of the first } \\
\text { Jewish immigrants to this country }\end{array}$ & - & 0.69 & - \\
\hline $\begin{array}{l}\text { WHO 13: I do NOT know much about the local } \\
\text { history of Jewish people* }\end{array}$ & - & 0.75 & - \\
\hline $\begin{array}{l}\text { WHO 3: I know about the history of Jewish people } \\
\text { in our ancestral land }\end{array}$ & - & - & 0.51 \\
\hline $\begin{array}{l}\text { WHO 6: I have NOT really been told much about our } \\
\text { Jewish history* }\end{array}$ & - & - & 0.47 \\
\hline WHO 7: I celebrate my Jewish history & - & - & 0.33 \\
\hline $\begin{array}{l}\text { WHO 12: The broad history of Jews is something } \\
\text { that I do NOT know much about* }\end{array}$ & - & - & 0.71 \\
\hline WHO 15: I am NOT familiar with Jewish history* & - & - & 0.67 \\
\hline $\begin{array}{l}\text { WHO 16: I remember the general history of Jewish } \\
\text { people }\end{array}$ & - & - & 0.75 \\
\hline
\end{tabular}

$*$ Reverse-scored items. Items in bold indicate selected items. 


\section{Ethno-historical consciousness - WHAT scale}

An Exploratory Factor Analysis was conducted with the original 22 items using maximum likelihood estimation with oblique rotation. The 3-factor solution was not a good fit as items cross-loaded and there was no clear elbow in the scree plot. Thus a one factor solution explained a total of 33.41 percent of the variance. See Table 5.4 for the factor loadings. According to criteria a, b, c and d, the original 22 item scale was reduced to 12 items with 4 items in each conceptual domain, although the structure was unifactorial. Sample item: "I remember the injustices that have happened to Jews." As expected, the ethno-historical consciousness WHAT scale exhibited excellent reliability and convergent validity with Collective Self-Esteem, Perceived Collective Continuity and Perceived Group Entitativity (see Table 5.1). This means that the greater the remembrance of ethno-historical narratives, the greater the individual levels of Collective Self-Esteem, perceptions of collective continuity and group entitativity. 
Table 5.4: WHAT item loadings, 1-factor structure ${ }^{39}$ MLE (4 iterations)

WHAT 1: I know what historical events have defined Jews as a people

0.58

WHAT 2: I'm NOT really aware of Jewish people being treated differently by the larger society*

WHAT 3: I celebrate the points in history when Jews fought to maintain our culture

WHAT 4: I celebrate the historical achievements of Jewish people

0.71

WHAT 5: I know of the struggles that Jews have gone through

WHAT 6: Surviving is NOT really a defining part of Jewish history

WHAT 7: Discrimination against Jewish people is something I do NOT know much about*

WHAT 8: I have difficulty remembering basic historical events that shaped Jews as a people*

WHAT 9: I remember the injustices that have happened to Jews

WHAT 10: I can't remember hardships that Jewish people went through

WHAT 11: I do NOT know which events in history gave Jews a common identity*

WHAT 12: I appreciate the historical survival of Jews

WHAT 13: I remember the founding fathers and mothers of Jewish traditions

WHAT 14: The survival of Jewish people throughout history is NOT something I remember much about*

WHAT 15: I remember times when Jews have persevered and risen strong

WHAT 16: I do NOT know much about the cultural heroes of Jewish tradition*

WHAT 17: I believe that Jewish people suffer today from what happened in the past

WHAT 18: The founding experiences of Jews are NOT something I remember

WHAT 19: I'm NOT aware of Jewish people showing resistance to the larger society

WHAT 20: I remember the challenges faced by Jewish people throughout history

WHAT 21: I celebrate events in history where Jews have demonstrated resistance to forces from the larger society

WHAT 22: I remember how Jews have been discriminated against by the larger society throughout history

* Reverse-scored items. Items in bold indicate selected items.

\footnotetext{
${ }^{39}$ Items constructed for three conceptual domains: integrity: 1, 4, 8, 11, 13, 16, 18; suffering: $2,5,7,9,10,17,20,22$; and survival: $3,6,12,14,15,19,21$.
} 


\section{Vicarious experience of ethnic history - HOW scale}

An Exploratory Factor Analysis was conducted where the original 7 items were subjected to a Principal Components Analysis. The 1-factor solution explained a total of 42.83 percent of the variance, with item 3 removed as this did not significantly load on the factor. See Table 5.5 for the factor loadings. Sample item: "I can imagine being a part of the journeys my Jewish ancestors made." As expected, the HOW scale exhibited good reliability and convergent validity with Collective Self-Esteem, Perceived Collective Continuity, and Perceived Group Entitativity (see Table 5.1). This means that the more individuals experience ethnic history vicariously, the greater their Collective Self-Esteem, perceptions of collective continuity and group entitativity.

Table 5.5: HOW item loadings, 1-factor structure PCA (4 iterations)

\begin{tabular}{|c|c|}
\hline $\begin{array}{l}\text { HOW 1: I can imagine being apart of the journeys my Jewish ancestors } \\
\text { made }\end{array}$ & 0.63 \\
\hline $\begin{array}{l}\text { HOW 2: I do NOT have emotional connections to the struggles that } \\
\text { Jewish people have gone through* }\end{array}$ & 0.66 \\
\hline $\begin{array}{l}\text { HOW 3: I feel anger and frustration when I think of all the injustices and } \\
\text { discrimination experienced by Jews }\end{array}$ & - \\
\hline $\begin{array}{l}\text { HOW 4: When I look back in history to Jewish ancestors, I do feel that I } \\
\text { am a part of something great }\end{array}$ & 0.70 \\
\hline $\begin{array}{l}\text { HOW 5: It's hard for me to feel linked to the experiences of my Jewish } \\
\text { ancestors* }\end{array}$ & 0.75 \\
\hline $\begin{array}{l}\text { HOW 6: The historical achievements of Jewish people have little to do } \\
\text { with me on a personal level* }\end{array}$ & 0.77 \\
\hline $\begin{array}{l}\text { HOW 7: I feel proud when I learn about the struggles and battles of our } \\
\text { Jewish ancestors to keep our heritage alive }\end{array}$ & 0.67 \\
\hline
\end{tabular}

The intercorrelations of all the new scales are presented below in Table 5.6. The first column demonstrates that MEC is moderately positively correlated to the WHO (family, local, general), WHAT and HOW scales. Thus, concerns for collective continuity are positively related to individual awareness of social representations of ethnic history. 
The WHO, WHAT and HOW scales are also moderately positively correlated, demonstrating that subjects of remembrance, historical narratives and vicarious experience of ethnic history go hand in hand. Note that general Jewish history has a stronger correlation with remembrance of historical narratives, a pattern that corresponds to the ethnographic material presented in Chapter three on Jewish history and memory.

Table 5.6: Intercorrelations of MEC, WHO, WHAT and HOW scales

\begin{tabular}{lcccccc}
\hline & MEC & WHO & WHO & WHO & WHAT \\
& & Family & Local & General & \\
& & history & history & history & \\
\hline MEC & - & - & - & - & - \\
WHO Family history & $0.24^{* *}$ & - & - & - & - \\
WHO Local history & - & $0.40^{* *}$ & - & - & - \\
WHO General history & $0.35^{* *}$ & $0.42^{* *}$ & $0.38^{* *}$ & - & - \\
WHAT & $0.57^{* *}$ & $0.38^{* *}$ & $0.41^{* *}$ & $0.62^{* *}$ & - \\
HOW & $0.55^{* *}$ & $0.31^{* *}$ & $0.21^{*}$ & $0.26^{* *}$ & $0.55^{* *}$ \\
\hline
\end{tabular}

\section{Behavioural intentions for endogamy and selective dating behaviour}

The 4-item endogamy scale exhibited good reliability $(\alpha=0.85)$. Sample item: "I intend to marry someone who is Jewish." The 4-item dating scale also exhibited good reliability $(\alpha=0.85)$. Sample item: "I only date people who are Jewish." The validity of these two measures is evident in that intentions for endogamy and selective dating behaviour were significantly and positively correlated $\left(\mathrm{r}=.73^{* *}\right)$. 


\section{Discussion and Limitations}

The structure, reliability and validity of four original constructs were examined. Although Motivation for Ethno-cultural Continuity (MEC) was conceptually developed as a construct composed of three distinct domains (maintenance, transmission and endurance), it is in fact a unidimensional measure which has excellent reliability, convergent validity with Collective Self-Esteem, Perceived Collective Continuity and Perceived Group Entitativity, and discriminant validity with Assimilation. Thus, although participants in the focus groups spoke about wanting to maintain their culture, transmit it to their children and see their collective endure, these three domains are so closely interconnected that they function as a unified whole.

Subjects of remembrance, measured by the WHO scale, was conceptually developed as a 3-factor scale and was substantiated by the exploratory factor analysis. The subscales are reliable and convergent validity was obtained for all scales with Collective Self-Esteem and Perceived Collective Continuity for the local ethnic group subscale only. Ethno-historical consciousness is a cognitive measure that encompasses the remembrance of three types of narratives (integrity, suffering and survival). Its structure, however is unidimensional, with excellent reliability and convergent validity with Collective Self-Esteem, Perceived Collective Continuity and Perceived Group Entitativity. Thus, although participants in the focus groups discussed three conceptually distinct narratives, individual remembrance of these narratives is closely interrelated. Vicarious experience of ethnic history is measured by the HOW scale; as an affective measure it is a unidimensional construct that also demonstrates good reliability and convergent validity with the above measures. 
Overall, the total number of items in these four original and valid scales were reduced in order to (a) ensure concise and user-friendly measures that (b) will be used as independent variables in a predictive model of endogamy across three cultures in the same larger society (Chapter six) and within the same culture in four different communities (Chapter seven).

Limitations of the pilot study stem from the use of a solely Jewish sample to test scale validity and factor structure. As such, confirmatory factor analyses will be conducted with Māori and Chinese samples. However, given that all scales were 'derivedetic' measures i.e. developed from the three focus groups, it is probable that the factor structure will be equivalent across cultures. A further limitation is the sampling of highly identified participants from ethno-cultural organisations. Perhaps the distinct conceptual domains would not be as highly interrelated had unaffiliated individuals been sampled.

Next, Chapter six examines (a) the psychometric properties and structural equivalence of these scales across three cultures (b) mean group differences (c) the ability of Motivation for Ethno-cultural Continuity to predict intentions for endogamy above and beyond similarity, attraction, and social network approval, and (d) the ability of the cognitive and affective measures of individual awareness of social representations of ethnic history, WHAT and HOW to predict Motivation for Ethno-cultural Continuity. 


\section{Chapter 6: A Cross-cultural Comparison of ETHNO-CULTURAL CONTINUITY}

\section{Testing a predictive model for volitional endogamy across Jews, Māori and Chinese in New Zealand}

Chapter one presented ethno-cultural continuity as an acculturation goal for diaspora and indigenous peoples. The dynamics of continuity were outlined in Chapter two, whereby cultural transmission was noted to be the key mechanism, and parental homogeneity i.e. endogamy was emphasised as a transmission belt. Thus far, research on the factors that predict endogamy and its prelude, selective dating, has been conducted from an ethnocentric perspective and focused on group-level structural variables such as national policies, sex ratio and residential segregation; and individual-level variables such as ethnic identity, similarity, attraction, and social network approval. A new integrative framework was proposed (see Figure 2.1) whereby group-level and individual-level variables were posited to indirectly predict intentions for endogamy, mediated by individual concerns for collective continuity. Furthermore, it was purported that individual awareness of social representations of ethnic history shapes concerns for collective continuity. A revised model to be tested that includes only individual-level psychological variables is presented in Figure 6.1. Based on the qualitative research in Chapter four and the quantitative pilot study in Chapter five, the newly constructed measure of Motivation for Ethno-Cultural Continuity is included as a predictor of behavioural intentions for endogamy, and the new measures of ethno-historical consciousness and vicarious experience of ethnic history are included as predictors of Motivation for Ethno-cultural Continuity. 


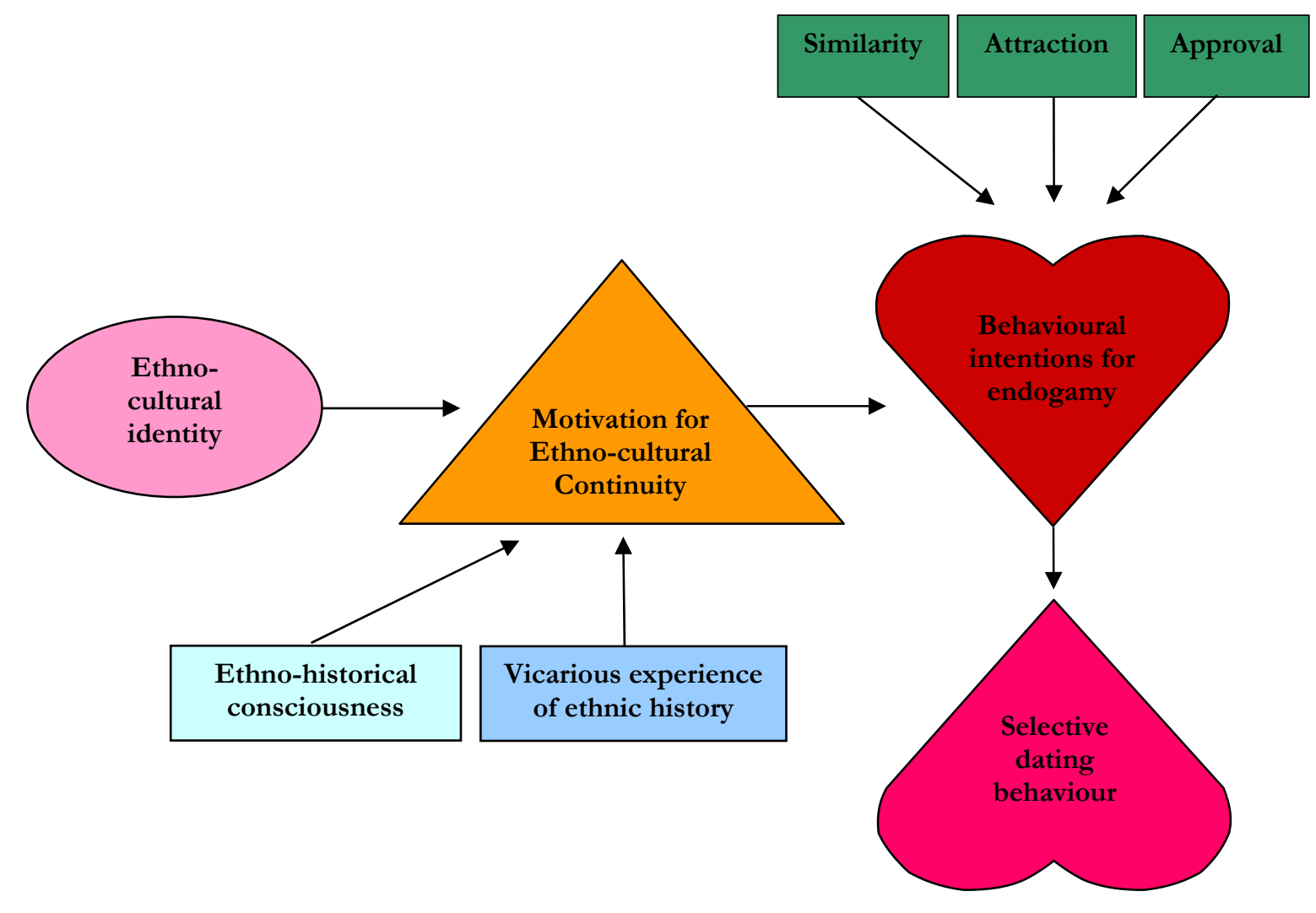

Figure 6.1: An individual-level predictive model for volitional endogamy 
Recall that Jews and Māori are 'small peoples' that have experienced existential uncertainty in the process of long-term acculturation, as discussed in Chapter three. Ethno-cultural continuity in these two groups has not been taken for granted. In contrast, Chinese are the antithesis of 'small peoples'; Han Chinese represent the largest ethno-cultural group in the world with a population size of over one billion people. Although ethno-cultural continuity is not of central concern, local expressions of Chineseness are. While Jews have emphasised ethnic endogamy as a mechanism for cultural transmission over 2,000 years of diaspora life, Māori have relied on inter-group strategies and the Treaty of Waitangi as a founding document that ensures their protection (and partnership) as the indigenous people of New Zealand. As for the power of memory to anchor collectives in the past and provide impetus for the future, this extends to all ethno-cultural groups. However, Jews have been particularly adept at detemporalising the past through the institutionalisation of rituals to commemorate historical events. With this in mind, several hypotheses can be formulated before conducting a quantitative comparison of ethno-cultural continuity among Jews, Māori and Chinese today.

\section{Research questions and hypotheses}

1. Do levels of Motivation for Ethno-cultural Continuity (MEC) and individual awareness of social representations of ethnic history differ across cultures?

It is hypothesized that Jewish and Māori participants will have greater levels of MEC than Chinese participants. It is also hypothesized that Jewish participants will have a greater awareness of social representations of ethnic history and significantly higher levels of WHO, WHAT and HOW than Māori and Chinese participants. 
2. Do intentions for endogamy and selective dating behaviour vary across cultures? It is hypothesized that Jewish participants will exhibit higher levels of both endogamy intentions and selective dating behaviour than Māori and Chinese participants.

3. Does Motivation for Ethno-cultural Continuity predict intentions for endogamy above and beyond similarity, attraction and social network approval?

It is hypothesized that MEC predicts intentions for endogamy above and beyond similarity, attraction and social network approval for Jewish and Māori participants. In contrast, it is hypothesized that MEC is not a significant predictor of endogamy above and beyond the ethnocentric variables for Chinese participants.

4. What is the function of Motivation for Ethno-cultural Continuity?

It is hypothesized that MEC mediates the relationship between individuallevel variables such as ethno-cultural identity, and intentions for endogamy.

5. Does individual awareness of social representations of ethnic history predict Motivation for Ethno-cultural Continuity above and beyond ethno-cultural identity? It is hypothesized that greater levels of ethno-historical consciousness (WHAT) and vicarious experience of ethnic history (HOW) lead to greater levels of MEC, and that individual awareness of social representations of ethnic history contribute to explaining the variance in MEC above that explained by ethno-cultural identity.

6. What is the strongest predictor of selective dating behaviour?

It is hypothesized that behavioural intentions for endogamy are the strongest predictor of selective dating behaviour, above and beyond similarity, attraction and social network approval.

7. Are the relationships specified in the model generalisable across cultures?

It is hypothesized that the predictive model will function consistently across the Jewish and Māori samples and that some of the relationships specified in the model will be shared across all three samples. 


\section{Procedure}

Ethical approval for this research was obtained from the Victoria University of Wellington School of Psychology Human Ethics Committee. Participation in the study was through a voluntary and anonymous online survey. Participants from all three ethnic groups were recruited from young adult ethno-cultural organisations and tertiary institutions in New Zealand cities in the North Island that have reasonably large concentrations of each ethnic group. Jewish participants were obtained in Wellington and Auckland through JewNet, the Australasian Union of Jewish Students (AUJS) and B'nei Brith Young Adults (BBYA). The Māori participants were obtained in Wellington and Gisborne through the School of Māori Studies at Victoria University of Wellington and the Māori Students' Association Ngai Tauira, the Whitirea Polytechnic Students' Association, Massey University of Wellington Māori Students’ Association Te Atawhai, Te Wānanga o Aotearoa Student Support and Tairawhiti Polytechnic in Gisborne. The Chinese participants were obtained in Wellington and Auckland through the Victoria University of Wellington Chinese Students' Association, the Wellington Chinese Sports and Cultural Centre and the Kiwi Asian Club at Auckland University. These organisations emailed their list of members and small A4 posters were placed on selected premises that invited individuals to complete an online questionnaire about their thoughts regarding the future continuity of their ethnic group, their ethnic history, and marrying a fellow ethnic group member; with the chance to win an ipod mini. After submitting the questionnaire an e-link invited participants to enter their contact details into a separate database for the ipod draw. As such, individual questionnaires and contact details could not be matched to ensure anonymity. Participants received an email notification of the draw results. 


\section{Participants}

The desired number of total participants was a minimum of 100 from each ethnic group as smaller samples are considered inadequate for structural equation modelling (Kline, 2005). All participants had the following characteristics in common: self-defined ethnocultural identity as Jewish, Māori or Chinese, New Zealand citizenship and single marital status. The number of participants, ethnic heritage, age, gender and generation are specified below in Table 6.1.

Table 6.1: Participant characteristics in the cross-cultural study

\begin{tabular}{|c|c|c|c|}
\hline & Jews & Māori & Chinese \\
\hline $\begin{array}{l}\text { Number of } \\
\text { completed surveys }\end{array}$ & 120 & 109 & 110 \\
\hline $\begin{array}{l}\text { Number of } \\
\text { participants in SEM } \\
\text { analyses }\end{array}$ & 106 & 103 & 102 \\
\hline $\begin{array}{l}\text { Number of } \\
\text { participants in } \\
\text { analyses of mean } \\
\text { group differences }\end{array}$ & 105 & 99 & 102 \\
\hline Ethnic heritage & $\begin{array}{l}88.6 \% \text { Jewish mother } \\
79 \% \text { Jewish father }\end{array}$ & $\begin{array}{l}\text { 81.8\% Māori mother } \\
69.7 \% \text { Māori father }\end{array}$ & $\begin{array}{l}96.1 \% \text { Chinese mother } \\
96.1 \% \text { Chinese father }\end{array}$ \\
\hline Age M (S.D.) & $23.7(4.44)$ & $26.37(5.39)$ & $24.55(4.78)$ \\
\hline Gender & $\begin{array}{l}61 \text { females } \\
44 \text { males }\end{array}$ & $\begin{array}{l}77 \text { females } \\
22 \text { males }\end{array}$ & $\begin{array}{l}51 \text { females } \\
51 \text { males }\end{array}$ \\
\hline First generation & $47(44.8 \%)$ & - & $22(21.6 \%)$ \\
\hline Second generation & $36(34.3 \%)$ & - & $39(38.2 \%)$ \\
\hline Third generation & $18(17.1 \%)$ & - & $40(39.2 \%)$ \\
\hline Fourth generation & $4(3.8 \%)$ & - & $1(1 \%)$ \\
\hline
\end{tabular}

Note that the final number of participants used in the analyses is lower than the number of people who actually completed the survey due to age restrictions and outliers. 
Looking at the ethnic heritage of participants, we can see that not all came from endogamous families. More Jewish participants had a Jewish mother than a Jewish father, with non-Jewish parents designated as another ethnic group/nationality, or Christian, Atheist or Agnostic. A similar pattern was observed for Māori participants; most nonMāori parents were Pākehā/New Zealand European, and a few were Pacific Islanders. In contrast, most Chinese participants have parents who were both Chinese, with nonChinese parents being either Asian, New Zealand European or from other ethnic groups/nationalities.

A one-way ANOVA revealed a significant difference in mean age between the three ethnic groups $\underline{\mathrm{F}}(2,303)=8.49, \underline{\mathrm{p}}<0.001$. A Tukey post-hoc test showed that the Māori sample was a few years older than the Jewish and Chinese samples. No difference in age was found between the latter two groups.

In terms of gender distribution, a chi-squared test revealed a significant relationship between ethnicity and gender $\mathrm{X}^{2}(2, \mathrm{n}=306)=17.33, \mathrm{p}<0.001$; while there were more females than males in the Jewish and Māori samples, the gender ratio was even for the Chinese sample. A chi-squared test also confirmed a significant relationship between ethnicity and generation $\mathrm{X}^{2}(2, \mathrm{n}=306)=19.28, \mathrm{p}<0.01$; the Jewish sample consisted of participants who were predominantly first and second generation New Zealanders, in contrast, the Chinese sample was comprised of an older community of predominantly second and third generation migrants ${ }^{40}$. As indigenous peoples, it is not meaningful to speak of generational differences among the Māori sample.

Concerning Jewish religious identification, 32 Jewish participants were Orthodox, 10 were Conservative, 37 were Reform, 12 were Cultural and 3 were Secular.

\footnotetext{
40 This sample of Chinese draws upon the older New Zealand community given that $75 \%$ of the Chinese population in New Zealand are first generation migrants.
} 
With regards to Māori identification, participants were asked to write down with which iwi they identify. Some individuals responded with the names of their hapu (extended family), some with names of their iwi (tribe) and yet others with the name of their waka (canoe, or superordinate confederation). Differentiation was made possible using the following websites: http://iwihapu.natlib.govt.nz/iwi-hapu/index.htm and www.teara.govt.nz, with participant origins spread out over the whole north island. Overall, 20 participants affiliated with the iwi of Ngāti Porou; 10 participants with the iwi Ngāti Kahungunu; 7 participants with the iwi Te Aitanga a Hauiti; and 6 participants respectively in the iwi Ngāi Tahu and Ngāi Tuhoe; the remaining 35 participants identified with 2 different hapū, 13 different iwi, and 3 different waka.

Concerning Chinese identification with specific groups of Chinese, 87 participants identified as New Zealand Chinese, 2 as Mainland Chinese, 4 as Taiwanese, 5 as Hong Kong Chinese, 2 as Malay Chinese, and 1 as Vietnamese Chinese.

\section{Materials: Questionnaire design}

The final questionnaire was composed of eight sections which measured (a) demographic information; (b) ethno-cultural identity; (c) awareness of social representations of ethnic history; (d) motivation for ethno-cultural continuity; (e) perceived similarity, attraction and social network approval; and ( $f$ ) intentions for endogamy and selective dating behaviour (see Appendix E).

The questionnaire was presented online and an opening paragraph explained the purpose of the study. Once all the required information had been completed on each page, participants were directed to the subsequent webpage. As such, there were no missing values. All scale responses were coded on 7-point Likert scales with scores ranging from 1 (strongly disagree) to 7 (strongly agree) unless otherwise specified. Negatively-worded items were reverse-scored prior to calculating means. Item wording 
was identical across all three ethno-cultural groups except for the noun or adjective referring to the particular group.

\section{Demographic information}

The demographic items assessed for all three ethnic groups include: citizenship, ethnicity of mother and father, age, gender, and generation (this was calculated by asking the birthplace of the participant, their parents and grandparents). Demographic items specific to Jews include identification with a specific Jewish denomination; items specific to Māori include identification with particular iwi (tribe(s)); Items specific to Chinese include identification with a particular Chinese group (see participant characteristics above in Table 6.1).

\section{Ethno-cultural identity}

The strength of an individual's ethno-cultural identity was measured using Cameron's (2004) 3-factor scale of social identity. Of six items from each subscale (in-group ties, centrality and affect), only the first four items were used in this study to give a total of 12 items. An example item from the affect subscale is "In general, I'm glad to be J/M/C." As Cameron found moderate positive correlations between the subscales and the overall strength of ethno-cultural identity is of central concern in this study (rather than scores on each of the three subscales), responses on all twelve items were averaged to give a mean score for Jewish, Māori and Chinese identity. High scores represent strong ethnocultural identification (see Appendix E, Section 2). 


\section{Individual awareness of social representations of ethnic history: WHO, WHAT, HOW}

The 3-factor WHO scale finalised in the pilot study was composed of 12 items, with four items representing each subscale (family, local and general ethnic history). An example item from the local subscale is "I know about the experiences of the first $\mathrm{J} / \mathrm{M} / \mathrm{C}$ immigrants to this country." As the 3-factor structure of WHO is still under investigation, confirmatory factor analyses will be conducted across the three ethnocultural samples. High scores represent greater remembrance of ethnic history relating to that particular subject (see Appendix E, Section 3).

The unifactorial WHAT scale finalised in the pilot study was composed of 12 items, with four items representing each conceptual domain (narratives of ethnic integrity, suffering and survival). An example item from the suffering domain is "I remember the injustices that have happened to $\mathrm{J} / \mathrm{M} / \mathrm{C}$." Items were averaged to give a mean score for ethno-historical consciousness, whereby high scores represent greater cognitive remembrance (see Appendix E, Section 4).

The unifactorial HOW scale measures a vicarious experience of ethno-cultural history. Although the scale was reduced to 6 items in the pilot study, all original 7 items were included for testing across the three ethnic groups. An example item is "I can imagine being a part of the journeys my J/M/C ancestors made.” Items were averaged to give a mean score for an individual's vicarious experience of history whereby high scores represent greater affective remembrance (see Appendix E, Section 5). 


\section{Motivation for Ethno-cultural Continuity (MEC)}

The unifactorial MEC scale finalised in the pilot study analysis was composed of 18 items, six items representing each conceptual domain (maintenance, transmission and endurance). An example item from the transmission domain is "Ultimately, I would like my children to identify as J/M/C." Item responses were averaged to give a mean score for Jewish, Māori and Chinese Motivation for Ethno-cultural Continuity. High scores represent a strong motivation (see Appendix E, Section 6).

\section{Similarity, attraction and social network approval}

Perceived similarity of fellow ethnic group members, subjective attraction to fellow ethnic group members and social network approval of marriage within the same ethnic group was measured using items by Liu, Campbell and Condie (1995).

Three items assessed overall similarity to fellow ethnic group members, similarity in values and communications styles. Items were measured on a 7-point Likert scale with scores ranging from 1 (not at all similar) to 7 (very similar). An example item is "How similar overall do you feel to other $\mathrm{J} / \mathrm{M} / \mathrm{C}$ people?" Responses were averaged to give an overall scale score for perceived similarity where high scores indicate greater similarity among ethnic group members.

Three items assessed subjective attraction to fellow ethnic group members in terms of physical attraction, desirability as romantic partners and sex appeal. Items were measured on a 7-point Likert scale with scores ranging from 1 (not at all) to 7 (extremely). An example item is "How physically attractive do you think J/M/C people are?" Responses were averaged to give an overall scale score for attraction where high scores indicate greater attraction to fellow ethnic group members. 
Three items assessed social network approval of endogamy regarding participants' parents, friends, and friends and family of the prospective partner. Items were measured on a 7-point Likert scale with scores ranging from 1 (not at all happy) to 7 (extremely happy). An example item is "How do you think your parents would feel about your marrying someone who is $\mathrm{J} / \mathrm{M} / \mathrm{C}$ ?" Responses were averaged to give an overall scale score for social network approval where high scores indicate greater approval for endogamy (see Appendix E, Sections 7a-c).

\section{Intentions for endogamy and selective dating behaviour}

The intentions for endogamy scale finalised in the pilot study consisted of four questions. An example item is "I intend to marry someone who is $\mathrm{J} / \mathrm{M} / \mathrm{C}$." Responses were averaged to give an overall scale score for intentions for ethnic endogamy where high scores indicate stronger behavioural intentions to marry a fellow Jewish, Māori or Chinese person.

The selective dating scale finalised in the pilot study consisted of four questions. An example item is "I only date people who are J/M/C." Responses were averaged to give an overall scale score for selective dating behaviour where high scores are indicative of intra-ethnic dating (see Appendix E, Sections 8a \& b). 


\section{Results}

Analyses presented in this section are as follows: (a) psychometric properties of scales; (b) structural equivalence and item bias analysis of the Motivation for Ethno-cultural Continuity and WHO, WHAT and HOW scales; (c) mean group differences; and (d) testing the predictive model of endogamy across ethno-cultural groups.

\section{Scale psychometric properties}

Table 6.2 below presents the number of scale items, scale reliabilities, means and standard deviations for the raw scales across the Jewish, Māori and Chinese samples.

Table 6.2: Scale psychometric properties (cross-cultural comparison)

\begin{tabular}{lccccccc}
\hline & \multicolumn{3}{c}{ Jews } & \multicolumn{2}{l}{ Māori } & & Chinese \\
\hline & $\mathrm{N}$ items & $\alpha$ & $\mathrm{M}(\mathrm{S} . \mathrm{D})$. & $\alpha$ & $\mathrm{M}(\mathrm{S} . \mathrm{D})$. & $\alpha$ & $\mathrm{M}(\mathrm{S} . \mathrm{D})$. \\
Ethnic identity & 12 & 0.86 & $5.98(0.87)$ & 0.84 & $5.89(0.92)$ & 0.80 & $5.06(0.88)$ \\
WHO & 12 & 0.89 & $5.11(1.13)$ & 0.94 & $5.42(1.33)$ & 0.93 & $4.61(1.30)$ \\
WHAT & 12 & 0.88 & $6.04(0.88)$ & 0.92 & $5.66(1.25)$ & 0.86 & $4.11(1.11)$ \\
HOW & 7 & 0.81 & $5.46(1.08)$ & 0.82 & $5.71(1.14)$ & 0.84 & $4.22(1.23)$ \\
MEC & 18 & 0.94 & $6.24(0.86)$ & 0.94 & $6.40(0.78)$ & 0.95 & $5.49(1.07)$ \\
Similarity & 3 & 0.83 & $5.17(1.24)$ & 0.80 & $5.25(1.24)$ & 0.86 & $4.35(1.35)$ \\
Attraction & 3 & 0.91 & $4.95(1.32)$ & 0.88 & $5.92(1.14)$ & 0.92 & $4.50(1.37)$ \\
Approval & 3 & 0.74 & $5.70(1.13)$ & 0.86 & $5.76(1.23)$ & 0.68 & $5.53(0.89)$ \\
Endogamy & 4 & 0.87 & $4.68(1.77)$ & 0.74 & $3.97(1.56)$ & 0.82 & $3.66(1.52)$ \\
Dating & 4 & 0.67 & $3.03(1.61)$ & 0.57 & $3.68(1.52)$ & 0.78 & $3.22(1.61)$ \\
\hline
\end{tabular}




\section{Ethno-cultural identity, similarity, attraction and social network approval}

With regards to strength of ethno-cultural identity, the 12-item scale by Cameron (2004) demonstrated excellent reliability across all three ethnic groups. It is worth noting that overall, ethno-cultural identity among participants is rather high (above the scale midpoint of 4). This is likely due to the sampling methodology, whereby individuals were recruited from ethno-cultural organisations. As their membership is voluntary, it is likely that affiliated persons identify more strongly with their ethno-cultural group than nonaffiliated people. Thus, although the results of analyses conducted in this thesis characterize one strata of ethno-cultural group membership, they do not represent the whole spectrum of ethno-cultural identity - in particular the unaffiliated.

Reliabilities of the similarity and attraction scales are all high, and the reliability of the social network approval scale for Māori participants is just under the recommended alpha value of 0.70 .

\section{Testing scale structural equivalence across cultures}

Before meaningful comparisons of Motivation for Ethno-cultural Continuity (MEC) and individual awareness of social representations of ethnic history could be made across the three ethnic groups, it was important to examine the MEC, WHO, WHAT and HOW scales for structural equivalence and item bias. Note that item bias analysis depends on the factorial structure of each scale, whereby items are analysed for each subscale in multi-factorial scales. Furthermore, item bias analysis is only meaningful if the structure of the scale is equivalent across ethnic groups. Recall that while the MEC, WHO and WHAT scales were each constructed with three subscales, Exploratory Factor Analysis (EFA) conducted in the pilot study demonstrated that only WHO was adequately represented by a 3-factor model; MEC and WHAT were represented best by unifactorial models. Prior to conducting item bias analysis, the structural equivalence of each scale 
across ethnic groups was examined through multi-group Confirmatory Factor Analysis using Structural Equation Modelling with the AMOS version 6.0 statistical package. In addition, the 3-factor structure of the WHO scale was verified.

\section{Testing the structural equivalence of Motivation for Ethno-cultural Continuity}

The unifactorial structure was tested across all three ethnic groups simultaneously to check for structural equivalence (see Figure 6.2 below). It is important to consider the proportion of the sample size relative to the number of free parameters with an ideal ratio of 10:1; when sample size is small it is important that indicators have high factor loadings (Marsh \& Hau, 1999). In this case, the sample size of each ethnic group (approximately 100 participants) is small relative to the number of estimated parameters (one factor variance, 18 error variances and 17 free factor loadings, giving a total of 36 parameters). Thus, when conducting the CFA with all 18 items, good model fit is not expected with these small samples. However, if there is considerable similarity among items in the MEC scale, the option of item deletion can be exercised. This will (a) enable the development of concise, user-friendly scales (b) minimise the effects of "bloated specifics", constructs with items that overlap too much $^{41}$ (Cattell, 1961, cited in Little, Cunningham, Shahar \& Widaman, 2002) and (c) reduce the total number of estimated parameters and improve model fit by removing items with shared measurement error.

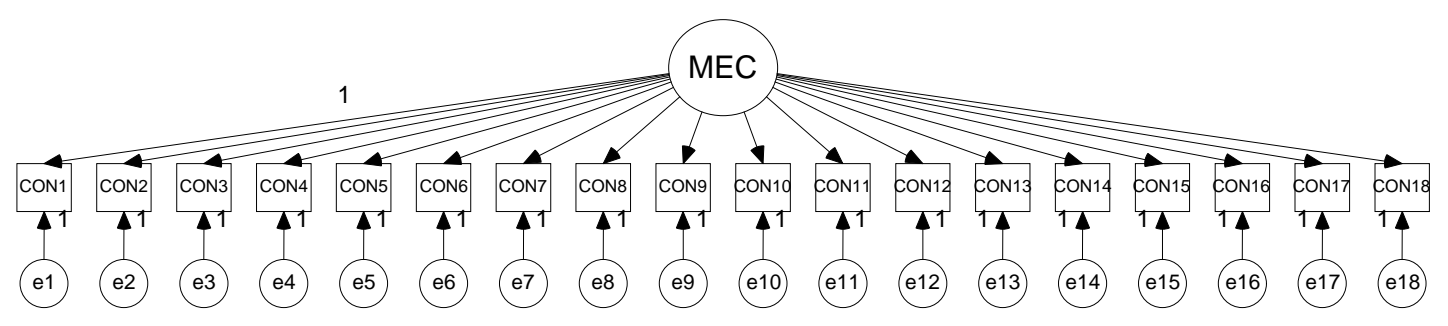

Figure 6.2: CFA of Motivation for Ethno-cultural Continuity (1-factor)

${ }^{41}$ Small sample size relative to the number of estimated parameters similarly occurs for the WHO and WHAT scales. Reducing the number of items improved model fit. 
The data were examined for normality. Kline (2005) notes that non-normal distributions are indicated by skew and kurtosis. Indices for both are provided by AMOS for all 18 items. In general, skew values larger than 3.0 and kurtosis values greater than 10.0 indicate a problem with normality, and kurtosis values exceeding 20.0 point to serious issues with the distribution of item responses. Overall, MEC items in all three ethnic groups demonstrated small negative values for skewness (responses tend to be above the mean). For the Jewish sample, item 12 was problematic with a skew value of -3.29 . In terms of kurtosis, higher values were found among items 12 (12.08) and 6 (10.65). No problem items were detected for the Māori and Chinese samples.

Before conducting the multi-group confirmatory factor analysis to test for structural equivalence, analyses were conducted for each sample separately. The specified models must show good fit in accordance with various indices which evaluate (a) the manner in which the observed covariance matrix is represented by the predicted matrix, (b) the comparative fit of the predicted model covariance matrix with one that assumes variable independence, and (c) model parsimony. Although McDonald \& Ho (2002) comment on the controversial nature of cut-off criteria for various fit indices and advise caution, the following are several key indices with their recommended criteria: The chisquared statistic evaluates criteria (a) and should be non-significant; a smaller value indicates greater similarity of the sample and population matrices. As this index is affected by sample size and is often significant, other fit indices should be used, such as the normed chi-square or chi-square ratio which divides the chi-squared statistic by the degrees of freedom, where a value of less than 3 indicates acceptable fit (Kline, 1998, cited in Garson, 2008; The goodness of fit index (GFI) also evaluates criteria (a) and should be greater than 0.90 (Garson, 2008); The comparative fit index (CFI) and normed fit index (NFI) examine criteria (b) and should be greater than 0.90 for acceptable fit (Hu \& Bentler, 1999; Garson, 2008); The Root Mean Square Error of Approximation 
(RMSEA) evaluates criteria (c) whereby values should be between 0.05 and 0.08 . The standardised root-mean-square residual (sRMR) examines criteria (a) whereby values below 0.10 indicate reasonable fit (Kline, 2005).

In general, there is no set number of how many acceptable fit indices are needed. The common practice is to report several because there is not one standard marker of good model fit. The chi-squared statistic and degrees of freedom must be presented; accompanying fit indices are reported according to discretion, from at least two additional fit indices and upwards (McDonald \& Ho, 2002). Jaccard \& Wan (1996, cited in Garson, 2008) recommend one indice from each category outlined above (a, b \& c). Kline (2005) notes that aside from fit indices, model fit should also be ascertained according to the amount of variance explained in the endogenous variables, and the consideration of alternative models.

Three separate confirmatory factor analyses were conducted with all MEC items loading significantly on the unique factor for the Jewish, Māori and Chinese samples (see Table 6.3 for the factor loadings). 
Table 6.3: Factor loadings of the 18-item MEC scale for Jews, Māori and Chinese

\begin{tabular}{|c|c|c|c|}
\hline & Jews & Māori & Chinese \\
\hline $\begin{array}{l}\text { Item 1: Continuing to practice my } \mathrm{J} / \mathrm{M} / \mathrm{C} \text { traditions } \\
\text { and celebrations is important to me }\end{array}$ & .85 & .78 & .69 \\
\hline $\begin{array}{l}\text { Item 2: Ultimately, I would like my children to identify } \\
\text { as } \mathrm{J} / \mathrm{M} / \mathrm{C}\end{array}$ & .77 & .57 & .79 \\
\hline $\begin{array}{l}\text { Item 3: The future continuity of our } \mathrm{J} / \mathrm{M} / \mathrm{C} \\
\text { community is NOT a concern of mine }\end{array}$ & .76 & .76 & .74 \\
\hline $\begin{array}{l}\text { Item 4: Maintaining my J/M/C heritage is NOT } \\
\text { something I really care about }\end{array}$ & .85 & .90 & .84 \\
\hline $\begin{array}{l}\text { Item 5: I would like to encourage my children to learn } \\
\text { Hebrew/Māori/Chinese }\end{array}$ & .73 & .79 & .52 \\
\hline Item 6: I want to keep J/M/C culture alive & .82 & .88 & .76 \\
\hline $\begin{array}{c}\text { Item 7: } \mathrm{My} \mathrm{J} / \mathrm{M} / \mathrm{C} \text { heritage and traditions are } \\
\text { something I can easily disregard }\end{array}$ & .47 & .66 & .75 \\
\hline $\begin{array}{l}\text { Item 8: It's of little consequence if my children } \\
\text { DON'T identify with their } \mathrm{J} / \mathrm{M} / \mathrm{C} \text { heritage }\end{array}$ & .76 & .62 & .66 \\
\hline $\begin{array}{l}\text { Item 9: Long-term, I would like my grandchildren and } \\
\text { great-grandchildren to continue our J/M/C } \\
\text { heritage }\end{array}$ & .71 & .84 & .88 \\
\hline $\begin{array}{l}\text { Item 10: I do NOT mind setting aside the traditions of } \\
\mathrm{my} / \mathrm{M} / \mathrm{C} \text { heritage }\end{array}$ & .80 & .64 & .76 \\
\hline $\begin{array}{l}\text { Item 11: I do NOT care if my children are unaware of } \\
\mathrm{J} / \mathrm{M} / \mathrm{C} \text { traditions and values }\end{array}$ & .69 & .77 & .78 \\
\hline $\begin{array}{l}\text { Item 12: The endurance of } \mathrm{J} / \mathrm{M} / \mathrm{C} \text { people does NOT } \\
\text { really matter }\end{array}$ & .56 & .75 & .72 \\
\hline $\begin{array}{l}\text { Item 13: I would like to keep on living according to } \\
\text { the traditions of } \mathrm{my} \mathrm{J} / \mathrm{M} / \mathrm{C} \text { heritage }\end{array}$ & .85 & .60 & .59 \\
\hline $\begin{array}{l}\text { Item 14: I want to transmit to my children a love for } \\
\text { and interest in their } \mathrm{J} / \mathrm{M} / \mathrm{C} \text { heritage }\end{array}$ & .73 & .85 & .85 \\
\hline $\begin{array}{l}\text { Item 15: I do NOT really care about ensuring the } \\
\text { future of } \mathrm{J} / \mathrm{M} / \mathrm{C} \text { people }\end{array}$ & .72 & .63 & .72 \\
\hline $\begin{array}{l}\text { Item 16: Maintaining } \mathrm{my} \mathrm{J} / \mathrm{M} / \mathrm{C} \text { traditions and } \\
\text { language is NOT important to me }\end{array}$ & .76 & .66 & .61 \\
\hline $\begin{array}{l}\text { Item 17: I think it's good to create an environment at } \\
\text { home where my J/M/C traditions can be a } \\
\text { normal part of life for my children }\end{array}$ & .82 & .74 & .69 \\
\hline $\begin{array}{l}\text { Item 18: I want to ensure the future of our } \mathrm{J} / \mathrm{M} / \mathrm{C} \\
\text { heritage }\end{array}$ & .74 & .88 & .86 \\
\hline
\end{tabular}

Due to the low ratio of cases to parameters, model fit was poor for all three groups

(see Table 6.4). 
Table 6.4: CFA fit indices for the 18-item MEC scale for Jews, Māori and Chinese

\begin{tabular}{|c|c|c|c|c|c|c|c|}
\hline & $X^{2}(d f)$ & $\mathrm{X}^{2}$ ratio & RMSEA & sRMR & GFI & NFI & CFI \\
\hline Jews & $\begin{array}{l}520.15^{* * *} \\
(135)\end{array}$ & 3.85 & .17 & .07 & .66 & .71 & .77 \\
\hline Māori & $\begin{array}{l}344.93 * * * \\
(135)\end{array}$ & 2.56 & .12 & .06 & .73 & .79 & .86 \\
\hline Chinese & $\begin{array}{l}360.61 \text { *** } \\
(135)\end{array}$ & 2.60 & .13 & .06 & .74 & .77 & .85 \\
\hline
\end{tabular}

In order to (a) develop concise user-friendly scales (b) remove bloated specifics and (c) improve model fit, redundant items were deleted across all three ethnic groups by examining the strength of factor loadings, measurement error covariances, and modification indices. Items were deleted one by one and the CFA was re-run each time. Since the individual samples consisted of approximately 100 cases, a better ratio of cases to parameters was established by reducing the 18-item MEC scale to 10 items, hence improving model fit. Items $6,7,8,11,12,15,16$, and 18 were deleted. Good model fit of the single-factor 10-item MEC scale was obtained for the Jewish, Māori and Chinese samples separately (see rows $1-3$ in Table 6.5 below). Next, the multi-group CFA was conducted, with excellent fit indices confirming the structural equivalence across all three ethnic groups (see row 4 in Table 6.5).

Table 6.5: CFA fit indices for the 10-item ${ }^{42}$ MEC scale for Jews, Māori and Chinese

\begin{tabular}{|c|c|c|c|c|c|c|c|}
\hline & $X^{2}(d f)$ & $\mathrm{X}^{2}$ ratio & RMSEA & sRMR & GFI & NFI & CFI \\
\hline Jews & $\begin{array}{l}59.91 \text { ** } \\
(35)\end{array}$ & 1.71 & .08 & .04 & .90 & .93 & .97 \\
\hline Māori & $\begin{array}{l}80.04 * * * \\
(35)\end{array}$ & 2.29 & .11 & .05 & .86 & .89 & .94 \\
\hline Chinese & $\begin{array}{l}76.19 \text { *** } \\
(35)\end{array}$ & 2.18 & .11 & .05 & .87 & .89 & .94 \\
\hline $\begin{array}{l}\text { Multi- } \\
\text { group } \\
\text { analysis }\end{array}$ & $\begin{array}{l}216.14 * * * \\
(105)\end{array}$ & 2.06 & .06 & .04 & .88 & .90 & .95 \\
\hline
\end{tabular}

${ }^{42}$ Items $1,4,10 \& 13=$ maintenance; $2,5,14 \& 17=$ transmission; $3 \& 9=$ endurance. 
This means that it is psychometrically valid to compare MEC levels across the Jewish, Māori and Chinese samples and that item bias analysis for the MEC scale must be conducted for the scale as a whole.

\section{Testing the structural equivalence of subjects of remembrance (WHO)}

Confirmatory factor analyses were conducted to examine the factor structure of the 12 item WHO scale across the three samples. Within each ethnic group, a 3-factor model whereby four items loaded on each subscale (family, local and general ethnic history), was tested against an alternative single-factor model (see Figures 6.3 and 6.4).

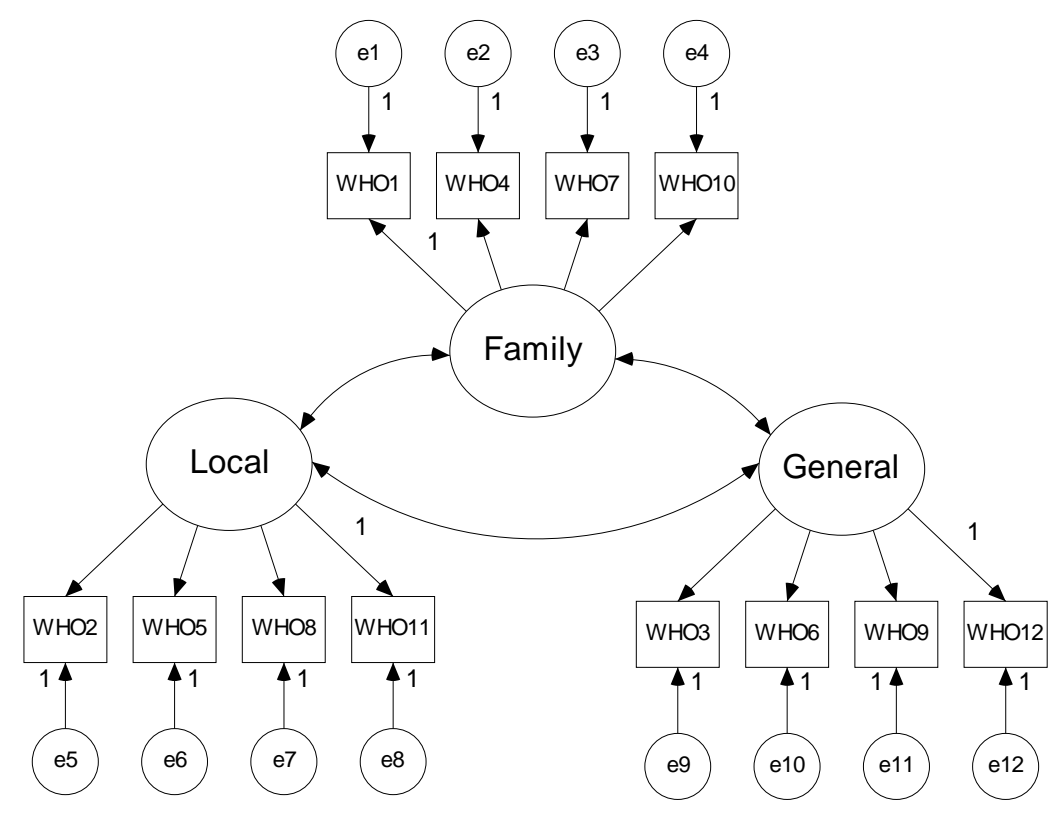

Figure 6.3: CFA of subjects of remembrance (WHO, 3-factors)

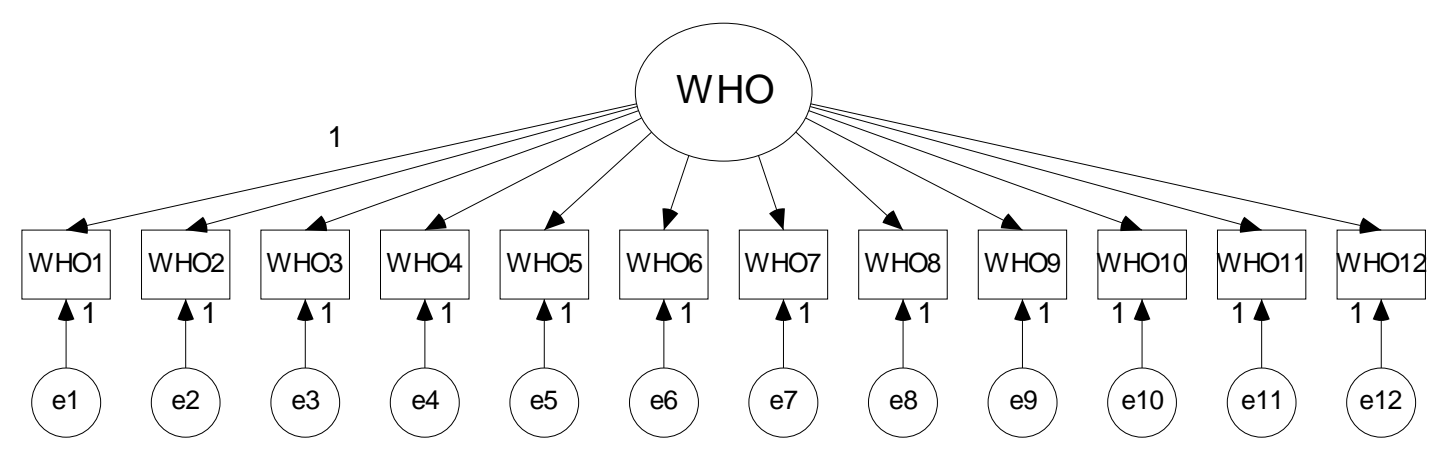

Figure 6.4: CFA of subjects of remembrance (WHO, 1-factor) 
With regards to data normality, items exhibited small negative values for skew although no values were above 3.0 and no values were above 10.0 for kurtosis across all three samples. For the Jewish sample, the 3-factor CFA showed excellent model fit (see row 1 in Table 6.6 below).

Table 6.6: CFA fit indices for the 12-item WHO scale for Jews, Māori and Chinese

\begin{tabular}{|c|c|c|c|c|c|c|c|c|}
\hline & & $X^{2}(d f)$ & $\mathrm{X}^{2}$ ratio & RMSEA & sRMR & GFI & NFI & CFI \\
\hline \multirow[t]{2}{*}{ Jews } & $\begin{array}{l}\text { 3-factor } \\
\text { model }\end{array}$ & $\begin{array}{l}75.16^{*} \\
(51)\end{array}$ & 1.47 & .07 & .07 & .90 & .89 & .96 \\
\hline & $\begin{array}{l}1 \text {-factor } \\
\text { model }\end{array}$ & $\begin{array}{l}234.97 \text { *** } \\
(54)\end{array}$ & 4.35 & .18 & .11 & .69 & .65 & .70 \\
\hline \multirow[t]{2}{*}{ Māori } & $\begin{array}{l}\text { 3-factor } \\
\text { model }\end{array}$ & $\begin{array}{l}143.88^{* * *} \\
(51)\end{array}$ & 2.82 & .13 & .06 & .79 & .84 & .89 \\
\hline & $\begin{array}{l}1 \text {-factor } \\
\text { model }\end{array}$ & $\begin{array}{l}159.82^{* * * *} \\
(54)\end{array}$ & 2.96 & .14 & .06 & .79 & .82 & .87 \\
\hline \multirow[t]{2}{*}{ Chinese } & $\begin{array}{l}\text { 3-factor } \\
\text { model }\end{array}$ & $\begin{array}{l}121.61 \text { *** } \\
(51)\end{array}$ & 2.38 & .12 & .06 & .81 & .85 & .91 \\
\hline & $\begin{array}{l}1 \text {-factor } \\
\text { model }\end{array}$ & $\begin{array}{l}157.21 \text { *** } \\
(54)\end{array}$ & 2.91 & .14 & .07 & .79 & .81 & .86 \\
\hline
\end{tabular}

All items loaded significantly on their respective latent factor with no cross-loadings (see Table 6.7 below). Furthermore, the three latent factors demonstrated moderate positive intercorrelations (family and local ethnic history $\mathrm{r}=.54$; family and general ethnic history $\mathrm{r}=.55$; general and local ethnic history $\mathrm{r}=.61$ ). The alternative unifactorial model showed poorer fit (see row 2 in Table 6.6). A chi-squared difference test showed that the 3 -factor model was a significantly better fit than the single-factor model for the Jewish sample $\left[\mathrm{X}^{2}(3)=159.81^{* * *}\right]$. This means that Jews differentiate between remembering family ethnic history, local ethnic group history and general ethnic group history. 
Table 6.7: Factor loadings of the 3-factor 12-item WHO scale for Jews

\begin{tabular}{|c|c|c|}
\hline \multirow[t]{4}{*}{$\begin{array}{l}\text { Family ethnic } \\
\text { history }\end{array}$} & $\begin{array}{l}\text { Item 1: I know what Jewish life was like for my family } \\
\text { back in their home towns }\end{array}$ & .83 \\
\hline & $\begin{array}{l}\text { Item 4: I do NOT know much about my family's Jewish } \\
\text { background }\end{array}$ & .74 \\
\hline & $\begin{array}{l}\text { Item 7: The Jewish roots of my family are something I do } \\
\text { NOT know much about }\end{array}$ & .88 \\
\hline & $\begin{array}{l}\text { Item 10: I have stories about my family's experiences } \\
\text { related to being Jewish }\end{array}$ & .72 \\
\hline \multirow[t]{4}{*}{$\begin{array}{l}\text { Local ethnic } \\
\text { history }\end{array}$} & $\begin{array}{l}\text { Item 2: I am aware of the history of Jewish people here, in } \\
\text { the country where I live }\end{array}$ & .77 \\
\hline & $\begin{array}{l}\text { Item 5: I know about the experiences of the first Jewish } \\
\text { immigrants to this country }\end{array}$ & .74 \\
\hline & $\begin{array}{l}\text { Item 8: I am NOT really aware of the experiences faced by } \\
\text { Jews in this country }\end{array}$ & .72 \\
\hline & $\begin{array}{l}\text { Item 11: I do NOT know much about the local history of } \\
\text { Jewish people }\end{array}$ & .67 \\
\hline \multirow[t]{4}{*}{$\begin{array}{l}\text { General ethnic } \\
\text { history }\end{array}$} & $\begin{array}{l}\text { Item 3: The broad history of Jews is something that I do } \\
\text { NOT know much about }\end{array}$ & .79 \\
\hline & $\begin{array}{l}\text { Item 6: I know about the history of Jewish people in our } \\
\text { ancestral land }\end{array}$ & .86 \\
\hline & Item 9: I remember the general history of Jewish people & .74 \\
\hline & Item 12: I am NOT familiar with Jewish history & .68 \\
\hline
\end{tabular}

In contrast, the 3-factor model was not the best fit for the Māori and Chinese samples (see rows 3 and 5 in Table 6.6) because the three latent factors demonstrated high positive intercorrelations (family and local ethnic history $r=.96$ for Māori, $r=.82$ for Chinese; family and general ethnic history $r=.88$ for Māori, $r=.90$ for Chinese; general and local ethnic history $r=.91$ for Māori, $r=.87$ for Chinese). This indicated that a singlefactor model would be more representative of the construct for Māori and Chinese. However, the fit was slightly worse for the unifactorial model than that for the 3 -factor model (see rows 4 and 6 in Table 6.6; a significant chi squared difference was found for Māori $X^{2}(3)=15.94^{* *}$; and for Chinese $\left.X^{2}(3)=35.6^{* * *}\right)$. This was likely due to item redundancy as all items demonstrated strong significant loadings on the single latent variable (see Table 6.8 for item loadings). 
Table 6.8: Factor loadings of the single-factor 12-item WHO scale for Māori and Chinese

\begin{tabular}{lcc}
\hline & Māori & Chinese \\
\hline Item 1 & .63 & 59 \\
Item 2 & .87 & .79 \\
Item 3 & .64 & .74 \\
Item 4 & .73 & .79 \\
Item 5 & .78 & .69 \\
Item 6 & .74 & .67 \\
Item 7 & .73 & .73 \\
Item 8 & .72 & .74 \\
Item 9 & .70 & .68 \\
Item 10 & .74 & .68 \\
Item 11 & .79 & .77 \\
Item 12 & .81 & .82 \\
\hline
\end{tabular}

To improve model fit, items 5, 6 and 1 were deleted by examining factor loadings and measurement error covariances. The reduced 9-item WHO scale showed an improvement in model fit (see rows 1 and 2 in Table 6.9 below). To test for structural equivalence of the unifactorial model across the Māori and Chinese samples a multigroup CFA was conducted, demonstrating excellent fit (see row 3 in Table 6.9). This means that in contrast to the Jewish sample, the Māori and Chinese samples do not make a distinction between subjects of remembrance (Chinese family history, New Zealand Chinese history and general Chinese history and similarly Māori family history, tribal history and general Māori history are very strongly associated). 
Table 6.9: CFA fit indices for the single-factor 9-item WHO scale for Māori and Chinese

\begin{tabular}{llllllll}
\hline & $\mathbf{X}^{\mathbf{2}} \mathbf{( d f )}$ & $\mathbf{X}^{2}$ ratio & RMSEA & sRMR & GFI & NFI & CFI \\
\hline Māori & $\begin{array}{l}54.85^{* *} \\
(27)\end{array}$ & 2.03 & .10 & .05 & .90 & .91 & .95 \\
Chinese & $\begin{array}{l}49.47^{* *} \\
(27)\end{array}$ & 1.83 & .09 & .05 & .91 & .91 & .96 \\
$\begin{array}{l}\text { Multi- } \\
\text { group } \\
\text { analysis }\end{array}$ & $\begin{array}{l}104.32^{* * *} \\
\text { (54) }\end{array}$ & 1.93 & .07 & .05 & .90 & .91 & .95 \\
\hline
\end{tabular}

Overall, the results show that it is not psychometrically valid to compare WHO levels across the three ethnic groups since the Jewish sample differentiates between family, local and general ethnic history whereas the Māori and Chinese samples do not. Given that WHO does not demonstrate structural equivalence across the three groups, item bias analysis for this scale will not be conducted.

\section{Testing the structural equivalence of ethno-historical consciousness (WHAT)}

The unifactorial structure was tested across all three ethnic groups simultaneously to confirm structural equivalence (see Figure 6.5).

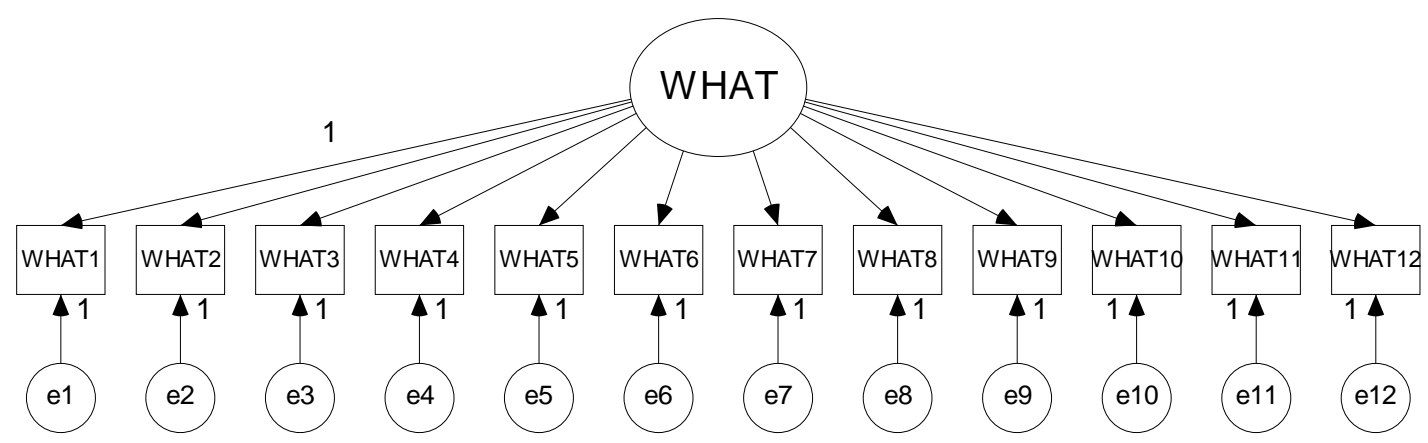

Figure 6.5: CFA of ethno-historical consciousness (WHAT, 1-factor) 
With regards to data normality, items exhibited small negative values for skew although no values were above 3.0 and no values for kurtosis were above 10.0 across the three samples. All items loaded significantly on the single factor across all three groups (see Table 6.10).

Table 6.10: Factor loadings of the single-factor 12-item WHAT scale for Jews, Māori and Chinese

\begin{tabular}{|c|c|c|c|}
\hline & Jews & Māori & Chinese \\
\hline $\begin{array}{l}\text { Item 1: I remember the founding fathers and } \\
\text { mothers of Jewish tradition }\end{array}$ & .62 & .69 & .71 \\
\hline $\begin{array}{l}\text { Item 2: I remember the injustices that have } \\
\text { happened to Jews }\end{array}$ & .69 & .91 & .86 \\
\hline $\begin{array}{l}\text { Item 3: I celebrate the points in history when Jews } \\
\text { fought to maintain our culture }\end{array}$ & .72 & .90 & .67 \\
\hline $\begin{array}{l}\text { Item 4: I have difficulty remembering basic } \\
\text { historical events that shaped Jews } \\
\text { as a people }\end{array}$ & .63 & .51 & .49 \\
\hline $\begin{array}{l}\text { Item 5: I'm NOT really aware of Jewish people } \\
\text { being treated differently by the larger society }\end{array}$ & .43 & .74 & .43 \\
\hline Item 6: I appreciate the historical survival of Jews & .54 & .59 & .60 \\
\hline $\begin{array}{l}\text { Item 7: I do NOT know which events in history } \\
\text { gave Jews their common identity }\end{array}$ & .55 & .72 & .53 \\
\hline $\begin{array}{l}\text { Item 8: Discrimination against Jewish people is } \\
\text { something I do NOT know much about }\end{array}$ & .70 & .55 & .30 \\
\hline $\begin{array}{l}\text { Item 9: I remember events in history where Jews } \\
\text { have demonstrated resistance to forces } \\
\text { from the larger society }\end{array}$ & .59 & .79 & .55 \\
\hline $\begin{array}{l}\text { Item 10: I do NOT know much about the cultural } \\
\text { heroes of Jewish history }\end{array}$ & .79 & .75 & .51 \\
\hline $\begin{array}{l}\text { Item 11: I remember how Jews have been } \\
\text { discriminated against by the larger society } \\
\text { throughout history }\end{array}$ & .56 & .69 & .61 \\
\hline $\begin{array}{l}\text { Item 12: The survival of Jewish people throughout } \\
\text { history is NOT something I remember } \\
\text { much about }\end{array}$ & .75 & .78 & .69 \\
\hline
\end{tabular}

However, there were particularly weak loadings in the Chinese sample, leading to a poorer overall model fit compared to the Jewish and Māori samples (see Table 6.11). 
Table 6.11: CFA fit indices for the 12-item WHAT scale for Jews, Māori and Chinese

\begin{tabular}{|c|c|c|c|c|c|c|c|}
\hline & $X^{2}(d f)$ & $\mathrm{X}^{2}$ ratio & RMSEA & sRMR & GFI & NFI & CFI \\
\hline Jews & $\begin{array}{l}137.35^{* * *} \\
(54)\end{array}$ & 2.54 & .12 & .08 & .82 & .76 & .84 \\
\hline Māori & $\begin{array}{l}113.86^{* * *} \\
(54)\end{array}$ & 2.11 & .10 & .06 & .83 & .87 & .92 \\
\hline Chinese & $\begin{array}{l}200.61 * * * \\
(54)\end{array}$ & 3.72 & .16 & .11 & .75 & .64 & .70 \\
\hline
\end{tabular}

To create concise, user-friendly scales, remove bloated specifics and improve model fit items 7, 8, 10, and 12 were deleted. The 8-item WHAT scale demonstrated an improved fit across all three ethnic groups (see rows $1-3$ in Table 6.12). Next, a multi-group CFA demonstrated good fit (see row 4 in Table 6.12), confirming the structural equivalence of the single-factor model. This means that it is psychometrically valid to compare WHAT levels across Jews, Māori and Chinese, and that item bias analysis for the WHAT scale must be conducted for the full scale.

Table 6.12: CFA fit indices for the 8-item WHAT scale for Jews, Māori and Chinese

\begin{tabular}{|c|c|c|c|c|c|c|c|}
\hline & $X^{2}(d f)$ & $\mathrm{X}^{2}$ ratio & RMSEA & sRMR & GFI & NFI & CFI \\
\hline Jews & $\begin{array}{l}38.38^{* *} \\
(20)\end{array}$ & 1.91 & .09 & .06 & .92 & .85 & .92 \\
\hline Māori & $\begin{array}{l}39.7 * * \\
(20)\end{array}$ & 1.99 & .10 & .05 & .91 & .92 & .96 \\
\hline Chinese & $\begin{array}{l}44.47^{* *} \\
(20)\end{array}$ & 2.22 & .11 & .06 & .91 & .85 & .91 \\
\hline $\begin{array}{l}\text { Multi- } \\
\text { group } \\
\text { analysis }\end{array}$ & $\begin{array}{l}122.55^{* * *} \\
(60)\end{array}$ & 2.04 & .06 & .06 & .91 & .88 & .94 \\
\hline
\end{tabular}

Testing the structural equivalence of vicarious experience of ethnic history (HOW)

The single-factor 7-item measure of vicarious experience of ethnic history was tested for structural equivalence across the Jewish, Māori and Chinese samples. 


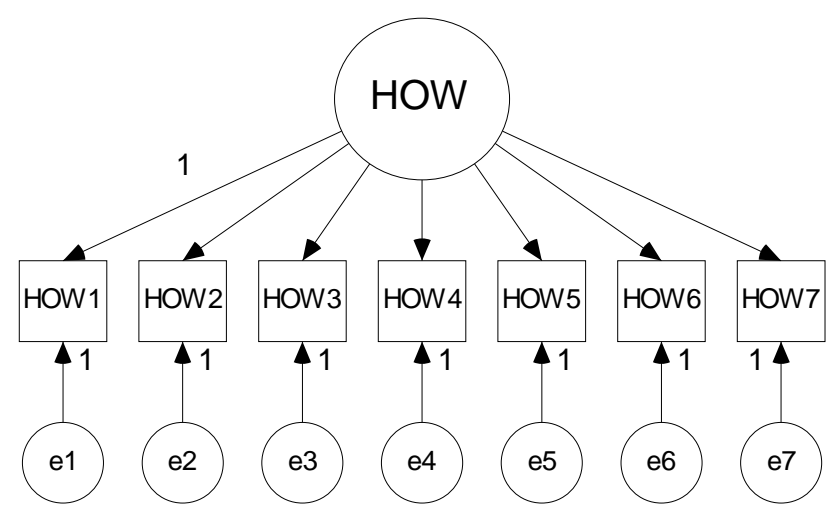

Figure 6.6: CFA of vicarious experience of ethnic history (HOW, 1-factor)

Note that for the HOW scale, the sample size of each ethnic group is reasonable relative to the number of estimated parameters (14). With regards to data normality, items exhibited small negative values for skew, although no values were above 3.0 and no values were above 10.0 for kurtosis across all three samples. All items loaded significantly on the single factor (see Table 6.13).

Table 6.13: Factor Loadings of the 7-item HOW scale

\begin{tabular}{|c|c|c|c|}
\hline & Jews & Māori & Chinese \\
\hline $\begin{array}{l}\text { Item 1: I can imagine being a part of the } \\
\text { journeys my Jewish ancestors made }\end{array}$ & .64 & .75 & .63 \\
\hline $\begin{array}{l}\text { Item 2: I do NOT have emotional connections } \\
\text { to the struggles that Jewish people have } \\
\text { gone through }\end{array}$ & .77 & .76 & .63 \\
\hline $\begin{array}{l}\text { Item 3: I feel anger and frustration when I think } \\
\text { of all the injustices and discrimination } \\
\text { experienced by Jews }\end{array}$ & .45 & .52 & .42 \\
\hline $\begin{array}{l}\text { Item 4: When I look back in history to Jewish } \\
\text { ancestors, I do feel that I am a part of } \\
\text { something great }\end{array}$ & .49 & .63 & .79 \\
\hline $\begin{array}{l}\text { Item 5: It's hard for me to feel linked to the } \\
\text { experiences of my Jewish ancestors }\end{array}$ & .68 & .74 & .72 \\
\hline $\begin{array}{l}\text { Item 6: The historical achievements of Jewish } \\
\text { people have little to do with me on a } \\
\text { personal level }\end{array}$ & .80 & .58 & .63 \\
\hline $\begin{array}{l}\text { Item 7: I feel proud when I learn about the } \\
\text { struggles and battles of our Jewish } \\
\text { ancestors to keep our heritage alive }\end{array}$ & .72 & .81 & .78 \\
\hline
\end{tabular}


Indices demonstrated good model fit for the Jewish and Māori samples but poorer fit for the Chinese sample (see Table 6.14).

Table 6.14: CFA fit indices for the 7-item HOW scale for Jews, Māori and Chinese

\begin{tabular}{llllllll}
\hline & $\mathbf{X}^{\mathbf{2}} \mathbf{( d f )}$ & $\mathbf{X}^{\mathbf{2}}$ ratio & $\mathbf{R M S E A}$ & sRMR & GFI & NFI & CFI \\
\hline Jews & $36.08^{* *}$ & 2.58 & .12 & .06 & .91 & .87 & .91 \\
& $(14)$ & & & & & & \\
Māori & $41.13^{* * *}$ & 2.94 & .14 & .06 & .90 & .87 & .91 \\
& $(14)$ & & & & & & \\
\multirow{2}{*}{ Chinese } & $\begin{array}{l}58.96^{* * *} \\
(14)\end{array}$ & 4.21 & .18 & .07 & .88 & .80 & .84 \\
& & & & & & \\
\hline
\end{tabular}

To improve model fit item 2 was deleted ${ }^{43}$. The 6-item HOW scale demonstrated an improved fit for the Māori and Chinese samples (see rows 1-3 in Table 6.15). A multigroup CFA demonstrated excellent fit (see row 4 in Table 6.15), confirming structural invariance of the unifactorial scale. This means that it is psychometrically valid to compare HOW levels across Jews, Māori and Chinese and that item bias analysis for the HOW scale must be conducted for the scale as a whole.

Table 6.15: CFA fit indices for the 6-item HOW scale for Jews, Māori and Chinese

\begin{tabular}{llllllll}
\hline & $\mathbf{X}^{\mathbf{2}} \mathbf{( d f )}$ & $\mathbf{X}^{2}$ ratio & RMSEA & sRMR & GFI & NFI & CFI \\
\hline Jews & $\begin{array}{l}24.47^{* *} \\
(9)\end{array}$ & 2.72 & .13 & .06 & .92 & .87 & .91 \\
Māori & $\begin{array}{l}16.29 \\
(9)\end{array}$ & 1.81 & .09 & .05 & .95 & .93 & .96 \\
Chinese & $\begin{array}{l}30.06^{* * *} \\
(9)\end{array}$ & 3.34 & .15 & .07 & .91 & .87 & .90 \\
$\begin{array}{l}\text { Multi- } \\
\text { group } \\
\text { analysis }\end{array}$ & $\begin{array}{l}70.82^{* * *} \\
(27)\end{array}$ & 2.62 & .07 & .06 & .93 & .89 & .93 \\
\hline
\end{tabular}

${ }^{43}$ Although this item did not exhibit the weakest factor loadings, its error term was correlated with those of items 5 and 4 in the Māori and Chinese samples. 


\section{Summary of structural invariance across groups}

Given that the subjects of remembrance WHO scale had a different factor structure across ethnic groups that impeded meaningful cross-cultural comparisons of score levels, there is no rationale for conducting item bias analysis. In contrast, the ethno-historical consciousness WHAT scale, vicarious experience of ethnic history HOW scale and the Motivation for Ethno-cultural Continuity (MEC) scale demonstrated structural equivalence across ethnic groups, enabling meaningful cross-cultural comparisons of score levels. Since the WHAT, HOW and MEC scales are unifactorial, item bias analyses were conducted for each whole scale.

\section{How to test for item bias}

According to van de Vijver and Leung (1997, p. 7), "bias refers to the presence of factors that challenge the validity of cross-cultural comparisons" such as participant response styles. In this thesis, two are of particular concern: acquiescence response bias refers to individual tendencies to consistently agree with items regardless of content; in contrast, extreme response bias refers to individual tendencies to take item content into consideration and display more definitive agreement or disagreement. Differences in response bias have been found whereupon individuals from collectivistic nations tend towards acquiescent responses and those from individualistic nations lean towards extreme responses (Smith \& Fischer, 2008). In this thesis, item bias analysis was conducted across the Jewish, Māori and Chinese samples. As participants came from three collectivistic cultures although they have lived for multiple generations in the same individualistic nation, it is difficult to hypothesize which type of response bias may be evident across the three groups. 
Response styles lead to two kinds of item bias: acquiescent responding means that bias on item scores is the same for all score levels - this is known as uniform bias; in contrast, with extreme responding, bias is not the same across score levels - known as non-uniform bias. Only unbiased scale items should be used to make meaningful crosscultural comparisons.

To conduct item bias analysis, van de Vijver and Leung (1997) recommend using Cleary \& Hilton's (1968) analysis of variance method. This procedure involves examining items individually for uniform and non-uniform bias. First, data from the three ethnic groups were merged and ethnicity was coded such that Jews=1, Māori=2 and Chinese $=3$. Next, total scale scores for each participant were calculated. The third step was to concatenate or group together scale scores into levels such that there were a minimum of 50 persons per level. Given that there were just over 300 participants in this study, scale score frequency distributions were calculated in order to identify cut-off points to form six score level groups of approximately equal size (prior to this step, box and whisker plots were used to check for outlier values which were deleted). Once the score-level groups were calculated, the ANOVA was conducted where the observed item mean was the dependent variable and ethnic group and six scale score levels constituted the independent variables. The ANOVA results were examined for the significance of two effects: (a) main effect of ethnic group; and (b) interaction effect of score level and ethnic group. When both (a) and (b) were non-significant, the item was not biased and could be used for meaningful cross-cultural comparisons as it demonstrated full score equivalence across groups (Fontaine, 2005). This meant that scale items had the same mean score for individuals in the same level across ethnic groups. When the main effect (a) was significant, the item displayed uniform bias whereby participants of at least one ethnic group demonstrated acquiescence response bias. When the interaction (b) was 
significant, the item demonstrated non-uniform bias whereby participants of at least one ethnic group demonstrated extreme response bias.

In accordance with Fischer (personal communication), ANOVAs were conducted for all scale items simultaneously in order to detect the item with the largest bias. This was selected by visual examination of the profile plots (score levels by item mean), and selecting the item with the highest significant $\underline{F}$ value. Once this item was removed, scale score levels were recalculated and ANOVAs for all remaining scale items were conducted (known as an iterative procedure). Analyses continued in this manner until there were no further biased items.

\section{Biased items}

Items that were biased include item 3 in the HOW scale, items 3, 8 and 10 in the WHAT scale and items 4, 5, 6, 7, 9, 10, 11, 14, 15, 16, 18 in the MEC scale (see Appendix F for analysis details).

\section{Integrating results from the CFA and item bias analysis}

For the purposes of investigating mean group differences in Motivation for Ethnocultural Continuity, ethno-historical consciousness and vicarious experience of ethnic history, only the unbiased items that loaded on the multi-group CFA were used (items 1, 2, 3, 13 and 17 for MEC; items 1, 2, 4, 5, 6, 9 and 11 for WHAT and items 1, 4, 5, 6 and 7 for HOW). Reliabilities of the revised scales were good (see Table 6.16). 
Table 6.16: Scale reliabilities including unbiased items for Jews, Māori and Chinese

\begin{tabular}{lccc}
\hline & MEC scale $^{44}$ & WHAT scale $^{45}$ & HOW scale \\
& & & \\
\hline Nitems & 5 & 7 & 5 \\
Jews & 0.89 & 0.74 & 0.77 \\
Māori & 0.87 & 0.85 & 0.80 \\
Chinese & 0.84 & 0.79 & 0.83 \\
\hline
\end{tabular}

\section{Mean group comparisons}

Following the removal of biased items from the MEC, WHAT and HOW scales, mean group comparisons can proceed (note that item bias analysis could not be conducted for the endogamy intentions and selective dating scales due to their small number of items). To control for participant differences in age and gender, one-way Analyses of Covariance were conducted where ethnicity served as the independent variable and participant age and gender constituted the covariates ${ }^{46}$. Table 6.17 presents the descriptive statistics (adjusted means) for the revised scales.

Table 6.17: Descriptive statistics (adjusted mean, std.error) for the revised scales for Jews, Māori and Chinese

\begin{tabular}{lccccc}
\hline & MEC & WHAT & HOW & Endogamy & Dating \\
\hline N items & 5 & 7 & 5 & 4 & 3 \\
Jews & $6.12(0.11)$ & $6.11(0.11)$ & $5.36(0.12)$ & $4.66(0.16)$ & $3.06(0.18)$ \\
Māori & $6.10(0.11)$ & $5.66(0.11)$ & $5.77(0.13)$ & $4.02(0.17)$ & $3.23(0.19)$ \\
Chinese & $5.41(0.11)$ & $4.21(0.11)$ & $4.11(0.12)$ & $3.63(0.16)$ & $3.05(0.18)$ \\
\hline
\end{tabular}

\footnotetext{
${ }^{44}$ Items $1 \& 13=$ maintenance; $2 \& 17=$ transmission; $3=$ endurance

${ }^{45}$ Items $1 \& 4$ = integrity; 2, 5 \& $11=$ suffering; 6 \& $9=$ survival

${ }^{46}$ Given that demographic differences in generation were only available for the two migrant groups, Jews and Chinese, and not for Māori as indigenous peoples, generation was not entered as a covariate.
} 
After adjusting for participant differences in age and gender, a moderate significant effect was found for ethnicity on Motivation for Ethno-cultural Continuity $[\underline{F}(2,301)=14.31$, $\mathrm{p}<0.001$, partial eta squared $=.09]$. Post-hoc tests demonstrated that Jews and Mãori had higher levels of MEC than Chinese. There were no significant differences between the two former groups. Note that overall levels of MEC were quite high (above the scale mid-point). Thus, MEC can be measured across the three ethnic groups, and although there are differences in motivation strength, ethno-cultural continuity is important for Jewish, Māori and Chinese participants.

A large significant effect was found for ethnicity on ethno-historical consciousness after accounting for the effect of the covariates $[\underline{F}(2,301)=85.33, \underline{p}<0.001$, partial eta squared $=.36]$. Post-hoc tests demonstrated that Jews remembered more historical narratives than Māori and Chinese, and Māori also remembered more historical narratives than Chinese. Similarly, a large significant effect was found for ethnicity on vicarious experience of ethnic history $[\underline{\mathrm{F}}(2,301)=48.68, \underline{\mathrm{p}}<0.001$, partial eta squared $=.24]$. Post-hoc tests demonstrated that Māori had a greater vicarious experience of ethnic history than Jews and Chinese, and Jews had a greater vicarious experience than Chinese.

The 4-item scale for endogamy intentions demonstrated good reliability across all three ethnic groups ( $\alpha=0.87$ for Jews, $\alpha=0.74$ for Māori and $\alpha=0.82$ for Chinese). A moderate significant effect was found for ethnicity on endogamy intentions after accounting for the effect of the covariates $[\underline{\mathrm{F}}(2,301)=10.51, \underline{\mathrm{p}}<0.001$, partial eta squared $=.07]$. Post-hoc tests demonstrated that Jews had greater intentions to marry another Jewish person than Māori had intentions to marry another Māori person and Chinese had intentions to marry another Chinese person. There were no significant differences between the two latter groups. Overall, while the mean endogamy intentions of these 
Jewish participants were above the scale mid-point of four, indicating a mild intention to marry another Jewish person, the intentions of these Māori and Chinese participants were on or slightly below the scale mid-point, indicating a more neutral attitude towards endogamy.

The 4-item scale for selective dating behaviour only demonstrated good reliability for the Chinese sample $(\alpha=0.78)$, but not for the Jewish or Māori samples $(\alpha=0.67$ and $\alpha=0.57$ respectively). The removal of item 2 led to improvements in scale reliability to $\alpha=0.72$ for Jews and $\alpha=0.70$ for Māori; reliability remained the same at $\alpha=0.77$ for Chinese. After accounting for the effect of the covariates, no significant differences were found between groups $[\mathrm{F}(2,301)=0.27, \mathrm{p}=.76$, partial eta squared $=.002]$. Note that the mean selective dating behaviour of all participants was below the scale mid-point of four, indicating that on average these Jewish, Māori and Chinese participants did not engage in selective dating. 


\section{Testing the predictive model of volitional endogamy across samples of Jews, Māori and Chinese in New Zealand}

This section presents structural equation models to test the predictive model of endogamy for each ethnic group separately. Subsequently, path models are presented which test for invariant paths across ethnic groups in order to investigate the crosscultural generalisability of the model.

The proposed model for ethno-cultural continuity (Figure 6.1) presented earlier outlines how ethno-cultural identity, ethno-historical consciousness and vicarious experience of ethnic history shape Motivation for Ethno-cultural Continuity; how this motivation in turn predicts behavioural intentions for endogamy; how the three traditionally examined variables of similarity, attraction and social network approval directly predict intentions for endogamy; and how intentions for endogamy in turn predict selective dating behaviour. Demographic variables are not included as predictors of endogamy. Below is a graphic representation of the structural model to be tested (Figure 6.7).

Note that the influence of ethno-historical consciousness (WHAT), and vicarious experience of ethnic history (HOW) on Motivation for Ethno-cultural Continuity is omitted at this first stage in order to focus on what variables predict endogamy intentions. Once a well-fitting model is achieved, the constructs WHAT and HOW will be added to determine if awareness of social representations of ethnic history contributes in predicting the variance in Motivation for Ethno-cultural Continuity above and beyond that accounted for by ethno-cultural identity. 


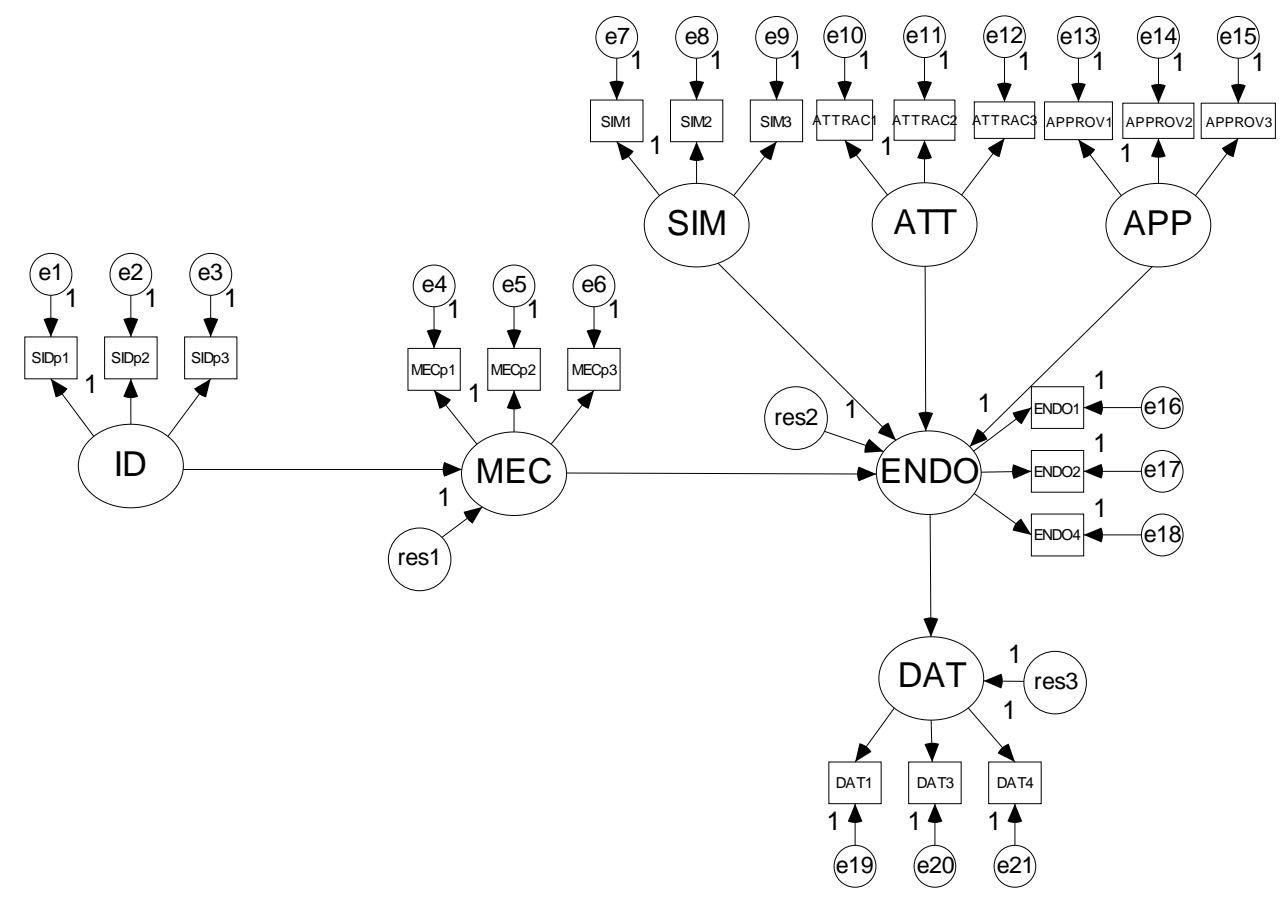

Figure 6.7: Testing a predictive model of volitional endogamy

Three parcels ${ }^{47}$ were created for each of the following scales: Ethno-cultural identity (ID), Motivation for Ethno-cultural Continuity (MEC), ethno-historical consciousness (WHAT) and vicarious experience of ethnic history (HOW) scales. The parcels demonstrated good reliability across all three ethnic groups (see Table 6.18).

Table 6.18: Reliability of item parcels for the latent variables (cross-cultural comparison)

\begin{tabular}{lllll}
\hline & ID & MEC & WHAT & HOW \\
\hline Jews & 0.90 & 0.94 & 0.76 & 0.75 \\
Māori & 0.89 & 0.92 & 0.85 & 0.83 \\
Chinese & 0.86 & 0.91 & 0.83 & 0.83 \\
\hline
\end{tabular}

\footnotetext{
${ }^{47}$ When sample sizes are small and constructs are unidimensional, using item parcels enables the estimation of fewer parameters and reduces shared error, thus improving model fit (Little, Cunningham, Shahar \& Widaman, 2002). The items used loaded on the multi-group CFA conducted earlier.
} 
Since there were only three indicators for the latent variables of similarity, attraction, and social network approval, no parcelling was necessary. For the latent variable of selective dating behaviour, item 2 was deleted to improve scale reliability across cultures, leaving three indicators. To achieve a just-identified measurement model ${ }^{48}$, three indicators were used for endogamy intentions.

\section{Testing the model among New Zealand Jews}

(i) The model in Figure 6.7 was tested in the sample of New Zealand Jews. Model fit was poor; attraction was not a significant predictor of intentions for endogamy and similarity and social network approval were no longer significant predictors when correlations were estimated with ethno-cultural identity as suggested by the modification indices. The model with improved fit is shown below (Figure 6.8).

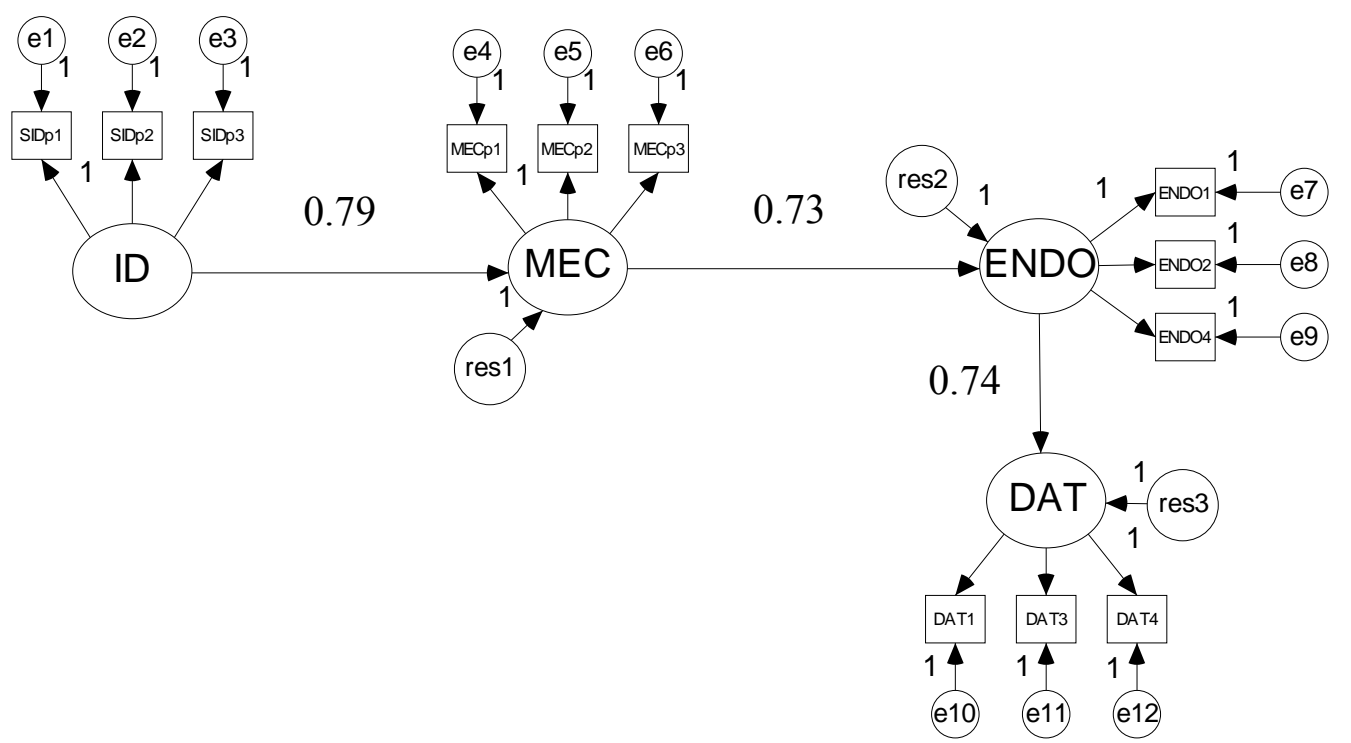

Figure 6.8: A predictive model of endogamy among New Zealand Jews

The goodness of fit indices were acceptable: $\mathrm{X}^{2}(51)=74.28, \mathrm{p}<.001, \mathrm{X}^{2} / \mathrm{df}=1.46$, RMSEA $=.07$, sRMR $=.04, \mathrm{GFI}=.90, \mathrm{NFI}=.93$, and CFI $=.98$. Thus, according to the hypothesized model, for the sample of New Zealand Jews, Motivation for Ethno-

\footnotetext{
${ }^{48}$ A just-identified model has the same number of parameters as elements in the covariance matrix. Underidentified models have more estimated parameters and overidentified models have fewer estimated parameters than elements in the covariance matrix (Garson, 2008).
} 
cultural Continuity (MEC) mediated the relationship between ethno-cultural identity and intentions for endogamy. In fact, when MEC and identity were included in the predictive model, traditionally examined variables of similarity, attraction and social network approval were no longer significant predictors. Intentions for endogamy were a strong and unique predictor of selective dating behaviour ${ }^{49}$. Overall, 53 percent and 55 percent of the variance in endogamy intentions and selective dating were accounted for by the model. Ethno-cultural identity accounted for 63 percent of the variance in MEC.

(ii) The next step was to introduce the constructs of ethno-historical consciousness (WHAT) and vicarious experience of ethnic history (HOW) to see whether they contribute to predicting the variance in MEC. WHAT was the only significant predictor, with poor model fit $\left[\mathrm{X}^{2}(86)=162.26^{* * *}\right]$. Examination of the modification indices and path loadings suggested the estimation of a direct path from ID to WHAT. This is in accordance with theory described in Chapter two whereby greater ethnic identification leads to greater exposure to and salience of social representations of ethnic history, and consequently to a greater individual awareness, measured by the cognitive construct $\mathrm{WHAT}^{50}$. The final model is presented in Figure 6.9.

\footnotetext{
${ }^{49}$ Direct paths from identity to endogamy and identity to dating were non-significant. Alternative models were tested which demonstrated poorer fit (identity mediating the relationship between MEC and intentions for endogamy; selective dating mediating the relationship between MEC and intentions for endogamy).

${ }^{50}$ An alternative model whereby ethno-historical consciousness predicted ethno-cultural identity resulted in poorer fit.
} 


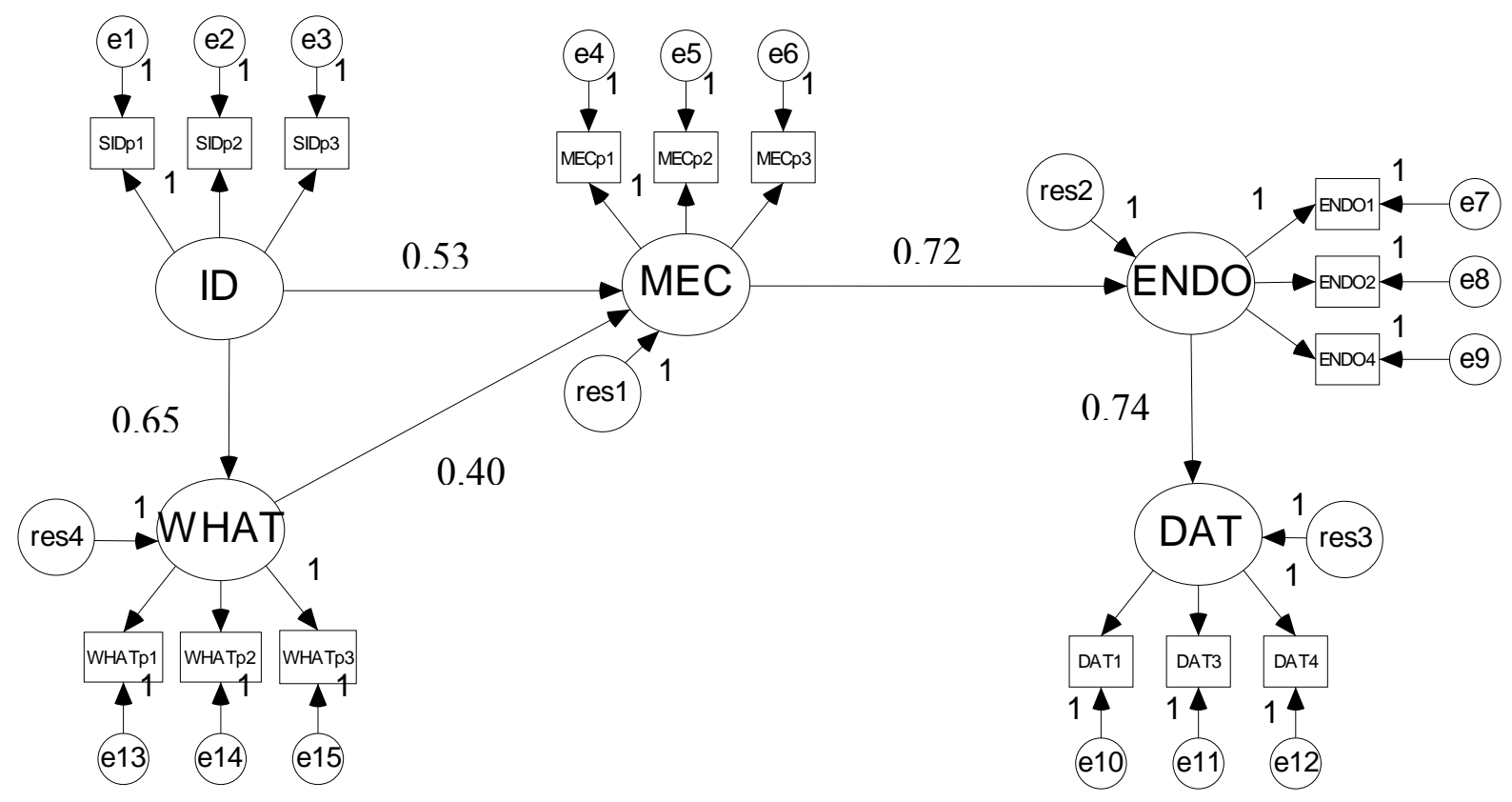

Figure 6.9: Including ethno-historical consciousness in a predictive model of endogamy among New Zealand Jews

The goodness of fit indices were acceptable: $\mathrm{X}^{2}(85)=112.43, \mathrm{p}<.001, \mathrm{X}^{2} / \mathrm{df}=1.32$, RMSEA $=.06$, sRMR $=.05$, GFI $=.88, \mathrm{NFI}=.91$, and CFI $=.98$. A chi-squared difference test demonstrated that model fit improved significantly when the relationship between identity and WHAT was estimated $\left[\mathrm{X}^{2}(1)=49.83^{* * *}\right]$. Furthermore, when WHAT is included, 71 percent of the variance in MEC was accounted for (an increase from 63 percent). Thus, including ethno-historical consciousness is important when modelling the process of Jewish continuity.

\section{Testing the model among Māori}

(i) The model in Figure 6.7 was tested in the Māori sample. Model fit was poor $\left[\mathrm{X}^{2}(86)=170.38^{* * *}\right]$; perceived similarity and attraction were not significant predictors of intentions for endogamy. Modification indices suggested the estimation of a correlation between ethno-cultural identity and approval $(\mathrm{r}=0.56)$. The model with improved fit is presented below in Figure 6.10. 


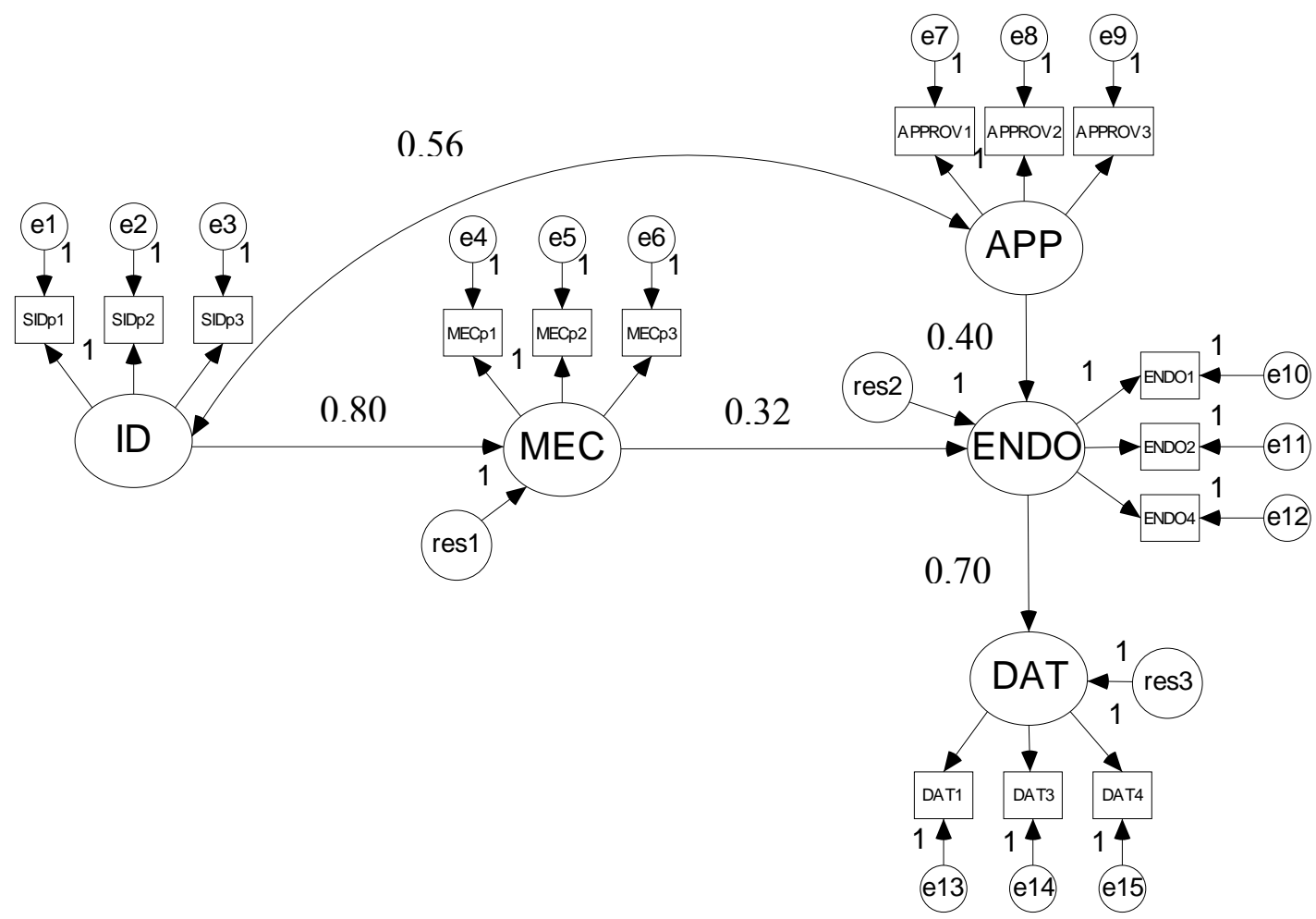

Figure 6.10: A predictive model of endogamy among Māori

The goodness of fit indices were acceptable: $\mathrm{X}^{2}(85)=141.14, \mathrm{p}<.001, \mathrm{X}^{2} / \mathrm{df}=1.66$, RMSEA $=.08$, sRMR $=.08$, GFI $=.85, \mathrm{NFI}=.86$, and CFI $=.94$. A chi-squared difference test demonstrated that model fit improved significantly when the relationship between identity and approval is accounted for $\left[\mathrm{X}^{2}(1)=29 \cdot 24^{* * *}\right]$. According to the hypothesized model, for the sample of Māori in New Zealand, Motivation for Ethnocultural Continuity (MEC), predicted intentions for endogamy above and beyond social network approval and mediated the relationship between ethno-cultural identity and intentions for endogamy. Intentions for endogamy were a strong and unique predictor of selective dating behaviour ${ }^{51}$. Overall, 38 percent and 50 percent of the variance in endogamy intentions and selective dating were accounted for by the model. Ethnocultural identity accounted for 63 percent of the variance in MEC.

51 Alternative paths were tested as in the Jewish sample, see footnote 43. 
(ii) Next the constructs of WHAT and HOW were introduced into the model. Due to multicollinearity ( $\mathrm{r}=.95)$, HOW was removed as it had a weaker loading on MEC $\left[\mathrm{X}^{2}(129)=292.11^{* * *}\right]$. To improve model fit, modification indices suggested the estimation of a direct path between ID and WHAT ${ }^{52}$. The final model is presented below in Figure 6.11.

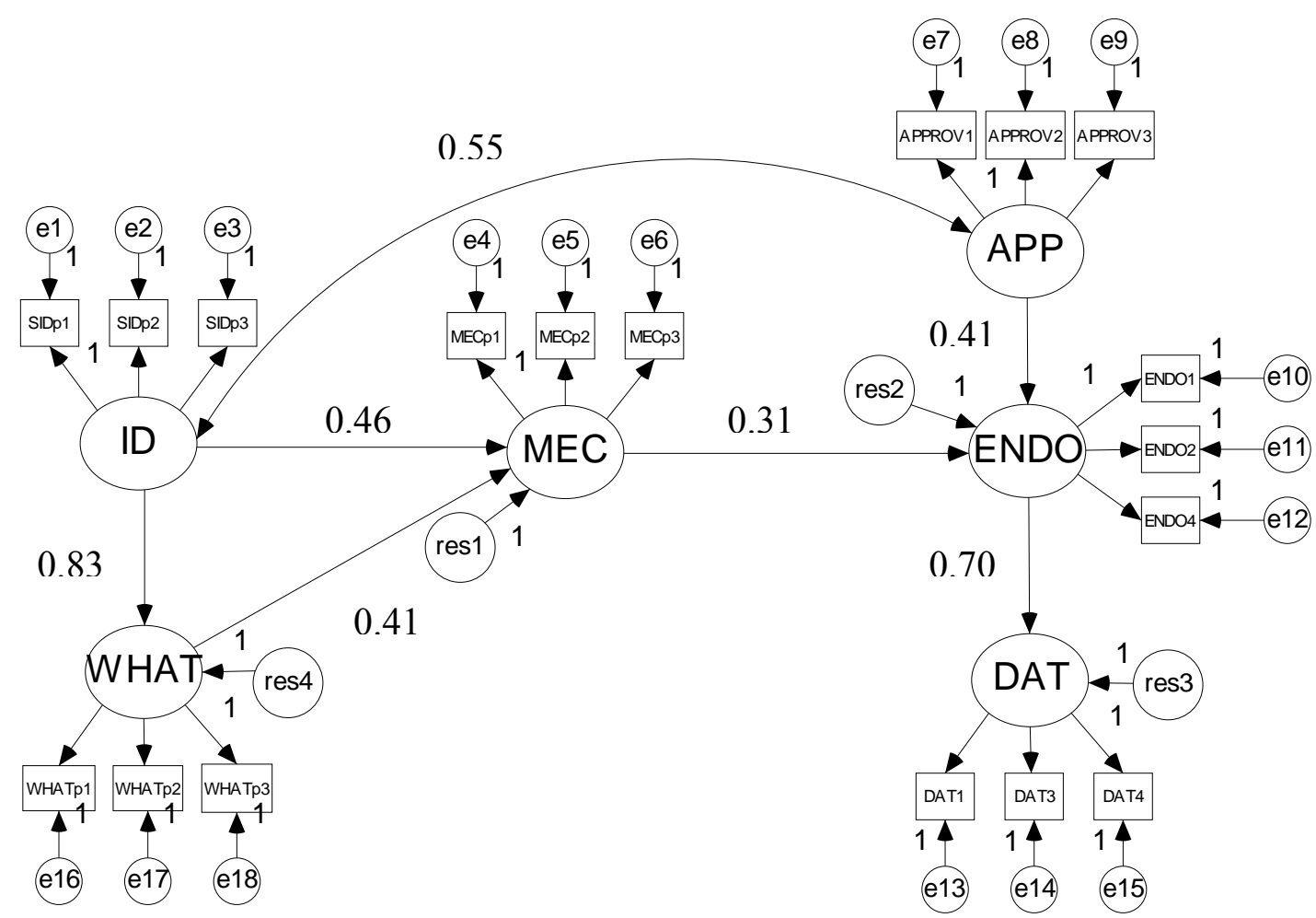

Figure 6.11: Including ethno-historical consciousness in a predictive model of endogamy among Māori

The goodness of fit indices were acceptable: $\mathrm{X}^{2}(128)=208.39, \mathrm{p}<.001, \mathrm{X}^{2} / \mathrm{df}=1.63$, RMSEA $=.08$, sRMR $=.07$, GFI $=.83, \mathrm{NFI}=.85$, and $\mathrm{CFI}=.93$. A chi-squared difference test demonstrated that model fit improved significantly when the relationship between identity and WHAT was estimated $\left[\mathrm{X}^{2}(1)=83.72^{* * *}\right]$. Furthermore, when ethno-historical consciousness was included in the model, 68 percent of the variance in

\footnotetext{
52 An alternative model was tested wherein ID mediated the relationship between WHAT and MEC. The factor loading of WHAT on MEC was not reduced, nor did this result in improved model fit.
} 
MEC was accounted for (an increase from 63 percent). Thus, including ethno-historical consciousness is important when modelling the process of Māori continuity.

\section{Testing the model among Chinese}

(i) The model in Figure 6.7 was tested in the Chinese sample. Motivation for Ethnocultural Continuity (MEC) was not a significant predictor of intentions for endogamy, nor was perceived similarity. A direct relationship between ethno-cultural identity and intentions for endogamy was also non-significant. Thus, attraction and social network approval were the only significant predictors of intentions for endogamy ${ }^{53}\left[X^{2}(51)=\right.$ 115.12***]. To improve model fit, modification indices suggested the estimation of a correlation between the two exogenous variables, see Figure 6.12 below.

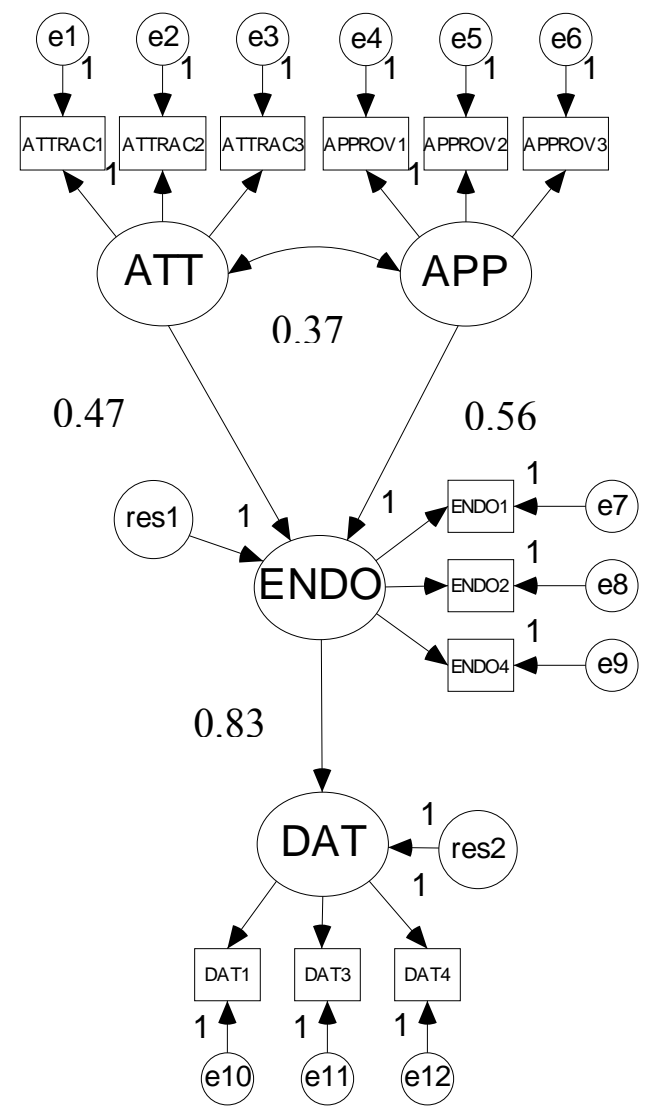

Figure 6.12: A predictive model of endogamy among Chinese

\footnotetext{
53 An alternative model was tested wherein selective dating was a predictor of endogamy intentions, yielding poorer model fit.
} 
A few of the goodness of fit indices were acceptable: $\mathrm{X}^{2}(50)=104.72, \mathrm{p}<.001, \mathrm{X}^{2} / \mathrm{df}=$ 2.09, RMSEA $=.10$, sRMR $=.08, \mathrm{GFI}=.86, \mathrm{NFI}=.85$, and CFI $=.91$. A chi-squared difference test revealed a significant improvement in model fit when the correlation between attraction and approval was estimated $\left[\mathrm{X}^{2}(1)=10.40 * *\right]$.

(ii) Given that MEC was not a significant predictor of endogamy intentions, the influence of WHAT and HOW on MEC will not be tested for the Chinese sample. Individual awareness of social representations of ethnic history is only of interest in this thesis in so far that it contributes to explaining the variance of a significant predictor of endogamy.

\section{Testing the cross-cultural generalisability of the predictive model}

Now that the predictive model of volitional endogamy has been tested within each ethnic group, the cultural generalisability of the model will be tested by examining shared paths which are invariant. Given that there was no need to constrain the measurement model across groups, path models were constructed that included paths shared with at least one other ethnic group. Indicators were composed of the means of the three parcels for each latent variable. Only endogenous variables had estimated error terms.

\section{How to test for invariant paths across ethnic groups}

First, baseline path models were established for each ethnic group. Then multi-group path models were conducted to examine overall model fit. Comparisons were made between the multi-group baseline model with unconstrained paths and a fully constrained model (where all shared paths were constrained to be equal across groups). This is known as an omnibus test. If a chi-squared difference test demonstrated a significant difference between the two models, this indicated that at least one of the paths varied across ethnic groups. The next step was to constrain each path separately to detect which were variant and which were invariant across groups. 


\section{Jews and Māori}

The paths that were shared between the Jewish and Māori samples were those from ethno-cultural identity (ID) to Motivation for Ethno-cultural Continuity (MEC); from ID to the ethno-historical consciousness WHAT scale, from WHAT to MEC; from MEC to intentions for endogamy (ENDO) and from ENDO to selective dating behaviour (DAT). Figures 6.13 and 6.14 below illustrate the baseline path models for each ethnic group.

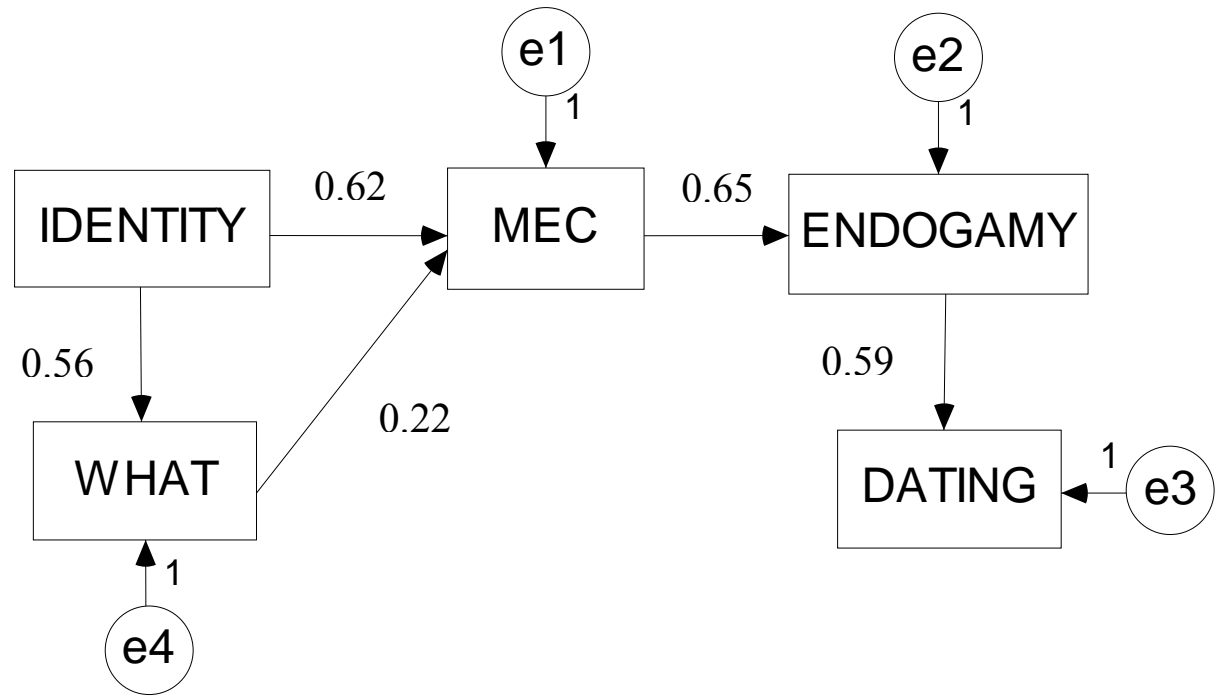

Figure 6.13: Path model for New Zealand Jews

The goodness of fit indices were acceptable: $\mathrm{X}^{2}(5)=4.43, \mathrm{p}>.05, \mathrm{X}^{2} / \mathrm{df}=.89$, RMSEA $=.00$, sRMR $=.03$, GFI $=.98, \mathrm{NFI}=.98$, and CFI $=1.0$. 


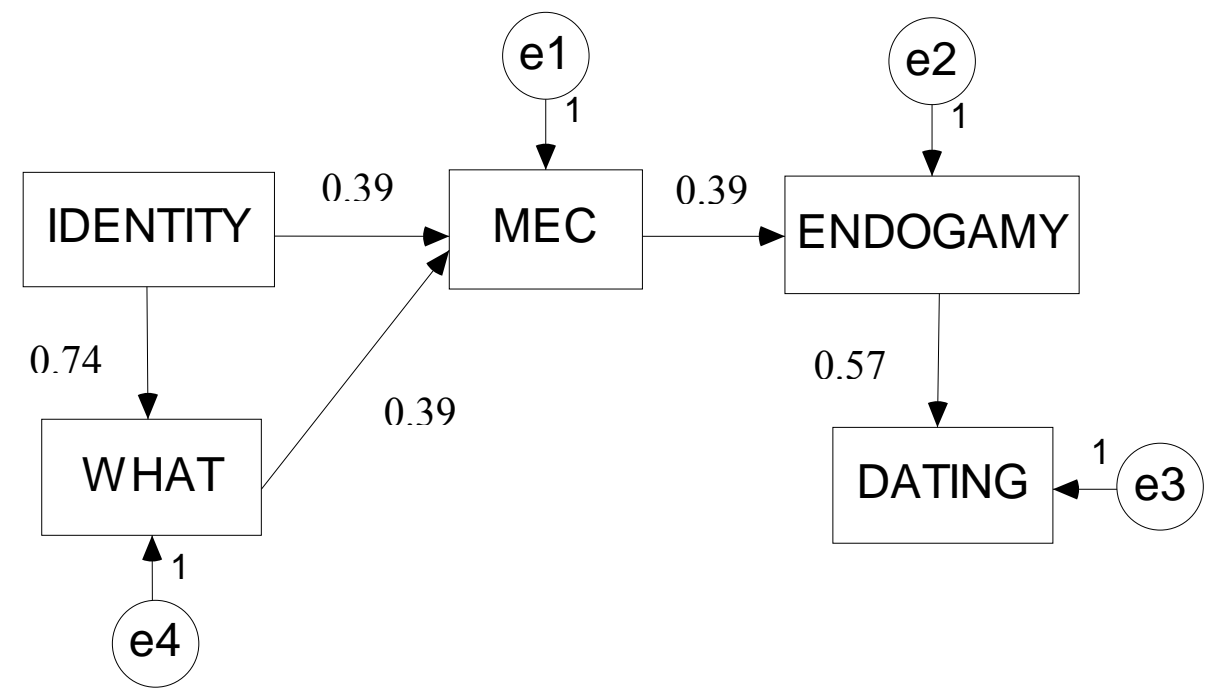

Figure 6.14: Path model for Māori (i)

The goodness of fit indices were acceptable: $\mathrm{X}^{2}(5)=6.41, \mathrm{p}>.05, \mathrm{X}^{2} / \mathrm{df}=1.28$, RMSEA $=.05, \mathrm{sRMR}=.07, \mathrm{GFI}=.98, \mathrm{NFI}=.97$, and $\mathrm{CFI}=.99$. Multi-group path models were conducted to test for invariant paths across the Jewish and Māori samples. Paths 1-5 shown below in Figure 6.15 were tested for invariance.

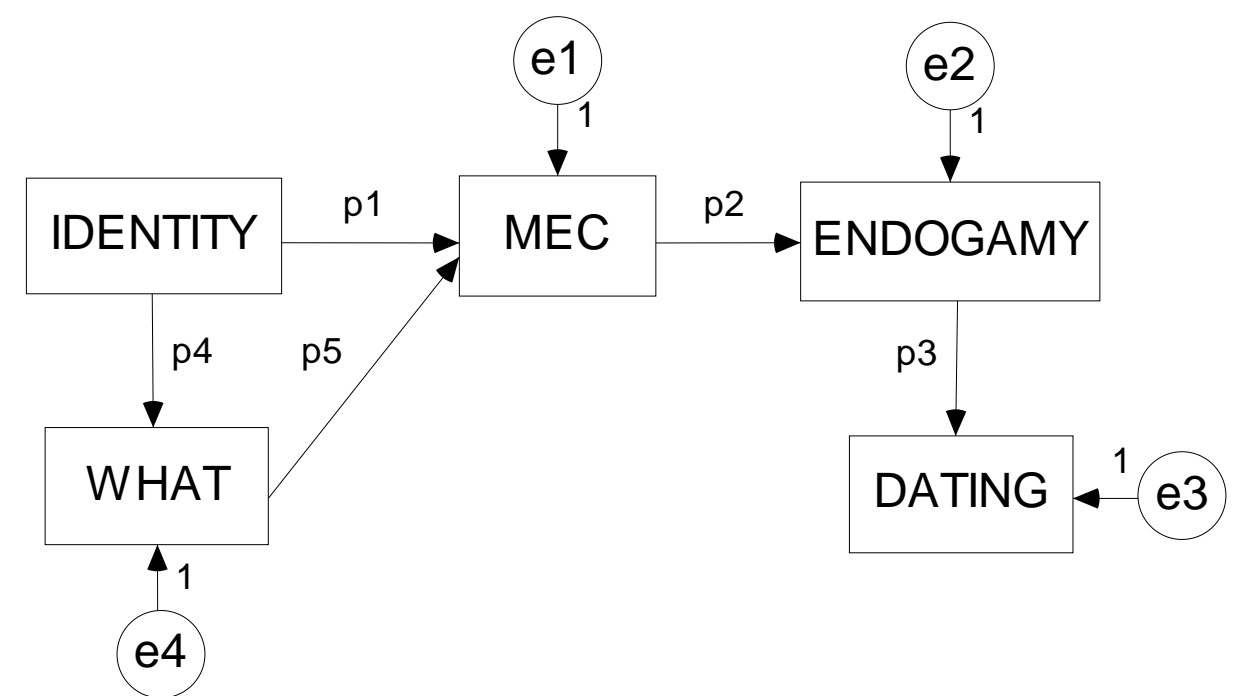

Figure 6.15: Multi-group path model for New Zealand Jews and Māori 
The goodness of fit indices of the unconstrained model (paths 1-5 were freely estimated) were acceptable: $\mathrm{X}^{2}(10)=10.84, \mathrm{p}>.05, \mathrm{X}^{2} / \mathrm{df}=1.08, \mathrm{RMSEA}=.02, \mathrm{sRMR}=.03$, GFI $=.95, \mathrm{NFI}=.94$, and $\mathrm{CFI}=.97$. This model was compared with the fully-constrained model (paths 1-5 were constrained to be equal across both ethnic groups). The chisquared value of this model $\left[\mathrm{X}^{2}(15)=39.15^{* * *}\right]$ and the baseline chi-squared of the unconstrained model were significantly different $\left[\mathrm{X}^{2}(5)=28.31 * * *\right]$, indicating that at least one of the paths varied across ethnic groups. Testing each path separately, chisquared difference tests showed that path one $\left[X^{2}(1)=9.03^{* *}\right]$ and path five $\left[X^{2}(4)=\right.$ $\left.14.23^{* *}\right]$ varied across groups. Overall, paths 2, 3 and 4 were invariant across the Jewish and Māori samples.

\section{Māori and Chinese}

The paths that were shared between the Māori and Chinese samples were those from social network approval (APP) and intentions for endogamy (ENDO), and from ENDO to selective dating behaviour (DAT). Figures 6.16 and 6.17 below illustrate the baseline model for each ethnic group.

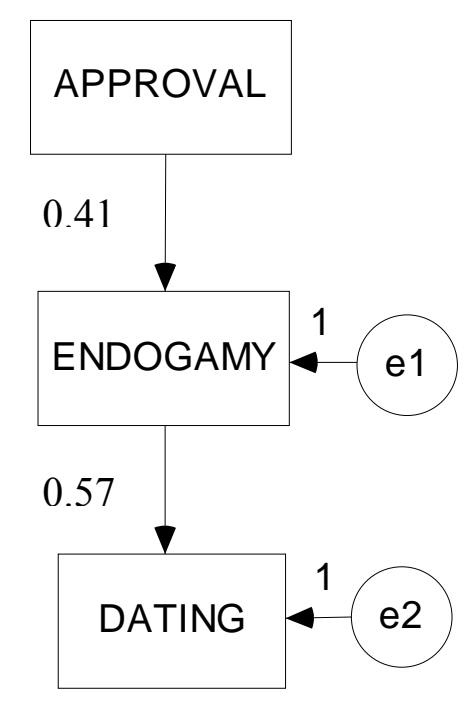

Figure 6.16: Path model for Māori (ii) 
The goodness of fit indices were as follows: $\mathrm{X}^{2}(1)=8.0, \mathrm{p}<.001, \mathrm{X}^{2} / \mathrm{df}=8.0$, RMSEA $=.26$, sRMR $=.08$, GFI $=.95$, NFI $=.88$, and CFI $=.89$. Note that the fit indices for the Māori sample were not very good because this simple model is not the best representation of the data for Māori.

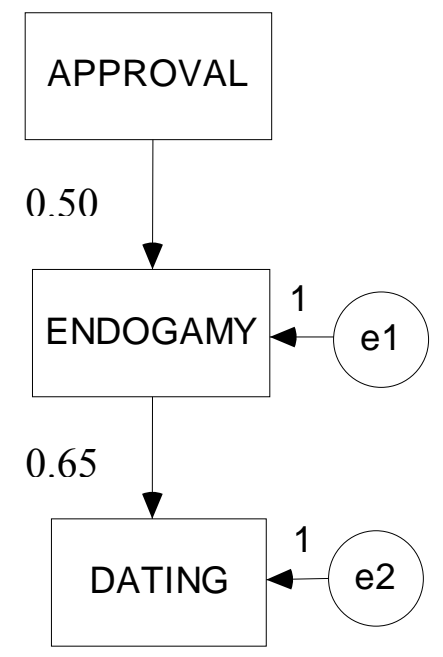

Figure 6.17: Path model for Chinese

The goodness of fit indices were acceptable: $\mathrm{X}^{2}(1)=0.2, \mathrm{p}<.001, \mathrm{X}^{2} / \mathrm{df}=0.2$,

RMSEA $=.00$, sRMR $=.02$, GFI $=.99, \mathrm{NFI}=.99$, and CFI $=1.0$. Multi-group path models were conducted to test for invariant paths across the Māori and Chinese samples. Paths 1 and 2 shown below in Figure 6.18 were tested for invariance.

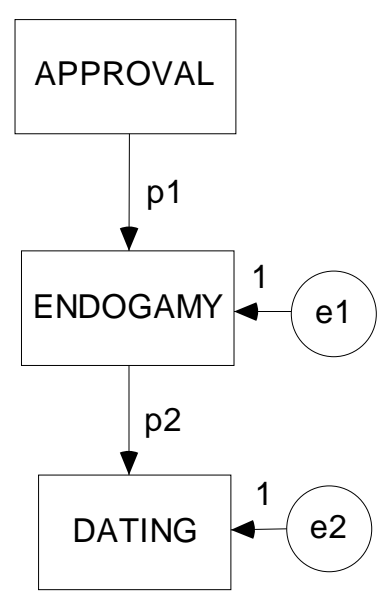

Figure 6.18: Multi-group path model for Māori and Chinese 
The goodness of fit indices of the unconstrained model were acceptable: $\mathrm{X}^{2}(2)=8.20$, $\mathrm{p}<.001, \mathrm{X}^{2} / \mathrm{df}=4.10, \mathrm{RMSEA}=.12, \mathrm{sRMR}=.08, \mathrm{GFI}=.98, \mathrm{NFI}=.95$, and $\mathrm{CFI}=.96$. A chi-squared difference test showed that there was no difference between the fully constrained model $\left[X^{2}(4)=11.61 *\right]$ and the unconstrained model $\left[X^{2}(2)=3.41\right]$. Thus, both paths were invariant across the Māori and Chinese samples.

\section{Jews, Māori and Chinese}

The only path that was shared among all three ethnic groups was that between intentions for endogamy (ENDO) and selective dating behaviour (DAT). The same model tested above between the Māori and Chinese samples served to test the path between ENDO and DAT across the Jewish, Māori and Chinese samples. As social network approval (APP) was not a significant predictor of ENDO for the Jewish sample, the path from APP to ENDO was constrained to 0.00 for the Jewish sample only. A few of the fit indices of the multi-group unconstrained model were acceptable: $\mathrm{X}^{2}(4)=28.55, \mathrm{p}<.001$, $\mathrm{X}^{2} / \mathrm{df}=7.14, \mathrm{RMSEA}=.14, \mathrm{sRMR}=.08, \mathrm{GFI}=.95, \mathrm{NFI}=.87$, and $\mathrm{CFI}=.88$. The model was compared with the fully constrained model $\left[\mathrm{X}^{2}(7)=32.65^{* * *}\right]$ whereby path 1 was constrained to be equal across the Māori and Chinese samples (we already know this path was invariant from the analyses above), and path 2 was constrained to be equal across the Jewish, Māori and Chinese samples. The chi-squared difference test was nonsignificant $\left[\mathrm{X}^{2}(3)=4.1\right]$. Thus, the path between ENDO and DAT was invariant across the Jewish, Māori and Chinese samples. These results confirm that across all three cultures, intentions for endogamy were strong and significant predictors of selective dating behaviour. 


\section{Discussion: Comparing the Ethno-cultural Continuity of Fiddlers with Warriors and Dragons}

As a cross-cultural comparison of ethno-cultural continuity, this study tested a predictive model of volitional endogamy that included the original construct of Motivation for Ethno-cultural Continuity. In so doing, this model went beyond the traditional ethnocentric perspective of research on endogamy by incorporating the long-term acculturation goal of ethno-cultural continuity. Each research question posited at the beginning of the chapter is addressed along with their accompanying hypotheses and results.

\section{Investigating mean group differences across three ethnic groups}

1. Do levels of Motivation for Ethno-cultural Continuity and individual awareness of social representations of ethnic history differ across cultures?

It was hypothesized that Jewish and Māori participants would have greater levels of MEC than Chinese participants. It was also hypothesized that Jewish participants would have a greater awareness of social representations of ethnic history and significantly higher levels of WHO, WHAT and HOW than Māori and Chinese participants.

Overall, while ethno-cultural continuity was important for all three ethnic groups (above the scale mid-point of 4), as hypothesized, Jews and Māori had significantly higher levels of MEC than Chinese. This is probably due to qualitative and quantitative differences in collective acculturation experiences, as outlined in Chapter three. While Chinese as a people are more secure due to their great population size, the collective experiences of Jews and Māori as 'small peoples' and their comparatively low ethnic vitality are likely to have had an impact on the subjective importance of ethno-cultural continuity.

A comparison of subjects of remembrance (WHO) across cultures was not possible since the construct did not exhibit structural equivalence. As for comparisons of 
ethno-historical consciousness, as hypothesized, remembrance of narratives (WHAT) was higher amongst Jews who remembered more narratives than Māori, who in turn remembered more narratives than Chinese. The observed difference between these groups may be due to qualitative differences in strategies for collective remembrance, in particular the emphasis in Jewish culture on rituals for commemorating historical events, as well as the instrumental role of history in Jewish life, a constitutional and prophetic narrative. While participants from all three ethnic groups remembered their ethnic history vicariously (HOW) as answers were above the scale mid-point of 4 , contrary to the original hypotheses, Māori had a greater vicarious experience of ethnic history than Jews, and Jews in turn had a greater vicarious experience than Chinese. Perhaps the recency of Māori history (hundreds of years) in contrast to the more distal Jewish history (thousands of years) contributes to this difference in affective remembrance.

2. Do intentions for endogamy and selective dating behaviour vary across cultures? It was hypothesized that Jewish participants would exhibit higher levels of both endogamy intentions and selective dating behaviour than Māori and Chinese participants.

While Jews demonstrated a mild intention to marry another Jewish person (only slightly above the scale mid-point of 4), Māori and Chinese were neutral towards endogamy (on and slightly below the scale mid-point). As hypothesized, Jews had greater intentions for endogamy than Māori and Chinese. This may be due to qualitative differences in strategies for collective continuity, as discussed in Chapter three. For Jews as an ethnic minority who primarily lived in the larger society with minimal political power, continuity rested on internal strategies such as endogamy. In contrast, Māori as indigenous peoples who can negotiate power-relations with the sovereign government have relied less on endogamy and more on inter-group strategies for revitalisation and continuity. As for 
Chinese, low endogamy intentions may be due to their great population size and minimal concern for collective continuity. Note that the mild intentions for endogamy among Jews may have been related to low perceived control or endogamy self-efficacy beliefs due to 'limited resources' i.e. the low ethnic vitality of the New Zealand Jewish community (this will be explored further in Chapter seven).

On average, Jews, Māori and Chinese did not engage in selective dating behaviour (all are below the scale mid-point of 4), with no significant differences across groups. While the low ethno-cultural vitality of the New Zealand Jewish community may be an inhibiting factor for selective dating, in comparison, Chinese and Māori have a greater pool of co-ethnic dating partners to choose from. The overall low levels of selective dating across all three ethnic groups may be due to positive inter-group relations in the larger New Zealand society, the fluidity of the dating scene for young adults, and differences in priorities where marriage may not have been of immediate concern for participants. Enjoying a present romance with any partner may trump future marital intentions with a co-ethnic partner.

\section{Investigating the predictive model across three ethnic groups}

3. Does Motivation for Ethno-cultural Continuity predict intentions for endogamy above and beyond similarity, attraction and social network approval?

It was hypothesized that MEC would predict intentions for endogamy above and beyond similarity, attraction and social network approval for Jewish and Māori participants. In contrast, it was hypothesized that MEC would not be a significant predictor of endogamy above and beyond the ethnocentric variables for Chinese participants.

As hypothesized, Motivation for Ethno-cultural Continuity (MEC) was a significant predictor of intentions for endogamy for both the Jewish and Māori samples, above and beyond traditional predictors of endogamy such as perceived similarity, attraction and 
social network approval. In fact, similarity and attraction were not significant for Jews or Māori when ethno-cultural identity was included in the model, and social network approval remained a significant predictor only for Māori.

However, MEC was not a significant predictor of intentions for endogamy for the Chinese sample. Thus, while MEC can be measured across all three ethnic groups, it has a different function. It seems that ethno-cultural continuity is functionally important only for 'small peoples' - for both ethno-cultural communities and indigenous peoples. Overall, as the low ethnic vitality of 'small peoples' is related to existential uncertainty, collective continuity is a real concern which impacts the individual behaviour of Jews and Māori but not of Chinese.

4. What is the function of Motivation for Ethno-cultural Continuity?

It was hypothesized that MEC would mediate the relationship between individual-level variables such as ethno-cultural identity, and intentions for endogamy.

As hypothesised, the relationship between ethno-cultural identity and intentions for endogamy was mediated by Motivation for Ethno-cultural Continuity for the Jewish and Māori samples. As such, MEC is a mediator variable; it is influenced by ethno-cultural identity and in turn shapes intentions for endogamy.

5. Does individual awareness of social representations of ethnic history predict Motivation for Ethno-cultural Continuity above and beyond ethno-cultural identity?

It was hypothesized that greater levels of ethno-historical consciousness (WHAT) and vicarious experience of ethnic history (HOW) would lead to greater levels of MEC, and that individual awareness of social representations of ethnic history would contribute to explaining the variance in MEC above that explained by ethno-cultural identity. 
As hypothesized, individual awareness of social representations of ethnic history contributed to the explained variance of Motivation for Ethno-cultural Continuity above that explained solely by ethno-cultural identity for both Jewish and Māori samples. However, the vicarious experience of ethnic history measure was not a significant predictor of MEC; for the sample of New Zealand Jews, HOW was not a significant predictor, and for the Māori sample it exhibited multicollinearity with WHAT.

6. What is the strongest predictor of selective dating behaviour?

It was hypothesized that behavioural intentions for endogamy would be the strongest predictor of selective dating behaviour, above and beyond similarity, attraction and social network approval.

As hypothesised, across all three ethnic groups intentions for endogamy were a strong and significant predictor of selective dating behaviour. This relationship was true to the Theory of Planned Behaviour as discussed in Chapter two, whereby intentions are immediate predictors of behaviour. Recall that since the population of interest was young, unmarried ethno-cultural adults who still exhibit agency in choice of marital partner, the closest behaviour to endogamy that could be measured was selective dating.

7. Are the relationships specified in the model generalisable across cultures?

It was hypothesized that the predictive model would function consistently across the Jewish and Māori samples and that some of the relationships specified in the model would be shared across all three samples.

As hypothesized, the predictive model of endogamy was almost identical in the Jewish and Māori samples, the only observed difference was that social network approval continued to be a significant predictor of endogamy intentions for Māori but not for Jews. Across both samples, ethno-cultural identity predicted ethno-historical consciousness; both constructs predicted Motivation for Ethno-cultural Continuity 
(MEC), and MEC in turn predicted endogamy intentions which directly predicted selective dating behaviour. The latter relationship was consistent across the Jewish, Māori and Chinese samples. Across the Māori and Chinese samples, the relation between social network approval and endogamy intentions was consistent.

Integrating the results from this study, it seems that the predictive model for volitional endogamy wherein individual concerns for collective continuity play a central role in predicting endogamy intentions functions only for 'small peoples'. This includes minority ethno-cultural groups (Jews) and indigenous peoples (Māori). For large peoples (Chinese), only traditional ethnocentric variables are predictors of endogamy intentions. Overall, the vitality of the ethno-cultural group has a direct impact not only upon individual levels of Motivation for Ethno-cultural Continuity, but also upon its function in a predictive model of endogamy.

\section{Limitations}

The first methodological limitation to be discussed arises from small sample sizes and the consequent limitations on model fit. Efforts were made to secure samples as large as possible. However, the number of parameters tested in the confirmatory factor analyses and structural equation models warranted larger samples. A second limitation is the sampling of highly identified participants from ethno-cultural organisations. As such, the results reported do not represent the whole spectrum of ethno-cultural young adults, in particular the unaffiliated. Perhaps such strong predictive paths would not be found amongst individuals who do not identify strongly with their ethno-cultural group. Furthermore, confirmatory factor analyses demonstrated the lack of the 3-factor structural equivalence for the WHO measure across cultures. This points to a limitation of the pilot study which tested the new measures on a sample of Jews only. It seems that 
subjects of remembrance are much more closely related for Māori and Chinese participants whilst they are clearly distinguished for Jewish participants.

Finally, a limitation stems from of the use of modification indices to alter the original predictive model. According to Kline (2005) and Garson (2008), model trimming can be conducted according to (a) theoretical justification, if a variable or path was predicted to have little or no influence and (b) empirical justification if paths are nonsignificant, if modification indices suggest a reduction of the chi-squared value if a path were estimated, if error terms covary, or for the sake of model parsimony. The risk associated with (b) is the capitalisation on chance variation of the samples in contrast to the variation in the population. Ethnocentric variables such as perceived similarity, attraction and social network approval were included in the original model because these variables had been consistently included in previous research on endogamy and selective dating. It was posited that MEC would predict endogamy intentions above and beyond these variables. Model trimming was conducted according to criteria a and b above, demonstrating that ethnocentric variables were indeed less important in predicting endogamy intentions among members of 'small peoples'. Thus, while the original model accounts for the predictive power of both ethnocentrism and continuity, the final models show that continuity plays a more important role in the endogamous behaviour of 'small peoples' (Jews and Māori) but ethnocentrism plays a more important role in the endogamous behaviour of 'large' peoples (Chinese).

Next, Chapter seven investigates the effect of vitality within the same ethnocultural group by examining the predictive model in samples of four Jewish diaspora communities in New Zealand, Australia, Canada and the United States. 


\section{CHAPTER 7: A Cross-NATIONAL COMPARISON OF JEWISH CONTINUITY IN THE DIASPORA}

\section{Testing a predictive model for volitional endogamy across Jews in New Zealand, Australia, Canada and the United States}

Over 2,000 years, the Jewish diaspora has experienced long-term acculturation and massive geographic dispersion. Jews lived primarily as sojourners in larger societies that differed widely in domains such as language, customs, civic policies, religious ideologies, and tolerance. Over different periods of time, some diaspora communities have been more successful than others in terms of Jewish population size, available resources, and cultural and intellectual creativity. During the Middle Ages, Prague became the cultural and religious centre of the Jewish people in Europe (see the vine relief inside the OldNew Synagogue in Prague, c1270, p.ii). Due to negative external forces such as antiSemitism, communities died and populations were transported from one continent to another. In the $21^{\text {st }}$ century, the strongest community is found in the United States, where 67.6 percent of diaspora Jewry reside. It is of interest to examine how community vitality impacts the psychological process of Jewish continuity. To this end, samples of Jews from the largest community in the United States (New York - 2,051,000 Jews) will be compared with samples of large Jewish communities from other settler societies that were a part of the former British Empire and share similar Anglo-Saxon cultures, in particular Canada (4.7 percent of diaspora Jewry; the largest community is in Toronto 180,000 Jews), Australia (1.3 percent of diaspora Jewry, the largest community is in Melbourne - 37,800 Jews) and New Zealand (0.05 percent of diaspora Jewry, the largest communities are in Auckland and Wellington - 4,300 Jews). As members of 'small peoples', Jews from all four communities should be concerned about ethno-cultural 
continuity. However, vitality may affect individual acculturation such that members of smaller communities who have limited resources may be more concerned about ethnocultural continuity than members of larger communities, but because of their limited resources they may not engage in as much continuity-enhancing behaviours (i.e. endogamy and selective dating) as members of larger communities.

\section{Research questions and hypotheses}

1. Do levels of Motivation for Ethno-cultural Continuity and individual awareness of social representations of ethnic history differ across communities that vary in vitality?

It is hypothesized that MEC may decrease as community vitality increases, with incrementally greater concerns among the major Jewish communities sampled in the United States, Canada, Australia and New Zealand. In contrast, individual awareness of social representations of ethnic history may increase as community vitality increases.

2. Do intentions for endogamy and selective dating behaviour differ across communities that vary in vitality?

It is hypothesized that intentions for endogamy and selective dating behaviour may increase as community vitality increases due to the greater pool of potential Jewish dating and marriage partners, with incrementally higher endogamy intentions and selective dating behaviour among the communities sampled in New Zealand, Australia, Canada and the United States.

3. How does the predictive model for volitional endogamy function across communities that vary in vitality?

It is hypothesized that MEC is a significant predictor for endogamy above and beyond similarity, attraction and social network approval for all four community samples. 
4. Do both cognitive and affective measures of individual awareness of social representations of ethnic history predict Motivation for Ethno-cultural Continuity above and beyond ethno-cultural identity?

Although only the cognitive measure - ethno-historical consciousness (WHAT) was a significant predictor of MEC for New Zealand Jews (see Chapter 6), it is hypothesized that across the sampled communities the affective measure - vicarious experience of ethnic history (HOW) is also a predictor of MEC above ethno-cultural identity.

\section{Procedure}

Ethical approval for this research was obtained from the Victoria University of Wellington School of Psychology Human Ethics Committee. Participation in the study was through the same voluntary and anonymous online survey used in the cross-cultural study (see Chapter six). Participants from all four communities were recruited from Jewish young adult ethno-cultural organisations and tertiary institutions in cities from four diaspora nations that have a high concentration of Jews. Since the total Jewish population in New Zealand is very small, data was collected from two major cities. Participants were obtained through the Australasian Union of Jewish Students (AUJS) in Auckland and Wellington, B'nei Brith Young Adults (BBYA) in Auckland and JewNet in Wellington. Australian Jewish participants were recruited through the Australasian Union of Jewish Students (AUJS) and Hagshama in Melbourne. In Canada, participants were obtained in Toronto through Hillel at the University of Toronto and at York University. In the United States, participants were recruited in New York through Hillel at New York University and Colombia University. Recruitment proceeded in the same manner described in Chapter six. Note that data collection in New York occurred over the Thanksgiving/Christmas period in 2005 which is a very busy time for students, limiting the sample size. 
Data collection in Canada occurred in January 2006 after the New Year's break. Data was collected in New Zealand in March 2006 and in Australia in April 2006.

\section{Participants}

Participants were sampled from four diaspora communities that vary greatly in vitality in terms of demographic characteristics. As in the cross-cultural comparison, the desired number of total participants was at least 100 from each Jewish community. All participants had the following characteristics in common: self-defined ethno-cultural identity as Jewish; New Zealand, Australian, Canadian or American citizenship; and single marital status. Table 7.1 below presents population and sample characteristics; the number of participants, ethnic heritage, age, gender, generation and religious identification. Note that as in the cross-cultural study, the final number of participants used in the analyses is lower than the number of people who actually completed the survey due to factors such as citizenship restrictions, age, and removing outliers for specific items.

Looking at the ethnic heritage of participants, it is evident that most Australian, Canadian and American Jews came from endogamous families, having both a Jewish mother and father. In contrast, more New Zealand Jews came from exogamous families with less than 90 percent having a Jewish mother and 80 percent having a Jewish father. Non-Jewish parents across all four samples were designated by another ethnic group/nationality or as Christian, Atheist or Agnostic. Two mothers were specified as having converted and these were counted as Jewish. 
Table 7.1: Population and sample characteristics in the cross-national study

\begin{tabular}{|c|c|c|c|c|}
\hline & $\begin{array}{c}\text { New Zealand Jews } \\
\text { (Auckland \& } \\
\text { Wellington) }\end{array}$ & $\begin{array}{c}\text { Australian } \\
\text { Jews } \\
\text { (Melbourne) }\end{array}$ & $\begin{array}{l}\text { Canadian } \\
\text { Jews } \\
\text { (Toronto) }\end{array}$ & $\begin{array}{c}\text { American } \\
\text { Jews } \\
\text { (New York) }\end{array}$ \\
\hline National Jewish & 6,800 & 101,000 & 371,000 & 5290,000 \\
\hline $\begin{array}{l}\text { population size } \\
\text { (absolute \& relative) }\end{array}$ & $0.17 \%$ & $0.50 \%$ & $1.20 \%$ & $1.80 \%$ \\
\hline Jewish Community & 4,300 & 37,800 & 180,000 & $2,051,000$ \\
\hline $\begin{array}{l}\text { sample size } \\
\text { (absolute } \& \text { relative) }\end{array}$ & $0.27 \%$ & $1.12 \%$ & $3.9 \%$ & $9.7 \%$ \\
\hline $\begin{array}{l}\text { N completed } \\
\text { surveys }\end{array}$ & 120 & 107 & 167 & 109 \\
\hline $\begin{array}{l}\mathrm{N} \text { participants in } \\
\text { SEM analyses }\end{array}$ & 106 & 108 & 160 & 107 \\
\hline $\begin{array}{l}\mathrm{N} \text { participants in } \\
\text { analyses of mean } \\
\text { group differences }\end{array}$ & 101 & 101 & 156 & 107 \\
\hline Ethnic heritage & $88.1 \%$ Jewish M & $98 \%$ Jewish M & $95.5 \%$ Jewish $\mathrm{M}$ & $94.4 \%$ Jewish M \\
\hline (Mother/Father) & $80.2 \%$ Jewish F & $99 \%$ Jewish F & $94.9 \%$ Jewish F & $95.3 \%$ Jewish F \\
\hline Age & $23.71(4.45)$ & $21.38(2.64)$ & $21.38(2.75)$ & $22.64(3.34)$ \\
\hline Gender & $\begin{array}{l}60 \text { females } \\
41 \text { males }\end{array}$ & $\begin{array}{l}64 \text { females } \\
37 \text { males }\end{array}$ & $\begin{array}{l}104 \text { females } \\
52 \text { males }\end{array}$ & $\begin{array}{l}69 \text { females } \\
38 \text { males }\end{array}$ \\
\hline First generation & $46(45.5 \%)$ & $17(16.8 \%)$ & $39(25 \%)$ & $11(10.3 \%)$ \\
\hline Second generation & $34(33.7 \%)$ & $43(42.6 \%)$ & $47(30.1 \%)$ & $29(27.1 \%)$ \\
\hline Third generation & $17(16.8 \%)$ & $40(39.6)$ & $45(28.8 \%)$ & $34(31.8 \%)$ \\
\hline Fourth generation & $4(4 \%)$ & $1(1 \%)$ & $25(16 \%)$ & $33(30.8 \%)$ \\
\hline Orthodox & $30.7 \%$ & $66.3 \%$ & $25 \%$ & $36.4 \%$ \\
\hline Conservative & $9.9 \%$ & $12.9 \%$ & $37.8 \%$ & $39.3 \%$ \\
\hline Reform & $35.6 \%$ & $5 \%$ & $25.6 \%$ & $15.9 \%$ \\
\hline Traditional/Cultural & $10.9 \%$ & $9.9 \%$ & $5.1 \%$ & $2.8 \%$ \\
\hline Secular & $3 \%$ & $1 \%$ & $3.2 \%$ & - \\
\hline
\end{tabular}

A one-way ANOVA revealed a significant difference in mean age between the four Jewish communities $\underline{F}(3,461)=13.00, \underline{p}<0.001$. A Tukey post-hoc test revealed that the New Zealand and American samples were a few years older than the Australian and Canadian samples. No significant differences in age were found between the former two and latter two groups. 
Regarding gender distribution, there were slightly more females than males in all four samples. However, a chi-squared test failed to reveal a significant relationship between ethnicity and gender $\mathrm{X}^{2}(3, \mathrm{n}=465)=1.43, \mathrm{p}=.70$. A chi-squared test did reveal a significant relationship between ethnicity and generation $\mathrm{X}^{2}(9, \mathrm{n}=465)=86.31$, $\mathrm{p}<0.001$, whereby the New Zealand sample consisted of participants who were predominantly first and second generation, in contrast to the Australian and Canadian samples which were mostly second and third generation and the American sample which was largely third and fourth generation (and thus the oldest migrant community sampled). These differences are consistent with the ethnographic characteristics of each of the four communities (see Chapter 3).

Before examining differences in Jewish religious identification in each sample, it is important to recall that Jews are an ethno-cultural and religious group (see Chapter 3). Heterogeneity in Jewish religious ideology was a reaction to large-scale acculturation (post-emancipation, i.e. once Jews were accorded citizenship rights). The resulting range in Jewish identification is characterised by differences in adherence to traditional customs, from being strictly kosher to setting aside kosher eating patterns, from prayers in Hebrew with men and women seated separately to prayers in English and mixed gender seating, and from the endorsement of endogamy to the acceptability of intermarriage. In general, Orthodox Jews are most traditional, followed by Conservative Jews and then Reform Jews who are less traditional.

Diaspora Jewish communities vary according to what religious denominations are practiced. Of the aggregate sample of 465 Jews across the four communities, 457 identified with a specific denomination. Across the four samples there were 176 Orthodox Jews, 124 Conservative Jews, 98 Reform Jews, 32 Traditional Jews, and 9 Secular Jews (not religious at all). Due to the low numbers in the latter two groups, analyses in this thesis regarding religious identification will only focus on the three 
principal groups: Orthodox, Conservative and Reform. Figure 7.1 below outlines the religious profiles of each of the four communities according to these three denominations. A chi-squared test revealed a significant relationship between country and religious identification $\mathrm{X}^{2}(6, \mathrm{n}=465)=87.57, \mathrm{p}<0.001$. While most New Zealand Jews self-identified as Reform ${ }^{54}$ and Orthodox (approximately a third in each denomination), two-thirds of Australian Jews identified as Orthodox. Approximately two-fifths of Canadian and American Jews identified as Conservative Jews ${ }^{55}$. While the identification of the remaining Canadian Jews was spread evenly across Orthodox and Reform, a third of American Jews identified as Orthodox and only one-sixth as Reform. Overall, the Australian sample was the most religious in terms of stricter adherence to Jewish law. Note that the distribution of religious denominations across these four samples was not representative of the distribution of religious denominations across the four Jewish community populations (see Chapter 3).

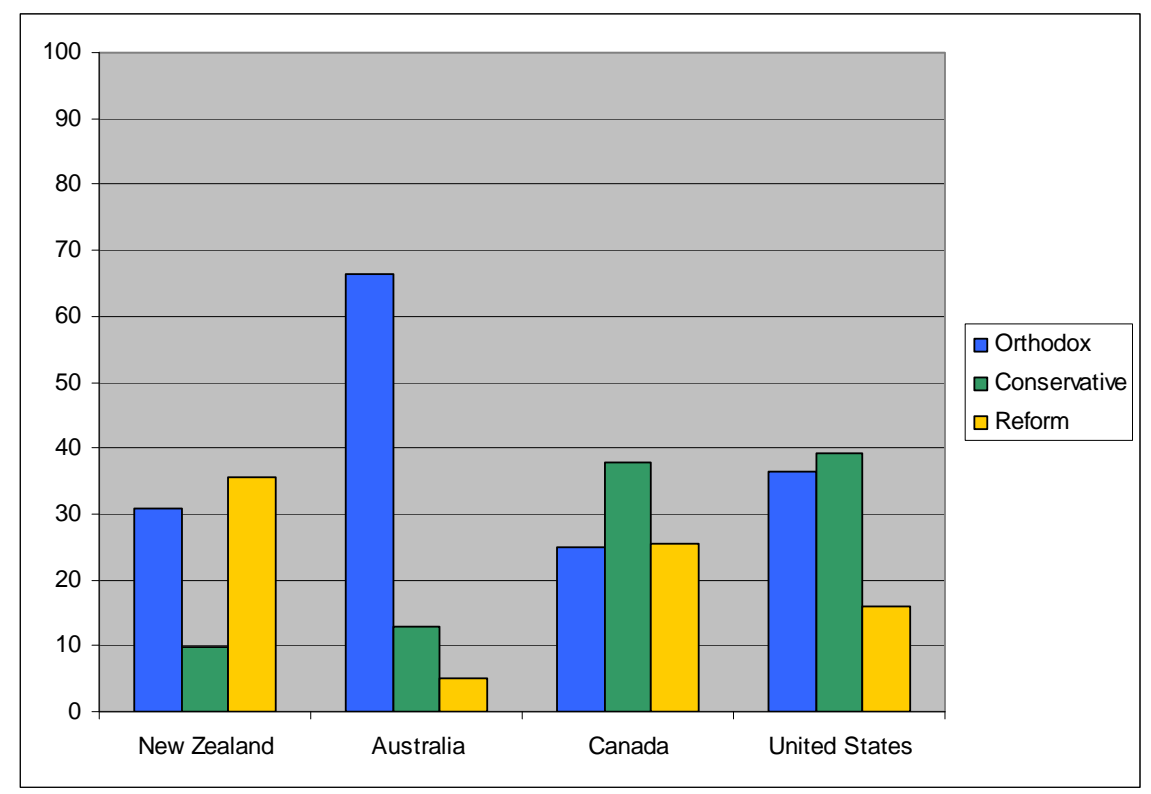

Figure 7.1: Religious identity profiles of Jewish community samples

\footnotetext{
${ }^{54}$ As the vitality of the New Zealand Jewish community is low and the incidence of intermarriage is high, many identify with Reform Judaism which is the denomination that officially welcomes intermarried families.

55 There are no official Conservative synagogues in New Zealand, hence few New Zealand Jews identify with this denomination.
} 


\section{Materials: Questionnaire design}

The questionnaire was identical to the online questionnaire for the cross-cultural study described in Chapter 6: (a) demographic information of participants; measures of (b) ethno-cultural identity; (c) individual awareness of social representations of ethnic history; (d) Motivation for Ethno-cultural Continuity; (e) perceived similarity, attraction and social network approval; and (f) intentions for endogamy and selective dating behaviour.

\section{Results}

Analyses presented in this section are as follows: (a) psychometric properties of scales;

(b) mean group differences; and (c) testing the predictive model of endogamy in four diaspora Jewish communities.

\section{Scale psychometric properties}

Table 7.2 below presents the number of scale items ${ }^{56}$, scale reliabilities, means and standard deviations for all scales across the four Jewish community samples. In general, the scale reliabilities range from good to excellent; the reliability of the social network approval scale for the Canadian sample and the reliabilities of the WHO-general, WHAT and HOW scale for the Australian sample were slightly below the recommended alpha value of 0.70 .

\footnotetext{
56 The items used were the same unbiased items in the cross-cultural study (Chapter six) so that comparisons of all six samples in this thesis could be made.
} 
Table 7.2: Scale psychometric properties (cross-national comparison)

\begin{tabular}{|c|c|c|c|c|c|c|c|c|c|}
\hline & & $\mathrm{Ner}$ & w Zealand & & ustralia & & Canada & Un & ited States \\
\hline & $\begin{array}{c}\mathrm{N} \\
\text { items }\end{array}$ & $\alpha$ & $\mathrm{M}(\mathrm{S} . \mathrm{D})$ & $\alpha$ & $\mathrm{M}(\mathrm{S} . \mathrm{D})$ & $\alpha$ & $\mathrm{M}(\mathrm{S} . \mathrm{D})$ & $\alpha$ & $\mathrm{M}(\mathrm{S} . \mathrm{D})$ \\
\hline $\begin{array}{l}\text { Ethnic } \\
\text { Identity } \\
\text { WHO }\end{array}$ & 12 & 0.86 & $6.00(0.82)$ & 0.83 & $6.35(0.64)$ & 0.84 & $6.00(0.78)$ & 0.88 & $6.19(0.77)$ \\
\hline Family & 4 & 0.89 & $5.17(1.53)$ & 0.77 & $5.88(1.08)$ & 0.84 & $5.59(1.24)$ & 0.81 & $5.47(1.22)$ \\
\hline Local & 4 & 0.82 & $4.29(1.48)$ & 0.84 & $5.41(1.31)$ & 0.81 & $4.89(1.40)$ & 0.80 & $5.44(1.11)$ \\
\hline General & 4 & 0.85 & $5.62(1.26)$ & 0.67 & $6.38(0.71)$ & 0.75 & $5.84(1.06)$ & 0.82 & $5.98(1.02)$ \\
\hline WHAT & 7 & 0.73 & $6.13(0.79)$ & 0.69 & $6.40(0.63)$ & 0.75 & $6.22(0.77)$ & 0.79 & $6.22(0.77)$ \\
\hline HOW & 5 & 0.79 & $5.39(1.15)$ & 0.64 & $5.85(0.87)$ & 0.71 & $5.53(1.01)$ & 0.79 & $5.68(1.07)$ \\
\hline MEC & 5 & 0.89 & $6.16(1.00)$ & 0.81 & $6.71(0.48)$ & 0.86 & $6.37(0.82)$ & 0.86 & $6.54(0.70)$ \\
\hline Similarity & 3 & 0.85 & $5.18(1.23)$ & 0.86 & $5.63(1.13)$ & 0.78 & $5.21(1.13)$ & 0.81 & $5.45(0.92)$ \\
\hline Attraction & 3 & 0.90 & $4.99(1.27)$ & 0.77 & $5.30(1.02)$ & 0.89 & $5.31(1.15)$ & 0.86 & $5.24(1.05)$ \\
\hline Approval & 3 & 0.75 & $5.69(1.13)$ & 0.71 & $5.92(1.37)$ & 0.66 & $6.12(1.03)$ & 0.76 & $6.04(1.21)$ \\
\hline Endogamy & 4 & 0.88 & $4.72(1.77)$ & 0.73 & $6.34(0.91)$ & 0.84 & $6.02(1.23)$ & 0.93 & $5.94(1.57)$ \\
\hline Dating & 3 & 0.72 & $3.04(1.82)$ & 0.84 & $5.72(1.77)$ & 0.82 & $5.29(1.87)$ & 0.86 & $5.16(2.07)$ \\
\hline
\end{tabular}

\section{Ethno-cultural identity}

Overall, ethno-cultural identity among participants was very high (above the scale midpoint of 4 , averaging 6.12 when the samples are aggregated). This is likely due to the sampling methodology which is the same as in the cross-cultural study, whereby individuals were recruited from ethno-cultural organisations. As their membership is voluntary, it is likely that affiliated persons identify more strongly with their ethnocultural group than non-affiliated people. Thus, although the results of analyses conducted in this thesis characterize one strata of young diaspora Jews, they do not represent the whole spectrum of Jewish identity - in particular the unaffiliated. 


\section{Mean group comparisons}

Meaningful comparisons of Motivation for Ethno-cultural Continuity, subjects of remembrance, ethno-historical consciousness and vicarious experience of ethnic history were made across the four diaspora Jewish community samples without conducting item bias analyses since the samples were from the same ethno-cultural group. The items used in the mean group comparisons were the unbiased items from the cross-cultural comparisons in Chapter six so that scores from all six samples could be compared.

To control for participant differences in age and religious identification ${ }^{57}$, one-way Analyses of Covariance were conducted where country served as the independent variable and participant age and religious identity constituted the covariates ${ }^{58}$. Table 7.3 below presents the adjusted means and standard errors.

Table 7.3: Descriptive statistics (adjusted mean, std.error) for New Zealand, Australian, Canadian and American Jews.

\begin{tabular}{lcccc}
\hline & New Zealand & Australia & Canada & United States \\
\hline MEC & $6.31(.08)$ & $6.55(.08)$ & $6.49(.06)$ & $6.59(.07)$ \\
WHO & & & & \\
Family & $5.34(.14)$ & $5.76(.14)$ & $5.65(.11)$ & $5.48(.12)$ \\
Local & $4.32(.15)$ & $5.18(.15)$ & $5.02(.11)$ & $5.48(.13)$ \\
General & $5.68(.11)$ & $6.24(.11)$ & $5.93(.09)$ & $5.97(.10)$ \\
WHAT & $6.16(.08)$ & $6.34(.08)$ & $6.30(.06)$ & $6.24(.07)$ \\
HOW & $5.42(.11)$ & $5.69(.11)$ & $5.62(.08)$ & $5.74(.10)$ \\
Endogamy & $4.95(.14)$ & $5.98(.13)$ & $6.28(.10)$ & $6.03(.12)$ \\
Dating & $3.38(.19)$ & $5.22(.19)$ & $5.67(.15)$ & $5.26(.17)$ \\
\hline
\end{tabular}

\footnotetext{
${ }^{57}$ Religious identification was included as a covariate since the proportion of identification with the three major denominations (from the less traditional Reform to Conservative and to the more traditional Orthodox) in each sample was not representative of the religious affiliation of their respective populations. In contrast, demographic differences in generation do reflect actual population characteristics of the four Jewish communities; as such generation was not included as a covariate.

${ }^{58}$ Gender was not included as a covariate since its distribution did not differ across the four samples.
} 
After adjusting for participant age and religious denomination, there was no significant difference in MEC levels across the four Jewish communities $[\underline{\mathrm{F}}(3,392)=2.53$, $\mathrm{p}=0.06$, partial eta squared $=.02]$. Note that overall levels of MEC were quite high (above the scale mid-point). Thus, MEC is very important to Jews in all four communities.

A mixed between-within ANCOVA was conducted revealing a small significant main effect for subjects of remembrance (WHO) after accounting for the effect of the covariates [Wilks' Lambda $=0.95, \mathrm{~F}(2,391)=10.40, \mathrm{p}<.001$, partial eta squared $=.05]$. Post-hoc tests demonstrated that general Jewish history is remembered more than both family and local Jewish history, and family Jewish history is remembered more than local Jewish history. A small significant main effect for country was also found $[\mathrm{F}(3,392)=6.20, \mathrm{p}<0.001$, partial eta squared $=.05]$, whereby New Zealand Jews recalled less than Australian, Canadian and American Jews. There was also a significant interaction effect between country and subjects of remembrance [Wilks' Lambda $=0.91, \mathrm{~F}(6,782)=6.06, \mathrm{p}<0.001$, partial eta squared $=.04]$. Unlike New Zealand, Australian and Canadian Jews, American Jews did not recall more family history than local history.

A one-way Analysis of Covariance revealed that there were no significant differences in ethno-historical consciousness (WHAT) across New Zealand, Australian, Canadian and American Jews after accounting for the effect of the covariates $[\mathrm{F}(3,392)=0.93, \mathrm{p}=.43$, partial eta squared $=.01]$. Similarly, there were no significant differences in vicarious experience of history between New Zealand, Australian, Canadian and American Jews $[\mathrm{F}(3,392)=1.72, \mathrm{p}=.16$, partial eta squared $=.01]$ 
A strong significant effect was found for country on endogamy intentions after accounting for the effect of the covariates $[\mathrm{F}(3,392)=20.68, \mathrm{p}<0.001$, partial eta squared $=.14]$. Post-hoc tests demonstrated that New Zealand Jews had significantly lower endogamy intentions than Australian, Canadian, and American Jews. Similarly, a strong significant effect was found for country on selective dating $[\mathrm{F}(3,392)=31.18$, $\mathrm{p}<0.001$, partial eta squared $=.19]$. Post-hoc tests demonstrated that New Zealand Jews had lower selective dating behaviour than Australian, Canadian, and American Jews. Note that the mean selective dating behaviour of the New Zealand sample is below the scale mid-point of four, indicating that on average they do not engage in selective dating, in contrast to Australian, Canadian and American Jews who do date fellow Jews.

\section{Testing the predictive model across four samples of diaspora Jews}

This section presents structural equation models to test the predictive model for each Jewish community sample separately. Subsequently, path models are presented which test for invariant paths across the four samples in order to investigate the generalisability of the model across communities that vary in vitality.

The proposed model for ethno-cultural continuity (Figure 6.1) has already been tested for the New Zealand Jewish sample in Chapter 6. While similarity, attraction and social network approval were not significant, ethno-cultural identity and Motivation for Ethno-cultural Continuity (MEC) were significant predictors of behavioural intentions for endogamy. Furthermore, intentions for endogamy were a strong and significant predictor of selective dating behaviour. In addition, WHAT as a cognitive measure of individual awareness of social representations of ethnic history was a significant predictor of MEC. Now the predictive model will be tested across the Australian, Canadian and American Jewish samples. 
A graphic representation of the structural model to be tested is re-presented below (same as Figure 6.7; note that the influence of WHAT and HOW on MEC is omitted at this first stage).

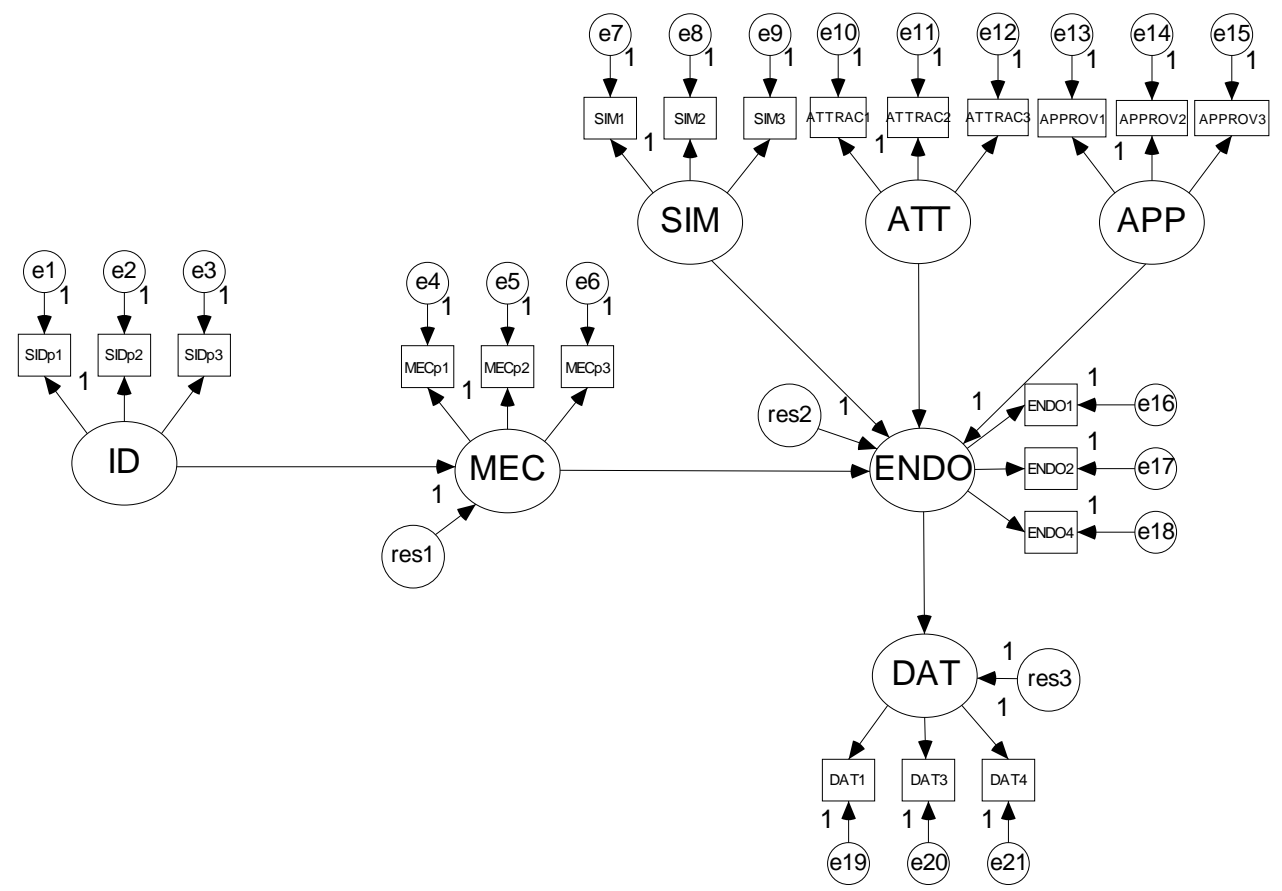

Figure 7.2: Testing a predictive model of volitional endogamy

The same item parcels that were used to test the model in the New Zealand Jewish sample will be used for the Australian, Canadian and American samples. The reliability of the item parcels for the latent constructs of ethnic identity (ID), Motivation for Ethnocultural Continuity (MEC), the ethno-historical consciousness measure WHAT and vicarious experience of ethnic history measure HOW are presented below in Table 7.4. Across the three Jewish samples the item parcels demonstrated good reliability for their respective latent variables. 
Table 7.4: Reliability of item parcels for the latent variables (cross-national comparison)

\begin{tabular}{lllll}
\hline & ID & MEC & WHAT & HOW \\
\hline Australia & 0.87 & 0.95 & 0.78 & 0.75 \\
Canada & 0.84 & 0.90 & 0.70 & 0.72 \\
United States & 0.87 & 0.91 & 0.76 & 0.84 \\
\hline
\end{tabular}

\section{Testing the model among Australian Jews}

(i) The model in Figure 7.2 was tested in the sample of Australian Jews. Model fit was poor; attraction was not a significant predictor of intentions for endogamy and social network approval was no longer a significant predictor when a correlation was estimated with ethno-cultural identity as suggested by the modification indices. The estimation of a correlation between similarity and ethno-cultural identity, and a direct path from similarity to selective dating led to improved model fit ${ }^{59}$, illustrated below in Figure 7.3.

\footnotetext{
${ }^{59}$ Direct paths from identity to endogamy and identity to dating were non-significant. An alternative model was tested whereby selective dating mediated the relationship between MEC and intentions for endogamy, resulting in worse fit.
} 


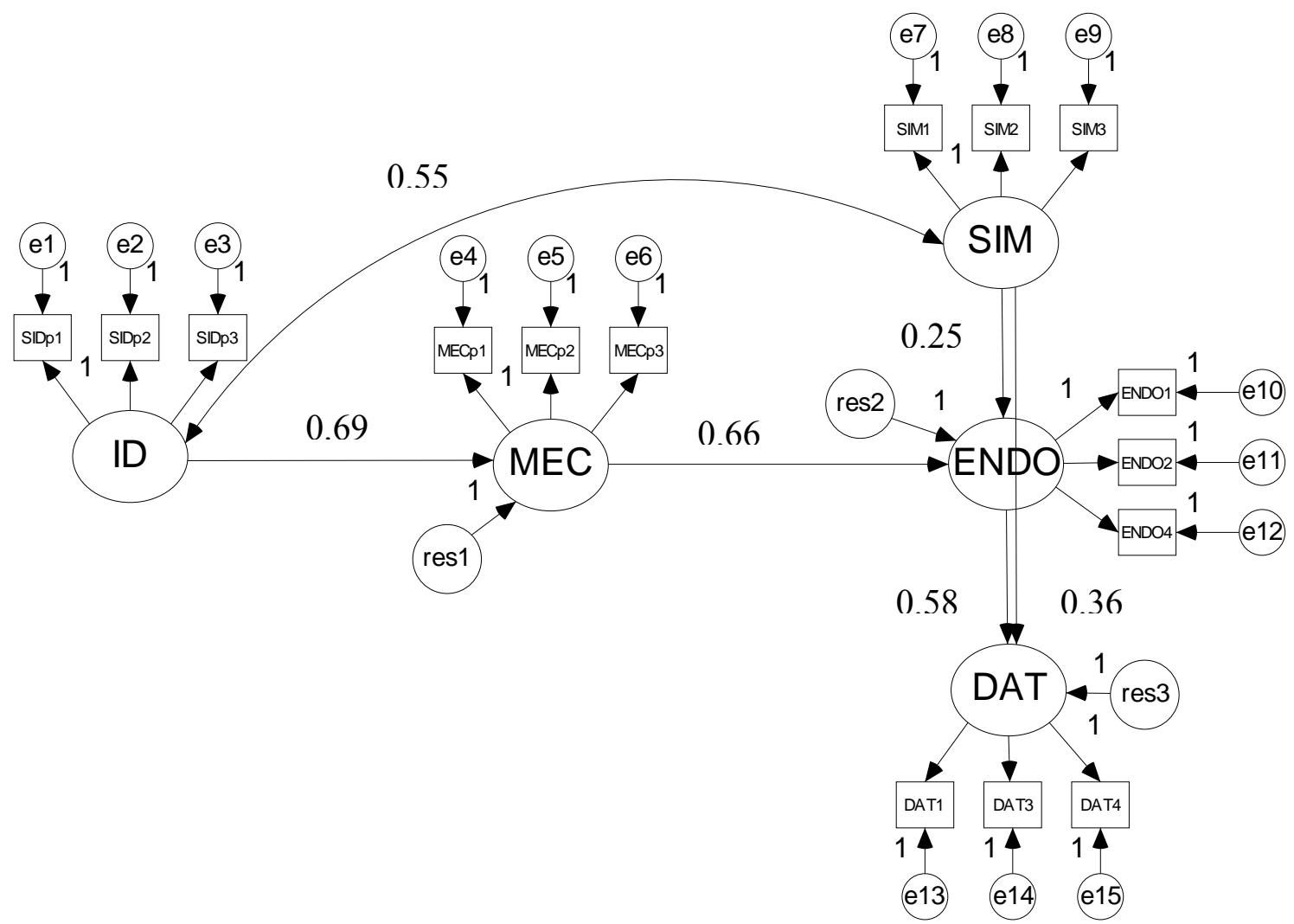

Figure 7.3: A predictive model of endogamy among Australian Jews

Most of the goodness of fit indices were acceptable: $\mathrm{X}^{2}(84)=177.03, \mathrm{p}<.001, \mathrm{X}^{2} / \mathrm{df}=$ 2.11, RMSEA $=.10$, sRMR $=.07$, GFI $=.92$, NFI $=.87$, and CFI $=.93$. As hypothesized, Motivation for Ethno-cultural Continuity (MEC) mediated the relationship between ethno-cultural identity and intentions for endogamy, and intentions for endogamy were a strong and unique predictor of selective dating behaviour. Overall, 62 percent and 67 percent of the variance in endogamy intentions and selective dating were accounted for by the model. Ethno-cultural identity accounted for 47 percent of the variance in MEC.

(ii) The next step was to introduce the constructs of ethno-historical consciousness (WHAT) and vicarious experience of ethnic history (HOW) to see whether they 
contribute to predicting the variance in MEC. Both were significant predictors, however model fit was poor $\left[\mathrm{X}^{2}(181)=448.87^{* * *}\right]$. Examination of the modification indices suggested the estimation of a correlation between WHAT and HOW. When this relationship was accounted for, WHAT was no longer a significant predictor of MEC, indicating that the relationship was fully mediated by HOW. Estimation of a direct path from WHAT to HOW, and from ethno-cultural identity to WHAT led to improved model fit ${ }^{60}$. This is in accordance with theory described in Chapter two whereby greater ethnic identification leads to greater exposure to and salience of social representations of ethnic history, and consequently to a greater individual awareness (measured by the cognitive construct WHAT and the affective construct HOW). The final model is presented below in Figure 7.4.

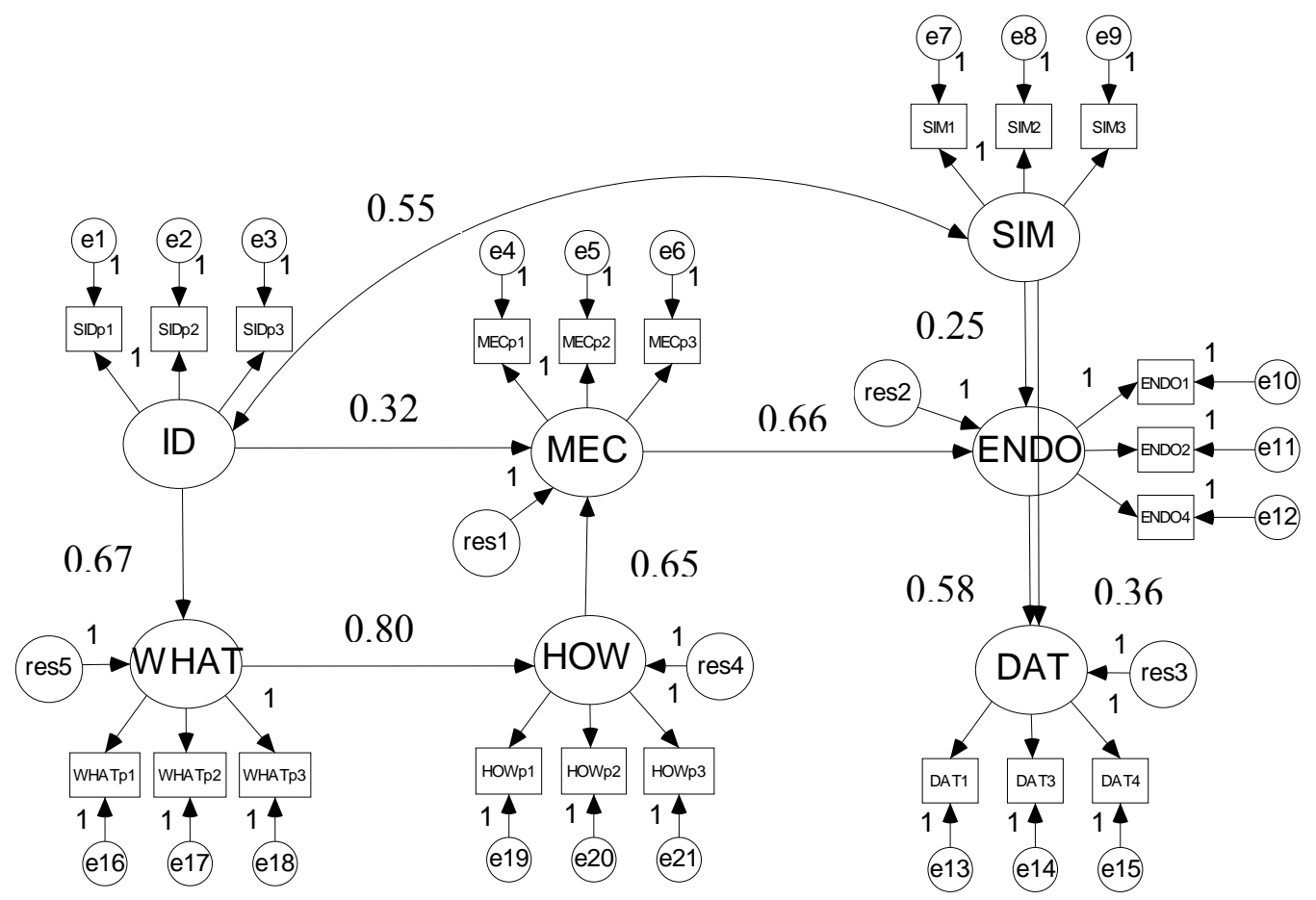

Figure 7.4: Including ethno-historical consciousness and vicarious experience of ethnic history in a predictive model of endogamy among Australian Jews

\footnotetext{
${ }^{60}$ An alternative model whereby individual awareness of social representations of ethnic history predicted ethno-cultural identity resulted in poorer fit.
} 
A few of the goodness of fit indices were acceptable: $\mathrm{X}^{2}(180)=367.72, \mathrm{p}<.001$, $\mathrm{X}^{2} / \mathrm{df}=2.04, \mathrm{RMSEA}=.10, \mathrm{sRMR}=.08, \mathrm{GFI}=.77, \mathrm{NFI}=.80$, and $\mathrm{CFI}=.88$

A chi-squared difference test demonstrated improved model fit $\left[\mathrm{X}^{2}(1)=81.15^{* * *}\right]$. Overall, when both cognitive and affective measures of individual awareness of social representations of ethnic history were included, 74 percent of the variance in MEC was accounted for (an increase from 47 percent). Furthermore, vicarious experience of ethnic history mediated the relationship between ethno-historical consciousness and Motivation for Ethno-cultural Continuity.

\section{Testing the model among Canadian Jews}

(i) The model in Figure 7.2 was tested in the sample of Canadian Jews. Model fit was poor; perceived similarity and social network approval were not significant predictors of intentions for endogamy. A correlation between ethno-cultural identity and attraction, and a direct path from attraction to selective dating behaviour was estimated as suggested by the modification indices ${ }^{61}$. This model with improved fit is presented in Figure 7.5.

\footnotetext{
${ }^{61}$ Direct paths from identity to endogamy and dating were non-significant. An alternative model was tested whereby selective dating mediated the relationship between MEC and intentions for endogamy, resulting in worse fit.
} 


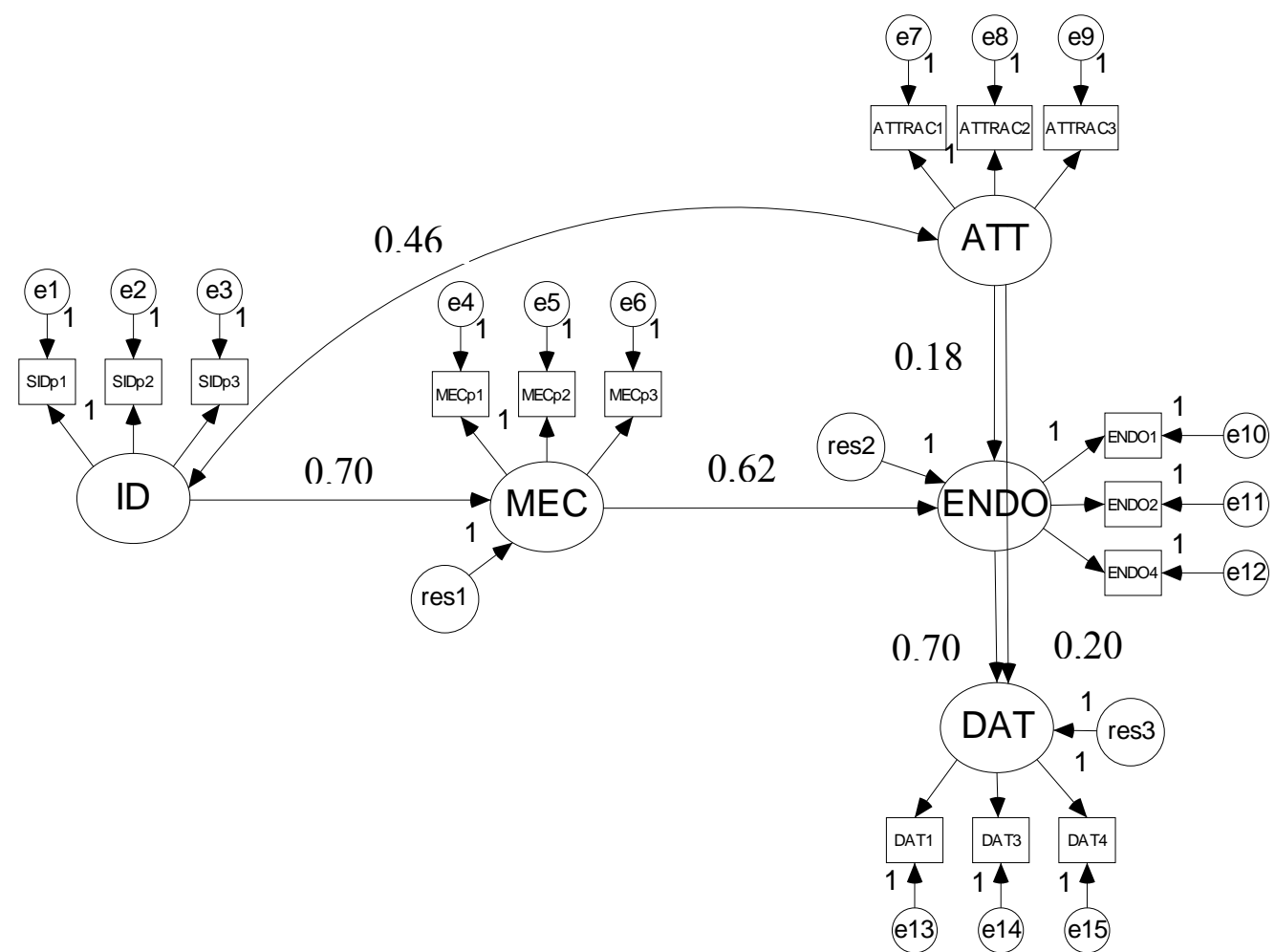

Figure 7.5: A predictive model of endogamy among Canadian Jews

The goodness of fit indices were acceptable: $\mathrm{X}^{2}(84)=157.27, \mathrm{p}<.001, \mathrm{X}^{2} / \mathrm{df}=1.87$, RMSEA $=.07$, sRMR $=.07$, GFI $=.89, \mathrm{NFI}=.90$, and CFI $=.95$. As hypothesized, MEC mediated the relationship between ethno-cultural identity and endogamy intentions, and endogamy intentions predicted selective dating. Overall, this model accounted for 49 percent and 64 percent of the variance in endogamy intentions and selective dating respectively. Ethno-cultural identity accounted for 49 percent of the variance in MEC.

(ii) The next step was to introduce the constructs WHAT and HOW to see whether they contribute to predicting the variance in MEC. Both were significant predictors, but model fit was poor $\left[\mathrm{X}^{2}(181)=407.01^{* * *}\right]$. As in the analyses conducted for the sample of Australian Jews, estimation of a direct path from WHAT to HOW, and from ethnocultural identity to WHAT led to improved model fit, presented below in Figure 7.6. 


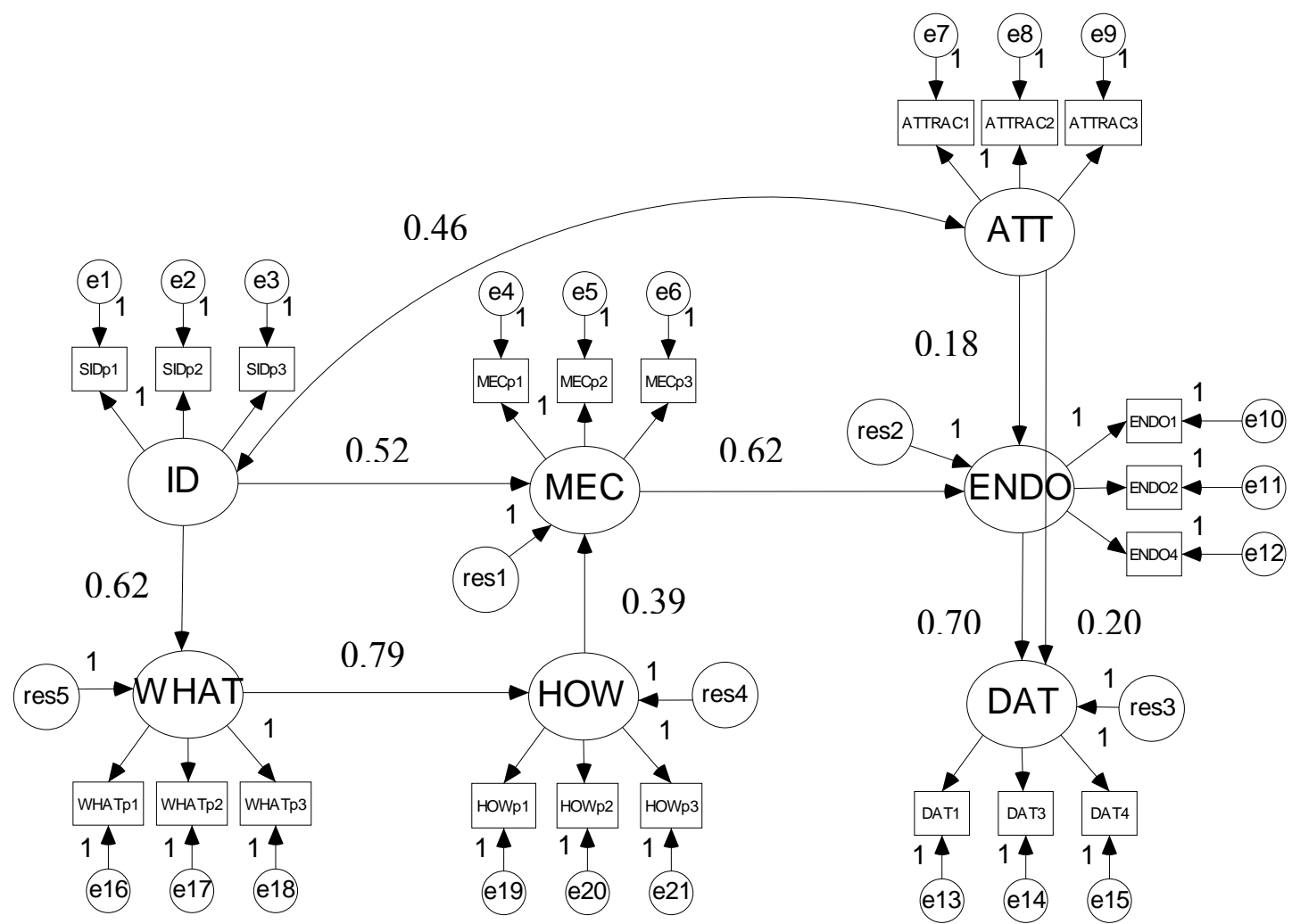

Figure 7.6: Including ethno-historical consciousness and vicarious experience of ethnic history in a predictive model of endogamy among Canadian Jews

Most of the goodness of fit indices were acceptable: $\mathrm{X}^{2}(180)=321.28, \mathrm{p}<.001, \mathrm{X}^{2} / \mathrm{df}=$ $1.79, \mathrm{RMSEA}=.07, \mathrm{sRMR}=.07, \mathrm{GFI}=.84, \mathrm{NFI}=.85$, and $\mathrm{CFI}=.93$. A chi-squared difference test confirmed improvement in model fit $\left[\mathrm{X}^{2}(1)=85.73^{* * *}\right]$. Overall, when both cognitive and affective measures of individual awareness of social representations of ethnic history were included, 61 percent of the variance in MEC was accounted for (an increase from 49 percent). As in the model for Australian Jews, the relationship between ethno-historical consciousness and Motivation for Ethno-cultural Continuity was mediated by vicarious experience of ethnic history. 


\section{Testing the model among American Jews}

(i) The model in Figure 7.2 was tested in the sample of American Jews. Model fit was poor; perceived similarity and attraction were not significant predictors of intentions for endogamy. A correlation between ethno-cultural identity and social network approval and a direct path from approval to selective dating behaviour were estimated as suggested by the modification indices ${ }^{62}$. This model is presented in Figure 7.7.

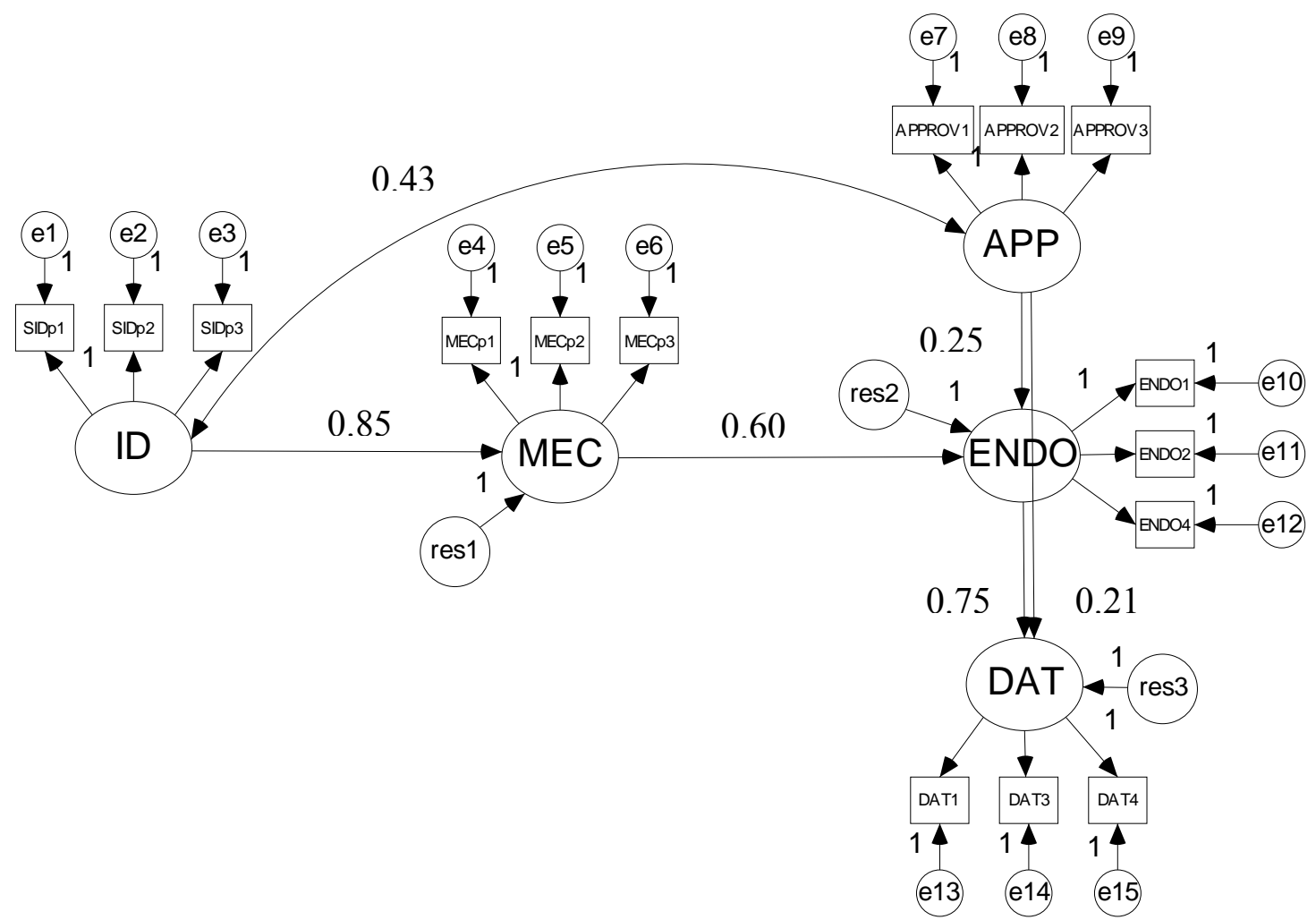

Figure 7.7: A predictive model of endogamy among American Jews

Several of the goodness of fit indices were acceptable: $\mathrm{X}^{2}(84)=156.61, \mathrm{p}<.001, \mathrm{X}^{2} / \mathrm{df}=$ 1.86, RMSEA $=.09$, sRMR $=.08$, GFI $=.83$, NFI $=.85$, and CFI $=.94$. As hypothesised, MEC mediated the relationship between ethno-cultural identity and

\footnotetext{
${ }^{62}$ Direct paths from identity to endogamy and dating were non-significant. An alternative model was tested whereby selective dating mediated the relationship between MEC and intentions for endogamy, resulting in worse fit.
} 
endogamy intentions, and endogamy intentions predicted selective dating. Overall, this model accounted for 53 percent and 74 percent of the variance in endogamy intentions and selective dating respectively. Ethno-cultural identity accounted for 72 percent of the variance in MEC.

(ii) The next step was to introduce WHAT and HOW to see whether they contribute to predicting the variance in MEC. Both were significant predictors, but model fit was poor $\left[\mathrm{X}^{2}(181)=442.78^{* * *}\right]$. As in the analyses conducted for the sample of Australian and Canadian Jews, estimation of a direct path from WHAT to HOW, and from ethnocultural identity to WHAT led to improved model fit. The model is presented below in Figure 7.8.

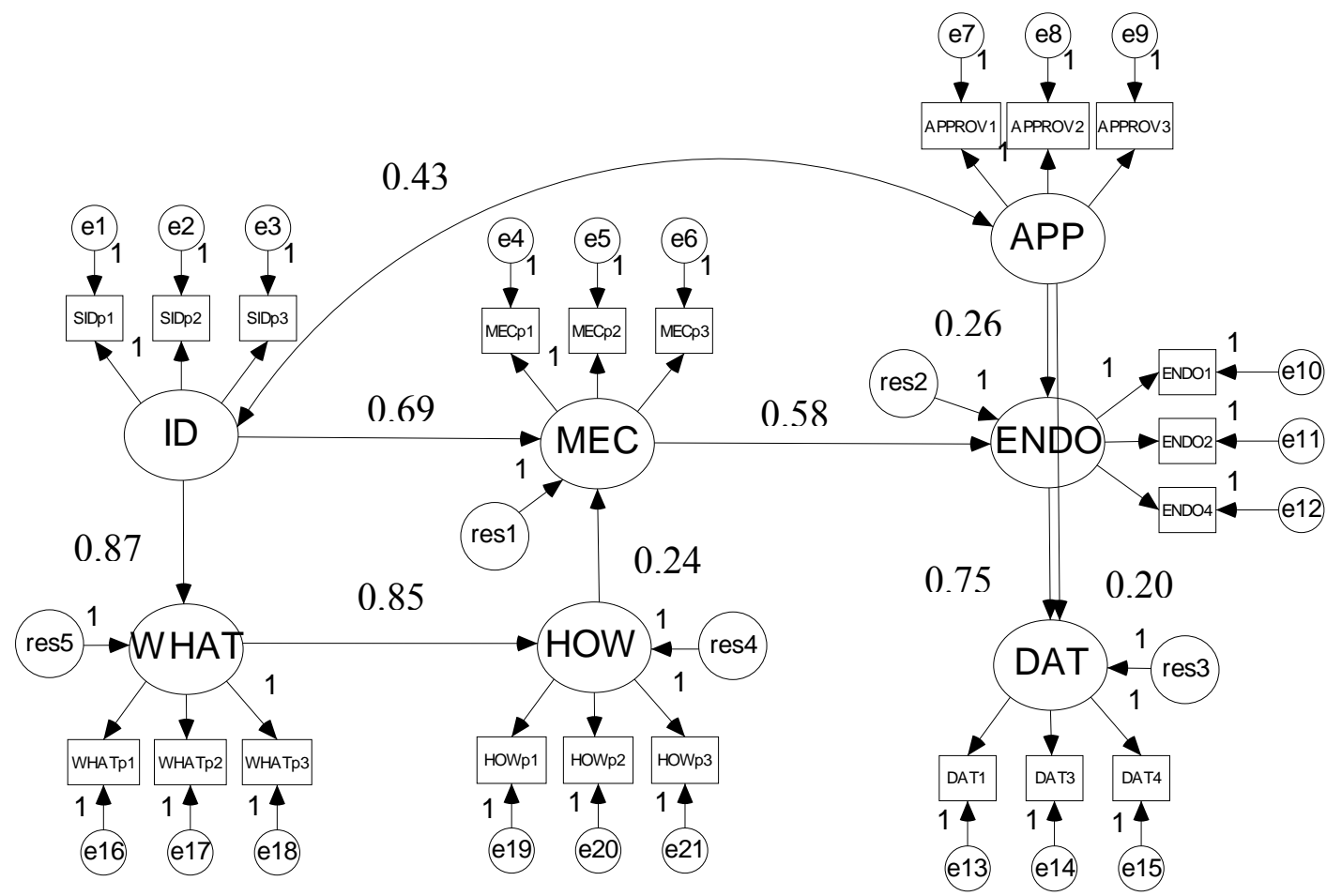

Figure 7.8: Including ethno-historical consciousness and vicarious experience of ethnic history in a predictive model of endogamy among American Jews

Most of the goodness of fit indices were acceptable: $\mathrm{X}^{2}(180)=312.59, \mathrm{p}<.001$,

$\mathrm{X}^{2} / \mathrm{df}=1.74, \mathrm{RMSEA}=.08, \mathrm{sRMR}=.08, \mathrm{GFI}=.78, \mathrm{NFI}=.83$, and $\mathrm{CFI}=.92$. 
A chi-squared difference test demonstrated that model fit improved significantly when this path was estimated $\left[\mathrm{X}^{2}(1)=130.19^{* * *}\right]$. Overall, when both cognitive and affective measures of individual awareness of social representations of ethnic history were included, 78 percent of the variance in MEC was accounted for (an increase from 72 percent). As in the model for Australian and Canadian Jews, the relationship between ethno-historical consciousness and Motivation for Ethno-cultural Continuity was mediated by vicarious experience of ethnic history.

\section{Testing the generalisability of the model across communities that vary in vitality}

Now that the predictive model of volitional endogamy has been tested within each community, the generalisability of the model across diaspora communities will be tested by examining shared invariant paths. Note that each community had unique latent variables that were significant predictors of endogamy intentions: while neither perceived similarity, attraction nor social network approval were significant for New Zealand Jews, similarity was only significant for the Australian Jewish sample, attraction was only significant for the Canadian Jewish sample, and social network approval was only significant for the American Jewish sample. At the same time, the models for each sample had many paths that were shared with other Jewish community groups.

As in Chapter six where the cross-cultural generalisability of the model was tested, path models were constructed given that there was no need to constrain the measurement model across groups. Indicators were composed of the means of the three parcels for each latent variable. Only endogenous variables had estimated error terms. First, a baseline path model was established for each Jewish sample followed by multigroup path models. Comparisons were made between the baseline model with unconstrained paths and a fully constrained model. If a chi-squared difference test demonstrated a significant difference between the two models, this meant that at least 
one of the paths varied across the four Jewish communities. The next step was to constrain each path separately to detect which paths were variant and which paths were invariant across the Jewish communities.

\section{Shared paths across New Zealand, Australian, Canadian and American Jews}

The paths that were shared between the Australian, Canadian and American Jewish samples were those from ethno-cultural identity (ID) to Motivation for Ethno-cultural Continuity (MEC); from ID to the ethno-historical consciousness WHAT scale, from WHAT to the ethno-historical consciousness HOW scale, from HOW to MEC; from MEC to intentions for endogamy (ENDO) and from ENDO to selective dating behaviour (DAT). Note that New Zealand Jews shared the same paths outlined above, excluding the paths from WHAT to HOW and HOW to MEC since HOW was not a significant predictor. Rather, a direct path from WHAT to MEC featured in the New Zealand Jewish sample. These shared paths are presented later in Figure 7.13, for the multi-group path model testing.

First, baseline path models for each community were established. In Chapter 6, Figure 6.13 outlined the baseline path model for New Zealand Jews, replicated here in Figure 7.9 to facilitate direct comparisons with the other Jewish samples. Figures 7.10, 7.11 and 7.12 below present the baseline path models for the Australian, Canadian and American samples. 


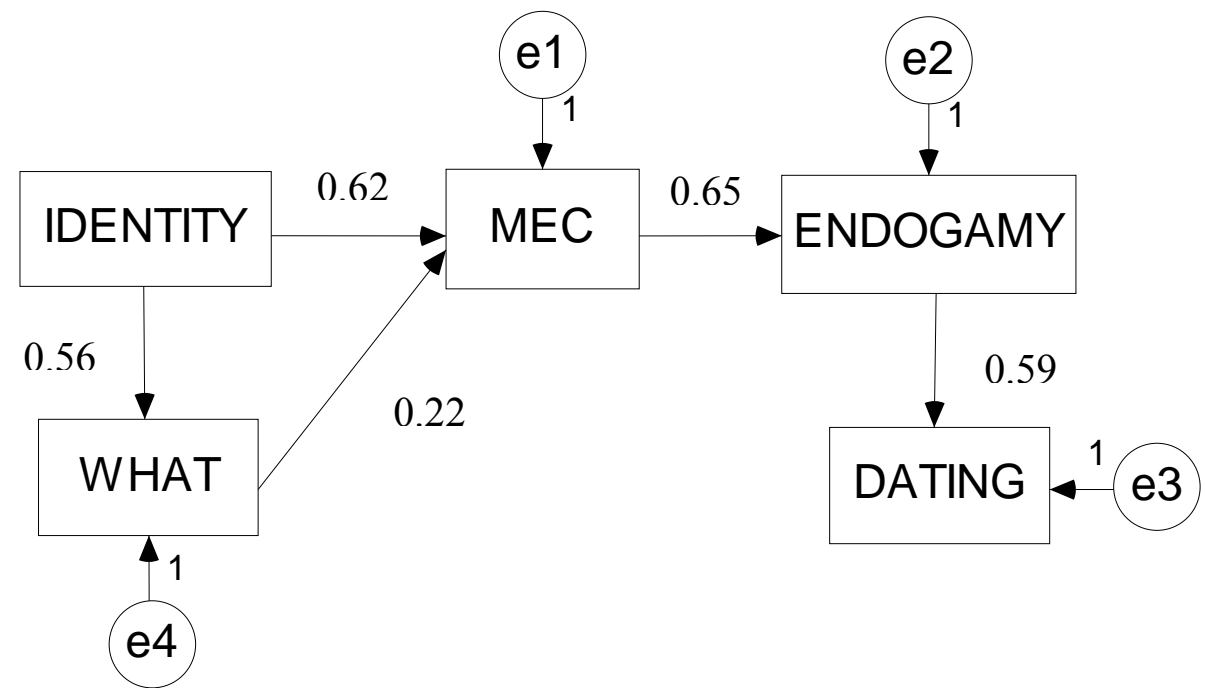

Figure 7.9: Path model for New Zealand Jews

The goodness of fit indices for the New Zealand Jewish sample were acceptable: $\mathrm{X}^{2}(5)=$ $4.43, \mathrm{p}>.05, \mathrm{X}^{2} / \mathrm{df}=.89, \mathrm{RMSEA}=.00, \mathrm{sRMR}=.03, \mathrm{GFI}=.98, \mathrm{NFI}=.98$, and CFI $=$ 1.0.

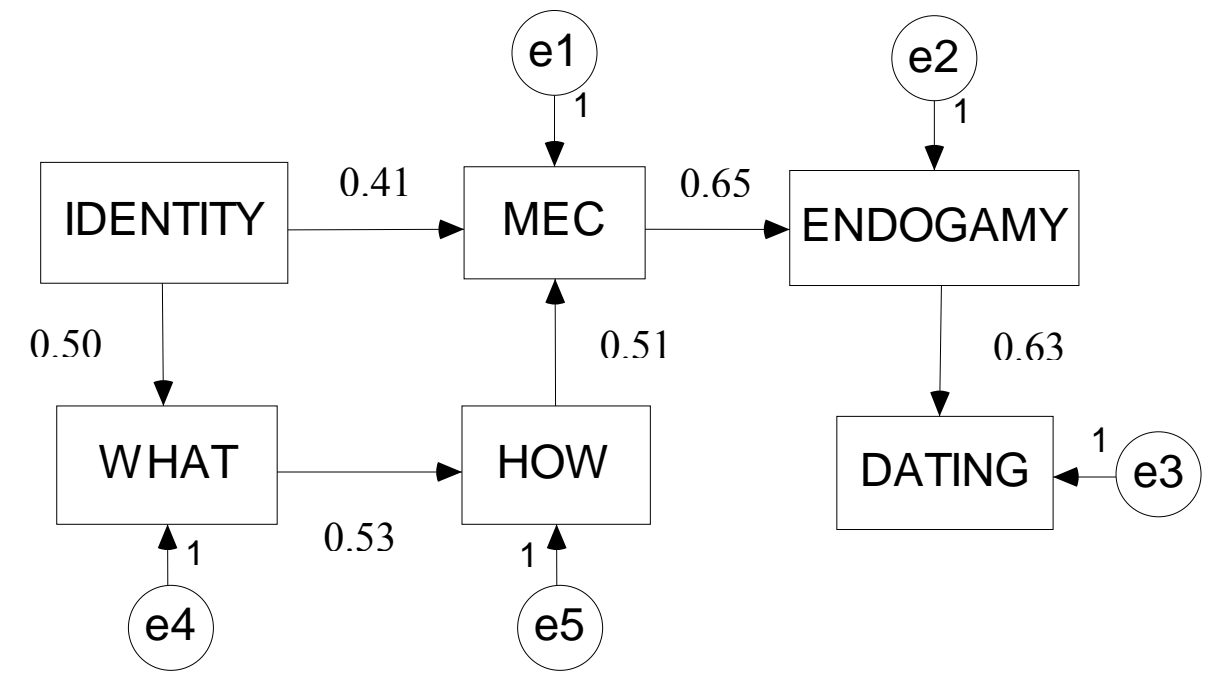

Figure 7.10: Path model for Australian Jews

Some of the goodness of fit indices for the Australian Jewish sample were acceptable: $\mathrm{X}^{2}(9)=40.29, \mathrm{p}<.001, \mathrm{X}^{2} / \mathrm{df}=4.48, \mathrm{RMSEA}=.18, \mathrm{sRMR}=.13, \mathrm{GFI}=.90, \mathrm{NFI}=.87$, and $\mathrm{CFI}=.90$. 


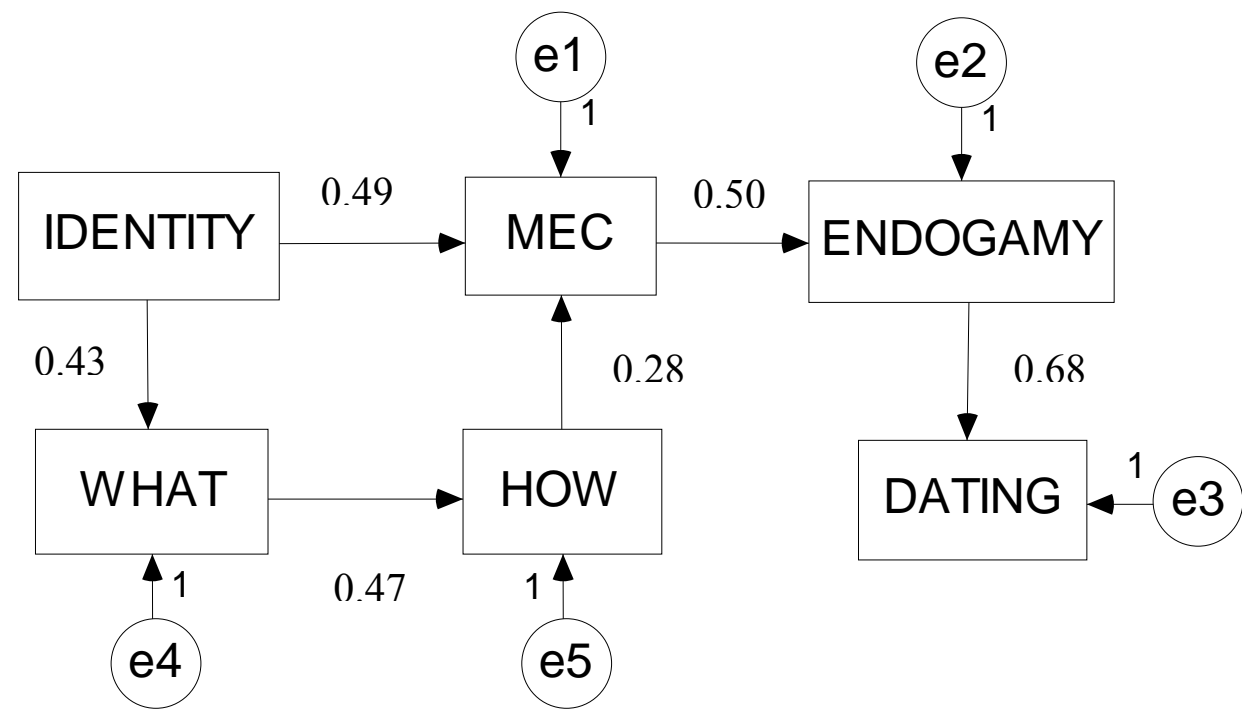

Figure 7.11: Path model for Canadian Jews

The goodness of fit indices for the Canadian Jewish sample were not satisfactory: $X^{2}(9)=$ 77.14, $\mathrm{p}<.001, \mathrm{X}^{2} / \mathrm{df}=8.57, \mathrm{RMSEA}=.22, \mathrm{sRMR}=.15, \mathrm{GFI}=.86, \mathrm{NFI}=.80$, and $\mathrm{CFI}=.81$.

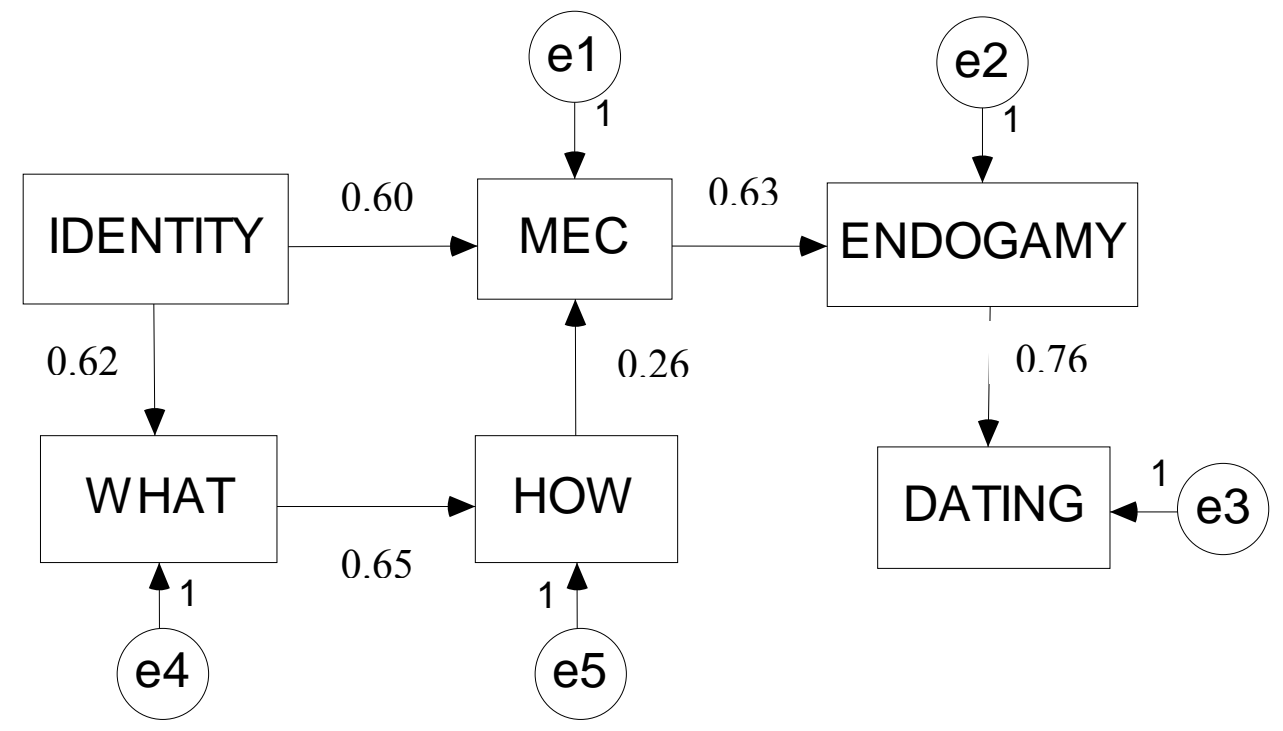

Figure 7.12: Path model for American Jews

The goodness of fit indices for the American Jewish sample were not satisfactory: $\mathrm{X}^{2}(9)=63.82, \mathrm{p}<.001, \mathrm{X}^{2} / \mathrm{df}=7.09, \mathrm{RMSEA}=.24, \mathrm{sRMR}=.11, \mathrm{GFI}=.84, \mathrm{NFI}=.85$, and $\mathrm{CFI}=.87$. 
Note that the model fit indices for the Australian, Canadian and American Jewish samples were not as good as those for the New Zealand Jewish sample because these path models omit other significant predictors, namely perceived similarity for Australian Jews, attraction for Canadian Jews and social network approval for American Jews.

Multi-group path models were conducted to test for invariant paths across all four Jewish community samples, specifically paths $1-4$ as shown below in Figure 7.13. Different path models were allowed whereby WHAT directly predicts MEC for New Zealand Jews (path 7); and WHAT predict HOW (path 5) which predicts MEC (path 6) for Australian, Canadian and American Jews.

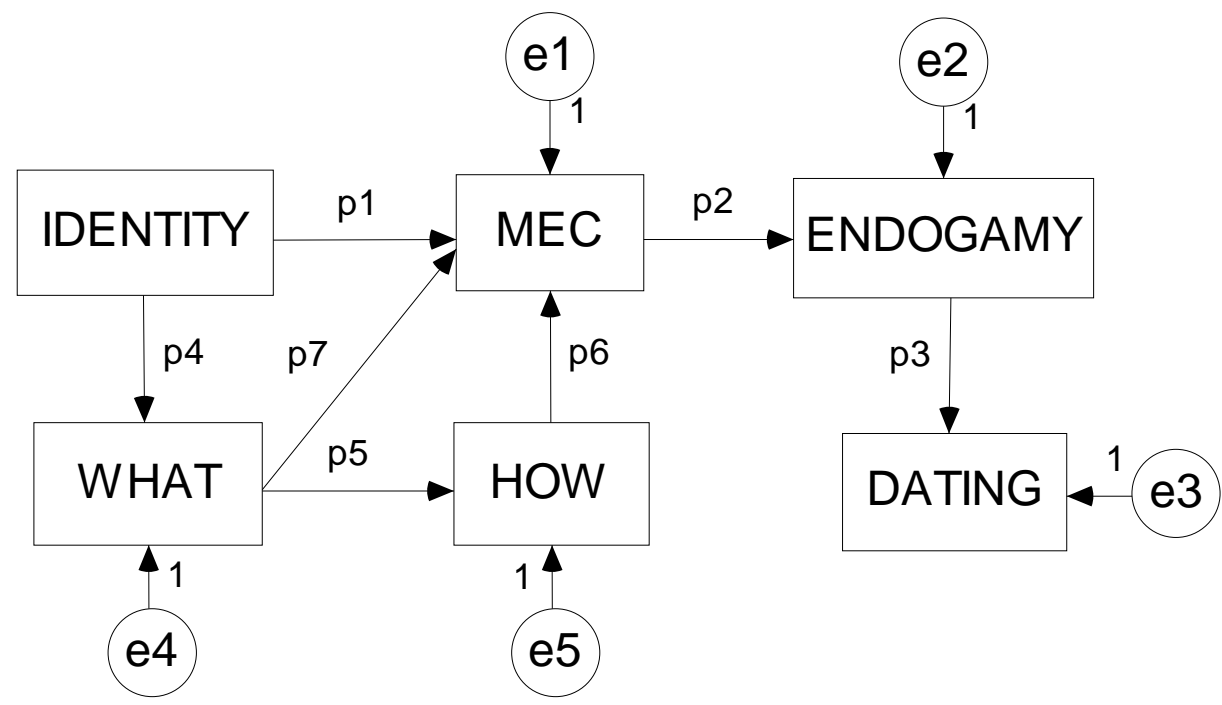

Figure 7.13: Multi-group path model for New Zealand, Australian, Canadian and American Jews

The goodness of fit indices of the unconstrained model were not satisfactory: $\mathrm{X}^{2}(32)=$ 185.63, $\mathrm{p}<.001, \mathrm{X}^{2} / \mathrm{df}=5.80, \mathrm{RMSEA}=.10, \mathrm{sRMR}=.03, \mathrm{GFI}=.88, \mathrm{NFI}=.86$, and $\mathrm{CFI}=.88$. This model was compared with the fully-constrained model (paths 1-6 were constrained to be equal across the Jewish samples; path 7 was modelled only for New Zealand Jews). The chi-squared value of this model $\left[\mathrm{X}^{2}(48)=238.39 * * *\right]$ and the baseline chi-squared of the unconstrained model were significantly different $\left[\mathrm{X}^{2}(16)=52.76^{* * *}\right]$, 
indicating that at least one of the paths varied across the four Jewish groups. Testing each path separately, chi-squared difference tests showed that path one was invariant across all four samples; path two was invariant across the New Zealand, Australian and Canadian samples $\left[\mathrm{X}^{2}(6)=15.43^{*}\right.$, the path loading for American Jews was significantly different]; path three was invariant across the Australian, Canadian and American samples $\left[\mathrm{X}^{2}(8)=30.63^{* * *}\right.$, the path loading for New Zealand Jews was significantly different]; path four was invariant across all four samples; path five was invariant across the Australian, Canadian and American samples (this path was not estimated for New Zealand Jews); path six was invariant across the Canadian and American samples $\left[\mathrm{X}^{2}(14)=25.03^{*}\right.$, the path loading for Australian Jews was significantly different $]$. Path 7 was only modelled for New Zealand Jews and hence was not tested for invariance.

\section{Summary: Shared and unique paths across four diaspora Jewish samples}

Ten direct paths were tested across the four Jewish community samples. Some of these paths were shared across all four samples, some were shared amongst three samples, some amongst two samples and some were unique. Figure 7.14 below outlines each of these ten paths.

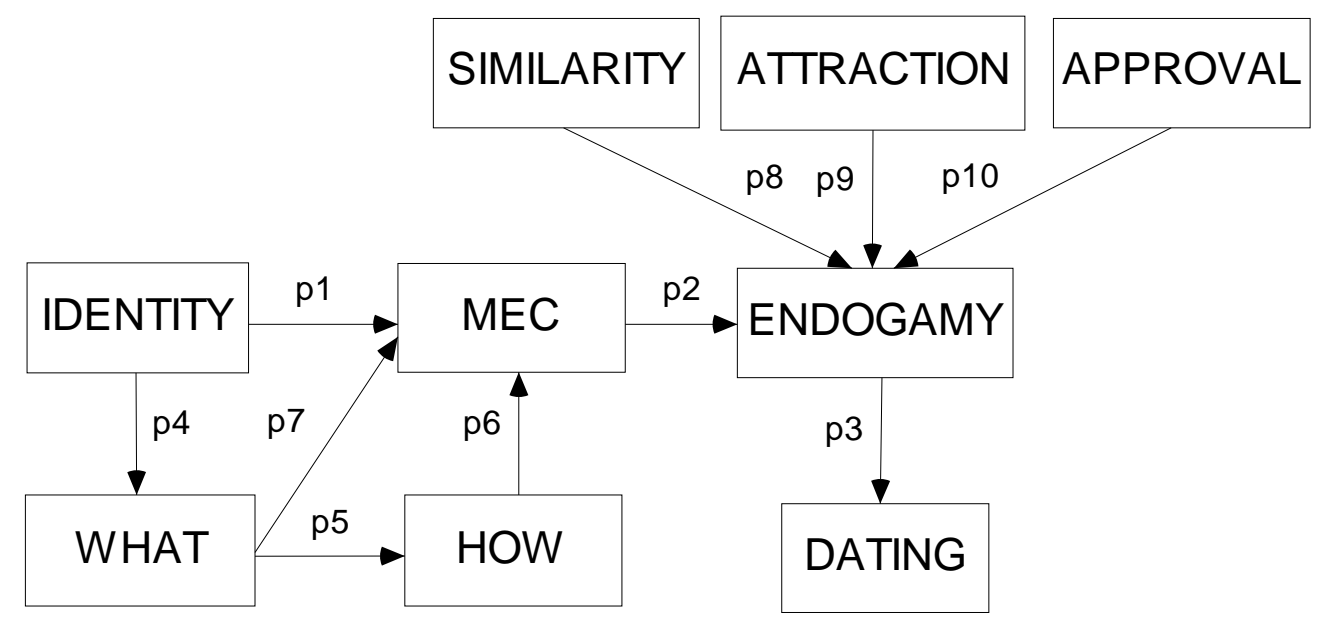

Figure 7.14: Shared and unique paths in a predictive model of endogamy among diaspora Jews 
Table 7.5 summarizes the samples which demonstrated invariance for each path.

Table 7.5: Shared and unique paths among New Zealand, Australian, Canadian and American Jews

\begin{tabular}{lcccc}
\hline & New Zealand & Australia & Canada & United States \\
\hline Path 1 & $*$ & $*$ & $*$ & $*$ \\
Path 2 & $*$ & $*$ & $*$ & $*$ \\
Path 3 & & $*$ & $*$ & $*$ \\
Path 4 & $*$ & $*$ & $*$ & $*$ \\
Path 5 & & & & \\
Path 6 & $*$ & $*$ & $*$ & $*$ \\
Path 7 & & & & \\
Path 8 & & & & \\
Path 9 & & & & \\
Path 10 & & & & \\
\hline
\end{tabular}

In terms of shared paths, 1 and 4 were invariant across all four samples, path 2 was invariant across New Zealand, Australian and Canadian Jews, paths 3 and 5 were invariant across Australian, Canadian and American Jews, path 6 was invariant across Canadian and American Jews. As for unique paths, path 7 was significant for New Zealand Jews, path 8 for Australian Jews, path 9 for Canadian Jews and path 10 for American Jews. 


\section{Discussion}

As a cross-national comparison of Jewish continuity in the diaspora, this study tested a predictive model of volitional endogamy and investigated the effect of ethnic vitality within the same ethno-cultural group on the strength and function of Motivation for Ethno-cultural Continuity, ethno-historical consciousness and vicarious experience of ethnic history. In addition, differences in endogamy intentions and selective dating were examined. Each research question posited at the start of the chapter is addressed along with their accompanying hypotheses and results.

\section{Investigating mean group differences across four Jewish communities}

1. Do levels of Motivation for Ethno-cultural Continuity and individual awareness of social representations of ethnic history differ across communities that vary in vitality? It was hypothesized that MEC would decrease as community vitality increases, with incrementally greater concerns among the communities sampled in the United States, Canada, Australia and New Zealand. In contrast, individual awareness of social representations of ethnic history would increase as community vitality increases.

As members of 'small peoples', Jews in New Zealand, Australia, Canada and the United States would all be concerned about ethno-cultural continuity. Although vitality could affect individual acculturation such that members of smaller communities who have limited resources would be more concerned about ethno-cultural continuity than members of larger communities, the results revealed that by and large, all four samples had very high levels of MEC (above 6 on a 7-point scale). After accounting for participant differences in age and religious identification, there was no significant difference in Motivation for Ethno-cultural Continuity across the four Jewish community 
samples. Thus, community vitality did not have an impact upon levels of MEC among young affiliated diaspora Jews.

With regards to subjects of remembrance across the four Jewish community samples, general Jewish history was remembered more, followed by family Jewish history and then local Jewish history. New Zealand Jews recalled less than Australian, Canadian and American Jews; this may be an indirect effect of vitality whereby the quality and quantity of ethno-cultural education could influence the remembrance of family, local and general Jewish history. An interaction was found between country and subjects of remembrance whereby American Jews did not recall local Jewish history less than they did family history. Perhaps this was due to generational differences where the American Jewish sample had larger numbers of third and fourth generation Jews and family history may be closely related to the history of the American Jewish community.

As for ethno-historical consciousness across the four Jewish community samples, there were no significant differences between groups after accounting for participant differences in age and religious identification. New Zealand, Australian, Canadian and American Jews all had high levels of awareness of Jewish historical narratives (above 6 in a 7-point scale). Thus, community vitality did not affect the cognitive remembrance of ethno-historical narratives among young affiliated diaspora Jews.

Similarly, in terms of a vicarious experience of ethnic history, there were no significant differences between groups after accounting for participant differences in age and religious identification. By and large, all four samples had moderately high levels of vicarious experience of history (above 5 on a 7 -point scale). Thus, community vitality did not have an impact upon the affective remembrance of ethnic history among young affiliated diaspora Jews. Overall, across four groups of diaspora Jews sampled from the largest communities in four different countries, community vitality did not have an impact upon levels of motivation (MEC), cognition (WHAT) and affect (HOW). 
2. Do intentions for endogamy and selective dating behaviour differ across communities that vary in vitality?

It was hypothesized that intentions for endogamy and selective dating behaviour would increase as community vitality increases due to the greater pool of potential Jewish dating and marriage partners, with incrementally higher endogamy intentions and selective dating behaviour among the communities sampled in New Zealand, Australia, Canada and the United States.

The results demonstrated that both endogamy intentions and selective dating were much lower among New Zealand Jews than Australian, Canadian and American Jews. While New Zealand Jews demonstrated mild endogamy intentions (above 4 on a 7-point scale), they did not engage in selective dating behaviour (below 4 on a 7 -point scale). In contrast, there were no significant differences among Australian, Canadian and American Jews who all demonstrated strong intentions for endogamy and moderate selective dating behaviour. Although the Australian, Canadian and American Jewish communities greatly differ in vitality, their endogamy and dating behaviour did not. In contrast to the findings by Rabinowitz (1989) where relative community size was correlated negatively to intermarriage, in this study neither absolute nor relative vitality was correlated with endogamy intentions or selective dating behaviour. This suggests that community vitality impacts behaviour when community numbers are below a certain threshold. This threshold lies in between the sampled New Zealand community population size (absolute $=4,300$ and relative $=0.27 \%$ ), and the sampled Australian community population size (absolute $=37,800$ and relative $=1.12 \%$ ). Recall that absolute community size indicates the available marriage market and structural opportunities within the ethnic group, whilst relative community size indicates opportunities for outgroup contact, and the influence a minority group has within the larger society. It seems that the largest Jewish communities in New Zealand have a critically low 
population that is related to low behavioural intentions for endogamy and not engaging in selective dating behaviour when compared to the largest Jewish communities in Australia, Canada and the United States. This is compounded with geographical isolation from other Jewish communities.

The Theory of Planned Behaviour provides some insight in understanding just how vitality may impact behavioural intentions. Ajzen (1991, p.196) states that "the more resources and opportunities individuals believe they possess, and the fewer obstacles or impediments they anticipate, the greater should be their perceived behavioural control over the behaviour." What could be a greater obstacle to endogamy for New Zealand Jews than the lack of available resources, i.e. potential marriage partners? It is inferred that the small marriage market may induce low endogamy efficacy beliefs among New Zealand Jews, which are related in turn to weak intentions for endogamy and not engaging in selective dating behaviour.

Note that dating services do exist online such as www.Jdate.com; these global electronic services render the international marriage market more accessible and serve to complement the subsequent face-to-face interaction necessary when establishing a relationship for marriage. While technologies are certainly useful in maintaining relationships, it is difficult to establish meaningful (trans-Pacific) relationships solely through technology.

Overall, while community vitality did not impact motivation (MEC) or cognitive and affective measures of individual awareness of social representations of ethnic history, it did impact behavioural intentions and behaviour. 


\section{Investigating the predictive model across four Jewish communities}

3. How does the predictive model for volitional endogamy function across communities that vary in vitality?

It was hypothesized that MEC would be a significant predictor for endogamy above and beyond similarity, attraction and social network approval for all four community samples.

Across the four samples of diaspora Jewry, Motivation for Ethno-cultural Continuity (MEC) was a strong and significant predictor of behavioural intentions for endogamy. For New Zealand Jews, it was the only direct predictor of endogamy. For Australian, Canadian and American Jews, it was the stronger of two direct predictors of endogamy. Similarity was a significant predictor for endogamy only in the Australian Jewish sample, attraction was a significant predictor for endogamy only in the Canadian Jewish sample and social network approval was a significant predictor for endogamy only in the American Jewish sample. Thus, the traditionally-examined ethno-centric variables were inconsistent predictors of intentions for endogamy. Although there is no theoretical explanation for the significance of these variables in one community but not in another, the inconsistent nature of these predictors in contrast to the very consistent nature of MEC is striking. Furthermore, MEC consistently mediated the relation between ethnocultural identity and endogamy intentions. Thus, individuals who strongly identified as Jews had a greater Motivation for Ethno-cultural Continuity and consequently had greater intentions for endogamy. 
4. Do both cognitive and affective measures of individual awareness of social representations of ethnic history predict Motivation for Ethno-cultural Continuity above and beyond ethno-cultural identity?

Although only the cognitive measure - ethno-historical consciousness (WHAT) was a significant predictor of MEC for New Zealand Jews (see Chapter 6), it was hypothesized that across the sampled communities the affective measure - vicarious experience of ethnic history (HOW) would also be a predictor of MEC above ethno-cultural identity.

The results showed that ethno-historical consciousness (WHAT) and a vicarious experience of ethnic history (HOW) contributed to explaining the variance in MEC over and above that explained by ethno-cultural identity. Furthermore, in three of the Jewish samples WHAT predicted MEC indirectly as the relationship was mediated by HOW. Thus, greater awareness of ethno-historical narratives (a cognitive remembrance of social representations of ethnic history) led to a vicarious experience of ethnic history (an affective remembrance of social representation of ethnic history), which in turn led to greater Motivation for Ethno-cultural Continuity.

In addition, it is important to note that while ethno-cultural identity directly predicted MEC, it also had an indirect path through WHAT and HOW. Thus, individuals who had a stronger ethno-cultural identity remembered more ethnic historical narratives and had greater vicarious experience of ethnic history, which in turn led to greater Motivation for Ethno-cultural Continuity.

Integrating the results from this study, it seems that across four Jewish community samples that vary in vitality, the predictive model for volitional endogamy functions in a very similar manner. Although differences in vitality within the same ethno-cultural group did not impact levels of motivation (measured by Motivation for Ethno-cultural Continuity), cognition (measured by ethno-historical consciousness) and affect (measured 
by vicarious experience of ethnic history), it strongly impacted levels of behavioural intentions and behaviour (measured by intentions for endogamy and selective dating).

\section{Limitations}

The first methodological limitation to be discussed refers to the timing of data collection (near Christmas for the American sample) and the nature of email membership lists wherein individuals frequently choose not to open mass emails; these are likely to have affected total sample size for both the cross-national and cross-cultural studies. Larger samples would have led to an improvement in fit indices for the structural equation models, especially for the Australian model which had a large number of estimated parameters. Another limitation is that all participants had strong ethno-cultural identity, as they were recruited from ethno-cultural organisations with which they were voluntarily affiliated. Hence, these samples are not representative of the entire spectrum of ethnocultural young adults, in particular the unaffiliated.

In addition, caution must be exercised regarding the generalisability of the influence of community vitality. The strongest, most vibrant metropolitan communities were sampled in four countries; these are not representative of other communities. To determine more carefully the effects of vitality, several communities within the same country should be sampled. Furthermore, while the effects of vitality within multicultural, heterogeneous societies were investigated, the effects of vitality in mono-cultural, homogeneous societies are unknown. Moreover, only Jewish continuity in Anglo-Saxon societies was examined; the compatibility of Judaism with the larger society may not be equivalent in other regions e.g. France, Italy, and North Africa. This may also impact the acculturation strategies chosen by individuals and the frequency of endogamy/exogamy in society. 
In addition, future-oriented behavioural intentions for endogamy were examined in this thesis. Bagozzi (1991, p. 195) notes that "as the gap in time between t1 and t2 widens, the chances will increase that one will change one's intention or that unexpected events will make one's intention impractical or undesireable." Thus, many intervening factors can alter the original intentions for endogamy amongst the ethno-cultural young adults sampled in these studies, whose lives are in a constant state of flux.

Next, Chapter eight synthesizes the results of the qualitative and quantitative studies conducted and highlights conclusions that can be drawn in the domains of mate selection, social representations of ethnic history, and the importance of examining psychological variables such as Motivation for Ethno-cultural Continuity and individual awareness of social representations of ethnic history in the new and exciting study of long-term acculturation. 


\section{CHAPTER 8: DISCUSSION AND CONCLUSIONS}

This thesis has compared the long-term acculturation of Jews with Māori and Chinese, investigating the stage of the journey of ethno-cultural continuity that occurs prior to marriage. Several research domains have been considered, integrating established theory and advancing an unexplored realm of acculturation through the creation of new constructs and the empirical testing of a predictive model of volitional endogamy within and across ethno-cultural groups. The studies described herein have contributed to research on mate selection, social representations of history and acculturation.

\section{Contribution to research on mate selection}

\section{The role of Motivation for Ethno-cultural Continuity in predicting endogamy for 'small peoples'}

Previous demographic, sociological and psychological research on factors that predict ethnic endogamy have examined structural group-level variables such as national policies, historical discrimination, group visibility, group size, continuous immigration, sex ratio, residential segregation, employment segregation, social distance, involvement in ethnocultural organisations, behavioural acculturation, educational attainment, social network approval, parental socialization and traditional lifestyle (Kitano, Yeung, Chai \& Hatanaka, 1984; Qian \& Lichter, 2007; Tubergen \& Maas, 2007; Kalmijn, 1998; Pagnini \& Morgan, 1990; Kalmijn, Liefbroer, van Poppel \& van Solinge, 2006; Mamet, Jacobson \& Heaton, 2005). Individual-level variables have also been examined such as preferences in spouse characteristics (Kalmijn, 1998; Stopes-Roe \& Cochrane, 1988), and social network approval, similarity, attraction and ethnic identity are variables that have predicted selective dating (Liu, Campbell \& Condie, 1995; Mok, 1999; Brown, McNatt \& Cooper, 2003). 
Thus far, endogamy and selective dating have been interpreted as a manifestation of ethnocentrism. Research on the cultural bases for marriage has shown that the ideology of romantic love underlies marriages in Western cultures, while family alliance underlies marriages in traditional Eastern cultures (Dion \& Dion, 1993). Until now, research had not stipulated any greater ideological variable, in particular ethnocultural continuity that provides a basis for endogamous marriage among ethnic minority members. Even research specifically on Jewish continuity has side-stepped ideological or motivational predictors of endogamy, concentrating on demographic, cognitive, behavioural and affective variables (Cohen \& Eisen, 2000; Horowitz, 2000; National Jewish Population Survey 2000-01; Cohen, 2006). The quantitative studies in Chapters six and seven established that similarity, attraction, and social network approval were not consistently significant predictors of ethnic endogamy among four samples of diaspora Jews, one sample of indigenous Māori and one sample of New Zealand Chinese. In contrast, Motivation for Ethno-cultural Continuity (MEC) was not only a consistent predictor of endogamy intentions for individuals who belong to 'small peoples' that is to say for the Jewish and Māori samples, but also the strongest predictor of endogamy intentions for the Jewish samples. In fact, MEC fully mediated the relation between ethno-cultural identity and intentions for endogamy.

MEC is an original construct based on qualitative research with three focus groups that captures an ideological concern for collective continuity at the individual level. Its structure is unifactorial, simultaneously encompassing the desires for cultural maintenance (self-oriented), transmission (family-oriented) and endurance (grouporiented). MEC bears no relationship to assimilation, and is positively correlated to constructs such as Collective Self-Esteem and Perceived Group Entitativity. A 10-item MEC scale was established in multi-group confirmatory factor analysis that demonstrated excellent reliability across all six samples. This scale is culture-general and can be used in 
future research to examine Motivation for Ethno-cultural Continuity in other ethnocultural groups (see Appendix G).

\section{Contribution to research on social representations of history}

\section{The structure of individual awareness of social representations of ethnic history}

Memory forms the umbilical cord which binds together generations of ethno-cultural groups, attaching the present to the past and providing nourishment for the future. Indeed, the collective consciousness, resistance and survival of groups arise from collective memory (Cattell \& Climo, 2002). Social representations theory (Moscovici, 1984, 1993) and the study of social representations of ethnic history has enabled psychologists to understand how history shapes collective identity (Liu et al., 1999), serving both intra-group and inter-group purposes such as self-enhancement and social differentiation (Breakwell, 1993). This thesis proposed that social representations of ethnic history also serve collective self-preservation, as ethnic groups call upon their historical map to navigate their future.

It was hypothesized that at the individual level, the stronger an individual's identity, the greater their exposure to social representations of history and the greater their salience. The predictive model of endogamy proposed that the greater an individual's awareness of ethnic history, the greater their concerns for continuity and the greater their engagement in continuity-enhancing behaviour, such as endogamy intentions and selective dating. Indeed, this is what was found. 
Three original constructs that measure individual awareness of social representations of ethnic history were developed based on qualitative research with three focus groups. Subjects of remembrance are measured by the WHO scale (only Jews differentiate between family, local and general Jewish history). Ethno-historical consciousness is measured by the WHAT scale (a unifactorial structure that incorporates the cognitive remembrance of narratives of ethnic integrity, suffering and survival). Research on social representations of ethnic history has been centred on narratives of inter-group conflict (Liu, 1999; Liu \& Goldstein-Hawes et al., 2003; Sen \& Wagner, 2004). However, this thesis has demonstrated that while negative narratives of intergroup conflict and suffering are certainly remembered by ethno-cultural groups, they are accompanied by positive inter-group narratives of survival, and positive intra-group narratives of ethnic integrity. Vicarious experience of ethnic history is measured by the HOW scale (a unifactorial structure that encompasses an affective remembrance of ethnic history). Positive correlations were found with measures of Collective SelfEsteem, Perceived Collective Continuity and Perceived Group Entitativity. A 12-item WHO scale, 8-item WHAT scale, and 6-item HOW scale were established in multi-group confirmatory factor analyses demonstrating good reliability across all six samples. These scales are culture-general and can be used in future research to examine individual awareness of social representations of ethnic history in other ethno-cultural groups (see Appendix G). 


\section{The function of ethno-historical consciousness and vicarious experience of ethnic history}

The inclusion of WHAT and HOW in the structural equation models consistently increased the proportion of the explained variance in Motivation for Ethno-cultural Continuity (MEC) above that accounted for by ethno-cultural identity in five samples. An indirect path from ethno-cultural identity to WHAT, from WHAT to HOW and from HOW to MEC emerged in three samples. This means that the stronger an individual's ethno-cultural identity, the greater their awareness of ethno-historical narratives and the greater their vicarious experience of ethnic history; the latter in turn leads to greater Motivation for Ethno-cultural Continuity. Thus, cognitive measures of individual awareness of social representations of ethnic history predict affective measures, which in turn predict motivation. Taken as a whole, social representations of ethnic history do serve collective self-preservation, as individual awareness of such representations fuels their Motivation for Ethno-cultural Continuity, which in turn predicts continuity-enhancing behaviours such as endogamy and selective dating.

\section{Contribution to acculturation theory and research}

\section{Investigating long-term acculturation and ethno-cultural continuity}

The current paradigm of acculturation research examines the impact of group-level variables and individual characteristics on individual acculturation outcomes (Berry \& Sam, 1997). Three established conceptual approaches to acculturation research include the stress and coping framework, the culture learning approach and the social identity approach (Ward, 2001), the latter serving as the basis for this thesis. Research has overwhelmingly shown that ethno-cultural individuals prefer to maintain attachments to their heritage culture and also adapt to the larger society, an acculturation strategy known 
as integration (Berry et al., 1989, Berry et al., 2006). In general, five methodological approaches have been employed to examine acculturation, from studies that are crosscultural and cross-national, developmental, longitudinal and generational in nature (Ward, 2007), all examining differences in individual-level acculturation. The impact of societal characteristics on the acculturation of individuals has also been examined (Berry et al., 2006; Berry, 2001; Bourhis et al., 1997; Navas et al., 2005; Ward \& Leong, 2006).

This thesis contributes to theory and literature on acculturation by:

a) Examining the influence of characteristics of the ethno-cultural group on individual acculturation, specifically vitality within and across ethnic groups;

b) Introducing the concept of long-term acculturation which goes beyond current approaches of acculturation that look at individual adaptation in the present to investigating the future continuity of ethno-cultural groups;

c) Considering the influence of collective experiences of acculturation in the past, such as existential uncertainty, on the present acculturation of individuals;

d) Acknowledging the consequences of individual behaviour in the present for the continuity of the collective in the future.

Spicer (1971) theorised that persistent cultural systems such as the Jewish people were due to the process of continued opposition with the larger society. However, under conditions expounded by multiculturalism where such opposition is reduced or eliminated altogether, internal impetus is needed to ensure collective continuity. Indeed, when external conditions are favourable, Maimon (2007) outlined that ethno-cultural groups can be thriving (collective integration) or drifting (collective assimilation) if they lack internal momentum ${ }^{63}$. While structural variables that affect internal momentum were noted such as demography, power structures and leadership, psychological variables had yet to be examined. This thesis has contributed to the literature by examining assimilation has been examined within the Jewish community in the United States (Dershowitz, 1997). 
psychological variables such as Motivation for Ethno-cultural Continuity, a construct that is shaped by ethno-cultural identity, ethno-historical consciousness and vicarious experience of ethnic history and is able to predict individual behaviours such as endogamy and selective dating that facilitate the collective continuity of 'small peoples'.

\section{The influence of ethno-cultural vitality on continuity}

\section{'Small peoples' and the effect of vitality across ethno-cultural groups}

This thesis has demonstrated that the existential uncertainty experienced by 'small peoples' (Kundera, 1993) has a psychological impact upon the long-term acculturation of minority individuals. The Jews are the quintessential 'small people', surviving for 2,000 years as a collective in exile and acculturating to life in the diaspora while preserving their heritage culture in both tolerant and anti-Semitic societies (just over two-fifths of world Jewry has returned to live in Israel, their ancestral land). Māori are indigenous to New Zealand and are also a 'small people', acculturating to Western life after approximately 200 years of European colonisation. Māori are currently engaging in the process of cultural revitalization in the journey of collective endurance and self-determination. In contrast, the Chinese are the antithesis of 'small peoples'. There are over 1.2 billion ethnic Han Chinese, compared to only 13 million Jews and 618,000 Māori. Furthermore, only 4 percent of Chinese people live in the diaspora. Thus, the long-term acculturation of individual overseas Chinese is not at all critical to the continuity of the Chinese collective. Quite the reverse is true for the acculturation of individual diaspora Jews and individual Māori in New Zealand.

Past collective experiences and the existential uncertainty of 'small peoples' such as Jews and Māori have an impact on the acculturation of Jewish and Māori individuals today in that concerns for collective continuity, operationalised by the original construct Motivation for Ethno-Cultural Continuity (MEC), were greater for New Zealand Jews 
and Māori compared to Chinese. Furthermore, MEC was a significant predictor of intentions for endogamy and selective dating behaviour only for Jews and Māori. Thus, the vitality of the ethno-cultural group in terms of its demographic characteristics influenced not only the strength of MEC, but also its function at the individual level. In addition, it seems that ethno-cultural vitality changes the meaning of endogamy; for Chinese it may be a manifestation of ethno-centrism as only attraction and social network approval were significant predictors; for 'small peoples' such as Jews and Māori it is instrumental, facilitating individual cultural maintenance, cultural transmission and collective endurance.

\section{Small communities and the effect of vitality within ethno-cultural groups}

Ethno-cultural communities vary in terms of migration history, experiences of discrimination, contribution to the larger society, population size, institutional resources and creativity. Comparing the continuity of four Jewish communities in the diaspora that vary greatly in vitality in terms of their absolute and relative population size, from 4,300 Jews in Auckland and Wellington, New Zealand ( $0.27 \%$ of the regional population); 37,800 Jews in Melbourne, Australia (1.2\%); 180,000 Jews in Toronto, Canada (3.9\%); to 2,051,000 Jews in New York, America (9.7\%), community vitality did not have an impact upon the strength of Motivation for Ethno-cultural Continuity, ethno-historical consciousness or vicarious experience of ethnic history among individual Jews as moderate to high mean levels were found among all four samples. However, community vitality did influence individual behavioural intentions for endogamy and selective dating behaviour. Note that absolute and relative community size did not have an incremental effect; rather, there was a specific threshold which seemed to thwart the endogamy intentions and selective dating among New Zealand Jews specifically. Only mild endogamy intentions were evident and individuals did not engage in selective dating 
behaviour. In contrast, Australian, Canadian and American Jews exhibited on average strong intentions for endogamy and did engage in selective dating. It seems that (a) the absolute size of the Jewish communities sampled in New Zealand, indicative of a minute marriage market, combined with (b) the relative size of the Jewish communities, indicative of increased outgroup contact, and (c) the geographic isolation of the New Zealand Jewish community from world Jewry, have a cumulative impact to produce weak endogamy intentions and impede individuals from engaging in selective dating.

Just how community vitality impacts behavioural intentions and behaviour may be elucidated by principles from the Theory of Planned Behaviour (Azjen, 1991), more specifically the role of beliefs that one can perform the targeted behaviour. Beliefs can vary according to contextual conditions, and ethnic vitality is one such condition. Individual perceptions of control that one can or cannot marry endogamously may indeed be influenced by evident 'resources' or the size of the pool of prospective marriage partners. In New Zealand, the available marriage market is evidently small, and unless individuals emigrate to larger communities, perceptions of control are likely to be weak and may have an attenuating effect on behavioural intentions for endogamy and selective dating behaviour.

\section{Limitations and Future Research}

All the studies presented in this thesis are characterised by the limitation of small individual sample size and sampling highly identified participants through ethno-cultural organisations. This limitation, however, is consistent across the studies and consequently participants were matched as closely as possible along demographic characteristics. These studies do not represent the whole spectrum of ethno-cultural young adults. 
Regarding limitations specific to the cross-cultural study, continuity was examined in four Anglosaxon multicultural settler societies; continuity in more homogeneous societies e.g. Japan has yet to be examined. Furthermore, ethno-cultural idiosyncrasies in continuity should be noted: Jews underwent extreme cultural loss in the Holocaust, the impact of the establishment of the State of Israel in helping to revitalize Diaspora Jewry (through language, food, literature and identity) should be acknowledged; Māori are still undergoing the process of cultural revitalization through formal education and the institutionalised recognition of Māori culture; and the old New Zealand Chinese community is currently moving from the previous strategy of collective assimilation to integration in New Zealand society. In addition, although all three cultures are ethncultural groups, the influence of religion in the continuity of Judaism must also be considered especially under negative external conditions where sources of protection and impetus for continuity may be Divine. Overall, journeys of ethno-cultural continuity may take similar paths, but they are not identical.

As for limitations of the cross-national study, it is difficult to separate the effects of absolute vs. relative community size on behaviour. A more detailed examination of the influence of vitality could be conducted by examining different communities within the same country; for instance comparing Jewish communities in the New York metropolitan area 2,051,000 (9.7\%), Boston area 254,000 (4.4\%), Atlanta 86,000 (2.1\%), Milwaukee 21,000 (1.2\%) and Memphis 8,500 (0.7\%).

Limitations regarding the construct of Motivation for Ethno-cultural Continuity relate to the inability of the scale factor structure to replicate the three domains of continuity discussed in the focus groups. Although the items were drawn from focus group statements, perhaps making more clear definitive items regarding different subjects would have enabled a 3-factor structure to emerge. In addition, some predictive power 
may have been lost by using culture-general vs. culture-specific measures, for instance "I want to celebrate Passover/Waitangi Day/Chinese New Year with my children.”

As for limitations regarding the measures of individual awareness of social representations of ethnic history, although focus groups participants spoke of three conceptually distinct narratives, they were strongly interrelated such that a single-factor structure emerged in the WHAT measure. Thus, it was not possible to decipher whether all three narratives are of equal importance in shaping MEC. Furthermore, historically tribal history is most important for Māori and clan history most important for Chinese, yet they were strongly interrelated with family and ethnic history to form a single-factor measure of WHO, which impeded comparisons with Jews who clearly distinguished between the three subjects of remembrance. In addition, perhaps some predictive power was lost in using culture-general vs. culture-specific measures, for instance "I remember the suffering Jews went through in the Holocaust/ Māori after British Colonisation/ Chinese under the Poll Tax."

Research on the long-term acculturation of ethno-cultural groups has only just begun. Many questions can be formulated to explore uncharted territories in acculturation: Does Motivation for Ethno-cultural Continuity (MEC) predict other continuity-enhancing behaviours? Are there differences in MEC among affiliated and unaffiliated individuals and does it have the same function? What are the effects of individual differences in religious denomination and cultural immersion, such as living in an ethnic neighbourhood, having ethnic friends, ethnic language proficiency, traditional eating practices, ethnic education and visiting ancestral land on MEC levels and continuity-enhancing behaviours such as endogamy and selective dating? Direct measures of attitudes towards the target behaviour (endogamy/selective dating), perceived group vitality and perceived behavioural control of endogamy could also be included in the predictive model of endogamy to more clearly understand the impact of vitality on 
behaviour. It is likely that favourable attitudes towards endogamy persist in the face of low behavioural intentions that are due to marriage market constraints.

Future research could develop the four methods of ensuring continuity presented in Chapter four relating to the self, family, ethno-cultural group and larger society. The impact of cultural tightness/looseness of the ethno-cultural group and its interaction with the tightness/looseness of the larger society could also be investigated. Indeed, collective interests are of central concern in tight cultures whereas individual interests are of central concern in loose cultures (Triandis, 1989). While internal impetus for continuity such as MEC might be higher among individuals from tight cultures, external conditions for continuity might be more favourable in larger societies that are loose and tolerate difference.

This thesis has examined the continuity of Jews as the quintessential 'small people' and made comparisons with Māori as an indigenous people and Chinese as the antithesis of 'small peoples'; it would be of interest to examine the psychological processes behind the continuity of other ethnic groups like Australian Aborigines, an indigenous people who, unlike New Zealand Māori, do not have a treaty with the sovereign government to protect their rights and heritage culture; other old diaspora peoples like the Armenians; and new diaspora peoples like the Tibetans. 


\section{Practical applications}

A number of practical applications stem from the research findings and theoretical implications summarized above; some are culture-general and others are culture-specific.

\section{Small communities of 'small peoples'}

If behaviour is what matters for continuity, small communities of 'small peoples' are in big trouble. As their limited 'resources' impede selective dating and endogamy which are particularly important methods of cultural transmission that enable collective continuity by facilitating enculturation in an ethno-cultural home environment (Alba, 1990; Pagnini \& Morgan, 1990; Schönfplug, 2001a; Phillips \& Chertok, 2004), they will need to rely on other methods of transmission such as formal ethno-cultural education. That continuityenhancing behaviours such as endogamy and selective dating are hindered by low collective vitality points to the precariousness of small communities of 'small peoples' not only at a cross-national level (e.g. New Zealand has 6,800 Jews vs. United States with 5,290,000 Jews); but also at a within-nation level (e.g. Sioux Falls in South Dakota with 195 Jews vs. New York metropolitan area with 2,051,000 Jews) ${ }^{64}$.

\section{Enhancing internal collective momentum}

At a global level, UNESCO's Universal Declaration on Cultural Diversity has been ratified by 192 Member States of the General Assembly of the United Nations, emphasising the preservation and transmission of cultural heritage. At national and local levels, governments enact multicultural policies and in some cases provide resources for the protection and propagation of minority ethnic groups and indigenous peoples. However, as noted thirty years ago, "The strength of Jewish identification, and its modes

${ }^{64}$ Sklare and Greenblum's (1967) study of Jewish Identity on the Suburban Frontier highlights some of the difficulties faced by small communities within the United States. 
of expression, will have to come from internalized desires for group survival and the strength and influence of the community's socio-religious structure in communicating and reinforcing the group's norms, sentiments, values and interests" (Medding, 1968, p. 277). Indeed, the construct of Motivation for Ethno-cultural Continuity (MEC) developed in this thesis captures such an internalized desire for group survival. Methods of enhancing MEC to ensure that ethnic communities are thriving instead of drifting entities could be developed, targeting different life stages e.g. primary, secondary and tertiary school age-groups not only to bolster ethno-cultural identity, but also to encourage the cognitive and in particular affective remembrance of collective history. Interventions at the family and school-levels could include personalized experiences of rituals and classroom activities to increase a vicarious experience of ethnic history. The efficacy of programs such as March of the Living in terms of increasing endogamy intentions and communal involvement have been examined (Helmreich, 2005), however, its impact on individual-level social representations of ethnic history and Motivation for Ethno-cultural Continuity are yet unknown.

\section{Acknowledging the instrumental value of endogamy}

Ethno-cultural groups and indigenous peoples such as Māori who are invested in collective continuity can learn from the Jewish experience of acculturation in exile for over 2,000 years. Māori as a colonized people have only experienced 200 years of acculturation. Although they are extremely inclusive in defining who belongs in the Māori world and whole-heartedly welcome individuals with mixed heritage, the high incidence of exogamy means that not all individuals with Māori heritage actually identify as such. Furthermore, individuals who identify with multiple heritage cultures are less competent in Māoritanga than individuals who solely identify as Māori (Howard \& Didham, 2004). Durie (1998, 2003, 2005), has emphasised Māori self-determination 
through collective political strategies that engage with the New Zealand government, and has acknowledged the central role of the family as guardians of Māori culture. However, ethnic endogamy as an internal strategy for ensuring continuity has not been voiced. This is reflected in the mean levels of endogamy intentions of Māori participants resting on the scale mid-point of four. Surely acknowledging the instrumental value of endogamy as a transmission belt, as an additional method of ensuring Māori continuity, could be beneficial. Note that the instrumental value of endogamy for the continuity of the New Zealand Chinese community is attenuated due to the continuous immigration of Chinese to New Zealand ${ }^{65}$.

\section{Acknowledging ethno-cultural birthright}

The Jewish people, in turn, can learn from the Māori experience of acculturation. Their inclusive definitions of belonging, whereby an individual with any proportion of Māori heritage can identify as Māori and be acknowledged as such, contrasts vividly with the extremely exclusive Jewish definitions of belonging. Although an ethno-cultural group, criteria for belonging to the Jewish people have been regulated by religious authorities. While Orthodox recognise only the matrilineal descent rule, Reform recognise cognatic descent (through both the mother and father, or only the father). Why 'small peoples' such as the Jews should be so restrictive in membership not only eludes collective interests of continuity, but also robs individuals of Jewish descent with a genuine interest in their heritage from their birthright. Indeed, while acknowledging the continual importance of endogamy for transmitting Jewish heritage, many have been calling for greater inclusiveness in the Jewish world (Dershowitz, 1997).

${ }_{65}$ The population of Chinese in New Zealand increased from 105,057 in 2001 to 147,570 in 2006 (Statistics New Zealand, 2008). 


\section{Conclusion}

The field of long-term acculturation can provide culture-general principles and be sensitive to culture-specific ideas and processes. Ethno-cultural continuity encompasses the journey of an ethnic group as it adapts to the larger society and perpetuates its heritage culture - much like a vine transplanted to a new environment adjusts and contributes to the local ecosystem, and continues to produce its specific variety of fruit.

Although continuity is a group-oriented acculturation goal for diaspora and indigenous peoples, each group has its unique collective experiences and hopes for the future: Jews aim for quantitative and qualitative continuity ${ }^{66}$ of Jewish life in both the diaspora and in Israel where they can be self-determined once more; Māori aim for quantitative and qualitative continuity in the framework of self-determination as indigenous peoples in New Zealand; and the Chinese diaspora aim for qualitative continuity only, interested in ensuring local expressions of their heritage culture.

Continuity for the sake of...? When I began my doctoral studies, I had the privilege of meeting Harry Triandis at the 2004 International Academy for Intercultural Research conference in Taiwan. I asked him what he thought of ethno-cultural continuity; dismissing the notion, he commented that capturing the best elements from different cultures was of greater value! As a Jewish person who cares about Jewish continuity, I was taken aback by his answer which disregarded the love that individuals have for their particular heritage. After all is said and done, while ethno-cultural continuity may be a theoretical global goal to ensure cultural diversity and enhance creativity, it is uniquely meaningful for ethno-cultural group members.

\footnotetext{
${ }^{66}$ Jewish religious beliefs and practices are included in the qualitative continuity of the Jewish people.
} 
"Ui mai ki ahau he aha e mea nui o te ao māku e ki atu he tāngata, he tāngata, he tāngata -

You ask of me, what is the most important thing in this world.

My reply must be: It is people, it is people, it is people."

'Small peoples' value their heritage culture, and the most important thing may in fact be 'my people', stretching back in time to 'my ancestors' and extending forward in time to 'my children', and 'my children's children'. This genuine care for one's people can be applied in accordance with a quote by the Jewish sage Hillel: "If I am not for myself, who will be for me? If I am only for myself, what am I? If not now, when?” When transposed to the collective, this passage means that 'small peoples' must protect their own heritage culture, and also look beyond their world and empathise with other peoples. And there is no time like the present to take care of the future of one's people. 


\section{REFERENCES}

Abric, J.C. (1993). Central system, peripheral system: Their functions and roles in the dynamics of social representations. Papers on Social Representations, 2(2), 75-128.

Abulof, U. (2007). "Still on the Roof" Israeli-Jewish existential insecurity: The survival-identity complex. Unpublished Ph.D. thesis, Hebrew University of Jerusalem, Jerusalem.

Adair, V., \& Dixon, R. (1998). The family in Aotearoa New Zealand. Auckland: Addison Wesley Longman NZ Ltd.

Alba, R.D (1990). Ethnic identity: The transformation of White America. RI: Yale University Press.

Alba, R.D. \& Golden, R.M. (1986). Patterns of ethnic marriage in the United States. Social Forces, 65, 202-223.

Alba, R. D., \& Nee, V. (2003). Rethinking assimilation theory for a new era of immigration. In M. M. Suarez-Orozco, C. Suarez-Orozco \& D. B. Qin (Eds.), The new immigration: and interdisciplinary reader (pp. 35-65). New York: Routledge.

Allen, J., Basilier Vaage, A., \& Hauff, E. (2006). Refugees and asylum seekers in societies. In D. L. Sam \& J. W. Berry (Eds.), The Cambridge handbook of acculturation psychology (pp. 198-217). New York: Cambridge University Press.

American Jewish Committee. (2005). Jewish Geography. New York: American Jewish Committee.

Ang, I. (2000). Can one say no to Chineseness? Pushing the limits of the diasporic paradigm. In R. Chow (Ed.), Modern Chinese literary and cultural studies in the Age of Theory: Reimagining a field. (pp. 281-300). Durham: Duke University Press.

Argyle, M. (1969). Social interaction. London: Methuen. 
Armitage, C. J., \& Conner, M. (2001). Efficacy of the theory of planned behaviour: A meta-analytic review. British Journal of Social Psychology, 40, 471-499.

Asa-El, A. (2004). Diaspora: The lost tribes of Israel. Westport, Conn: Hugh Lauter Levin Associates, Inc.

Asbury, J.E. (1995). Overview of focus groups research. Qualitative Health Research, 5(4), 414-420.

Atkinson, J. M., \& Heritage, J. (1984). Structures of social action: Studies in conversation analysis. Cambridge: Cambridge University Press.

Australian Bureau of Statistics. (2008). www.censusdata.abs.gov.au. Sourced 2008.

Azjen, I. (1991). The theory of planned behavior. Organizational Behaviour and Human Decision Processes, 50, 179-211.

Bagozzi, R. P. (1992). The self-regulation of attitudes, intentions, and behavior. Social Psychology Quarterly (June), 178-204.

Banister, J. (1987). China's changing population. Stanford, CA: Stanford University Press.

Barron, M. L. (1972). Intergroup aspects of choosing a mate. In M. L. Barron (Ed.), The blending American: Patterns of inermarriage (pp. 36-47). Chicago: Quandrangle Books.

Barry, D. T., \& Grilo, C. M. (2003). Cultural, self-esteem and demographic correlates of perception of personal and group discrimination among East Asian immigrants. American Journal of Ortho-psychiatry, 73, 223-229.

Bateman, D. (Ed.) (2000) The New Zealand Encyclopaedia, $5^{\text {th }}$ ed. Auckland: David Bateman Ltd. 
Bayme, S. (1994). Intermarriage and communal policy: Prevention, conversion, and outreach. In S. Bayme \& G. Rosen (Eds.), The Jewish family and Jewish continuity. (pp. 285-293). New Jersey: Ktav Publishing House.

Bayme, S. (2002). Jewish arguments and counterarguments. New Jersey: Ktav Publishing House/American Jewish Committee.

Bellah, R.N., Masden, R., Sullivan, W., Swidler, A., \& Tipton, S.M. (1985). Habits of the heart: Individualism and commitment in American life. CA: University of California Press.

Berman, L.A. (1968). Jews and intermarriage. New York: Thomas Yoseloff.

Berry, J. W. (1989). Imposed etics-emics-derived etics: The operationalization of a compelling idea. International Journal of Psychology, 24, 721-735.

Berry, J. W. (1990). Psychology of acculturation. In R. W. Brislin (Ed.), Applied crosscultural psychology (pp. 232-253). California: Sage.

Berry, J. W. (2001). A psychology of immigration. Journal of social issues, 57, 615-631.

Berry, J. W. (2003). Conceptual approaches to acculturation. In K. M. Chun, P. B. Organista \& G. Marin (Eds.), Acculturation: Advances in theory, measurement, and applied research (pp. 17-34). Washington, DC: American Psychological Association.

Berry, J. W. (2005). Acculturation: Living successfully in two cultures. International Journal of Intercultural Relations, 29(6), 697-712.

Berry, J. W. (2007). Globalisation and acculturation. International Journal of Intercultural Relations, doi:10.1016/jijintrel.2008.04.001.

Berry, J. W., Kim, U., Power, S., Young, M. J., \& Bujaki, M. (1989). Acculturation attitudes in plural societies. Applied Psychology, 38, 185-206. 
Berry, J. W., Phinney, J. S., Sam, D. L., \& Vedder, P. (2006). Immigrant youth in cultural transition. New Jersey: Lawrence Erlbaum Associates.

Berry, J. W., Poortinga, Y., Segall, M. H., \& Dasen, P. (2002). Cross-Cultural Psychology: Research and Applications: Cambridge University Press.

Berry, J. W., \& Sam, D. L. (1997). Acculturation and adaptation. In J. W. Berry, M. H. Segall \& C. Kagitcibasi (Eds.), Handbook of cross-cultural psychology (Vol. 3, pp. 291326). Boston: Allyn \& Bacon.

Billig, M. (1988). Social representation, anchoring and objectification: A rhetorical analysis. Social Behaviour, 3, 1-16.

Birman, D., \& Trickett, E. J. (2001). Cultural transitions in first-generation immigrants: Acculturation of Soviet Jewish refugee adolescents and parents. Journal of CrossCultural Psychology, 32(4), 456-477.

Blau, P. M., Blum, T. C., \& Schwartz, J. E. (1982). Heterogeneity and intermarriage. American Sociological Review, 47, 45-62.

Bloodworth, D. (1969). Chinese looking glass: A brilliant study of Chinese national psychology during 3000 years of history and culture. Great Britain: Penguin Books.

Bochner, S. (1986). Coping with unfamiliar cultures: Adjustment or culture learning? Australian Journal of Psychology, 38, 347-358.

Bochner, S. (2006). Sojourners. In D. L. Sam \& J. W. Berry (Eds.), The Cambridge handbook of acculturation psychology. (pp. 181-197). New York: Cambridge University Press.

Bodde, D. (1981). Essays on Chinese civilization. New Jersey: Princeton University Press.

Bol Jun Lee, J. (2003). Eating porkchops and Puha with chopsticks: Māori-Chinese constructions. In M. Ip (Ed.), Unfolding history, evolving identity: The Chinese in New Zealand (pp. 94-112). Auckland: Auckland University Press. 
Boneva, B. S., \& Frieze, I. H. (2001). Toward a concept of a migrant personality. Journal of Social Issues, 57(3), 477-491.

Bossard, J. H. S., \& Stoker Boll, E. (1972). When the children come in interfaith marriages. In M. L. Barron (Ed.), The blending American: Patterns of intermarriage (pp. 296-308). Chicago: Quadrangle Books.

Bourhis, R. Y., Moïse, C., Perreault, S., \& Sénécal, S. (1997). Towards an interactive acculturation model: A social psychological approach. International Journal of Psychology, 32, 369-386.

Boyd, R., \& Richersen, P. (1985). Culture and the evolutionary process. Chicago: University of Chicago Press.

Braun, V., \& Clarke, V. (2006). Using thematic analysis in psychology. Qualitative research in psychology, 3, 77-101.

Braziel, J. E., \& Mannur, A. (Eds.). (2003). Theorizing diaspora. Massachusetts: Blackwell Publishing.

Breakwell, G. M. (1993). Integrating paradigms, methodological implications. In G. M. Breakwell \& D. V. Canter (Eds.), Empirical approaches to social representations (pp. 180-201). Oxford: Oxford University Press.

Breakwell, G. M. (2001). Social representational constraints upon identity processes. In K. Deaux \& G. Philogene (Eds.), Representations of the social (pp. 271-284). Oxford: Blackwell Publishers.

Broughton J, Fergusson DM, Rimene C, Horwood LJ, \& Sporle A. (2000). Nga Tini Aho $\mathrm{O} \mathrm{Te}$ Ao Hou. The many strands of contemporary Māori society: Māori ethnicity and identity in the Christchurch Health and Development Study. Dunedin: NTMHRU. 
Brown, L. M., NcNatt, P. S., \& Cooper, G. D. (2003). Ingroup romantic preferences among Jewish and non-Jewish White undergraduates. International Journal of Intercultural Relations, 27, 335-354.

Brown, M., \& Lightman, B. (1999). Creating the Jewish future. California: Altamira Press.

Bryant, F.B., \& Yarnold, P.R. (1995). Principal components analysis and exploratory and confirmatory fctor analysis. In Grimm, L.G. \& Yarnold, P.R. (Eds.), Reading and understanding multivariate statistics. (pp.99-136). Washington, D.C.: American Psychological Association.

Buber, M. (1967). On Judaism. New York: Schocken Books Inc.

Buss, D. M., et al., (1990). International preferences in selecting mates: A study of 37 cultures. Journal of Cross-Cultural Psychology, 21(1), 5-47.

Callister, P. (2004). Ethnicity measures, intermarriage and social policy. Social Policy Journal of New Zealand, 23, 109-141.

Callister, P., Didham, R., \& Potter, D. (2005). Ethnic intermarriage in New Zealand. Wellington: Statistics New Zealand.

Cameron, J. E. (2004). A three-factor model of social identity. Self and Identity, 3(3), 239-262.

Campbell, D.T. (1958). Common fate, similarity, and other indices of the status of aggregates of person as social entities. Behavioral Science, 3, 14-25.

Cartier, C. (2003). Regions of diaspora. In L. J. C. Ma \& C. Cartier (Eds.), The Chinese diaspora: Space, place, mobility and identity (pp. 379-390). Oxford: Rowman \& Littlefield Publishers. 
Castano, E., Sacchi, S., \& Gries, P. H. (2003). The perception of the Other in international relations: Evidence for the polarizing effect of entitativity. Political Psychology, 24(3), 449-468.

Castano, E., Yzerbyt, V., \& Bourguignon, D. (2007). We are one and I like it: The impact of ingroup entitativity on ingroup identification. European Journal of Social Psychology, 37, 735-754.

Castro, P. (2003). Dialogues in social psychology - Or, how new are new ideas? In J. László \& W. Wagner (Eds.), Theories and controversies in societal psychology (pp. 32-54). Budapest: New Mandate.

Cattell, M. G., \& Climo, J. J. (2002). Meaning in social memory and history: Anthropological perspectives. In J. J. Climo \& M. G. Cattell (Eds.), Social memory and history: Anthropological perspectives (pp.1-38). California: AltaMira Press.

Cavalli-Sforza, L. L., \& Feldman, M. W. (1981). Cultural transmission and evolution: A quantitative approach. New Jersey: Princeton University Press.

Chandler, M.J. \& Proulx, T. (2008). Personal persistence and persistent peoples: Continuity in the lives of individual and whole cultural communities. In F. Sani (Ed.), Self-continuity: Individual and collective perspectives. (pp. 213-226). Hillsdale: LEA.

Chin, J. L., Mio, J. S., \& Iwamasa, G. Y. (2006). Ethical conduct of research with Asian and Pacific Islander American populations. In J. E. Trimble \& C. B. Fisher (Eds.), Handbook of Ethical Research with Ethnocultural Populations and Communities (pp. 117-135). California: Sage.

Chiswick, C. U., \& Chiswick, B. R. (2001). The cost of living Jewishly and Jewish continuity. Contemporary Jewry, 21, 78-90.

Chun, A. (2000). Fuck Chineseness: On the ambiguities of ethnicity as culture as identity. In R. Chow (Ed.), Modern Chinese literary and cultural studies in the age of theory: Reimagining a field (pp.111-138). Durham: Duke University Press. 
Cleary, T.A. and Hilton, T.L. (1968). An investigation of item bias. Educational and Psychological Measurement, 28, 61-75.

Cohen, R. (1997). Global diasporas: An introduction. London: University College London Press.

Cohen, S. J. D. (1999). The beginnings of Jewishness: Boundaries, varieties, uncertainties. California: University of California Press.

Cohen, S. M. (2006). A Tale of Two Jewries: The "Inconvenient Truth" for American Jews. New York: Steinhardt Foundation.

Cohen, S. M., \& Eisen, A. M. (2000). The Jew within: Self, family and community in America. Bloomington: Indiana University Press.

Cohn-Sherbok, D. (2002). Anti-Semitism. Sparkford: Sutton Publishing.

Coney, S. (1995). I Do: 125 years of weddings in New Zealand. Auckland: Hodder Moa Beckett.

Connor, J. W. (1974). Acculturation and family continuities in three generations of Japanese Americans. Journal of Marriage and the Family, 36(1), 159-165.

Deci, E.L. (1975). Intrinsic motivation. New Yorl: Plenum.

Deci, E. L., \& Ryan, R. M. (1985). Intrinsic motivation and self-determination theory of human behavior. New York: Plenum.

Deci, E. L., \& Ryan, R. M. (1991). A motivational approach to Self: Integration in personality. Nebraska Symposium on Motivation, 38, 237-288.

DellaPergola, S. (1993). Modern Jewish Demography. In J. Wertheimer (Ed.), The modern Jewish experience (pp. 275-290). New York: New York University Press. 
Dershowitz, A. M. (1997). The vanishing American Jew. USA: Little Brown \& Company.

Dion, K. K., \& Dion, K. L. (1996). Cultural perspectives on romantic love. Personal Relationships, 3, 5-17.

Djao, W. (Ed.). (2003). Being Chinese: Voices from the diaspora. Tucson: University of Arizona Press.

Driedger, L. (2003). Race and ethnicity: Finding identities and equalities. Ontario: Oxford University Press.

Durie, A. (1997). Te aka matua: Keeping a Māori identity. In T. Whaiti (Ed.), Mai i rangiatea (pp. 142-162). Auckland: Auckland University Press.

Durie, M. (1998). Te mana, te kawanatanga: The politics of Māori self-determination. Melbourne: Oxford University Press.

Durie, M. (2003). Launching Māori futures. Wellington: Huia Publishers.

Durie, M. (2005). Nga tai matatu: Tides of Māori endurance. Melbourne: Oxford University Press.

Elazar, D. (1999). Psychology and Judaism. In J. Neusner, A. J. Avery-Peck \& W. S. Green (Eds.), Encyclopedia of Judaism (pp. 1089-1109). New York: Continuum Publishing Co.

Esses, V. M., Jackson, L. M., \& Armstrong, T. L. (1998). Intergroup competition and attitudes toward immigrants and immigration. Journal of Social Issues, 54, 699-724.

Fenton, S. (2003). Ethnicity: Key concepts. Oxford: Blackwell Publishing. 
Fiese, B. H., Tomcho, T. J., Douglas, M., Josephs, K., Poltrock, S., \& Baker, T. (2002). A review of 50 years of research on naturally occurring family routines and rituals: Cause for celebration? Journal of Family Psychology, 16(4), 381-390.

Fishman, J. A. (1961). Childhood indoctrination of minority group membership. In M. L. Barron (Ed.), Minorities in a changing world. New York: Alfred A Knopf.

Fitzgerald, C. P. (1967). The Chinese view of their place in the world. London: Oxford University Press.

Fleras, A. (1999). Recalling Aotearoa: Indigenous politics and ethnic relations in New Zealand. Melbourne: Oxford University Press.

Fletcher, G. J. O., Simpson, J. A., Thomas, G., \& Giles, L. (1999). Ideals in intimate relationships. Journal of Personality and Social Psychology, 76(1), 72-89.

Flick, U. (2002). An introduction to qualitative research. London: Sage.

Fong, N. B. (1959). The Chinese in New Zealand: A study in assimilation. Hong Hong: Oxford University Press.

Fontaine, J. (2005). Equivalence. In Kempf-Leonard (Ed.), Encyclopedia of social measurement (Vol. 1, pp. 803-813). London: Academic Press.

Friesen, J. D. (1990). Rituals and family strength. Direction, 19(1), 39-48.

Frye Jacobson, M. F. (1998). Whiteness of a different color: European immigrants and the alchemy of race. Massachusetts: Harvard University Press.

Gans, H. J. (1979). Symbolic ethnicity. Ethnic and Racial Studies, 2, 1-20.

Gardikiotis, A., Martin, R., \& Hewstone, M. (2004). The representation of majorities and minorities in the British press: A content analytic approach. European Journal of Social Psychology, 34, 637-646. 


\section{Garson, G.D. (2008) Structural Equation Modeling. http://www2.chass.ncsu.edu/garson/pa765/structur.htm. Accessed 2008.}

Georgas, J., \& Kalantzi-Azizi. (1992). Value acculturation and response tendencies of biethnic adolescents. Journal of Cross-Cultural Psychology, 23(2), 228-239.

Goetz, P. W. (Ed.) (1987a) Encyclopaedia Britannica (15 ed., Vols. 25), 1038-1047. Chicago: Encyclopaedia Britannica Inc.

Goetz, P. W. (Ed.) (1987b) Encyclopaedia Britannica (15 ed., Vols. 28), 451-483. Chicago: Encyclopaedia Britannica Inc.

Goodenough, W. (1981). Culture, language and society (2 ed.) Menlo Park, CA: Benjamin/Cummings.

Gordon, A. I. (1972). Intermarriage: What it is. In M. L. Barron (Ed.), The blending American: Patterns of intermarriage (pp. 6-10). Chicago: Quadrangle Books.

Graves, T. D. (1967). Psychological acculturation in a tri-ethnic community. Southwestern Journal of Anthropology, 23, 337-350.

Green, W.S. (1999). History, The conception of in classical Judaism. In J. Neusner, A. J. Avery-Peck \& W. S. Green (Eds.), Encyclopedia of Judaism (pp. 380-406). New York: Continuum Publishing Co.

Gumperz, J. J., \& Berenz, N. (1993). Transcribing conversational exchange. In J. A. Edwards \& M. D. Lampert (Eds.), Talking data: Transcription and coding in discourse research (pp. 91-121). New Jersey: Erlbaum.

Gungwu, W. (1991). The Chineseness of China. Hong Kong: Oxford University Press.

Gungwu, W. (2003). Don't leave home: Migration and the Chinese. Singapore: Eastern Universities Press. 
Halbwachs, M. (1925). Les cadres sociaux de la memore. Paris: Librairie Felix Alcan.

Harré, R. (1984). Some reflections on the concept of "Social Representation". Social Research, 51, 927-938.

Harris, K.M., Florey, F., Tabor, J., Bearman, P.S., Jones, J. \& Udry, J.R. (2003). The National Longitudinal Study of Adolescent Health. http://www.cpc.unc.edu/projects/addhealth. Sourced 2008.

Helmreich, W. B. (2005). Long-range effects of the March of the Living on participants. New York: City University of New York.

Hemara, W. (2000). Mãori pedagogies: A view from the literature. Wellington: New Zealand Council for Education Research.

Hindman, D. B., Littlefield, R., Preston, A., \& Neumann, D. (1999). Structural pluralism, ethnic pluralism and community newspapers. Journalism and Mass Communication Quarterly, 76(2), 250-263.

Ho, E. (2003). Reluctant exiles or roaming transnationals? The Hong Kong Chinese in New Zealand. In M. Ip (Ed.), Unfolding history, evolving identity: The Chinese in New Zealand (pp. 165-184). Auckland: Auckland University Press.

Holy, L. (1996). Anthropological perspectives on kinship. Chicago: Pluto Press.

Hooft, E. A. J., Born, M., Taris, T. W., \& Flier, H. (2006). The cross-cultural generalizability of the theory of planned behavior: A study on job seeking in the Netherlands. Journal of Cross-Cultural Psychology, 37(2), 127-135.

Horenczyk, G., \& Tatar, M. (1998). Friendship expectations among immigrant adolescents and their host peers. Journal of Adolescence, 21, 69-82.

Horowitz, B. (2000). Connections and Journeys: Assessing Critical Opportunities for Enhancing Jewish Identity. New York: United Jewish Appeal - Federation of New York. 
Howard, S., \& Didham, R. (2005). Ethnic intermarriage and ethnic transference amongst the Mãori population: Implications for the measurement and definition of ethnicity. Wellington: Statistics New Zealand.

Hu, L.-T. \& Bentler, P.M. (1999). Cutoff criteria for fit indices in covariance structure analysis: Conventional criteria versus new alternatives. Structural Equation Modeling, 6, 1-55.

Human Rights Commission (2005). New Zealand Diversity Action Program: Racial equality the facts of the matter. www.hrc.co.nz/hrc new/hrc/cms/files/documents/26-Feb2006 17-39-54 Racial Equality Fact Sheet.pdf. Sourced 2008.

Hsu, F. L. K., \& Serrie, H. (1998). The overseas Chinese. New York: University Press of America Inc.

Human Rights Commission. (2007). Perceived Discrimination in New Zealand. Wellington: UMR Research Limited.

Hutchby, I., \& Wooffitt, R. (1998). Conversation Analysis: Principles, practice and applications. Cambridge: Polity.

Hwang, S. S., Saenz, R., \& Aguirre, B. E. (1997). Structural and assimilationist explanations of Asian American intermarriage. Journal of Marriage and the Family, 59, 758-772.

Inman, A., Howard, E. E., Beaumont, R. L., \& Walker, J. A. (2007). Cultural transmission: Influence of contextual factors in Asian Indian immigrant parents' experiences. Journal of Counselling Psychology, 54(1), 93-100.

Ip, M. (1995). Chinese New Zealanders: Old settlers and new immigrants. In S. W. Grief (Ed.), Immigration and national identity in New Zealand (pp. 161-202). Palmerston North: Dunmore Press. 
Ip, M. (1996). Dragons on the long white cloud: The making of Chinese New Zealanders. North Shore City: Tandem Press.

Ip, M. (2003). Chinese immigrants and transnationals in New Zealand: A fortress opened. In L. J. C. Ma \& C. Cartier (Eds.), The Chinese diaspora: Space, place, mobility and identity (pp. 339-358). Oxford: Rowman \& Littlefield.

Isajiw, W.W. (1974). Definitions of ethnicity. Ethnicity, 1, 111-124.

Jackson, M. (2003). The part- Māori syndrome. Mana, 52 (June-July), 62.

Jewish Outreach Institute. (2008). http://joi.org. Sourced 2008.

Jewish People Policy Planning Institute (JPPPI) (Ed.). (2005). The Jewish people between thriving and decline. Jerusalem: The Jewish Agency for Israel.

Johnson, P. (1987). A history of the Jews. London: George Weidenfeld \& Nicolson, Ltd.

Johnston, R., Poulsen, M., \& Forrest, J. (2005). Ethnic residential segregation across an urban system: The Māori in New Zealand, 1991-2001. The Professional Geographer, 57(1), 115-129.

Kalmijn, M. (1998). Intermarriage and homogamy: Causes, patterns, trends. Annual Review of Sociology, 24, 395-422.

Kalmijn, M., Liefbroer, A. C., van Poppel, F., \& van Solinge, H. (2006). The family factor in Jewish-Gentile intermarriage: a sibling analysis of the Netherlands. Social Forces, 84(3), 1348-1358.

Kamenetz, R. (1994). The Jew in the lotus. San Francisco: Harper Collins.

Keysar, A., Kosmin, B., Lerer, N., \& Mayer, A. J. (1991). Exogamy in first marriages and remarriages. Contemporary Jewry, 12, 45-66. 
King, M. (2002). At the edge of memory. New Zealand: Penguin.

King, M. (2004). Nga invi o te motu: 1000 years of Māori history. Auckland: Reed publishing.

Kitano, H. L., Yeung, W. T., Chai, L., \& Hatanaka, H. (1984). Asian-American interracial marriage. Journal of Marriage and the Family, 46, 179-190.

Kline, R. B. (2005). Principles and practice of structural equation modeling. New York: The Guilford Press.

Krueger, R. A. (1994). Focus groups: A practical guide for applied research (2 ed.). London: Sage.

Kukutai, T. (2004). The problem of defining an ethnic group for public policy: Who is Māori and does it matter? Social Policy Journal of New Zealand, 23, 86-108.

Kulczycki, A., \& Lobo, A. P. (2002). Patterns, determinants, and implications of intermarriage among Arab Americans. Journal of Marriage and the Family, 64, 202210.

Kundera, M. (1993). Les testaments trabis. Saint-Amand: Editions Gallimard.

Kvernmo, S. (2006). Indigenous peoples. In D. L. Sam \& J. W. Berry (Eds.), The Cambridge handbook of acculturation psychology (pp. 233-250). New York: Cambridge University Press.

Kwok-bun, C. (2005). Chinese identities, ethnicity and cosmopolitanism. New York: Routledge.

LaFromboise, T., Coleman, H., \& Gerton, J. (1993). Psychological impact of biculturalism: Evidence and theory. Psychological Bulletin, 114, 395-412.

Lalonde, R. N., \& Cameron, J. E. (1993). An intergroup perspective on immigrant acculturation with a focus on collective strategies. International Journal of Psychology, 28(1), 57-74. 
Lalonde, R. N., Hynie, M., Pannu, M., \& Tatla, S. (2004). The role of culture in interpersonal relationships: Do second generation South Asian Canadians want a traditional partner? Journal of Cross-Cultural Psychology, 35(5), 503-524.

Langellier, K. M. (2002). Performing family stories, forming cultural identity: Franco American memere stories. Communication Studies (Spring).

Langman, P. F. (1999). Jewish issues in multiculturalism: A handbook for educators and clinicians. New Jersey: Jason Aronson Inc.

Lasker, A. A., \& Lasker, J. N. (1991). Do they want their children to be like them? Parental heritage and Jewish identity. Contemporary Jewry, 12, 109-125.

Laszlo, J., \& Wagner, W. (Eds.). (2003). Theories and controversies in societal psychology. Budapest: New Mandate Publishing House.

Lazarus, R. S., \& Folkman, S. (1984). Stress, coping and appraisal. New York: Springer.

Leach, M.S. \& Braithwaite, D.O. (1996). A binding tie: Supportive communication of family kinkeepers. Journal of Applied Communication Research, 24, 200-216.

Lee, Q. (1994). Delineating Asian (Hong Kong) intellectuals: Speculation on intellectual problematics and post/coloniality. Third Text, 26, 11-23.

Levine, H. (1997). Constructing collective identity: A comparative analysis of New Zealand Jews, Māori and Urban Papua New Guineans. Frankfurt: Peter Lang.

LeVine, R.A. (1974). Parental goals: A cross-cultural view. Teacher's College Record, 76, 226-239.

LeVine, R. A., \& Campbell, D. T. (1972). Ethnocentrism: Theories of conflict, ethnic attitudes and group behavior. New York: Wiley. 
Little, T. D., Cunningham, W. A., Shahar, G., \& Widaman, K. F. (2002). To parcel or not to parcel: Exploring the question, weighing the merits. Structural equation modeling, 9(2), 151-173.

Liu, J. H. (1999). Social representations of history: Preliminary notes on content and consequences around the Pacific Rim. International Journal of Intercultural Relations, 23(2), 215-236.

Liu, J. H., Campbell, S. M., \& Condie, H. (1995). Ethnocentrism in dating preferences for an American sample: The ingroup bias in social context European Journal of Social Psychology, 25, 95-115.

Liu, J. H., Goldstein-Hawes, R., Hilton, D. J., Huang, L. L., Gastardo-Conaco, C., Dresler-Hawke, E., et al. (2005). Social representations of events and people in world history across twelve cultures. Journal of Cross-Cultural Psychology, 36(2), 171 191.

Liu, J. H., \& Hilton, D. (2005). How the past weighs on the present: Social representations of history and their role in identity politics. British Journal of Social Psychology, 44, 537-556.

Liu, J. H., \& Sibley, C. (2006). Differential effects of societal anchoring and attitude certainty in determining support or opposition to (bi)cultural diversity in New Zealand. Papers on Social Representations, 15, 1-15.

Liu, J. H., Wilson, M. S., McClure, J., \& Higgins, T. R. (1999). Social identity and the perception of history: Cultural representations of Aotearoa/New Zealand. European Journal of Social Psychology, 29, 1021-1047.

Logan, B. (2004). Waking up to marriage: Why it's vital to couples, kids, and country. Auckland: Maxim Institute.

Luhtanen, R., \& Crocker, J. (1992). A collective self-esteem scale: Self-evaluation of one's social identity. Personality and Social Psychology Bulletin, 18(3), 302-318. 
Ma, L. J. C. (2003). Space, place and transnationalism in the Chinese diaspora. In L. J. C. Ma \& C. Cartier (Eds.), The Chinese diaspora: Space, place, mobility and identity (pp. 149). Oxford: Rowman \& Littlefield.

Maaka, R., \& Fleras, A. (2000). Engaging with indigeneity: Tino rangatiratanga in Aotearoa. In D. Ivison, P. Patton \& W. Sanders (Eds.), Political theory and the rights of indigenous peoples (pp. 89-109). Melbourne: Cambridge University Press.

Maaori.com (2008). http://maaori.com/Whakapapa/whakpap2.htm. Sourced 2008.

Macaulay, R. K. S. (1991). "Coz it izny spelt when they say it": Displaying dialect in writing. American Speech, 66(3), 280-291.

MacDonald, K. (2002). A people that shall dwell alone: Judaism as a group evolutionary strategy, with diaspora peoples. San Jose: Writers Club Press.

Macpherson, C., \& Spoonley, P. (2004). Mediated ethnicity: Media and the management of ethnic images in Aotearoa. In P. Spoonley, C. Macpherson \& D. Pearson (Eds.), Tangata tangata: The changing ethnic contours of New Zealand. (pp.221-245). Victoria: Dunmore Press.

Maimon, D. (2007). Alternative Futures Project Summary Document JP2030 Version 6(2). Jerusalem: JPPPI Jewish People Policy Planning Institute.

Mamet, R., Jacobson, C., \& Heaton, T. (2005). Ethnic intermarriage in Beijing and Xinjiang, China, 1990. Journal of Comparative Family Studies, 36(1), 187-204.

Markova, I. (2003). Les focus groups. In S. Moscovici \& F. Buschini (Eds.), Les méthodes des sciences humaines. Paris: Presses Universitaires de France.

Marsh, H.W. \& Hau, K.-T. (1999). Confirmatory factor analysis: Strategies for small sample sizes. In R.H. Hoyle (Ed.), Statistical strategies for small sample research. (pp.252-284). Thousand Oaks, CA: Sage. 
McCabe, M.P. (1984). Toward a theory of adolescent dating. Adolescence, 19, 159-170.

McDaniel, C.O. (1969). Dating roles and reasons for dating. Journal of marriage and the family, 31, 97-107.

McMinn, J. G. (2003). Perceiver differences and judgements of group entitativity. University of Pittsburgh, Pittsburgh.

Medding, P. Y. (1968). From Assimilation to Group Survival. Melbourne: Cheshire Publishing.

Merton, R.K. (1941). Intermarriage and the social structure. Psychiatry, 4, 361-374.

Metge, J. (1967). The Mãoris of New Zealand. London: Routledge \& Kegan Paul Ltd.

Meyer, M. A. (1974). Ideas of Jewish history. New York: Behrman House.

Moeke-Pickering, T. (1996). Māori identity from within whanau: A review of the literature. Hamilton: University of Waikato.

Moghaddam, F. M., Taylor, D. M., \& Lalonde, R. N. (1987). Individualistic and collective integration orientations among Iranians in Canada. International Journal of Psychology, 22, 301-313.

Mok, T. A. (1999). Asian American Dating: Important factors in partner choice. Cultural Diversity and Ethnic Minority Psychology, 5(2), 103-117.

Moloney, G., \& Walker, I. (2002). Talking about transplants: Social representations and the dialectical, dilemmatic nature of organ donation and transplantation. British Journal of Social Psychology, 41.

Montreuil, A., \& Bourhis, R. Y. (2001). Majority acculturation orientations toward "valued" and "devalued" immigrants. Journal of Cross-Cultural Psychology, 32(6), 698719. 
Morgan, D. (1998). The focus group guidebook: The focus group kit 1. CA: Sage.

Moro, M. (1997). The Italian-American family over three generations: Family competence, individuation, ethnic identity and self esteem. Dissertation abstracts international section A: Humanities and social sciences, 58(3-A).

Moscovici, S. (1961). La psychanalyse, son image et son public: Presses Universitaires de France.

Moscovici, S. (1984). The phenomenon of social representations. In R. Farr \& S. Moscovici (Eds.), Social representations (pp. 3-69). Cambridge: Cambridge University Press.

Moscovici, S. (1998). The history and actuality of social representations. In U. Flick (Ed.), The psychology of the social (pp. 209-247). Cambridge: Cambridge University Press.

Murphey, R. (1986). History and geography: Introduction. In R. F. Dernberger, K. J. DeWoskin, S. M. Goldstein, R. Murphey \& M. K. Whyte (Eds.), The Chinese: Adapting the past, building the future (pp. 5-28). Ann Arbor: University of Michigan.

Murphy, H.M.B. (1965). Migration and the major mental disorders. In M.B. Kentor (Ed.). Mobility and mental health. Springfield, IL: Charles C Thomas.

Murphy, N. (2003). Joe Lum v.The Attorney General: The politics of exclusion. In M. Ip (Ed.), Unfolding history, evolving identity: The Chinese in New Zealand (pp. 48-67). Auckland: Auckland University Press.

National Jewish Population Survey (2000-01). New York: United Jewish Communities. North American Jewish Data Bank [Distributor].

Navas, M., Garcia, M. C., Sanchez, J., Rojas, A. J., Pumares, P., \& Fernandez, J. S. (2005). Relative acculturation extended model (RAEM): New contributions with regard to the study of acculturation. International Journal of Intercultural Relations, 29(1), 2137. 
Navas, M., Rojas, A. J., Garcia, M. C., \& Pumares, P. (2007). Acculturation strategies and attitudes according to the relative acculturation extended model (RAEM): The perspectives of natives versus immigrants. International Journal of Intercultural Relations, 31(1), 67-86.

Neusner, J. (1999a). Conversion in Judaism. In J. Neusner, A. J. Avery-Peck \& W. S. Green (Eds.), Encyclopedia of Judaism (pp. 112-126). New York: Continuum Publishing Co.

Neusner, J. (1999b). Israel the people in Medieval and modern times. In J. Neusner, A. J. Avery-Peck \& W. S. Green (Eds.), Encyclopedia of Judaism (pp. 499-515). New York: Continuum Publishing Co.

Neville, P. (1999). The Holocaust. Cambridge: Cambridge University Press.

Ng, J. (1995). Windows on a Chinese past. Dunedin: Otago Heritage Books.

Ng, J. (1999). Chinese settlement in New Zealand, past, present and future. Christchurch: New Zealand Centre for Chinese Studies.

$\mathrm{Ng}$, J. (2001). Chinese settlement in New Zealand, past and present. http://www.stevenyoung.co.nz/The-Chinese-in-New-Zealand/History-ofChinese-in-NewZealand/Chinese-settlement-in-NZ-past-and-present.html. Sourced 2008.

Ng, J. (2003). The sojourner experience: The Cantonese goldseekers in New Zealand, 1865-1901. In M. Ip (Ed.), Unfolding history, evolving identity: The Chinese in New Zealand (pp. 5-30). Auckland: Auckland University Press.

Nutin, J.R. (1985). Future time perspective and motivation: Theory and research method. Hillsdale, NJ: Erlbaum.

Ochs, E. (1979). Transcription as theory. In E. Ochs \& B. B. Schiefflen (Eds.), Developmental pragmatics. (pp.167-182). New York: Academic Press. 
Office of Ethnic

Affairs

(2005).

Ethnic

profiles.

www.ethnicaffairs.govt.nz/oeawebsite.nsf/wpg URL/Resources-Profiles-and-

Statistics-Ethnic-Profiles?OpenDocument. Sourced 2008.

Orfali, B., \& Markova, I. (2002). Analogies in focus groups: from the victim to the murderer and from the murderer to the victim. European Review of Applied Psychology, 52, 263-271.

Pagnini, D. L., \& Morgan, S. P. (1990). Intermarriage and social distance among U.S. immigrants at the turn of the century. American Journal of Sociology, 96(2), 405-432.

Pan, L. (Ed.). (1998). The encyclopedia of the Chinese overseas. Surrey: Curzon.

Phillips, B. \& Chertok, F. (2004). Jewish identity among the adult children of intermarriages: Event borizon or navigable horizon? Paper presented at the Association for Jewish Studies $36^{\text {th }}$ annual conference, Chicago, IL.

Phinney, J. S., Horenczyk, G., Liebkind, K., \& Vedder, P. (2001). Ethnic identity, immigration and well-being: An interactional perspective. Journal of Social Issues, 57, 493-510.

Pillemer, D.B. (2004). Can the psychology of memory enrich historical analyses or trauma? History and Memory, 16(2), 140-154.

Podhoretz, N. (2000). Still here--and more. National Review, 52(1), 30-34.

Polek, E., \& Van Oudenhoven, J. P. (2007). Cosmopolitan identity - the overlooked element in policies on immigrants' adaptation. Poster presented at the International Academy for Intercultural Research, 5th biennial conference, Groningen.

Portes, A., Fernandez-Kelly, P., \& Haller, W. (2005). Segmented assimilation on the ground: The new second generation in early adulthood. Ethnic and Racial Studies, 28(6), 1000-1040. 
Portes, A., \& Rumbaut, R. G. (2005). Introduction: The second generation and the Children of Immigrants Longitudinal Study. Ethnic and Racial Studies, 28(6), 983999.

Porton, G.G. (1999). Israel the people in Judaism in Medieval and modern times. In J. Neusner, A. J. Avery-Peck \& W. S. Green (Eds.), Encyclopedia of Judaism (pp. 499514). New York: Continuum Publishing Co.

Potter, J. \& Wetherell, M. (1998). Social representations, discourse analysis, and racism. In U.Flick (Ed.) Psychology of the social. (pp.138-155). Cambridge: Cambridge University Press

Qian, Z. (1997). Breaking the racial barriers: Variations in interracial marriage between 1980 and 1990. Demography, 34(2), 263-277.

Qian, Z. (1999). Who intermarries? Education, nativity, region, and interracial marriage, 1980 and 1990. Journal of Comparative Family Studies, 30(4), 579-598.

Qian, Z., \& Lichter, D. T. (2007). Social boundaries and marital assimilation: Interpreting trends in racial and ethnic intermarriage. American Sociological Review, 72, 68-94.

Rabinowitz, J. (1989). The paradoxical effects of Jewish community size on Jewish communal behaviour: Intermarriage, synagogue membership and giving to local Jewish federations. Contemporary Jewry, 10 (1), 9-15.

Reber, A. S. (Ed.) (1995) Dictionary of psychology. London: Penguin.

Redfield, R., Linton, R. \& Herskovitz, M.J. (1936). Memorandum on the study of acculturation. American Anthropologist, 38, 149-152.

Reedy, T. (1991). Viewpoint. Listener, (June 10), 7.

Reinharz, S. (2005). Blaming Women Begets No Babies. Forward. http://my.brandeis.edu/news/item?news item id=104185. Accessed 2008. 
Riddell, K. (2000). 'Improving' the Māori: Counting the ideology of intermarriage. New Zealand Journal of History, 34(1), 80-97.

Ritsner, M., \& Ponizovsky, A. (2003). Age differences in stress process of recent immigrants. Comprehensive Psychiatry, 44(2), 135-141.

Robinson, L. (2006). Acculturation in the United Kingdom. In D. L. Sam \& J. W. Berry (Eds.), The Cambridge handbook of acculturation psychology (pp. 385-400). New York: Cambridge University Press.

Rosenthal, D. A., Bell, R., Demetriou, A., \& Efklides, A. (1989). From collectivism to individualism? The acculturation of Greek immigrants in Australia. International Journal of Psychology, 24, 57-71.

Ryabov, I., \& Van Hook, J. (2006). School segregation and academic achievement among Hispanic children. Social Science Research, 36, 767-788.

Ryan, R. M., \& Deci, E. L. (2000). Self-determination theory and the facilitation of intrinsic motivation, social development, and well-being. American Psychologist, 55(1), 68-78.

Sacks, J. (2000). Radical then, radical now. London: Continuum.

Salkin, J. (1999). Judaism, Definition of. In J. Neusner, A. J. Avery-Peck \& W. S. Green (Eds.), Encyclopedia of Judaism (pp. 579-588). New York: Continuum Publishing Co.

Sani, F., \& Bowe, M. (2004). Perceived group historical continuity: Its functions and its relationship with group identification. Paper presented at the Collective remembering, collective emotions and shared representations of history: Functions and dynamics; Small meeting of EAESP, Aix-en-Provence. 
Sani, F., Bowe, M., \& Herrera, M. (2007). Perceived Collective continuity: Seeing groups as temporally enduring entities. In F. Sani (Ed.), Self-continuity: Individual and collective perspectives. (pp. 159-172). Hillsdale: LEA.

Sani, F., Bowe, M., Herrera, M., Manna, C., Cossa, T., Miao, X., et al. (2007). Perceived collective continuity: Seeing groups as entities that move through time. European Journal of Social Psychology, 37(6), 1118-1134.

Saxe, L., Kadushin, C., Hecht, S., Rosen, M. I., Phillips, B., \& Kelner, S. (2004). Evaluating Birthright Israel: Long-term impact and recent findings: Maurice and Marilyn Cohen Center for Modern Jewish Studies, Brandeis University.

Scheffler, H.W. (1964). Descent concepts and descent groups: The Māori case. Journal of the Polynesian Society, 73, 126-133.

Schönpflug, U. (2001a). Intergenerational transmission of values: The role of transmission belts. Journal of Cross-Cultural Psychology, 32(2), 174-185.

Schönpflug, U. (2001b). Cultural transmission: A multidisciplinary research field. Journal of Cross-Cultural Psychology, 32(2), 131-134.

Schwartz, B., Zerubavel, Y., \& Barnett, B. M. (1986). The recovery of Masada: A study in collective memory. The Sociological Quarterly, 27(2), 147-164.

Schwartz, D. (1999). Israel the people in Judaism, The classical statement. In J. Neusner, A. J. Avery-Peck \& W. S. Green (Eds.), Encyclopedia of Judaism (pp. 484-499). New York: Continuum Publishing Co.

Sedgewick, C. P. (1998). The Chinese in New Zealand: Persistence, change and innovation. In F. L. K. Hsu \& H. Serrie (Eds.), The overseas Chinese: Ethnicity in national context (pp. 115-142). New York: University Press of America. 
Sen, R., \& Wagner, W. (2004). History as a symbolic resource for political propaganda and mass action: The case of Hindu-Muslim conflict in India. Paper presented at the Collective remembering, emotions and shared representations of history: Functions and dynamics, EAESP small group meeting, Aix-en-Provence.

Shaughnessy, E. L. (2005). Ancient China: Life, myth and art. London: Duncan Baird.

Sheffer, G. (2005). Is the Jewish diaspora unique? Reflections on the diaspora's current situation. Israel Studies, 10(1), 1-35.

Simmons, T. \& O'Connell, M. (2003). Married-couple and unmarried-partner households: 2000. Washington, DC: U.S. Census Bureau.

Sklare, M., \& Greenblum, J. (1967). Jewish identity on the suburban frontier: A study of group survival in the open society. Chicago: University of Chicago Press.

Skeldon, R. (2003). The Chinese diaspora or the migration of Chinese peoples? In L. J. C. Ma \& C. Cartier (Eds.), The Chinese diaspora: Space, place, mobility and identity (pp. 5166). Oxford: Rowman \& Littlefield.

Skelton, T. \& Allen, T. (1999). Culture and global change. London: Routledge.

Smith, P. B., \& Fischer, R. (2008). Acquiescence, extreme response bias and culture: A multilevel analysis. In F. Van de Vijver, D. A. van Hemert \& Y. Poortinga (Eds.), Multilevel analysis of individuals and cultures. New Jersey: Lawrence Erlbaum.

Sodowsky, G.R. \& Plake, B.S. (1992). A study of acculturation differences among international people and suggestions for sensitivity to within-group differences. Journal of Counselling and Development, 71, 53-59.

Spicer, E. H. (1971). Persistent cultural systems. Science (November), 795-800.

Spoonley, P. (1999). The challenge of cross-cultural research. In M. Tolich (Ed.), Social science research in New Zealand (pp. 51-61). Auckland: Pearson Education. 
Stanislawski, M. (1999). The crisis of Jewish secularism. In L. M. Brown \& B. Lightman (Eds.), Creating the Jewish future (pp. 131-142). California: AltaMira Press.

Statistics New Zealand. (2008). www.stats.govt.nz. Sourced 2008.

Stein, A.A. (1976). Conflict and cohesion: A review of the literature. Journal of Conflict Resolution, 20, 143-172.

Stephan, C. W., \& Stephan, W. G. (1989). After intermarriage: Ethnic identity among mixed-heritage Japanese-Americans and Hispanics. Journal of Marriage and the Family, 51, 507-519.

Stewart, D. W., \& Shamsadani, P. N. (1990). Focus groups: Theory and practice. California: Sage.

Stopes-Roe, M., \& Cochrane, R. (1988). Marriage in two cultures. British Journal of Social Psychology, 27, 159-169.

Strauss, A., \& Corbin, J. (1998). Basics of qualitative research: Techniques and procedures for developing Grounded Theory. California: Sage.

Suarez-Orozco, C., \& Todorova, I. L. (2006). Projecting the voices of Mexican-origin children. Research in Human Development, 3(4), 211-228.

Sussman, N. M., Truong, N., \& Lim, J. (2006). Who experiences "America the beautiful"? Ethnicity moderating the effect of acculturation on body image and risks for eating disorders among immigrant women. International Journal of Intercultural Relations, 31, 29-49.

Swora, M. G. (2001). Commemoration and the healing of memories in Alcoholics Anonymous. Ethos, 29(1), 58-77.

Tajfel, H. (1978). Differentiation between social groups. London: Academic Press. 
Tajfel, H. (1982). Social psychology of intergroup relations. Annual Review of Psychology, 33 , $1-39$.

Tang, S., \& Zuo, J. (2000). Dating Attitudes and Behaviors of American and Chinese College Students. Social Science Journal, 37(1), 67-78.

Tartakovsky, E., \& Schwartz, S. H. (2001). Motivation for emigration, values, wellbeing and identification among young Russian Jews. International Journal of Psychology, 36(2), 88-99.

Tashakkori, A. \& Teddlie, C. (1998). Mixed methodology: Combining qualitative and quantitative approaches. CA: Sage.

Tobin, D., Tobin, G. A., \& Rubin, S. (2005). In every tongue: The racial and ethnic diversity of the Jewish people. San Francisco: Institute for Jewish and community research.

Triandis, H. C. (1989). The self and social behavior in differing cultural contexts. Psychological Review, 96(3), 506-520.

Trimble, J. E., \& Mohatt, G. V. (2006). The virtuous and responsible researcher in another culture. In J. E. Trimble \& C. B. Fisher (Eds.), The handbook of ethical research with ethnocultural populations and communities (pp. 325-334). California: Sage.

Tu, W. (1994). Cultural China: The periphery as center. In Tu (Ed.) The living tree: The changing meaning of being Chinese today. (pp.1-34). Stanford: Stanford University Press.

UNESCO. (1999). Towards a constructive pluralism. http://portal.unesco.org/culture/en/ev.phpURL ID=22512\&URL DO=DO TOPIC\&URL SECTION=201.html. Sourced 2008.

UNESCO. (2001). UNESCO Universal Declaration on Cultural Diversity. Paris: UNESCO. 
UNESCO (2005). $4^{\text {th }}$ Youth Forum of the $33^{\text {rd }}$ UNESCO general conference. http://unesco.takingitglobal.org/themes2005.en.html?theme $=$ unique. Sourced 2008.

van de Vijver, F. J. R., \& Leung, K. (1997). Methods and analysis for cross-cultural research. California: Sage.

van Oudenhoven, J. P. (2006). Immigrants. In D. L. Sam \& J. W. Berry (Eds.), The Cambridge handbook of acculturation psychology (pp. 163-180). New York: Cambridge University Press.

van Tubergen, F., \& Maas, I. (2007). Ethnic intermarriage among immigrants in the Netherlands: An analysis of population data. Social Science Research, 36(3), 10651086.

Vaughan, G., \& Hogg, M. (1998). Introduction to social psychology. Victoria: Prentice Hall.

Verkuyten, M. (2005). The social psychology of ethnic identity. New York: Psychology Press.

Verkuyten, M., \& Aslan Yildiz, A. (2007). National (dis)idenfitication and ethnic and religious identity: A study among Turkish-Dutch Muslims. Personality and Social Psychology Bulletin, 33(10), 1448-1462.

Verkuyten, M., \& de Wolf, A. (2002). Being, feeling and doing: Discourses and ethnic self-definitions among minority group members. Culture and Psychology, 8(4), 271299.

Waite, L., \& Friedman, J. S. (1997). The impact of religious upbringing and marriage markets on Jewish intermarriage. Contemporary Jewry, 18, 1-23.

Waldegrave, C. (2003). Focus groups. In C. Davidson \& M. Tolich (Eds.), Social science research in New Zealand: Pearson Education NZ Ltd. 
Walker, R. (1996). Nga pepa a Ranginui: Thought-provoking views on the issues affecting Māori and Pakeha. Auckland: Penguin.

Walker, R. (2004). Ka whawhai tonu matou: Struggle without end. Auckland: Penguin Books.

Ward, C. (1996). Acculturation. In D. Landis \& R. S. Bhagat (Eds.), Handbook of intercultural training. (pp.124-147) California: Sage.

Ward, C. (2001). The A,B,Cs of acculturation. In D. Matsumoto (Ed.), The handbook of culture and psychology (pp. 411-445). Oxford: Oxford University Press.

Ward, C. (2005). Acculturation, identity and adaptation in dual heritage adolescents. International Journal of Intercultural Relations, 30(2), 243-259.

Ward, C. (2007). Thinking outside the Berry boxes: New perspectives on identity, acculturation and intercultural relations. International Journal of Intercultural Relations, 32, 105-114.

Ward, C., Bochner, S., \& Furnham, A. (2001). The psychology of culture shock. Sussex: Routledge.

Ward, C., \& Kennedy, A. (2001). Coping with cross-cultural transition. Journal of CrossCultural Psychology, 32(5), 636-642.

Ward, C., \& Leong, C.-H. (2006). Intercultural relations in plural societies. In D. L. Sam \& J. W. Berry (Eds.), The Cambridge handbook of acculturation psychology (pp. 484-503). New York: Cambridge University Press.

Waters, M. C., \& Jiménez, T. R. (2005). Assessing immigrant assimilation: New empirical and theoretical challenges. Annual Review of Psychology, 31, 105-126.

Weber, M. (1968). Basic sociological terms. In G. Roth \& C. Wittich (Eds.), Economy and society. (pp. 3-62). Berkeley: University of California Press. 
Wegner, D. M., \& Wheatley, T. (1999). Apparent mental causation. American Psychologist, 54(7), 480-492.

Weiss-Rosmarin, T. (1977). Jewish survival. New York: Ktav Publishing House.

Wengraf, T. (2001). Qualitative research interviewing: Biographic narrative and semi-structured methods. London: Sage.

Wertheimer, J. (2005). Jews and the Jewish birthrate. Commentary. http://www.simpletoremember.com/vitals/jews-and-jewish-birthrate.htm. Accessed 2008.

Willig, C. (2001). Introducing qualitative research in psychology. Buckingham: Open University Press.

Wolin, S.J. \& Bennett, L.A. (1984). Family rituals. Family Process, 23, 401-420.

Wong, K. (2003). A place to stand: The Chun family experience. In M. Ip (Ed.), Unfolding history, evolving identity: The Chinese in New Zealand (pp. 113-135). Auckland: Auckland University Press.

Wouk, H. (2000). The will to live on. New York: Harper Collins.

Yerushalmi, Y. H. (1982). Zakhor: Jewish history and Jewish memory. Seattle: University of Washington Press.

Yee, B. (2003). Coping with insecurity: Everyday experiences of Chinese New Zealanders. In M. Ip (Ed.), Unfolding history, evolving identity: The Chinese in New Zealand (pp. 215-235). Auckland: Auckland University Press.

Young, S. (2005). From assimilation to multiculturalism: Evidence of an evolving model of settlement for the Chinese community in New Zealand from 1950 to the present. www.stevenyoung.co.nz/The-Chinese-in-New-Zealand/MNZS/FromAssimilation-to-Multiculturalism-Literature-review.html. Accessed 2008. 
Zarrow, P. (2004). Historical Trauma: Anti-Manchuism and memories of atrocity in late Qing China. History and Memory, 16(2), 67-107.

Zenner, W. (1991). Minorities in the middle: A cross cultural analysis. Albany: State University of New York Press.

Zimbardo, P. G., \& Boyd, J. N. (1999). Putting time in perspective: A valid, reliable individual-differences metric. Journal of Personality and Social Psychology, 77(6), 1271-1288. 


\section{Appendix A: Cultural streams of THE JEWISH PEOPLE DUE TO LONG-TERM ACCULTURATION IN THE DIASPORA}

\begin{tabular}{ll}
\hline Ashkenazi & Originate near the Rhône basin (Franco-Germany and the Polish-Russian \\
Jews & territories). From 1791-1917 Jews were forced to live in an area known as the \\
& Pale of Settlement, living in shtetls or little Jewish towns. Anti-Semitism was rife \\
& as Jews suffered under the crusades and pogroms. Today Ashkenazi Jews \\
& account for approximately 80 percent of world Jewry (though at their peak in \\
& 1931 they constituted 92 percent of world Jewry). \\
Sephardi & Originate from the Iberian peninsula (Spain and Portugal). The Jewish Golden \\
Jews & Age in Spain under the rule of the Moors (700s - 1100s CE) was known for its \\
& religious and secular cultural productivity. Christian hostility led to forced \\
& conversions and murders. The secret practice of Judaism led to the emergence of \\
& crypto Jews, known as Conversos. Jews suffered most under the Spanish \\
& Inquisition and were expelled in 1492. Many Sephardi Jews migrated to The \\
& Netherlands, North Africa and the Ottoman Empire. Jews were interpreters on \\
& Columbus' ships to America and Cabral's ships to Brazil.
\end{tabular}

\footnotetext{
Mizrahi Jews Those who remained in the land of Israel, in North Africa (Morocco, Tunisia, Algeria), Egypt, and Asia (Persia, Syria, Lebanon, Yemen, Afganistan, Kurdistan). The Babylonian and Egyptian diaspora academies were intellectually vigorous. The status of Mizrahi Jews varied from living in destitution in Yemen to being successful merchants in Iraq. Forced conversions to Islam were experienced under Shi'ite rule. Most Mizrahi Jews were forced to leave their homes in Arab nations when the State of Israel was established.

Italian Jews The oldest and most stable diaspora Jewish community, the Bene Roma have preserved special religious rites that are distinct from the Ashkenazi and Sephardi. Jews settled in the region during the Roman Empire, and after the destruction of the Second Temple thousands of Jewish prisoners of war were brought back as slaves. Jews were discriminated against by the Papal authority and segregated with the establishment of the Jewish ghetto in 1555 .
} 


Indian Jews The Cochin Jews arrived in India during the reign of King Solomon; the Bene
Israel Jews were established off the coast of Mumbai after a shipwreck during
their escape from Syrian and Greek rule BCE; Sephardi Jews settled in Cochin
following the expulsion from Spain; Baghdadi Jews settled over the last 200 years
as traders and refugees; the B'nei Menashe in Manipur and Mizoram settled from
China. The Jews in India vary greatly in terms of physiognomy; many are
indistinguishable from non-Jewish Indians and Chinese. A rare historical
occurrence, Jews in India were free from persecution. Acculturation with their
Hindu neighbours has influenced religious customs, food and dress. Most moved
to Israel in the 1970s.
Jewish communities lived in Kaifeng and Shanghai, as Jewish merchants travelled
the Silk Road from Persia. Jews acculturated to Confucian society, and despite
the absence of specific anti-Jewish persecution, Chinese Jews suffered along with
other ethnic minorities and were required to intermarry to hasten assimilation.
Before the 17 $7^{\text {th }}$ century, 5,000 Jews were living in Kaifeng until a civil war
destroyed most of the population; the remaining community disappeared in the
mid-1800s, though today people are aware of their Jewish heritage. The Shanghai
community was established by Baghdadi Jews in the 1800s. Most Jews left in the
1950s due to Chinese civil war.

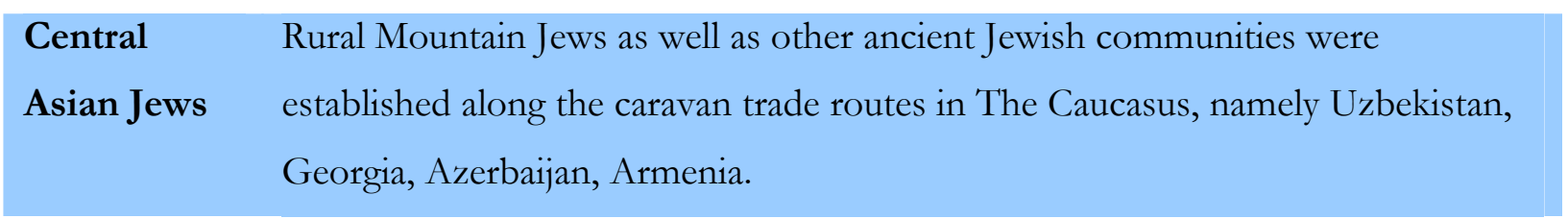

Beta Israel The Jewish community in Ethiopia, also known as Falashas or 'exiles'.

Descendants of the entourage that accompanied the Queen of Sheba (from the tribe of Dan), Beta Israel lived in agricultural communities. They are physically and culturally similar to local Ethiopians though the observance of religious traditions and consistent persecution has kept their identity distinct. In 1985 and 1991, 30,000 Beta Israel were rescued and brought to Israel. 


Ancient
African Jews Lemba of South Africa, the Igbo in Nigeria, and the House of Israel in
Ghana. Acculturation in geographically challenging areas and the effects of
Jewish traditions and ancestral stories of migration persist. A new community
called Abayudaya in Uganda converted to Judaism over a century ago.

Karaites Jews who observe the Torah, rejecting the Mishnah or Oral Law and Rabbinical rulings in the Talmud. Karaite communities survived separately from Rabbanite Jews in Israel and Egypt, travelling to Europe where their emphasis on religious as opposed to ethno-cultural identity spared them from as much persecution as other Jews. There are about 30,000 Karaite Jews in the world. 


\section{APPENDIX B: JEWISH RELIGIOUS DIVERSITY DUE TO DIFFERENT APPROACHES TO ACCULTURATION}

\begin{tabular}{|c|c|}
\hline Has & $\begin{array}{l}\text { Began in Eastern Europe in the 1700s, emphasising a more spiritually-centred } \\
\text { Jewish experience while maintaining Biblical and Rabbinical law. Characterised } \\
\text { by distinct dress and charismatic leaders, there are many Hasidic sects - the } \\
\text { Chabad-Lubavitch are well-known due to outreach work. }\end{array}$ \\
\hline $\begin{array}{l}\text { Orthodox } \\
\text { Judaism }\end{array}$ & $\begin{array}{l}\text { A movement that resisted assimilation in the face of political movements such } \\
\text { as socialism, and the emphasis on Jewish nationalism in the nascent Zionist } \\
\text { movement. Maintaining traditional Jewish beliefs in Divine revelation - that the } \\
\text { Torah is G-d given and cannot be altered, changes to religious traditions were } \\
\text { rejected. Laws relating to the Sabbath, Kashrut dietary laws and family purity } \\
\text { laws are strictly observed. Yet, acculturation did occur in the public realms of } \\
\text { language, dress education and national culture. }\end{array}$ \\
\hline $\begin{array}{l}\text { Conservative } \\
\text { Judaism }\end{array}$ & $\begin{array}{l}\text { Originated in Central Europe, it simultaneously recognised the value of Jewish } \\
\text { law and ethics, but allowed for agency of Jewish leaders in interpreting the law } \\
\text { to suit modern times. In the United States, the Conservative movement was } \\
\text { established in response to the Reform movement (see below) that had moved } \\
\text { too far 'left', distinguishing itself from Orthodoxy which was too far 'right'. }\end{array}$ \\
\hline Reform Judaism & $\begin{array}{l}\text { Originated in Germany after Jews were granted citizenship. In a conscious effort } \\
\text { to acculturate and be accepted into public life, the ethno-cultural dimension of } \\
\text { Judaism was left behind in the ghetto. Jews saw themselves as national citizens } \\
\text { whose religion was Jewish. In the United States, Reform Judaism grew } \\
\text { (Pittsburgh Platform, 1885). Revelation was rejected, the focus now on applying } \\
\text { Torah to modern life. Distinguishing ethics from law, kashrut was deemed as no } \\
\text { longer necessary and the messianic return to Israel no longer held as an ideal. } \\
\text { Worship includes the vernacular, and gender distinctions diminished. }\end{array}$ \\
\hline $\begin{array}{l}\text { Reconstructionist } \\
\text { Judaism }\end{array}$ & $\begin{array}{l}\text { Emerged from the Conservative movement in the United States in the mid- } \\
\text { 1900s, negating supernatural theology and the authority of Biblical and } \\
\text { Rabbinical law while emphasising shared historical experiences and Judaism as } \\
\text { an evolving civilization. }\end{array}$ \\
\hline Secular Jews & $\begin{array}{l}\text { Jews by descent that maintain a feeling of connectedness to the Jewish people, } \\
\text { retaining an ethno-cultural bond without observing religious laws or espousing } \\
\text { religious beliefs. }\end{array}$ \\
\hline
\end{tabular}




\section{APPENDIX C: SOURCES FOR DIASPORA LIFE IN FOUR COMMUNITIES}

\begin{tabular}{ll}
\hline New & - Levine, H. (1995). Migration or assimilation? The predicament of observant Jews. In \\
Zealand & Grief, S.W. Immigration and national identity in New Zealand: one people, two peoples, many peoples \\
& (pp. 203-216). Palmerston North: Dunmore Press. \\
- Levine, H. (1997). Constructing collective identity. Germany: Peter Lang. \\
- Levine, S. (1999). The New Zealand Jewish Community. Maryland: Lexington Books. \\
- Levine, H. \& Gezentsvey, M. (2005-6) The Wellington Cemetery Desecrations of 2004 - \\
Their impact on local Jews. Journal of New Zealand Studies, 91-109. \\
- Stephen Roth Institute for the Study of Contemporary Anti-Semitism and Racism \\
\\
(2005). Tel Aviv University (www.tau.ac.il/Anti-Semitism/asw2005/new-zealand.htm). \\
- Te Ara Encyclopaedia of New Zealand (www.teara.govt.nz).
\end{tabular}
Australia - Rutland, S.D. (2005). The Jews in Australia. Melbourne: Cambridge University Press.
- Szwarc, B. (2004). A demographic profile of the Jewish community in Victoria based on the 2001
Australian Bureau of Statistics Census. Jewish Community Council of Victoria.

Canada - Abella, I. (1990). A coat of many colors: Two centuries of Jewish life in Canada. Toronto: Lester \& Orpen Dennys.

- Adelman, H. \& Simpson, J.H. (1996). Multiculturalism, Jews and identities in Canada.

Jerusalem: The Magnes Press.

- Institute for International Affairs/B'nei Brith Canada (2000). From Immigration to Integration: The Canadian Jewish Experience.

- Shahar, C. \& Rosenbaum, T. (2006). The Jewish Community of Toronto/Jewish life in Greater Toronto 2001 Census Analysis Series, UJA Federation of Greater Toronto; UIA Canada.

- Tulchinsky, G. (1998). Branching Out: The transformation of the Canadian Jewish community.

Toronto: Stoddart Publishing Company.

- Weinfeld, M. (2001). Like everyone else, but different: The paradoxical success of Canadian Jews.

Toronto: McClelland \& Stuart.

United - Heilman, S.C. (1995). Portrait of American Jews. Seattle: University of Washington Press.

States - Mayer, E., Kosmin, B., \& Keysar, A. (2001). American Jewish Identity Survey. New York:

Centre for Jewish Studies, City University of New York.

- Sarna, J.D. (2004) American Judaism: A History. New Haven: Yale University Press.

- Telushkin, J. (2002). The Golden Land: The story of Jewish immigration to America. New York:

Harmony Books. 


\section{ApPendix D: Pilot Study Questionnaire}

1. What is your gender (tick one)?

\section{Section 1}

_ Female _ Male

2. What is your age?

_ years

3. Do you identify as Jewish (please specify below)?

- Yes _ No

4. Are your mother and father Jewish (if not, please specify below)?

$\begin{array}{lll}\text { Yes } & \text { No (Mother) Nother } \\ \text { Yes } & \text { No (Father) } & \text { Father }\end{array}$

5. Of what country are you a citizen (please specify below)?

6. Have you attended a Jewish community school for formal or informal education (tick one)?

- Yes $\quad$ No

7. How important is religion in your life (tick one)? Very important

\section{Section 2}

On this page are a number of statements concerning friends, social activities, etc. Please read each statement carefully and indicate, by circling a number on a 1 (strongly disagree) to 7 (strongly agree) scale that best represents your personal response. There are no right or wrong answers, and your first responses are usually the most accurate.

Bear in mind that we want to know what you think about being Jewish in Australia.

$\begin{array}{lllllll}1 & 2 & 3 & 4 & 5 & 6 & 7\end{array}$

strongly disagree somewhat disagree slightly disagree neutral slightly agree somewhat agree strongly agree

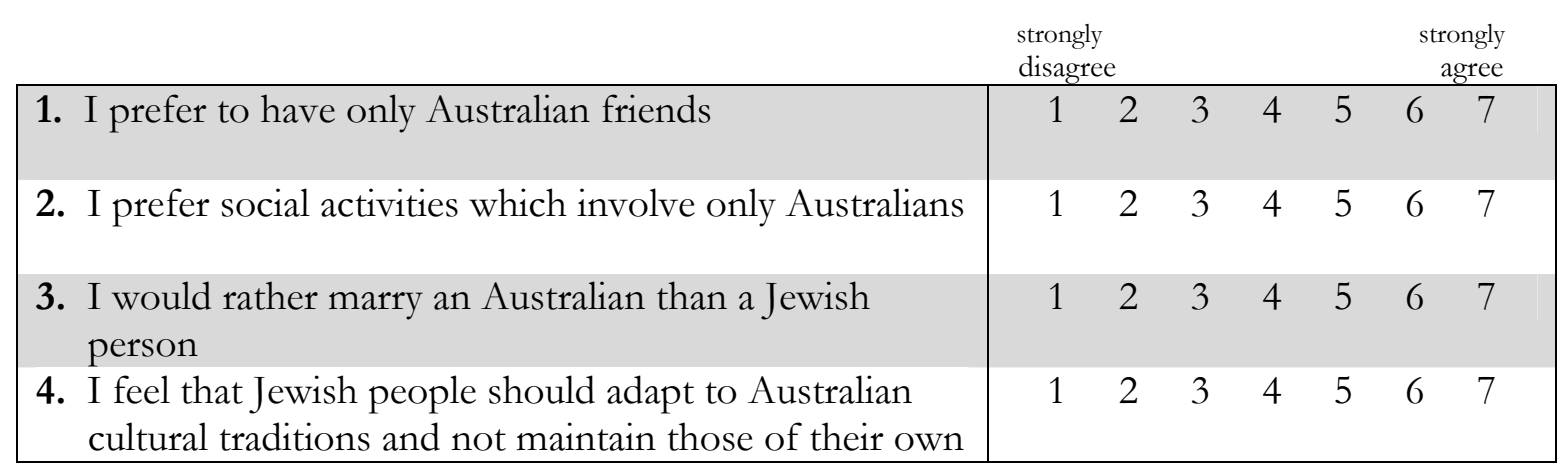




\section{Section 3}

On this page are a number of statements concerning what people think of being Jewish. Please read each statement carefully and indicate, by circling a number on a 1 (strongly disagree) to 7 (strongly agree) scale that best represents your personal response. There are no right or wrong answers, and your first responses are usually the most accurate.

Bear in mind that we want to know what you think about being Jewish.
1
2
3
45
6
7

strongly disagree somewhat disagree slightly disagree neutral slightly agree somewhat agree strongly agree

\begin{tabular}{|c|c|c|c|c|c|c|c|}
\hline & $\begin{array}{l}\text { strongly } \\
\text { disagree }\end{array}$ & & & & & & $\begin{array}{l}\text { ongly } \\
\text { gree }\end{array}$ \\
\hline 1. I often regret that I am Jewish & 1 & 2 & 3 & 4 & 5 & 6 & 7 \\
\hline 2. Overall, being Jewish is considered good by others & 1 & 2 & 3 & 4 & 5 & 6 & 7 \\
\hline $\begin{array}{l}\text { 3. Overall, being Jewish has very little to do with how } \\
\text { I feel about myself }\end{array}$ & 1 & 2 & 3 & 4 & 5 & 6 & 7 \\
\hline $\begin{array}{l}\text { 4. In general, I'm glad to be a part of the Jewish } \\
\text { people }\end{array}$ & 1 & 2 & 3 & 4 & 5 & 6 & 7 \\
\hline $\begin{array}{l}\text { 5. Most people consider the Jewish people, on the } \\
\text { average, to be more ineffective than other social } \\
\text { groups }\end{array}$ & 1 & 2 & 3 & 4 & 5 & 6 & 7 \\
\hline $\begin{array}{l}\text { 6. The Jewish people are an important reflection of } \\
\text { who I am }\end{array}$ & 1 & 2 & 3 & 4 & 5 & 6 & 7 \\
\hline $\begin{array}{l}\text { 7. Overall, I often feel that being Jewish is NOT } \\
\text { worthwhile }\end{array}$ & 1 & 2 & 3 & 4 & 5 & 6 & 7 \\
\hline 8. In general, others respect the Jewish people & 1 & 2 & 3 & 4 & 5 & 6 & 7 \\
\hline $\begin{array}{l}\text { 9. The Jewish people are unimportant to my sense of } \\
\text { what kind of a person I am }\end{array}$ & 1 & 2 & 3 & 4 & 5 & 6 & 7 \\
\hline 10. I feel good about being a part of the Jewish people & 1 & 2 & 3 & 4 & 5 & 6 & 7 \\
\hline $\begin{array}{l}\text { 11. In general, others think that the Jewish people are } \\
\text { unworthy }\end{array}$ & 1 & 2 & 3 & 4 & 5 & 6 & 7 \\
\hline $\begin{array}{l}\text { 12. In general, belonging to the Jewish people is an } \\
\text { important part of my self-image }\end{array}$ & 1 & 2 & 3 & 4 & 5 & 6 & 7 \\
\hline
\end{tabular}




\section{Section 4}

On this page are a number of statements concerning what people think about their Jewish heritage. Please read each statement carefully and indicate, by circling a number on a 1 (strongly disagree) to 7 (strongly agree) scale that best represents your personal response. There are no right or wrong answers, and your first responses are usually the most accurate.

Remember, we want to know what you personally think about your Jewish heritage.

\section{$\begin{array}{lllllll}1 & 2 & 3 & 4 & 5 & 6 & 7\end{array}$}

strongly disagree somewhat disagree slightly disagree neutral slightly agree somewhat agree strongly agree

\begin{tabular}{|c|c|c|c|c|c|c|c|}
\hline & $\begin{array}{l}\text { strong } \\
\text { disag }\end{array}$ & & & & & & $\begin{array}{l}\text { rongly } \\
\text { agree }\end{array}$ \\
\hline $\begin{array}{l}\text { 1. I would like to keep on living according to the } \\
\text { traditions of my Jewish heritage }\end{array}$ & 1 & 2 & 3 & 4 & 5 & 6 & 7 \\
\hline $\begin{array}{l}\text { 2. It is important for me to pass on my Jewish heritage } \\
\text { to my children }\end{array}$ & 1 & 2 & 3 & 4 & 5 & 6 & 7 \\
\hline $\begin{array}{l}\text { 3. The endurance of Jewish people is NOT really } \\
\text { important to me }\end{array}$ & 1 & 2 & 3 & 4 & 5 & 6 & 7 \\
\hline $\begin{array}{l}\text { 4. Maintaining my Jewish traditions and language is } \\
\text { NOT important to me }\end{array}$ & 1 & 2 & 3 & 4 & 5 & 6 & 7 \\
\hline $\begin{array}{l}\text { 5. The long term preservation of Jewish heritage is } \\
\text { Important }\end{array}$ & 1 & 2 & 3 & 4 & 5 & 6 & 7 \\
\hline $\begin{array}{l}\text { 6. The Jewish identity of my children does NOT really } \\
\text { matter }\end{array}$ & 1 & 2 & 3 & 4 & 5 & 6 & 7 \\
\hline $\begin{array}{l}\text { 7. I think it's important to preserve my Jewish } \\
\text { Traditions }\end{array}$ & 1 & 2 & 3 & 4 & 5 & 6 & 7 \\
\hline 8. I want to keep Jewish culture alive & 1 & 2 & 3 & 4 & 5 & 6 & 7 \\
\hline $\begin{array}{l}\text { 9. Ultimately I would like my children to identify as } \\
\text { Jews }\end{array}$ & 1 & 2 & 3 & 4 & 5 & 6 & 7 \\
\hline $\begin{array}{l}\text { 10. Maintaining my Jewish heritage is NOT something } \\
\text { I care about }\end{array}$ & 1 & 2 & 3 & 4 & 5 & 6 & 7 \\
\hline $\begin{array}{l}\text { 11. I would like to encourage my children to learn } \\
\text { Hebrew }\end{array}$ & 1 & 2 & 3 & 4 & 5 & 6 & 7 \\
\hline $\begin{array}{l}\text { 12. The future continuity of our Jewish community is } \\
\text { NOT a concern of mine }\end{array}$ & 1 & 2 & 3 & 4 & 5 & 6 & 7 \\
\hline $\begin{array}{l}\text { 13. Continuing to practice my Jewish traditions and } \\
\text { celebrations is important to me }\end{array}$ & 1 & 2 & 3 & 4 & 5 & 6 & 7 \\
\hline $\begin{array}{l}\text { 14. I will NOT force my children to identify with my } \\
\text { Jewish heritage }\end{array}$ & 1 & 2 & 3 & 4 & 5 & 6 & 7 \\
\hline
\end{tabular}




\begin{tabular}{|c|c|c|c|c|c|c|c|}
\hline & \multicolumn{2}{|c|}{$\begin{array}{l}\text { strongly } \\
\text { disagree }\end{array}$} & & & & \multicolumn{2}{|c|}{$\begin{array}{r}\text { strongly } \\
\text { agree }\end{array}$} \\
\hline $\begin{array}{l}\text { 15. Long-term, I would like my grandchildren and } \\
\text { great grandchildren to continue our Jewish heritage }\end{array}$ & 1 & 2 & 3 & 4 & 5 & 6 & 7 \\
\hline $\begin{array}{l}\text { 16. My Jewish heritage and traditions are something I } \\
\text { can easily disregard }\end{array}$ & 1 & 2 & 3 & 4 & 5 & 6 & 7 \\
\hline 17. I want to ensure the future of our Jewish heritage & 1 & 2 & 3 & 4 & 5 & 6 & 7 \\
\hline 18. I would like to teach Jewish values to my children & 1 & 2 & 3 & 4 & 5 & 6 & 7 \\
\hline $\begin{array}{l}\text { 19. Maintaining my Jewish heritage is something I } \\
\text { value }\end{array}$ & 1 & 2 & 3 & 4 & 5 & 6 & 7 \\
\hline $\begin{array}{l}\text { 20. It does NOT matter if my children don't identify } \\
\text { with their Jewish heritage }\end{array}$ & 1 & 2 & 3 & 4 & 5 & 6 & 7 \\
\hline $\begin{array}{l}\text { 21. The endurance of Jewish people does NOT really } \\
\text { matter }\end{array}$ & 1 & 2 & 3 & 4 & 5 & 6 & 7 \\
\hline $\begin{array}{l}\text { 22. I am worried that our Jewish heritage won't be } \\
\text { sustainable in the future }\end{array}$ & 1 & 2 & 3 & 4 & 5 & 6 & 7 \\
\hline 23. I do NOT give much thought to Jewish continuity & 1 & 2 & 3 & 4 & 5 & 6 & 7 \\
\hline $\begin{array}{l}\text { 24. I want to transmit to my children a love for and } \\
\text { interest in their Jewish heritage }\end{array}$ & 1 & 2 & 3 & 4 & 5 & 6 & 7 \\
\hline $\begin{array}{l}\text { 25. I do NOT mind setting aside the traditions of my } \\
\text { Jewish heritage }\end{array}$ & 1 & 2 & 3 & 4 & 5 & 6 & 7 \\
\hline $\begin{array}{l}\text { 26. I do NOT care if my children are unaware of } \\
\text { Jewish traditions and values }\end{array}$ & 1 & 2 & 3 & 4 & 5 & 6 & 7 \\
\hline $\begin{array}{l}\text { 27. It does NOT matter to me if I don't keep my } \\
\text { Jewish traditions and values }\end{array}$ & 1 & 2 & 3 & 4 & 5 & 6 & 7 \\
\hline $\begin{array}{l}\text { 28. I think it's good to create an environment at home } \\
\text { where my Jewish traditions can be a normal part of } \\
\text { life for my children }\end{array}$ & 1 & 2 & 3 & 4 & 5 & 6 & 7 \\
\hline $\begin{array}{l}\text { 29. I do NOT want to lose my Jewish heritage and } \\
\text { values }\end{array}$ & 1 & 2 & 3 & 4 & 5 & 6 & 7 \\
\hline $\begin{array}{l}\text { 30. I do NOT really care about ensuring the future of } \\
\text { Jewish people }\end{array}$ & 1 & 2 & 3 & 4 & 5 & 6 & 7 \\
\hline
\end{tabular}




\section{Section 5}

Below are a number of statements concerning what part(s) of Jewish history people are aware of. Please read each statement carefully and indicate, by circling a number on a 1 (strongly disagree) to 7 (strongly agree) scale that best represents your personal response. There are no right or wrong answers, and your first responses are usually the most accurate.

Remember, we want to know what part(s) of Jewish history you are personally aware of.

$\begin{array}{lllllll}1 & 2 & 3 & 4 & 5 & 6 & 7\end{array}$

strongly disagree somewhat disagree slightly disagree neutral slightly agree somewhat agree strongly agree

\begin{tabular}{|c|c|c|c|c|c|c|c|c|}
\hline & $\begin{array}{l}\text { stron } \\
\text { disa }\end{array}$ & & & & & & & $\begin{array}{l}\text { ngly } \\
\text { gree }\end{array}$ \\
\hline $\begin{array}{l}\text { 1. I remember stories about things that happened to my } \\
\text { family because they were Jewish }\end{array}$ & 1 & 2 & 3 & 4 & 5 & 6 & & 7 \\
\hline $\begin{array}{l}\text { 2. I am NOT really aware of the experiences faced by } \\
\text { Jews in this country }\end{array}$ & 1 & 2 & 3 & 4 & 5 & ( & & 7 \\
\hline $\begin{array}{l}\text { 3. I know about the history of Jewish people in our } \\
\text { ancestral land }\end{array}$ & 1 & 2 & 3 & 4 & 5 & ( & & 7 \\
\hline $\begin{array}{l}\text { 4. I do NOT know much about my family's Jewish } \\
\text { background }\end{array}$ & 1 & 2 & 3 & 4 & 5 & ( & & 7 \\
\hline $\begin{array}{l}\text { 5. I am aware of the history of Jewish people here, in the } \\
\text { country where I live }\end{array}$ & 1 & 2 & 3 & 4 & 5 & ( & & 7 \\
\hline $\begin{array}{l}\text { 6. I have NOT really been told much about our Jewish } \\
\text { history }\end{array}$ & 1 & 2 & 3 & 4 & 5 & ( & & 7 \\
\hline 7. I celebrate my Jewish history & 1 & 2 & 3 & 4 & 5 & ( & & 7 \\
\hline $\begin{array}{l}\text { 8. The part of Jewish history I am aware of is personal, } \\
\text { family history }\end{array}$ & 1 & 2 & 3 & 4 & 5 & ( & & 7 \\
\hline $\begin{array}{l}\text { 9. I do NOT have many stories about my family's } \\
\text { experiences related to being Jewish }\end{array}$ & 1 & 2 & 3 & 4 & 5 & ( & & 7 \\
\hline $\begin{array}{l}\text { 10. I know about the experiences of the first Jewish } \\
\text { immigrants to this country }\end{array}$ & 1 & 2 & 3 & 4 & 5 & ( & & 7 \\
\hline $\begin{array}{l}\text { 11. The Jewish roots of my family are something I do } \\
\text { NOT know much about }\end{array}$ & 1 & 2 & 3 & 4 & 5 & ( & & 7 \\
\hline $\begin{array}{l}\text { 12. The broad history of Jews is something that I do } \\
\text { NOT know much about }\end{array}$ & 1 & 2 & 3 & 4 & 5 & ( & & 7 \\
\hline $\begin{array}{l}\text { 13. I do NOT know much about the local history of } \\
\text { Jewish people }\end{array}$ & 1 & 2 & 3 & 4 & 5 & ( & & 7 \\
\hline $\begin{array}{l}\text { 14. I know what Jewish life was like for my family back } \\
\text { in their home towns }\end{array}$ & 1 & 2 & 3 & 4 & 5 & ( & & 7 \\
\hline 15. I am NOT familiar with Jewish history & 1 & 2 & 3 & 4 & 5 & 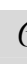 & & 7 \\
\hline 16. I remember the general history of Jewish people & 1 & 2 & 3 & 4 & 5 & ( & & 7 \\
\hline
\end{tabular}




\section{Section 6}

On this page are a number of statements concerning the different aspects of Jewish history people remember. Please read each statement carefully and indicate, by circling a number on a 1 (strongly disagree) to 7 (strongly agree) scale that best represents your personal response. There are no right or wrong answers, and your first responses are usually the most accurate.

Bear in mind that we want to know what aspects of Jewish history you personally remember.

\section{$\begin{array}{lllllll}1 & 2 & 3 & 4 & 5 & 6 & 7\end{array}$}

strongly disagree somewhat disagree slightly disagree neutral slightly agree somewhat agree strongly agree

\begin{tabular}{|c|c|c|c|c|c|c|c|}
\hline & \multicolumn{2}{|c|}{$\begin{array}{l}\text { strongly } \\
\text { disagree }\end{array}$} & & & & \multicolumn{2}{|c|}{$\begin{aligned} \begin{array}{c}\text { strongl } \\
\text { agrec }\end{array} \\
\end{aligned}$} \\
\hline $\begin{array}{l}\text { 1. I know what historical events have defined Jews as a } \\
\text { people }\end{array}$ & 1 & 2 & 3 & 4 & 5 & 6 & 7 \\
\hline $\begin{array}{l}\text { 2. I'm NOT really aware of Jewish people being } \\
\text { treated differently by the larger society }\end{array}$ & 1 & 2 & 3 & 4 & 5 & 6 & 7 \\
\hline $\begin{array}{l}\text { 3. I celebrate the points in history when Jews fought to } \\
\text { maintain our culture }\end{array}$ & 1 & 2 & 3 & 4 & 5 & 6 & 7 \\
\hline $\begin{array}{l}\text { 4. I celebrate the historical achievements of Jewish } \\
\text { people }\end{array}$ & 1 & 2 & 3 & 4 & 5 & 6 & 7 \\
\hline 5. I know of the struggles that Jews have gone through & 1 & 2 & 3 & 4 & 5 & 6 & 7 \\
\hline $\begin{array}{l}\text { 6. Surviving is NOT really a defining part of Jewish } \\
\text { history }\end{array}$ & 1 & 2 & 3 & 4 & 5 & 6 & 7 \\
\hline $\begin{array}{l}\text { 7. Discrimination against Jewish people is something I } \\
\text { do NOT know much about }\end{array}$ & 1 & 2 & 3 & 4 & 5 & 6 & 7 \\
\hline $\begin{array}{l}\text { 8. I have difficulty remembering basic historical events } \\
\text { that shaped Jews as a people }\end{array}$ & 1 & 2 & 3 & 4 & 5 & 6 & 7 \\
\hline $\begin{array}{l}\text { 9. I remember the injustices that have happened to } \\
\text { Jews }\end{array}$ & 1 & 2 & 3 & 4 & 5 & 6 & 7 \\
\hline $\begin{array}{l}\text { 10. I can't remember hardships that Jewish people } \\
\text { went through }\end{array}$ & 1 & 2 & 3 & 4 & 5 & 6 & 7 \\
\hline $\begin{array}{l}\text { 11. I do NOT know which events in history gave Jews } \\
\text { a common identity }\end{array}$ & 1 & 2 & 3 & 4 & 5 & 6 & 7 \\
\hline 12. I appreciate the historical survival of Jews & 1 & 2 & 3 & 4 & 5 & 6 & 7 \\
\hline $\begin{array}{l}\text { 13. I remember the founding fathers and mothers of } \\
\text { Jewish traditions }\end{array}$ & 1 & 2 & 3 & 4 & 5 & 6 & 7 \\
\hline $\begin{array}{l}\text { 14. The survival of Jewish people throughout history is } \\
\text { NOT something I remember much about }\end{array}$ & 1 & 2 & 3 & 4 & 5 & 6 & 7 \\
\hline
\end{tabular}




\begin{tabular}{|c|c|c|c|c|c|c|c|}
\hline & \multicolumn{5}{|c|}{$\begin{array}{l}\text { strongly } \\
\text { disagree }\end{array}$} & \multicolumn{2}{|c|}{$\begin{array}{r}\text { strongly } \\
\text { agree }\end{array}$} \\
\hline $\begin{array}{l}\text { 15. I remember times when Jews have persevered and } \\
\text { risen strong }\end{array}$ & 1 & 2 & 3 & 4 & 5 & 6 & 7 \\
\hline $\begin{array}{l}\text { 16. I do NOT know much about the cultural heroes of } \\
\text { Jewish tradition }\end{array}$ & 1 & 2 & 3 & 4 & 5 & 6 & 7 \\
\hline $\begin{array}{l}\text { 17. I believe that Jewish people suffer today from what } \\
\text { happened in the past }\end{array}$ & 1 & 2 & 3 & 4 & 5 & 6 & 7 \\
\hline $\begin{array}{l}\text { 18. The founding experiences of Jews are NOT } \\
\text { something I remember }\end{array}$ & 1 & 2 & 3 & 4 & 5 & 6 & 7 \\
\hline $\begin{array}{l}\text { 19. I'm NOT aware of Jewish people showing } \\
\text { resistance to the larger society }\end{array}$ & 1 & 2 & 3 & 4 & 5 & 6 & 7 \\
\hline $\begin{array}{l}\text { 20. I remember the challenges faced by Jewish people } \\
\text { throughout history }\end{array}$ & 1 & 2 & 3 & 4 & 5 & 6 & 7 \\
\hline $\begin{array}{l}\text { 21. I celebrate events in history where Jews have } \\
\text { demonstrated resistance to forces from the larger } \\
\text { society }\end{array}$ & 1 & 2 & 3 & 4 & 5 & 6 & 7 \\
\hline $\begin{array}{l}\text { 22. I remember how Jews have been discriminated } \\
\text { against by the larger society throughout history }\end{array}$ & 1 & 2 & 3 & 4 & 5 & 6 & 7 \\
\hline
\end{tabular}

\section{Section 7}

On this page are a number of statements about how people remember Jewish history. Please read each statement carefully and indicate, by circling a number on a 1 (strongly disagree) to 7 (strongly agree) scale that best represents your personal response. There are no right or wrong answers, and your first responses are usually the most accurate.

Keep in mind that we want to know how you personally remember Jewish history.

\section{$\begin{array}{llllllll}1 & 2 & 3 & 4 & 5 & 6 & 7\end{array}$} strongly disagree somewhat disagree slightly disagree neutral slightly agree somewhat agree strongly agree

\begin{tabular}{|c|c|c|c|c|c|c|c|}
\hline & \multicolumn{2}{|c|}{$\begin{array}{l}\text { strongly } \\
\text { disagree }\end{array}$} & & & & \multicolumn{2}{|c|}{$\begin{array}{r}\text { strongly } \\
\text { agree }\end{array}$} \\
\hline $\begin{array}{l}\text { 1. I can imagine being a part of the journeys my Jewish } \\
\text { ancestors made }\end{array}$ & 1 & 2 & 3 & 4 & 5 & 6 & 7 \\
\hline $\begin{array}{l}\text { 2. I do NOT have emotional connections to the } \\
\text { struggles that Jewish people have gone through }\end{array}$ & 1 & 2 & 3 & 4 & 5 & 6 & 7 \\
\hline $\begin{array}{l}\text { 3. I feel anger and frustration when I think of all the } \\
\text { injustices and discrimination experienced by Jews }\end{array}$ & 1 & 2 & 3 & 4 & 5 & 6 & 7 \\
\hline $\begin{array}{l}\text { 4. When I look back in history to Jewish ancestors, I } \\
\text { do feel that I am a part of something great }\end{array}$ & 1 & 2 & 3 & 4 & 5 & 6 & 7 \\
\hline $\begin{array}{l}\text { 5. It's hard for me to feel linked to the experiences of } \\
\text { my Jewish ancestors }\end{array}$ & 1 & 2 & 3 & 4 & 5 & 6 & 7 \\
\hline $\begin{array}{l}\text { 6. The historical achievements of Jewish people have } \\
\text { little to do with me on a personal level }\end{array}$ & 1 & 2 & 3 & 4 & 5 & 6 & 7 \\
\hline $\begin{array}{l}\text { 7. I feel proud when I learn about the struggles and } \\
\text { battles of our Jewish ancestors to keep our heritage } \\
\text { alive }\end{array}$ & 1 & 2 & 3 & 4 & 5 & 6 & 7 \\
\hline
\end{tabular}




\section{Section 8}

On this page are a number of statements concerning the historical aspects of Jewish history. Please read each statement carefully and indicate, by circling a number on a 1 (strongly disagree) to 7 (strongly agree) scale that best represents your personal response. There are no right or wrong answers, and your first responses are usually the most accurate.

Bear in mind that we want to know what you think about the historical aspects of Jewish history.
1
2
3
4
5
6
7

strongly disagree somewhat disagree slightly disagree neutral slightly agree somewhat agree strongly agree

\begin{tabular}{|c|c|c|c|c|c|c|c|}
\hline & \multicolumn{2}{|c|}{$\begin{array}{l}\text { strongly } \\
\text { disagree }\end{array}$} & & & & \multicolumn{2}{|c|}{$\begin{array}{r}\text { strongly } \\
\text { agree } \\
\end{array}$} \\
\hline $\begin{array}{l}\text { 1. Jewish people have passed on their traditions across } \\
\text { different generations }\end{array}$ & 1 & 2 & 3 & 4 & 5 & 6 & 7 \\
\hline $\begin{array}{l}\text { 2. Jewish history is a sequence of interconnected } \\
\text { events }\end{array}$ & 1 & 2 & 3 & 4 & 5 & 6 & 7 \\
\hline $\begin{array}{l}\text { 3. Shared values, beliefs and attitudes of Jewish people } \\
\text { have endurance across times }\end{array}$ & 1 & 2 & 3 & 4 & 5 & 6 & 7 \\
\hline $\begin{array}{l}\text { 4. Major phases in Jewish history are linked to one } \\
\text { another }\end{array}$ & 1 & 2 & 3 & 4 & 5 & 6 & 7 \\
\hline $\begin{array}{l}\text { 5. Throughout history the members of the Jewish } \\
\text { group have maintained their inclinations and } \\
\text { mentality }\end{array}$ & 1 & 2 & 3 & 4 & 5 & 6 & 7 \\
\hline $\begin{array}{l}\text { 6. There is NO connection between past, present, and } \\
\text { future events in Judaism }\end{array}$ & 1 & 2 & 3 & 4 & 5 & 6 & 7 \\
\hline $\begin{array}{l}\text { 7. Jewish people will always be characterised by } \\
\text { specific traditions and beliefs }\end{array}$ & 1 & 2 & 3 & 4 & 5 & 6 & 7 \\
\hline $\begin{array}{l}\text { 8. There is a causal link between different events in } \\
\text { Jewish history }\end{array}$ & 1 & 2 & 3 & 4 & 5 & 6 & 7 \\
\hline $\begin{array}{l}\text { 9. Judaism has preserved its traditions and customs } \\
\text { throughout history }\end{array}$ & 1 & 2 & 3 & 4 & 5 & 6 & 7 \\
\hline $\begin{array}{l}\text { 10. The main events in Jewish history are part of an } \\
\text { 'unbroken stream' }\end{array}$ & 1 & 2 & 3 & 4 & 5 & 6 & 7 \\
\hline $\begin{array}{l}\text { 11. Jewish people have maintained their values across } \\
\text { time }\end{array}$ & 1 & 2 & 3 & 4 & 5 & 6 & 7 \\
\hline $\begin{array}{l}\text { 12. There is NO continuity between different ages in } \\
\text { Jewish history }\end{array}$ & 1 & 2 & 3 & 4 & 5 & 6 & 7 \\
\hline
\end{tabular}




\section{Section 9}

On this page are a number of statements concerning the perception of Jewish people. Please read each statement carefully and indicate, by circling a number on a 1 (strongly disagree) to 7 (strongly agree) scale that best represents your personal response. There are no right or wrong answers, and your first responses are usually the most accurate.

Bear in mind that we want to know what you think about the Jewish people.

$\begin{array}{llllllll}1 & 2 & 3 & 4 & 5 & 6 & 7\end{array}$ strongly disagree somewhat disagree slightly disagree neutral slightly agree somewhat agree strongly agree

\begin{tabular}{|c|c|c|c|c|c|c|c|}
\hline & \multicolumn{2}{|c|}{$\begin{array}{l}\text { strongly } \\
\text { disagree }\end{array}$} & & & & \multicolumn{2}{|c|}{$\begin{array}{r}\text { strongly } \\
\text { agree } \\
\end{array}$} \\
\hline 1. Jews have many characteristics in common & 1 & 2 & 3 & 4 & 5 & 6 & 7 \\
\hline 2. Jews share a common past experience & 1 & 2 & 3 & 4 & 5 & 6 & 7 \\
\hline 3. Jews have a sense of common fate & 1 & 2 & 3 & 4 & 5 & 6 & 7 \\
\hline 4. There are strong ties among Jews & 1 & 2 & 3 & 4 & 5 & 6 & 7 \\
\hline 5. The Jewish people has real existence as a group & 1 & 2 & 3 & 4 & 5 & 6 & 7 \\
\hline 6. The Jewish people is just an abstraction & 1 & 2 & 3 & 4 & 5 & 6 & 7 \\
\hline 7. Jews have a characteristic nature & 1 & 2 & 3 & 4 & 5 & 6 & 7 \\
\hline 8. There are strong similarities between Jews & 1 & 2 & 3 & 4 & 5 & 6 & 7 \\
\hline $\begin{array}{l}\text { 9. There is no doubt about the existence of the Jewish } \\
\text { people }\end{array}$ & 1 & 2 & 3 & 4 & 5 & 6 & 7 \\
\hline 10. Jews have specific characteristics & 1 & 2 & 3 & 4 & 5 & 6 & 7 \\
\hline
\end{tabular}




\section{Section 10a}

On this page are a number of statements concerning people's intentions for marriage. Please read each statement carefully and indicate, by circling a number on a 1 (strongly disagree) to 7 (strongly agree) scale that best represents your personal response. There are no right or wrong answers, and your first responses are usually the most accurate.

Remember, we want to know what your personal intentions for marriage are.
1
2
3
45
6
7

strongly disagree somewhat disagree slightly disagree neutral slightly agree somewhat agree strongly agree

\begin{tabular}{|c|c|c|c|c|c|c|c|}
\hline & \multicolumn{2}{|c|}{$\begin{array}{l}\text { strongly } \\
\text { disagree }\end{array}$} & & & & \multicolumn{2}{|c|}{$\begin{array}{r}\text { strongly } \\
\text { agree }\end{array}$} \\
\hline 1. I intend to marry someone who is Jewish & 1 & 2 & 3 & 4 & 5 & 6 & 7 \\
\hline $\begin{array}{l}\text { 2. I am NOT planning to marry someone who is } \\
\text { Jewish }\end{array}$ & 1 & 2 & 3 & 4 & 5 & 6 & 7 \\
\hline $\begin{array}{l}\text { 3. When it comes to marriage, I will go back to the } \\
\text { Jewish people to find the right person }\end{array}$ & 1 & 2 & 3 & 4 & 5 & 6 & 7 \\
\hline $\begin{array}{l}\text { 4. When I make the decision about who to marry, it } \\
\text { will NOT be influenced by whether they are Jewish } \\
\text { or not }\end{array}$ & 1 & 2 & 3 & 4 & 5 & 6 & 7 \\
\hline
\end{tabular}

\section{Section 10b}

Below are a number of statements about people's current dating. Please read each statement carefully and indicate, by circling a number on a 1 (strongly disagree) to 7 (strongly agree) scale that best represents your personal response. There are no right or wrong answers, and your first responses are usually the most accurate.

Bear in mind that we want to know about your present dating.

\section{$\begin{array}{llllllll}1 & 2 & 3 & 4 & 5 & 6 & 7\end{array}$}

strongly disagree somewhat disagree slightly disagree neutral slightly agree somewhat agree strongly agree

\begin{tabular}{|c|c|c|c|c|c|c|}
\hline & \multicolumn{2}{|c|}{$\begin{array}{l}\text { strongly } \\
\text { disagree }\end{array}$} & & & & $\begin{array}{r}\text { strongly } \\
\text { agree }\end{array}$ \\
\hline 1. I only date people who are Jewish & 1 & 2 & 3 & $\overline{4}$ & 5 & 7 \\
\hline 2. I date people who are NOT Jewish & 1 & 2 & 3 & 4 & 5 & 7 \\
\hline $\begin{array}{l}\text { 3. I make an effort to only have romantic relationships } \\
\text { with other Jewish people }\end{array}$ & 1 & 2 & 3 & 4 & 5 & 7 \\
\hline $\begin{array}{l}\text { 4. The person I am currently (or most recently) } \\
\text { interested in romantically identifies with a different } \\
\text { ethnic group }\end{array}$ & 1 & 2 & 3 & 4 & & 7 \\
\hline
\end{tabular}

$\sim$ End of Questionnaire Thanks for your participation! 


\section{APPENDIX E: QUESTIONNAIRE FOR CROSS-CULTURAL AND CROSS-NATIONAL STUDIES}

1. What is your gender (tick one)?

\section{Section 1}

_ Female _ Male

2. What is your age?

- years

3. Of what country are you a citizen (please specify below)?

4. Is your mother $\mathrm{J} / \mathrm{M} / \mathrm{C}$ (if not, please specify below)?
- Yes No (Mother)

5. Is your father Jewish (if not, please specify below)?
— Yes No (Father)

6. Where were you born?

_ In New Zealand

Other

7. Were any of your parents born overseas?

Y Yes No

8. Were any of your grandparents born overseas?

Y Yes No

9a. Please select the kind of Jewish practice you feel most comfortable with (if any)?

Reform Conservative Orthodox

Other (please specify)

9b. Please note down the iwi you most strongly identify with (if any)?

9c. Please select the Chinese group you most strongly identify with (if any)?

Mainland Chinese Taiwanese Hong Kong Chinese New Zealand Chinese Other (please specify) 


\section{Section 2}

Below are a series of statements concerning what people think about being J/M/C. Please read each statement carefully and indicate, by circling a number on a 1 (strongly disagree) to 7 (strongly agree) scale that best represents your personal response. There are no right or wrong answers, and your first responses are usually the most accurate.

$\begin{array}{llllllll}1 & 2 & 3 & 4 & 5 & 6 & 7\end{array}$
strongly disagree somewhat disagree slightly disagree neutral slightly agree somewhat agree strongly agree

\begin{tabular}{|c|c|c|c|c|c|c|c|}
\hline & \multicolumn{2}{|c|}{$\begin{array}{l}\text { strongly } \\
\text { disagree }\end{array}$} & & & & \multicolumn{2}{|c|}{$\begin{array}{r}\text { strongly } \\
\text { agree }\end{array}$} \\
\hline 1. I have a lot in common with other $\mathrm{J} / \mathrm{M} / \mathrm{C}$ people & 1 & 2 & 3 & 4 & 5 & 6 & 7 \\
\hline 2. I often think about the fact that I am J/M/C & 1 & 2 & 3 & 4 & 5 & 6 & 7 \\
\hline 3. In general, I'm glad to be $\mathrm{J} / \mathrm{M} / \mathrm{C}$ & 1 & 2 & 3 & 4 & 5 & 6 & 7 \\
\hline 4. I feel strong ties to other $\mathrm{J} / \mathrm{M} / \mathrm{C}$ people & 1 & 2 & 3 & 4 & 5 & 6 & 7 \\
\hline $\begin{array}{l}\text { 5. Overall, being J/M/C has very little to do with how } \\
\text { I feel about myself }\end{array}$ & 1 & 2 & 3 & 4 & 5 & 6 & 7 \\
\hline 6. I often regret that $\mathrm{I}$ am $\mathrm{J} / \mathrm{M} / \mathrm{C}$ & 1 & 2 & 3 & 4 & 5 & 6 & 7 \\
\hline $\begin{array}{l}\text { 7. I find it difficult to form a bond with other } \mathrm{J} / \mathrm{M} / \mathrm{C} \\
\text { people }\end{array}$ & 1 & 2 & 3 & 4 & 5 & 6 & 7 \\
\hline $\begin{array}{l}\text { 8. In general, being } \mathrm{J} / \mathrm{M} / \mathrm{C} \text { is an important part of my } \\
\text { self-image }\end{array}$ & 1 & 2 & 3 & 4 & 5 & 6 & 7 \\
\hline 9. I don't feel good about being J/M/C & 1 & 2 & 3 & 4 & 5 & 6 & 7 \\
\hline $\begin{array}{l}\text { 10. I don't feel a sense of being "connected" with } \\
\text { other J/M/C people }\end{array}$ & 1 & 2 & 3 & 4 & 5 & 6 & 7 \\
\hline 11. The fact that $\mathrm{I}$ am $\mathrm{J} / \mathrm{M} / \mathrm{C}$ rarely enters my mind & 1 & 2 & 3 & 4 & 5 & 6 & 7 \\
\hline $\begin{array}{l}\text { 12. Generally, I feel good when I think about myself as } \\
\mathrm{J} / \mathrm{M} / \mathrm{C}\end{array}$ & 1 & 2 & 3 & 4 & 5 & 6 & 7 \\
\hline
\end{tabular}




\section{Section 3}

Below are a number of statements concerning awareness of $\mathrm{J} / \mathrm{M} / \mathrm{C}$ history.

Please read each statement carefully and indicate, by circling a number on a 1 (strongly disagree) to 7 (strongly agree) scale that best represents your personal response. There are no right or wrong answers, and your first responses are usually the most accurate.
1
2
3
4
5
6
7

strongly disagree somewhat disagree slightly disagree neutral slightly agree somewhat agree strongly agree

\begin{tabular}{|c|c|c|c|c|c|c|c|}
\hline & \multicolumn{2}{|c|}{$\begin{array}{l}\text { strongly } \\
\text { disagree }\end{array}$} & & & & \multicolumn{2}{|c|}{$\begin{array}{r}\text { strongly } \\
\text { agree }\end{array}$} \\
\hline $\begin{array}{l}\text { 1. I know what } \mathrm{J} / \mathrm{M} / \mathrm{C} \text { life was like for my family back } \\
\text { in their home towns }\end{array}$ & 1 & 2 & 3 & 4 & 5 & 6 & 7 \\
\hline $\begin{array}{l}\text { 2. I am aware of the history of } \mathrm{J} / \mathrm{M} / \mathrm{C} \text { people here, in } \\
\text { the country where I live }\end{array}$ & 1 & 2 & 3 & 4 & 5 & 6 & 7 \\
\hline $\begin{array}{l}\text { 3. The broad history of } \mathrm{J} / \mathrm{M} / \mathrm{C} \text { is something that I do } \\
\text { NOT know much about }\end{array}$ & 1 & 2 & 3 & 4 & 5 & 6 & 7 \\
\hline $\begin{array}{l}\text { 4. I do NOT know much about my family's J/M/C } \\
\text { background }\end{array}$ & 1 & 2 & 3 & 4 & 5 & 6 & 7 \\
\hline $\begin{array}{l}\text { 5. I know about the experiences of the first } \mathrm{J} / \mathrm{M} / \mathrm{C} \\
\text { immigrants to this country }\end{array}$ & 1 & 2 & 3 & 4 & 5 & 6 & 7 \\
\hline $\begin{array}{l}\text { 6. I know about the history of } \mathrm{J} / \mathrm{M} / \mathrm{C} \text { people in our } \\
\text { ancestral land }\end{array}$ & 1 & 2 & 3 & 4 & 5 & 6 & 7 \\
\hline $\begin{array}{l}\text { 7. The } \mathrm{J} / \mathrm{M} / \mathrm{C} \text { roots of my family are something I do } \\
\text { NOT know much about }\end{array}$ & 1 & 2 & 3 & 4 & 5 & 6 & 7 \\
\hline $\begin{array}{l}\text { 8. I am NOT really aware of the experiences faced by } \\
\mathrm{J} / \mathrm{M} / \mathrm{C} \text { in this country }\end{array}$ & 1 & 2 & 3 & 4 & 5 & 6 & 7 \\
\hline 9. I remember the general history of $\mathrm{J} / \mathrm{M} / \mathrm{C}$ people & 1 & 2 & 3 & 4 & 5 & 6 & 7 \\
\hline $\begin{array}{l}\text { 10. I have stories about my family's experiences related } \\
\text { to being J/M/C }\end{array}$ & 1 & 2 & 3 & 4 & 5 & 6 & 7 \\
\hline $\begin{array}{l}\text { 11. I do NOT know much about the local history of } \\
\mathrm{J} / \mathrm{M} / \mathrm{C} \text { people }\end{array}$ & 1 & 2 & 3 & 4 & 5 & 6 & 7 \\
\hline 12. I am NOT familiar with $\mathrm{J} / \mathrm{M} / \mathrm{C}$ history & 1 & 2 & 3 & 4 & 5 & 6 & 7 \\
\hline
\end{tabular}

${ }^{67}$ Items about local ethnic history were reworded for Māori e.g. I am aware of the history of my iwi. 


\section{Section 4}

On this page are a number of statements concerning the different aspects of $\mathrm{J} / \mathrm{M} / \mathrm{C}$ history. Please read each statement carefully and indicate, by circling a number on a 1 (strongly disagree) to 7 (strongly agree) scale that best represents your personal response. There are no right or wrong answers, and your first responses are usually the most accurate.
1
2
3
4
5
6
7

strongly disagree somewhat disagree slightly disagree neutral slightly agree somewhat agree strongly agree

\begin{tabular}{|c|c|c|c|c|c|c|c|}
\hline & \multicolumn{2}{|c|}{$\begin{array}{l}\text { strongly } \\
\text { disagree }\end{array}$} & & & & \multicolumn{2}{|c|}{$\begin{array}{r}\text { strongly } \\
\text { agree }\end{array}$} \\
\hline $\begin{array}{l}\text { 1. I remember the founding fathers and mothers of } \\
\mathrm{J} / \mathrm{M} / \mathrm{C} \text { traditions }\end{array}$ & 1 & 2 & 3 & 4 & 5 & 6 & 7 \\
\hline $\begin{array}{l}\text { 2. I remember the injustices that have happened to } \\
\mathrm{J} / \mathrm{M} / \mathrm{C}\end{array}$ & 1 & 2 & 3 & 4 & 5 & 6 & 7 \\
\hline $\begin{array}{l}\text { 3. I celebrate the points in history when } \mathrm{J} / \mathrm{M} / \mathrm{C} \text { fought } \\
\text { to maintain our culture }\end{array}$ & 1 & 2 & 3 & 4 & 5 & 6 & 7 \\
\hline $\begin{array}{l}\text { 4. I have difficulty remembering basic historical events } \\
\text { that shaped } \mathrm{J} / \mathrm{M} / \mathrm{C} \text { as a people }\end{array}$ & 1 & 2 & 3 & 4 & 5 & 6 & 7 \\
\hline $\begin{array}{l}\text { 5. I'm not really aware of } \mathrm{J} / \mathrm{M} / \mathrm{C} \text { people being treated } \\
\text { differently by the larger society }\end{array}$ & 1 & 2 & 3 & 4 & 5 & 6 & 7 \\
\hline 6. I appreciate the historical survival of $\mathrm{J} / \mathrm{M} / \mathrm{C}$ & 1 & 2 & 3 & 4 & 5 & 6 & 7 \\
\hline $\begin{array}{l}\text { 7. I do NOT know which events in history gave } \\
\mathrm{J} / \mathrm{M} / \mathrm{C} \text { a common identity }\end{array}$ & 1 & 2 & 3 & 4 & 5 & 6 & 7 \\
\hline $\begin{array}{l}\text { 8. Discrimination against } \mathrm{J} / \mathrm{M} / \mathrm{C} \text { people is something } \mathrm{I} \\
\text { do NOT know much about }\end{array}$ & 1 & 2 & 3 & 4 & 5 & 6 & 7 \\
\hline $\begin{array}{l}\text { 9. I remember events in history where } \mathrm{J} / \mathrm{M} / \mathrm{C} \text { have } \\
\text { demonstrated resistance to forces from the larger } \\
\text { society }\end{array}$ & 1 & 2 & 3 & 4 & 5 & 6 & 7 \\
\hline $\begin{array}{l}\text { 10. I do NOT know much about the cultural heroes of } \\
\mathrm{J} / \mathrm{M} / \mathrm{C} \text { tradition }\end{array}$ & 1 & 2 & 3 & 4 & 5 & 6 & 7 \\
\hline $\begin{array}{l}\text { 11. I remember how } \mathrm{J} / \mathrm{M} / \mathrm{C} \text { have been discriminated } \\
\text { against by the larger society throughout history }\end{array}$ & 1 & 2 & 3 & 4 & 5 & 6 & 7 \\
\hline $\begin{array}{l}\text { 12. The survival of } \mathrm{J} / \mathrm{M} / \mathrm{C} \text { people throughout history } \\
\text { is NOT something I remember much about }\end{array}$ & 1 & 2 & 3 & 4 & 5 & 6 & 7 \\
\hline
\end{tabular}




\section{Section 5}

On this page are a number of statements about how people remember $\mathrm{J} / \mathrm{M} / \mathrm{C}$ history. Please read each statement carefully and indicate, by circling a number on a 1 (strongly disagree) to 7 (strongly agree) scale that best represents your personal response. There are no right or wrong answers, and your first responses are usually the most accurate.
1
2
34
5
6
7

strongly disagree somewhat disagree slightly disagree neutral slightly agree somewhat agree strongly agree

strongly strongly

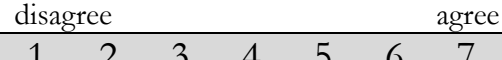

1. I can imagine being a part of the journeys my $\mathrm{J} / \mathrm{M} / \mathrm{C}$ ancestors made

2. I do NOT have emotional connections to the struggles that $\mathrm{J} / \mathrm{M} / \mathrm{C}$ people have gone through

3. I feel anger and frustration when I think of all the injustices and discrimination experienced by $\mathrm{J} / \mathrm{M} / \mathrm{C}$

4. When I look back in history to $\mathrm{J} / \mathrm{M} / \mathrm{C}$ ancestors, I do feel that I am a part of something great

5. It's hard for me to feel linked to the experiences of my J/M/C ancestors

6. The historical achievements of $\mathrm{J} / \mathrm{M} / \mathrm{C}$ people have little to do with me on a personal level

7. I feel proud when I learn about the struggles and battles of our $\mathrm{J} / \mathrm{M} / \mathrm{C}$ ancestors to keep our heritage alive 


\section{Section 6}

On this page are a number of statements concerning what people think about their $\mathrm{J} / \mathrm{M} / \mathrm{C}$ heritage. Please read each statement carefully and indicate, by circling a number on a 1 (strongly disagree) to 7 (strongly agree) scale that best represents your personal response. There are no right or wrong answers, and your first responses are usually the most accurate.

Remember, we want to know what you personally think about your $\mathrm{J} / \mathrm{M} / \mathrm{C}$ heritage.
1
2
3
4
5
6
7

strongly disagree somewhat disagree slightly disagree neutral slightly agree somewhat agree strongly agree

\begin{tabular}{|c|c|c|c|c|c|c|c|}
\hline & \multicolumn{2}{|c|}{$\begin{array}{l}\text { strongly } \\
\text { disagree }\end{array}$} & & & & \multicolumn{2}{|c|}{$\begin{array}{r}\text { strongly } \\
\text { agree }\end{array}$} \\
\hline $\begin{array}{l}\text { 1. Continuing to practice } \mathrm{my} \mathrm{J} / \mathrm{M} / \mathrm{C} \text { traditions and } \\
\text { celebrations is important to me }\end{array}$ & 1 & 2 & 3 & 4 & 5 & & \\
\hline 2. Ultimately, I would like my children to identify as $\mathrm{J} / \mathrm{M} / \mathrm{C}$ & 1 & 2 & 3 & 4 & 5 & c & \\
\hline $\begin{array}{l}\text { 3. The future continuity of our } \mathrm{J} / \mathrm{M} / \mathrm{C} \text { community is NOT } \\
\text { a concern of mine }\end{array}$ & 1 & 2 & 3 & 4 & 5 & C & \\
\hline $\begin{array}{l}\text { 4. Maintaining } \mathrm{my} / \mathrm{M} / \mathrm{C} \text { heritage is NOT something I } \\
\text { care about }\end{array}$ & 1 & 2 & 3 & 4 & 5 & ( & \\
\hline $\begin{array}{l}\text { 5. I would like to encourage my children to learn } \\
\text { Hebrew/Māori/Chinese }\end{array}$ & 1 & 2 & 3 & 4 & 5 & C & \\
\hline 6. I want to keep $\mathrm{J} / \mathrm{M} / \mathrm{C}$ culture alive & 1 & 2 & 3 & 4 & 5 & 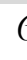 & \\
\hline $\begin{array}{l}\text { 7. } \mathrm{My} \mathrm{J} / \mathrm{M} / \mathrm{C} \text { heritage and traditions are something I can } \\
\text { easily disregard }\end{array}$ & 1 & 2 & 3 & 4 & 5 & 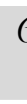 & . \\
\hline $\begin{array}{l}\text { 8. It's of little consequence if my children DON'T identify } \\
\text { with their } \mathrm{J} / \mathrm{M} / \mathrm{C} \text { heritage }\end{array}$ & 1 & 2 & 3 & 4 & 5 & 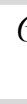 & \\
\hline $\begin{array}{l}\text { 9. Long-term, I would like my grandchildren and great- } \\
\text { grandchildren to continue our } \mathrm{J} / \mathrm{M} / \mathrm{C} \text { heritage }\end{array}$ & 1 & 2 & 3 & 4 & 5 & 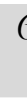 & \\
\hline $\begin{array}{l}\text { 10. I do NOT mind setting aside the traditions of my } \\
\mathrm{J} / \mathrm{M} / \mathrm{C} \text { heritage }\end{array}$ & 1 & 2 & 3 & 4 & 5 & 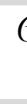 & \\
\hline $\begin{array}{l}\text { 11. I do NOT care if my children are unaware of } \mathrm{J} / \mathrm{M} / \mathrm{C} \\
\text { traditions and values }\end{array}$ & 1 & 2 & 3 & 4 & 5 & 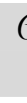 & \\
\hline $\begin{array}{l}\text { 12. The endurance of } \mathrm{J} / \mathrm{M} / \mathrm{C} \text { people does NOT really } \\
\text { matter }\end{array}$ & 1 & 2 & 3 & 4 & 5 & 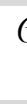 & \\
\hline $\begin{array}{l}\text { 13. I would like to keep on living according to the traditions } \\
\text { of } \mathrm{my} / \mathrm{M} / \mathrm{C} \text { heritage }\end{array}$ & 1 & 2 & 3 & 4 & 5 & 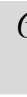 & \\
\hline $\begin{array}{l}\text { 14. I want to transmit to my children a love for and interest } \\
\text { in their } \mathrm{J} / \mathrm{M} / \mathrm{C} \text { heritage }\end{array}$ & 1 & 2 & 3 & 4 & 5 & 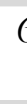 & \\
\hline $\begin{array}{l}\text { 15. I do NOT really care about ensuring the future of } \\
\mathrm{J} / \mathrm{M} / \mathrm{C} \text { people }\end{array}$ & 1 & 2 & 3 & 4 & 5 & ( & \\
\hline $\begin{array}{l}\text { 16. Maintaining my } \mathrm{J} / \mathrm{M} / \mathrm{C} \text { traditions and language is NOT } \\
\text { important to me }\end{array}$ & 1 & 2 & 3 & 4 & 5 & 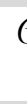 & \\
\hline $\begin{array}{l}\text { 17. I think it's good to create an environment at home } \\
\text { where my } J / M / C \text { traditions can be a normal part of life } \\
\text { for my children }\end{array}$ & 1 & 2 & 3 & 4 & 5 & ( & \\
\hline 18. I want to ensure the future of our $\mathrm{J} / \mathrm{M} / \mathrm{C}$ heritage & 1 & 2 & 3 & 4 & 5 & ( & \\
\hline
\end{tabular}




\section{Section $7 a$}

Below are three statements concerning your similarity with other $\mathrm{J} / \mathrm{M} / \mathrm{C}$ people. Please read each statement carefully and indicate, by circling a number on a 1 (not at all similar) to 7 (very similar) scale that best represents your personal response. There are no right or wrong answers.
1
2
3
$\begin{array}{lll}4 & 5 & 6\end{array}$
7

not at all similar somewhat dissimilar slightly dissimilar neutral slightly similar somewhat similar very similar

\begin{tabular}{|l|cccccccc|}
\hline & \multicolumn{1}{c}{$\begin{array}{c}\text { Not at all } \\
\text { similar }\end{array}$} & & \multicolumn{3}{c|}{$\begin{array}{c}\text { Very } \\
\text { similar }\end{array}$} \\
$\begin{array}{l}\text { 2. How similar overall do you feel to other J/M/C people? } \\
\text { 2. How similar do you feel to other J/M/C people in terms }\end{array}$ & 1 & 2 & 3 & 4 & 5 & 6 & 7 \\
of personal values? & 1 & 2 & 3 & 4 & 5 & 6 & 7 \\
$\begin{array}{l}\text { 3. How similar do you feel to other J/M/C people in terms } \\
\text { of communication style? }\end{array}$ & 1 & 2 & 3 & 4 & 5 & 6 & 7 \\
\hline
\end{tabular}

\section{Section $7 b$}

Below are three statements concerning your attraction to other $\mathrm{J} / \mathrm{M} / \mathrm{C}$ people. Please read each statement carefully and indicate, by circling a number on a 1 (not at all attractive) to 7 (very attractive) scale that best represents your personal response.

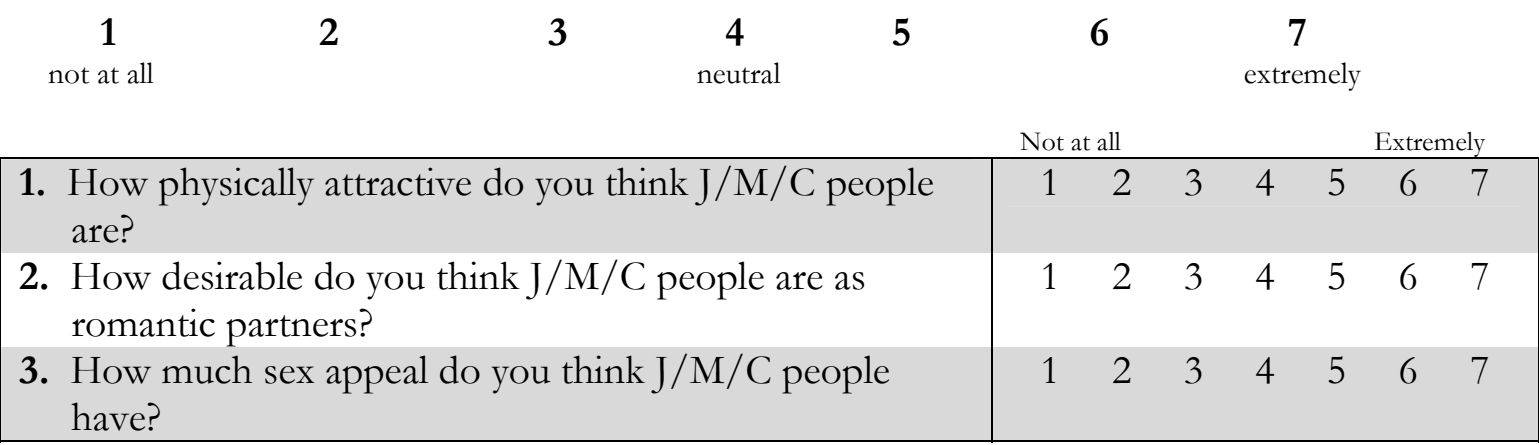

\section{Section 7c}

Below are three statements concerning your family and friends. Please read each statement carefully and indicate, by circling a number on a 1 (not at all happy) to 7 (very happy) scale that best represents your personal response.

$\begin{array}{ccccccc}\mathbf{1} & \mathbf{2} & \mathbf{3} & \mathbf{4} & \mathbf{5} & \mathbf{6} & \mathbf{7} \\ \text { not at all happy } & \text { very unhappy } & \text { somewhat unhappy } & \text { neutral } & \text { somewhat happy } & \text { very happy } & \text { extremely happy }\end{array}$

\begin{tabular}{|l|cccccccc|}
\multicolumn{1}{c}{} & \multicolumn{2}{c}{$\begin{array}{c}\text { Not at all } \\
\text { happy }\end{array}$} & & \multicolumn{2}{c}{$\begin{array}{c}\text { Extremely } \\
\text { happy }\end{array}$} \\
\hline $\begin{array}{l}\text { 1. How do you think your parents would feel about your } \\
\text { marrying someone who is J/M/C? }\end{array}$ & 1 & 2 & 3 & 4 & 5 & 6 & 7 \\
$\begin{array}{l}\text { 2. How do you think your friends would feel about your } \\
\text { marrying someone who is J/M/C? }\end{array}$ & 1 & 2 & 3 & 4 & 5 & 6 & 7 \\
$\begin{array}{l}\text { 3. How do you think the friends and family of someone } \\
\text { who is J/M/C would feel about him/her marrying } \\
\text { you? }\end{array}$ & 1 & 2 & 3 & 4 & 5 & 6 & 7 \\
\hline
\end{tabular}




\section{Section 8a}

On this page are a number of statements concerning your intentions for marriage. Please read each statement carefully and indicate, by circling a number on a 1 (strongly disagree) to 7 (strongly agree) scale that best represents your personal response. There are no right or wrong answers, and your first responses are usually the most accurate.

Remember, we want to know what your personal intentions for marriage are.
1
2
3
4
5
6
7

strongly disagree somewhat disagree slightly disagree neutral slightly agree somewhat agree strongly agree

\begin{tabular}{|c|c|c|c|c|c|c|c|}
\hline & \multicolumn{2}{|c|}{$\begin{array}{l}\text { strongly } \\
\text { disagree }\end{array}$} & & & & \multicolumn{2}{|c|}{$\begin{array}{r}\text { strongly } \\
\text { agree } \\
\end{array}$} \\
\hline 1. I intend to marry someone who is $\mathrm{J} / \mathrm{M} / \mathrm{C}$ & 1 & 2 & 3 & 4 & 5 & 6 & 7 \\
\hline $\begin{array}{l}\text { 2. I am NOT planning to marry someone who is } \\
\mathrm{J} / \mathrm{M} / \mathrm{C}\end{array}$ & 1 & 2 & 3 & 4 & 5 & 6 & 7 \\
\hline $\begin{array}{l}\text { 3. When it comes to marriage, I will go back to the } \\
\mathrm{J} / \mathrm{M} / \mathrm{C} \text { people to find the right person }\end{array}$ & 1 & 2 & 3 & 4 & 5 & 6 & 7 \\
\hline $\begin{array}{l}\text { 4. When I make the decision about who to marry, it } \\
\text { will NOT be influenced by whether they are J/M/C } \\
\text { or not }\end{array}$ & 1 & 2 & 3 & 4 & 5 & 6 & 7 \\
\hline
\end{tabular}

\section{Section $8 b$}

Below are a number of statements about your current dating. Please read each statement carefully and indicate, by circling a number on a 1 (strongly disagree) to 7 (strongly agree) scale that best represents your personal response. There are no right or wrong answers, and your first responses are usually the most accurate.

Bear in mind that we want to know about your present dating.

\section{$\begin{array}{lllllll}1 & 2 & 3 & 4 & 5 & 6 & 7\end{array}$} strongly disagree somewhat disagree slightly disagree neutral slightly agree somewhat agree strongly agree

\begin{tabular}{|c|c|c|c|c|c|c|c|}
\hline & \multicolumn{2}{|c|}{$\begin{array}{l}\text { strongly } \\
\text { disagree }\end{array}$} & & & & \multicolumn{2}{|c|}{$\begin{array}{r}\text { strongly } \\
\text { agree }\end{array}$} \\
\hline 1. I only date people who are $\mathrm{J} / \mathrm{M} / \mathrm{C}$ & 1 & 2 & 3 & $\overline{4}$ & 5 & 6 & 7 \\
\hline 2. I date people who are NOT J/M/C & 1 & 2 & 3 & 4 & 5 & 6 & 7 \\
\hline $\begin{array}{l}\text { 3. I make an effort to only have romantic relationships } \\
\text { with other } \mathrm{J} / \mathrm{M} / \mathrm{C} \text { people }\end{array}$ & 1 & 2 & 3 & 4 & 5 & 6 & 7 \\
\hline $\begin{array}{l}\text { 4. The person I am currently (or most recently) } \\
\text { interested in romantically identifies with a different } \\
\text { ethnic group }\end{array}$ & 1 & 2 & 3 & 4 & 5 & 6 & 7 \\
\hline
\end{tabular}

$\sim$ End of Questionnaire Thanks for your participation! 


\section{APPENDIX F: ITEM BIAS ANALYSIS}

\begin{tabular}{|c|c|c|c|}
\hline & Biased items & ANOVA & Type of bias* \\
\hline HOW & $\begin{array}{l}\text { Item 3: "I feel anger and frustration when I } \\
\text { think of all the injustices and discrimination } \\
\text { experienced by } \mathrm{J} / \mathrm{M} / \mathrm{C} \text { " }\end{array}$ & $\begin{array}{l}\text { Ethnicity } \\
\underline{\mathrm{F}}(2,286)=4.22, \underline{\mathrm{p}}<0.05 \\
\text { Ethnicity x level } \\
\underline{\mathrm{F}}(10,286)=2.24, \underline{\mathrm{p}}<0.05\end{array}$ & $\begin{array}{l}\text { Uniform \& } \\
\text { non-uniform: } \\
\text {-Chinese ARS } \\
\text {-Māori ERS } \\
\end{array}$ \\
\hline \multirow[t]{2}{*}{ WHAT } & $\begin{array}{l}\text { Item 10: "I do NOT know much about the } \\
\text { cultural heroes of J/M/C history" } \\
\text { Item 3: "I celebrate the points in history } \\
\text { when J/M/C fought to maintain our culture" }\end{array}$ & $\begin{array}{l}\text { Ethnicity } \\
\underline{\mathrm{F}}(2,274)=7.51, \mathrm{p}<0.01 \\
\text { Ethnicity } \\
\underline{\mathrm{F}}(2,275)=5.17, \mathrm{p}<0.01\end{array}$ & $\begin{array}{l}\text { Uniform: } \\
\text {-Māori ARS } \\
\text { Uniform: } \\
\text {-Chinese inverse } \\
\text { ARS }\end{array}$ \\
\hline & $\begin{array}{l}\text { Item 8: "Discrimination against } \mathrm{J} / \mathrm{M} / \mathrm{C} \\
\text { people is something I do NOT know much } \\
\text { about" }\end{array}$ & $\begin{array}{l}\text { Ethnicity } \\
\underline{\mathrm{F}}(2,275)=3.98, \underline{\mathrm{p}}<0.05\end{array}$ & $\begin{array}{l}\text { Uniform: } \\
\text {-Chinese ARS }\end{array}$ \\
\hline \multirow[t]{10}{*}{ MEC } & $\begin{array}{l}\text { Item 5: "I would like to encourage my } \\
\text { children to learn Hebrew/Māori/Chinese" }\end{array}$ & $\begin{array}{l}\text { Ethnicity } \\
\underline{F}(2,264)=8.32, \mathrm{p}<0.001 \\
\text { Ethnicity x level } \\
\mathrm{F}(10,264)=2.20, \mathrm{p}<0.05\end{array}$ & $\begin{array}{l}\text { Uniform \& non- } \\
\text { uniform: } \\
\text {-Chinese ARS } \\
\text {-Māori ERS }\end{array}$ \\
\hline & $\begin{array}{l}\text { Item 15: "I do NOT really care about } \\
\text { ensuring the future of } \mathrm{J} / \mathrm{M} / \mathrm{C} \text { people" }\end{array}$ & $\begin{array}{l}\text { Ethnicity } \\
\text { Ethnicity x level } \\
\underline{F}(10,264)=2.48, p<0.01\end{array}$ & $\begin{array}{l}\text { Uniform \& non- } \\
\text { uniform: } \\
\text {-Māori ARS } \\
\text {-Chinese ERS }\end{array}$ \\
\hline & Item 6: "I want to keep J/M/C culture alive" & $\begin{array}{l}\text { Ethnicity } \\
\underline{F}(2,264)=5.31, \underline{p}<0.01 \\
\text { Ethnicity x level } \\
\underline{F}(10,264)=4.75, \underline{p}<0.001\end{array}$ & $\begin{array}{l}\text { Uniform \& non- } \\
\text { uniform } \\
\text {-Māori ARS } \\
\text {-Chinese ERS }\end{array}$ \\
\hline & $\begin{array}{l}\text { Item 4: "Maintaining my J/M/C heritage is } \\
\text { NOT something I really care about" }\end{array}$ & $\begin{array}{l}\text { Ethnicity } \\
\underline{F}(2,264)=5.97, \underline{p}<0.01 \\
\text { Ethnicity x level } \\
\underline{F}(10,264)=5.50, \underline{p}<0.001\end{array}$ & $\begin{array}{l}\text { Uniform \& non- } \\
\text { uniform: } \\
\text {-Chinese ERS }\end{array}$ \\
\hline & $\begin{array}{l}\text { Item 18: "I want to ensure the future of our } \\
\text { J/M/C heritage" }\end{array}$ & $\begin{array}{l}\text { Ethnicity } \\
\underline{\mathrm{F}}(2,264)=5.89, \mathrm{p}<0.01 \\
\text { Ethnicity x level } \\
\underline{\mathrm{F}}(10,264)=2.89, \mathrm{p}<0.01\end{array}$ & $\begin{array}{l}\text { Uniform \& non- } \\
\text { uniform: } \\
\text {-Māori ARS } \\
\text {-Māori \& Chinese } \\
\text { ERS }\end{array}$ \\
\hline & $\begin{array}{l}\text { Item 16: "Maintaining my J/M/C traditions } \\
\text { and language is NOT important to me" }\end{array}$ & $\begin{array}{l}\text { Ethnicity } \\
\underline{F}(2,264)=5.34, p<0.01 \\
\text { Ethnicity x level } \\
\underline{F}(10,264)=1.98, \underline{p}<0.05\end{array}$ & $\begin{array}{l}\text { Uniform \& non- } \\
\text { uniform: } \\
\text {-Māori ARS } \\
\text {-Jews ERS }\end{array}$ \\
\hline & $\begin{array}{l}\text { Item 7: "My J/M/C heritage and traditions } \\
\text { are something I can easily disregard" }\end{array}$ & $\begin{array}{l}\text { Ethnicity } \\
\underline{F}(2,264)=3.46, \underline{p}<0.05 \\
\text { Ethnicity x level } \\
\underline{F}(10,264)=4.24, \underline{p}<0.001\end{array}$ & $\begin{array}{l}\text { Uniform \& non- } \\
\text { uniform: } \\
\text {-Māori ARS } \\
\text {-Jews ERS }\end{array}$ \\
\hline & $\begin{array}{l}\text { Item 14: "I want to transmit to my children a } \\
\text { love for an interest in their } \mathrm{J} / \mathrm{M} / \mathrm{C} \text { heritage }\end{array}$ & $\begin{array}{l}\text { Ethnicity } \\
\underline{F}(2,264)=5.97, \underline{p}<0.01 \\
\text { Ethnicity x level } \\
\underline{F}(10,264)=1.89, \underline{p}<0.05\end{array}$ & $\begin{array}{l}\text { Uniform \& non- } \\
\text { uniform: } \\
\text {-Māori ARS } \\
\text {-Chinese ERS }\end{array}$ \\
\hline & $\begin{array}{l}\text { Item 11: "I do NOT care if my children are } \\
\text { unaware of J/M/C traditions and values" } \\
\text { Item 9: "Long-term, I would like my } \\
\text { grandchildren and great-grandchildren to } \\
\text { continue our J/M/C heritage" }\end{array}$ & $\begin{array}{l}\text { Ethnicity x level } \\
\underline{F}(10,264)=2.06, \underline{p}<0.05 \\
\text { Ethnicity x level } \\
\underline{F}(10,264)=2.51, \underline{p}<0.01\end{array}$ & $\begin{array}{l}\text { Non-uniform: } \\
\text {-Māori ERS } \\
\text { Non-uniform: } \\
\text {-Jews ERS }\end{array}$ \\
\hline & $\begin{array}{l}\text { Item 10: "I do NOT mind setting aside the } \\
\text { traditions of my J/M/C heritage" }\end{array}$ & $\begin{array}{l}\text { Ethnicity x level } \\
\underline{F}(10,264)=2.12, \mathrm{p}<0.05\end{array}$ & $\begin{array}{l}\text { Non-uniform: } \\
\text {-Chinese ERS }\end{array}$ \\
\hline
\end{tabular}

$*$ ARS $=$ Acquiescence Response Bias and ERS $=$ Extreme Response Bias 


\section{APPENDIX G: FINAL SCALES}

\section{Motivation for Ethno-cultural Continuity (MEC)}

On this page are a number of statements concerning what people think about their heritage. Please read each statement carefully and indicate, by circling a number on a 1 (strongly disagree) to 7 (strongly agree) scale that best represents your personal response. There are no right or wrong answers, and your first responses are usually the most accurate. Remember, we want to know what you think about your heritage.

$$
1
$$$$
2
$$

3

4

5

6

7

strongly disagree somewhat disagree slightly disagree neutral slightly agree somewhat agree strongly agree

\begin{tabular}{|c|c|c|c|c|c|c|c|c|}
\hline & \multicolumn{2}{|c|}{$\begin{array}{l}\text { strongly } \\
\text { disagree }\end{array}$} & & & & \multicolumn{3}{|c|}{$\begin{array}{r}\text { strongly } \\
\text { agree }\end{array}$} \\
\hline $\begin{array}{l}\text { 1. Continuing to practice my } \\
\text { celebrations is important to me }\end{array}$ & 1 & 2 & 3 & 4 & 5 & 6 & & 7 \\
\hline 2. Ultimately, I would like my children to identify as & 1 & 2 & 3 & 4 & 5 & 6 & & 7 \\
\hline $\begin{array}{l}\text { 3. The future continuity of our __ community is NOT } \\
\text { a concern of mine }\end{array}$ & 1 & 2 & 3 & 4 & 5 & 6 & & 7 \\
\hline $\begin{array}{l}\text { 4. Maintaining my __ heritage is NOT something I } \\
\text { care about }\end{array}$ & 1 & 2 & 3 & 4 & 5 & 6 & & 7 \\
\hline $\begin{array}{l}\text { 5. I would like to encourage my children to learn } \\
\text { (language) }\end{array}$ & 1 & 2 & 3 & 4 & 5 & 6 & & 7 \\
\hline $\begin{array}{l}\text { 6. Long-term, I would like my grandchildren and great- } \\
\text { grandchildren to continue our }\end{array}$ & 1 & 2 & 3 & 4 & 5 & 6 & & 7 \\
\hline $\begin{array}{l}\text { 7. I do NOT mind setting aside the traditions of my } \\
\text { heritage }\end{array}$ & 1 & 2 & 3 & 4 & 5 & 6 & & 7 \\
\hline $\begin{array}{l}\text { 8. I would like to keep on living according to the traditions } \\
\text { of my heritage }\end{array}$ & 1 & 2 & 3 & 4 & 5 & 6 & & 7 \\
\hline $\begin{array}{l}\text { 9. I want to transmit to my children a love for and interest } \\
\text { in their }\end{array}$ & 1 & 2 & 3 & 4 & 5 & 6 & & 7 \\
\hline $\begin{array}{l}\text { 10. I think it's good to create an environment at home } \\
\text { where my traditions can be a normal part of life } \\
\text { for my children }\end{array}$ & 1 & 2 & 3 & 4 & 5 & 6 & & 7 \\
\hline
\end{tabular}




\section{Subjects of remembrance: WHO}

Below are a number of statements concerning awareness of history.

Please read each statement carefully and indicate, by circling a number on a 1 (strongly disagree) to 7 (strongly agree) scale that best represents your personal response. There are no right or wrong answers, and your first responses are usually the most accurate.
1
2
3
4
5
6
7

strongly disagree somewhat disagree slightly disagree neutral slightly agree somewhat agree strongly agree

\begin{tabular}{|c|c|c|c|c|c|c|c|}
\hline & \multicolumn{2}{|c|}{$\begin{array}{l}\text { strongly } \\
\text { disagree }\end{array}$} & & & & \multicolumn{2}{|c|}{$\begin{array}{r}\text { strongly } \\
\text { agree }\end{array}$} \\
\hline $\begin{array}{l}\text { 1. I know what } \\
\text { in their home towns }\end{array}$ & 1 & 2 & 3 & 4 & 5 & 6 & 7 \\
\hline $\begin{array}{l}\text { 2. I am aware of the history of ___ people here, in } \\
\text { the country where I live }\end{array}$ & 1 & 2 & 3 & 4 & 5 & 6 & 7 \\
\hline $\begin{array}{l}\text { 3. The broad history of } \\
\text { NOT know much about is something that I do }\end{array}$ & 1 & 2 & 3 & 4 & 5 & 6 & 7 \\
\hline $\begin{array}{l}\text { 4. I do NOT know much about my family's } \\
\text { background }\end{array}$ & 1 & 2 & 3 & 4 & 5 & 6 & 7 \\
\hline $\begin{array}{l}\text { 5. I know about the experiences of the first } \\
\text { immigrants to this country }\end{array}$ & 1 & 2 & 3 & 4 & 5 & 6 & 7 \\
\hline $\begin{array}{l}\text { 6. I know about the history ___ people in our } \\
\text { ancestral land }\end{array}$ & 1 & 2 & 3 & 4 & 5 & 6 & 7 \\
\hline $\begin{array}{l}\text { 7. The } \quad \text { roots of my family are something I do } \\
\text { NOT know much about }\end{array}$ & 1 & 2 & 3 & 4 & 5 & 6 & 7 \\
\hline $\begin{array}{l}\text { 8. I am NOT really aware of the experiences faced by } \\
\text { in this country }\end{array}$ & 1 & 2 & 3 & 4 & 5 & 6 & 7 \\
\hline 9. I remember the general history of ___ people & 1 & 2 & 3 & 4 & 5 & 6 & 7 \\
\hline $\begin{array}{l}\text { 10. I have stories about my family's experiences related } \\
\text { to being }\end{array}$ & 1 & 2 & 3 & 4 & 5 & 6 & 7 \\
\hline $\begin{array}{l}\text { 11. I do NOT know much about the local history of } \\
\text { people }\end{array}$ & 1 & 2 & 3 & 4 & 5 & 6 & 7 \\
\hline 12. I am NOT familiar with ___ history & 1 & 2 & 3 & 4 & 5 & 6 & 7 \\
\hline
\end{tabular}




\section{Ethno-historical consciousness: WHAT}

On this page are a number of statements concerning the different aspects of history. Please read each statement carefully and indicate, by circling a number on a 1 (strongly disagree) to 7 (strongly agree) scale that best represents your personal response. There are no right or wrong answers, and your first responses are usually the most accurate.
1
2
3
45
56
7

strongly disagree somewhat disagree slightly disagree neutral slightly agree somewhat agree strongly agree

\begin{tabular}{|c|c|c|c|c|c|c|c|}
\hline & \multicolumn{2}{|c|}{$\begin{array}{l}\text { strongly } \\
\text { disagree }\end{array}$} & & & & \multicolumn{2}{|c|}{$\begin{array}{r}\text { strongly } \\
\text { agree }\end{array}$} \\
\hline $\begin{array}{l}\text { 1. I remember the founding fathers and mothers of } \\
\text { traditions }\end{array}$ & 1 & 2 & 3 & 4 & 5 & 6 & 7 \\
\hline 2. I remember the injustices that have happened to & 1 & 2 & 3 & 4 & 5 & 6 & 7 \\
\hline $\begin{array}{l}\text { 3. I celebrate the points in history when } \\
\text { fought to maintain our culture }\end{array}$ & 1 & 2 & 3 & 4 & 5 & 6 & 7 \\
\hline $\begin{array}{l}\text { 4. I have difficulty remembering basic historical events } \\
\text { that shaped_ as a people }\end{array}$ & 1 & 2 & 3 & 4 & 5 & 6 & 7 \\
\hline $\begin{array}{l}\text { 5. I'm not really aware of } \\
\text { differently by the larger society }\end{array}$ & 1 & 2 & 3 & 4 & 5 & 6 & 7 \\
\hline 6. I appreciate the historical survival of & 1 & 2 & 3 & 4 & 5 & 6 & 7 \\
\hline $\begin{array}{l}\text { 7. I remember events in history where } \\
\text { demonstrated resistance to forces from the larger } \\
\text { society }\end{array}$ & 1 & 2 & 3 & 4 & 5 & 6 & 7 \\
\hline $\begin{array}{l}\text { 8. I remember how } \\
\text { against by the larger society throughout history }\end{array}$ & 1 & 2 & 3 & 4 & 5 & 6 & 7 \\
\hline
\end{tabular}




\section{Vicarious experience of ethnic history: HOW}

On this page are a number of statements about how people remember history. Please read each statement carefully and indicate, by circling a number on a 1 (strongly disagree) to 7 (strongly agree) scale that best represents your personal response. There are no right or wrong answers, and your first responses are usually the most accurate.

1

2

34

5

6

7

strongly disagree somewhat disagree slightly disagree neutral slightly agree somewhat agree strongly agree

\begin{tabular}{|c|c|c|c|c|c|c|c|}
\hline & \multicolumn{2}{|c|}{$\begin{array}{l}\text { strongly } \\
\text { disagree }\end{array}$} & & & & \multicolumn{2}{|c|}{$\begin{array}{r}\text { strongly } \\
\text { agree }\end{array}$} \\
\hline $\begin{array}{l}\text { 1. I can imagine being a part of the journeys my } \\
\text { ancestors made }\end{array}$ & 1 & 2 & 3 & 4 & 5 & 6 & 7 \\
\hline $\begin{array}{l}\text { 2. I feel anger and frustration when I think of all the } \\
\text { injustices and discrimination experienced by }\end{array}$ & 1 & 2 & 3 & 4 & 5 & 6 & 7 \\
\hline $\begin{array}{l}\text { 3. When I look back in history to } \\
\text { do feel that I am a part of something great }\end{array}$ & 1 & 2 & 3 & 4 & 5 & 6 & 7 \\
\hline $\begin{array}{l}\text { 4. It's hard for me to feel linked to the experiences of } \\
\text { my __ancestors }\end{array}$ & 1 & 2 & 3 & 4 & 5 & 6 & 7 \\
\hline $\begin{array}{l}\text { 5. The historical achievements of } \\
\text { little to do with me on a personal level }\end{array}$ & 1 & 2 & 3 & 4 & 5 & 6 & 7 \\
\hline $\begin{array}{l}\text { 6. I feel proud when I learn about the struggles and } \\
\text { battles of our__ ancestors to keep our heritage } \\
\text { alive }\end{array}$ & 1 & 2 & 3 & 4 & 5 & 6 & 7 \\
\hline
\end{tabular}

